GILDER NADER

\title{
DESENVOLVIMENTO DE TÉCNICAS DE CARACTERIZAÇÃO DE TRANSDUTORES PIEZELÉTRICOS
}

Tese Apresentada à Escola Politécnica da Universidade de São Paulo para Obtenção do Título de Doutor em Engenharia

Área de Concentração:

Engenharia Mecatrônica

Orientador:

Prof. Titular

Julio Cezar Adamowski

Co-Orientador:

Prof. Assistente

Emílio Carlos Nelli Silva

São Paulo 
A Julio e Emílio, que acreditaram na montagem do Laboratório de óptica. 


\section{Agradecimentos}

A realização desse trabalho foi possível graças a colaboração e ajuda de diversos grupos, agências de fomento e redes de pesquisa. Muitas informações foram trocadas no período que compreendeu o desenvolvimento desse trabalho. Todos aqui citados foram de grande importância e tomo a contribuição de todos com igual relevância.

Aos Prof. Dr. J. C. Adamowski e Prof. Dr. E. C. N. Silva por terem coordenado linearmente todo esse trabalho de doutorado, dado apoio constante e acreditarem na criação do laboratório de óptica.

Aos Prof. Dr. C. Negreira, Prof. Dr. I. Nuñes e ao MSc. Nicolás Pérez, do Laboratório de Acústica e Ultra-som do Instituto de Física da Universidade da República do Uruguai, pelos ensinamentos na área de transdutores piezelétricos e sistemas interferométricos. A todos os outros do grupo, meu muito obrigado pelo companheirismo.

Aos Prof. Dr. J. A. Eiras, Dr. M. H. Lente, Sr. F. J. Picon e aos outros membros do Grupo de Cerâmicas Ferroelétricas do Instituto de Física da UFSCar, pela grande colaboração na área de materiais piezelétricos.

Aos alunos de iniciação científica envolvidos nesse projeto: Alessandro Shirahige, que participou de grande parte desse trabalho e também desenhou todas as figuras em CAD, que ilustram essa tese; ao André Mecchi e Cleber Jacintho.

Aos Prof. Dr. O. Horikawa (POLI-USP), Prof. Dr. M. Muramatsu (IFUSP), Prof. Dr. P. A. M. dos Santos (IF-UFF), Prof. Dr. R. T. Higuti (UNESP - Ilha Solteira), Prof. Dr. R. C. Ibrahim (POLI-USP), Prof. Dr. F. Buiochi (POLI-USP), Prof. Dr. C. M. Furukawa (POLI-USP), Prof. Dr. N. Maruyama (POLI-USP), Prof. Dr. P. Nussensweig (IFUSP), Dr. M. Martineli (IFUSP), Dr. F. Montero de Espinosa (IA-Espanha) e ao Sr. M. Pérez (LME). Todos esses contribuíram com sugestões e/ou empréstimo equipamentos.

Ao Gilberto pelo suporte técnico na usinagem das peças fundamentais aos interferômetros.

Às agências de fomento e redes de pesquisa: FAPESP, CNPq, CAPES, FINEP/RECOPE, MON-Argentina e RITUL-Espanha. 


\section{Resumo}

O projeto de transdutores piezelétricos envolve modelagens matemáticas e verificações experimentais, que são necessárias para validá-los. Através das análises dos transdutores verificam-se as influências das condições de contorno experimentais e as dificuldades para modelá-las. No entanto, na literatura atual este ponto não é discutido de forma abrangente. Além disso, as propriedades elétricas, piezelétricas e mecânicas dos materiais devem ser conhecidas com precisão para que o modelo represente um transdutor físico. Estas propriedades são fornecidas pelos fabricantes em valores aproximados, porém algumas delas, como por exemplo, o amortecimento mecânico, não são fornecidas, o que dificulta a modelagem. Por estes motivos, este trabalho trata do desenvolvimento de técnicas de verificações experimentais de transdutores piezelétricos, visando esclarecer efeitos relacionados às variações nas condições de contorno devido à fixação de pequenos espelhos e a fixação do próprio transdutor num suporte, e propor formas de incorporar esses efeitos nos modelos matemáticos. Além disso, propõe-se uma metodologia para a determinação do coeficiente de amortecimento das cerâmicas piezelétricas. São apresentadas as técnicas ópticas utilizadas na medição dinâmica e estática de deslocamentos de transdutores piezelétricos, os problemas das influências mecânicas, como vibrações ambientes, nas análises ópticas e as respectivas soluções adotadas. As análises numéricas foram conduzidas com o software de elementos finitos ANSYS e os resultados comparados com as verificações experimentais. Os materiais analisados são piezocerâmicas PZT5A, piezoatuadores flextensionais, projetados pelo método de otimização topológica e um piezoatuador bilaminar. Nos resultados apresentados são mostrados os desvios e os comentários sobre as possíveis causas. 


\section{Abstract}

Piezoelectric transducer design is done by using numerical method and experimental analysis, which are needed to validate it. Transducers analysis allow us to verify the influence of experimental boundary conditions and the difficulties to model them. However, in the current literature this point is not discussed in a comprehensive way. In addiction, electrical, piezoelectric and mechanical material properties must be known with accuracy, to represent a real transducer. Approximately values of these properties are provided by manufacturers, however other property values are not provided, such as for example, mechanical damping, which causes difficulties for modelling. Therefore, this work is about the development of experimental techniques to analyze piezoelectric transducers, aiming to understand the effects related to boundary conditions changes due to stick of small mirrors and the way the transducer is held, and suggest of way to incorporate these effects in mathematical model. In addiction, suggests a methodology to determine the piezoceramics damping coefficient. It is described optical techniques used for displacement measurements of piezoelectric transducer in dynamic and static operation, problems related to mechanical influences in optical analysis, such as environment vibration, and respective applied solutions. Numerical analysis are conducted by using finite element software, ANSYS, and the results are compared with experimental verification. The materials analyzed are piezoceramic PZT-5A, flextensional piezoactuators, designed by using topology optimization and a bimorph pizoactuator. In the present results is shown the deviation and comments about possible cause. 


\section{Sumário}

Lista de Figuras $\quad$ v

Lista de Tabelas xii

Lista de Abreviaturas xiii

Lista de Símbolos $\quad$ XV

1 Introdução 1

1.1 Motivação . . . . . . . . . . . . . . . . . . . . . . 7

1.2 Materiais e Métodos . . . . . . . . . . . . . . . . 8

1.3 Objetivos ............................ 10

1.3.1 Desenvolvimento de Sistemas Ópticos de Medição . . . . . . . 10

1.3.2 Determinação das Propriedades dos Materiais Piezelétricos e Não-piezelétricos . . . . . . . . . . . . 10

1.3.3 Análise de Atuadores Piezelétricos . . . . . . . . . . . . . . . . 10

1.4 Organização da Tese . . . . . . . . . . . . . . . . . 11

2 Propriedades dos Materiais Piezelétricos e Não-piezelétricos 13

2.1 Equações Constitutivas da Elasticidade . . . . . . . . . . . . . . 14

2.1.1 Deformação Mecânica . . . . . . . . . . . . . . . . 14

2.1.2 Tensão Mecânica . . . . . . . . . . . . . . . . . . 16

2.1.3 Coeficientes Mecânicos . . . . . . . . . . . . . 16

2.2 Equações Constitutivas Piezelétricas . . . . . . . . . . . . . . . . . . 19

2.3 Caracterização Elétrica dos Materiais

Piezelétricos . . . . . . . . . . . . . . . . . 23 
2.3.1 Condições para Determinação das Constantes

Piezelétricas .................... . . . 24

2.3.2 Medições em Regime Estático e Semi-estático . . . . . . . . . 26

2.3.3 Método da Ressonância . . . . . . . . . . . . . . 26

2.4 Amortecimento . . . . . . . . . . . . . . . . . 33

2.4.1 Tipos de Amortecimento . . . . . . . . . . . . 33

2.5 Discussão . . . . . . . . . . . . . . . . . . . . . 37

3 Método de Elementos Finitos 38

3.1 Introdução ao $\mathrm{MEF}$. . . . . . . . . . . . . . . . . . . . . . 39

3.2 Equações Piezelétricas do Movimento

com Amortecimento . . . . . . . . . . . . . . . . . . . . . 40

3.2.1 Amortecimento Estrutural Mecânico . . . . . . . . . . . . 41

3.2.2 Amortecimento Dielétrico . . . . . . . . . . . . . . 42

3.3 Solução das Equações Piezelétricas . . . . . . . . . . . . . . . . . 42

3.3.1 Análise Estática . . . . . . . . . . . . . . 43

3.3 .2 Análise Dinâmica . . . . . . . . . . . . . . . 43

3.3.3 Análise Modal . . . . . . . . . . . . . . . . 45

3.4 Modelagem no ANSYS . . . . . . . . . . . . . . 46

3.4.1 Estados Planos .................. . . 47

3.4.2 Modelo Axi-simétrico . . . . . . . . . . . . . 50

3.5 Discussão . . . . . . . . . . . . . . . . . . . . . 52

4 Atuadores Piezelétricos 53

4.1 Atuador Piezelétrico Flextensional . . . . . . . . . . . . . 54

4.2 Atuadores Piezelétricos: Unilaminar e Bilaminar . . . . . . . . . . . 58

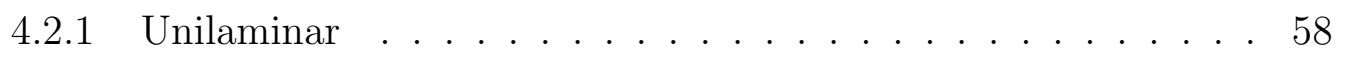

4.2 .2 Bilaminar ........................ 59

4.3 Atuador Piezelétrico Multicamadas $($ Stack $) \ldots . . . . . . . . .661$

4.4 Discussão . . . . . . . . . . . . . . . . . . . 62

5 Métodos Ópticos $\quad 63$

5.1 Técnica Interferométrica . . . . . . . . . . . . . . . . 64

5.1.1 Interferômetro de Michelson . . . . . . . . . . . . . 65 
5.2 Medição de Deslocamentos Superiores a $\lambda / 4$. . . . . . . . . . . 70

5.3 Medição de Deslocamentos Inferiores a $\lambda / 4$. . . . . . . . . . . . . 71

5.4 Vibração Ambiente . . . . . . . . . . . . . . . . . . . . 74

5.4.1 Influência do Ruído Ambiente nas Resposta do Deslocamento 74

5.5 Sistemas Ópticos Utilizados nas Medições . . . . . . . . . . . . . 76

5.5.1 Interferômetro de Michelson sem Controle de Vibração . . . . 76

5.5.2 Interferômetro de Michelson Estabilizado . . . . . . . . . . . . 79

5.5.3 Interferômetro de Mach-Zehnder em Quadratura . . . . . . . . 80

5.5.4 Sistema Óptico Não-Interferométrico . . . . . . . . . . . . . 85

6 Resultados Experimentais e Numéricos 88

6.1 Determinação do Amortecimento das Piezocerâmicas . . . . . . . . . 89

6.1.1 Modelagem no ANSYS . . . . . . . . . . . . 89

6.2 Piezoatuadores Flextensionais . . . . . . . . . . . . . . . . . . 94

6.2.1 Montagem dos Piezoatuadores Flextensionais . . . . . . . . . 95

6.2.2 Método de Elementos Finitos (MEF) . . . . . . . . . . . . . . 97

6.2.3 Análise da Admitância Elétrica . . . . . . . . . . . . . . . 100

6.2.4 Análises por Sistemas Ópticos . . . . . . . . . . . . . . 102

6.3 Influência do Espelho no Comportamento das Piezocerâmicas . . . 112

6.4 Atuadores Piezelétricos Aplicados à Interferometria . . . . . . . . . . 122

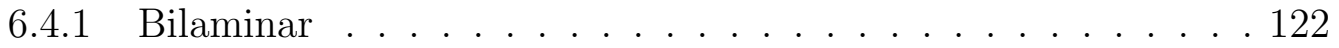

6.5 Pilhas Piezoatuadoras . . . . . . . . . . . . . . 127

6.6 Medição das Propriedades Eletro-piezo-mecânicas . . . . . . . . . . . 131

7 Conclusões e Perspectivas Futuras 134

7.1 Conclusões . . . . . . . . . . . . . . . . . . . . . . . 134

7.2 Perspectivas Futuras . . . . . . . . . . . . . 136

Referências Bibliográficas $\quad 138$

$\begin{array}{lr}\text { APÊNDICES } & 149\end{array}$

A Tensores do Materiais Piezelétricos - Conversão para o ANSYS 150

A.1 Polarização na direção $z$. . . . . . . . . . . . . . . . . 150

A.2 Polarização na direção $y$. . . . . . . . . . . . . . . . . . . . 151 
A.3 Polarização na direção $x$. . . . . . . . . . . . . . . . . . . . . . 152

B Coerência Temporal e Espacial 154

B.1 Coerência Temporal . . . . . . . . . . . . . . . . . . . . . . 154

B.2 Coerência Espacial . . . . . . . . . . . . . . . . 156

C Sistema Óptico a Fibras Ópticas 158 


\section{Lista de Figuras}

1.1 Visão frontal e lateral de um atuador piezelétrico flextensional projetado por otimização topológica e denominado f1c0815. . . . . . . . . 4

2.1 (a) deformação longitudinal, (b) deformação de cisalhamento simples e (c) deformação de cisalhamento puro. . . . . . . . . . . . 15

2.2 Piezocerâmica polarizada: (a) campo elétrico aplicado em sentido oposto ao da polarização; (b) campo elétrico aplicado no mesmo sentido da polarização; e (c) campo elétrico aplicado perpendicular à direção da polarização. . . . . . . . . . . . . . . . 20

2.3 Dimensões e condições das cerâmicas piezelétricas para a determinação das diferentes constantes longitudinais e transversais. (a) disco piezelétrico; (b) placa piezelétrica; (c) barra piezelétrica. Nestas os eletrodos são perpendiculares à direção da polarização. . . . . . . . . . . 25

2.4 Condição de determinação das constantes de cisalhamento. Eletrodos paralelos à direção da polarização. . . . . . . . . . . . . . . 25

2.5 (a) curva da resistência $(R)$ e reatância elétricas $(X)$ indicando a freqüência $f_{p}, f_{+1 / 2}$ e $f_{-1 / 2}$. (b) curva da condutância $(G)$ e susceptância $(B)$ elétricas indicando a freqüência $f_{s} \ldots \ldots \ldots 28$

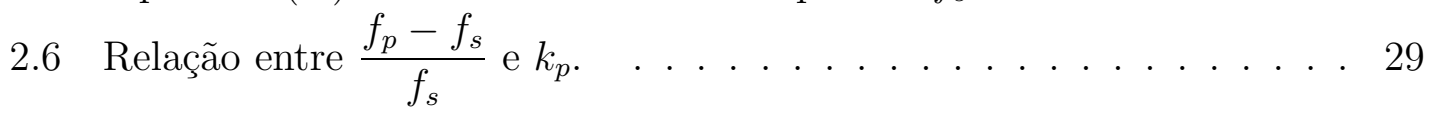

2.7 Vibração amortecida forçada. . . . . . . . . . . . . . . . . . 34 
2.8 Curva da amplitude de deslocamento por freqüência. A freqüência de ressonância corresponde ao ponto de amplitude de deslocamento máximo. (a) influência da variação da massa $(m)$; influência da variação da rigidez $(k)$; influência da variação do amortecimento, o símbolo $(\eta)$ é o fator de perdas. Nesta figura, o símbolo $>$ significa maior e o símbolo $<$ significa menor. . . . . . . . . . . . . . . 35

3.1 Modelo discretizado em vários elementos finitos: (a) indicando linhas, e áreas; (b) indicando os nós. . . . . . . . . . . . . . . . . . . 39

3.2 (a) cargas mecânicas e tensão elétrica em ambos eletrodos. (b) o eletrodo superior aterrado e inferior removido.

3.3 (a) Curva de resposta em freqüência da admitância elétrica, $f_{r}$ indica os pontos das freqüências de ressonância e $f_{a}$ os pontos das freqüências de anti-ressonância. (b) curva da fase elétrica.

3.4 (a) estado plano de tensões mecânicas; (b) estado plano de deformações mecânicas. A polarização de um material piezelétrico é considerada na direção $3 . \quad$. . . . . . . . . . . . . . . . . . . . . . . . . . . . . . . 48

3.5 (a) sistema axi-simétrico em coordenadas cilíndricas; (b) sistema em coordenadas cartesianas. . . . . . . . . . . . . . . 51

4.1 Diagrama da função da um transdutor piezelétrico flextensional. 55

4.2 Primeira e segunda geração de piezoatuadores flextensionais: (a) moonies $^{T M}$;

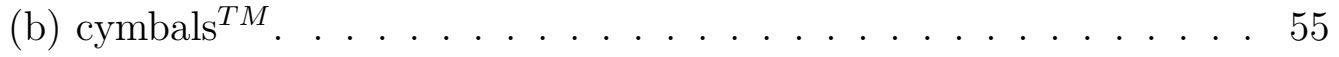

4.3 Esquema da amplificação gerada pela estrutura flexível. A contração da piezocerâmica na direção 1, produz um grande deslocamento da estrutura flexível na direção $3 . \quad$. . . . . . . . . . . . . . . 56

4.4 Piezoatuadores flextensionais ilustrando o deslocamento da piezocerâmica e da estrutura flexível. Superior f1a1025 e inferior f2b0830. 57

4.5 Flextensional com cerâmica de $3 \mathrm{~mm}$ de espessura e $1 \mathrm{~mm}$ de espes-

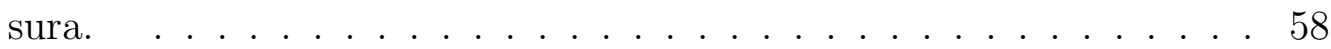

4.6 Atuador piezelétrico unilaminar: (a) vista frontal; (b) vista de perfil em repouso; (c) vista de perfil sob excitação. . . . . . . . . . . . . . 59 
4.7 Modelo de um bilaminar cantiléver. (a) em repouso e (b) excitado por um campo elétrico alternado. . . . . . . . . . . . . . . . . 60

4.8 Bilaminar cantilever operando em: (a) paralelo; (b) série. . . . . . . 61

4.9 Pilha piezoatuadora. . . . . . . . . . . . . . . . 62

4.10 Pilha piezoatuadora em um flextensional. . . . . . . . . . . . . . . 62

5.1 Interferômetro de Michelson. . . . . . . . . . . . . . . . . 65

5.2 Variação da intensidade de acordo com a fase. . . . . . . . . . . . . . 69

5.3 Medição por contagem de franjas. $n$ é o número de franjas relativas ao deslocamento pico-a-pico. . . . . . . . . . . . . 70

5.4 Calibração do interferômetro. $V_{0}$ é a amplitude do sinal de calibração. $\mathrm{V}_{C}$ é o "nível CC" dos sinais, devido aos feixes de interferência não possuírem exatamente a mesma intensidade. $\mathrm{V}_{D}$ é a resposta pico-a-

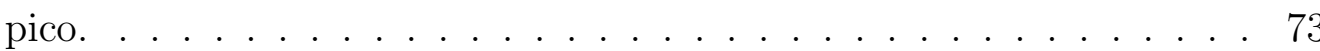

5.5 (a) ruído ambiente de baixa freqüência e sinal transiente esperado na resposta; (b) sinal observado no osciloscópio, o de baixa freqüência modula em amplitude o sinal de resposta. A notação (u.a.) significa

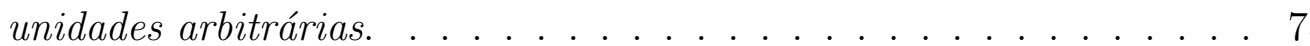

5.6 Evolução do sinal de resposta, observado em um osciloscópio. A aquisição deve ser realizada quando a resposta passa por um valor máximo. A notação (u.a.) significa unidades arbitrárias. . . . . . . . 76

5.7 Montagem experimental do interferômetro de Michelson. . . . . . . . 77

5.8 Foto do interferômetro de Michelson utilizado nas análises dos flex-

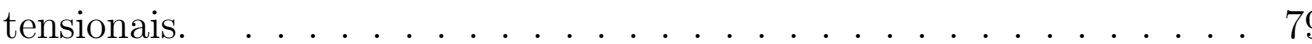

5.9 Interferômetro de Michelson estabilizado e controlado eletronicamente. 81

5.10 Interferômetro de Mach-Zehnder com dupla detecção de sinais ópticos defasados de $\pi / 2$.

5.11 Esquema gráfico do comportamento da polarização no interferômetro montado.

5.12 (a) Sinais de inteferência detectados em defasagem de $\pi / 2$. (b) Subtração dos sinais defasados, mostrando a resposta livre do ruído de baixas-freqüências. 
5.13 Foto do interferômetro de Mach-Zehnder modificado em regime de quadratura. ...................... 86

5.14 Esquema da montagem experimental utilizando o MTI-2000. . . . . 87

6.1 respostas elétricas da cerâmica de $5 \mathrm{~mm}$ de espessura na região da modo fundamental de vibração do comprimento. (a) curva da admitância elétrica e (b) curva da fase elétrica. . . . . . . . . . . . . . 91

6.2 respostas elétricas da cerâmica de $3 \mathrm{~mm}$ de espessura na região da modo fundamental de vibração do comprimento. (a) curva da admitância elétrica e (b) curva da fase elétrica. . . . . . . . . . . . . . 92

6.3 respostas elétricas da cerâmica de $1 \mathrm{~mm}$ de espessura na região da modo fundamental de vibração do comprimento. (a) curva da admitância elétrica e (b) curva da fase elétrica. . . . . . . . . . . . 93

6.4 Piezoatuadores flextensionais com cerâmicas de $5 \mathrm{~mm}$ de espessura. As demais dimensões das piezocerâmicas estão ilustradas na própria figura. Estes são denominados f1a1025, f1a0820, f1a20827 e f2b0830.

6.5 Piezoatuador flextensional f1b0820 com piezocerâmica de $3 \mathrm{~mm}$ de espessura. . . . . . . . . . . . . . . . . . . . . 97

6.6 Piezoatuador flextensional f1c0815 com piezocerâmica de $1 \mathrm{~mm}$ de espessura. ....................... . . 97

6.7 piezoatuador flextensional f1a1025 modelados por elementos finitos. (a) completo; (b) $1 / 4$ da simetria. . . . . . . . . . . . . . . . . . 98

6.8 Cargas mecânica e elétrica aplicadas ao flextensional na simulação. 99

6.9 Curvas de admitância elétrica experimental de simulada dos piezoatuadores flextensionais f1a1025 e f2b0830. . . . . . . . . . . . 101

6.10 Curvas de admitância elétrica experimental de simulada dos piezoatuadores flextensionais: (a) f1b0820 e (b) f1c0815. . . . . . . . . . . . 102

6.11 (a) Foto do fixador dos atuadores flextensionais ou piezocerâmicas na montagem no interferômetro laser. (b) esquema indicando o engaste dos três parafusos. . . . . . . . . . . . . . . . . . . . . 104

6.12 Sinal de excitação transiente dos atuadores flextensionais e cerâmicas piezelétricas. A voltagem é $30 \mathrm{~V}_{p-p}$. . . . . . . . . . . . . 105 
6.13 Resposta transiente do deslocamento dos piezoatuadores: f1a1025, f2b0830, f1a0820 e f1a20827, que utilizam uma cerâmica de 5 mm de espessura como elemento ativo. . . . . . . . . . . . . . 106

6.14 Espectro de magnitude do sinal de excitação transiente. ...... 107

6.15 Espectro de magnitude do sinal de excitação transiente e das respostas do deslocamento sob essa excitação dos flextensionais f1a1025, f2b0830, f1a0820 e f1a20827. . . . . . . . . . . . . . . 108

6.16 Resposta normalizada do deslocamento em freqüência do (a)f1a1025 e (b)f2b0830. . . . . . . . . . . . . . . . . . . . 109

6.17 Taxa de amplificação dos deslocamentos (a)f1a1025 e (b)f2b0830. . 109

6.18 sinais de excitação e resposta dos atuadores flextensionais. (a)intervalo linear; (b) intervalo não-linear. . . . . . . . . . . . . . . . . . . . . . 110

6.19 Resultados experimentais e simulados da análise estática do deslocamento dos piezoatuadores flextensionais: (a) f1a1025 e (b) f1b0820. . 111

6.20 Resultados experimentais e simulados do deslocamento do piezoatuador flextensional f1c0815. (a) intervalo linear e (b) intervalo nãolinear mostrando histerese ferrelétrica. . . . . . . . . . . . . . . 111

6.21 Resultados experimentais do deslocamento da cerâmica de $1 \mathrm{~mm}$ de espessura na direção 3, com e sem o espelho. . . . . . . . . . . . . 113

6.22 Resposta transiente das cerâmicas de $1 \mathrm{~mm}, 3 \mathrm{~mm}$ e $5 \mathrm{~mm}$ de espessura. Para todas essas, a resposta transiente simulada é idêntica. . . 113

6.23 Resposta do deslocamento com as cerâmicas sob excitação transiente. A espessura das cerâmicas é:(a) $5 \mathrm{~mm}$; (b) $3 \mathrm{~mm}$ e (c) $1 \mathrm{~mm} . \quad$. . . . 114

6.24 Análise no domínio das freqüências das respostas das piezocerâmicas de espessura:(a) $5 \mathrm{~mm}$; (b) $3 \mathrm{~mm}$ e (c) $1 \mathrm{~mm}$. . . . . . . . . . . 115

6.25 Condição de contorno para simular cerâmicas piezelétricas engastadas por três pontos. O elemento usando no engaste é o LINK1. . . . . 116

6.26 resultados da análise transiente da cerâmica de $1 \mathrm{~mm}$ de espessura, com espelho e com elemento LINK1. (a) resposta da análise transiente no domínio do tempo e (b) resposta no domínio das freqüências. 117 
6.27 análise elétrica da cerâmica de $1 \mathrm{~mm}$ de espessura com espelho fixado em sua superfície. (a) resultados experimentais da admitância elétrica e fase e (b) resultados numéricos. . . . . . . . . . . . . . . . . 117

6.28 Deformação da cerâmica de $1 \mathrm{~mm}$ de espessura para um mesmo valor de campo elétrico e engastadas pelo elemento LINK1. (a) sem espelho e (b) com espelho colado. . . . . . . . . . . . . . . . . 118

6.29 Resultado da deformação da cerâmica de $1 \mathrm{~mm}$ de espessura em análise estática, para um mesmo valor de campo elétrico e engastadas pelo elemento LINK1. (a) sem espelho e (b) com espelho colado. . 119

6.30 Foto da piezocerâmica com espelho engastada a uma estrutura em alumínio. . . . . . . . . . . . . . . . . . . . 119

6.31 Modelo completo da piezocerâmica com espelho, montada sobre uma base de alumínio com. . . . . . . . . . . . . . . . . . 120

6.32 Análise modal da piezocerâmica: (a) primeira freqüência de ressonância, (b) segunda freqüência de ressonância e (c) terceira freqüência de ressonância. . . . . . . . . . . . . . . . . 120

6.33 (a) Resposta em freqüência da admitância elétrica. (b) Resposta da fase. . . . . . . . . . . . . . . . . . . . . . . . . . . .

6.34 (a) Sinal senoidal de excitação transiente centrado em $10 \mathrm{kHz}$. (b) Espectro de freqüência do sinal de excitação. (c) Resposta da piezocerâmica ao sinal transiente. . . . . . . . . . . . . . . . . . 121

6.35 Atuador bilaminar: (a) foto com as escalas; (b) com o espelho e montado como uma viga em balanço. . . . . . . . . . . . . . . . 122

6.36 Cantiléver bilaminar engastado com 40 mm livres e com 20 mm livres. 123

6.37 Atuador bilaminar simulado no ANSYS (a) 2D ilustrando o primeiro modo; (b) o segundo modo de vibração. . . . . . . . . . . . . . . . . 124

6.38 Resultados experimental e simulado da resposta do deslocamento em freqüência. . . . . . . . . . . . . . . . . . . 125

6.39 Primeiro modo de vibração do atuador cantiléver bilaminar simulado no ANSYS com 20 mm livres. . . . . . . . . . . . . . . 125

6.40 Resultados experimental e simulados do cantiléver engastado com $20 \mathrm{~mm}$ livres e $14 \mathrm{~mm}$ livres. . . . . . . . . . . . . . . . 126 
6.41 Foto em duas perspectivas e as dimensões do engaste, do bilaminar e do espelho. . . . . . . . . . . . . . . . . . 126

6.42 (a) Curva de admitância elétrica experimental. (b) Curva de admitância elétrica experimental. . . . . . . . . . . . . . . . . 127

6.43 Piezoatuadores flextensionais, com pilhas piezoatuadoras, denominados f3a0930 e f3a1030. . . . . . . . . . . . . . . . . 128

6.44 Resposta do deslocamento das pilhas piezoatuadores nuas: (a) Intervalo linear e (b) intervalo não linear. . . . . . . . . . . . . . . . . . . 129

6.45 Comportamento não-linear das pilhas piezoatuadores para alto campo elétrico coercitivo: (a) resposta do deslocamento pelo tempo e (b) resposta do deslocamento por tensão elétrica. ......... 129

6.46 (a) Resposta do f3a0930 e (b) resposta do f3a1030. . . . . . . . . . . 130

6.47 Resposta do f3a1030 até o limite de $50 \mathrm{~V}$ de amplitude. . . . . . . . 131

6.48 Atuador f1c0930 submetido a campo elétrico acima de $30 \mathrm{~V}$ de amplitude. (a) resposta pelo tempo e (b) resposta por tensão. . . . . . 131

A.1 Cerâmica piezelétrica com polarização na direção z. . . . . . . . . . 150

A.2 Cerâmica piezelétrica com polarização na direção y . . . . . . . . . 152

A.3 Cerâmica piezelétrica com polarização na direção $x$. . . . . . . . . . 153

B.1 Interferômetro de Michelson, ilustrando a diferença $\delta$ no caminho óptico entre os feixes referência e sinal. . . . . . . . . . . . . . . 155

B.2 Fase $\phi$ entre duas ondas eletromagnéticas. . . . . . . . . . . . 155

B.3 Onda harmônica plana. A fase é constante ao longo da direção transversal da onda. . . . . . . . . . . . . . . . . . 156

C.1 Distribuição aleatória das fibras emissoras e sensoras de luz do MTI2000 .

C.2 Detecção das intensidades refletidas pela amostra, a medida que esta afasta-se das fibras. . . . . . . . . . . . . . . . . . . 159

C.3 Curva de calibração do sensor a fibra MTI-2000. . . . . . . . . . . . 160 


\section{Lista de Tabelas}

2.1 Relações mínimas entre as dimensões dos materiais piezelétricos, para a caracterização elétrica. . . . . . . . . . . . . . . 25

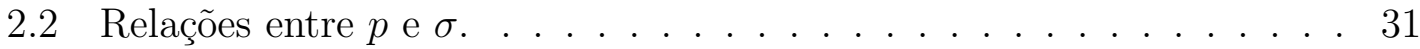

4.1 Aplicações dos piezoatuadores flextensionais em sistemas interferométricos. 57

6.1 Propriedades do PZT-5A usadas no ANSYS. . . . . . . . . . . . 90

6.2 Dimensões das piezocerâmicas (PZT-5A). . . . . . . . . . . . . . . 90

6.3 Propriedades do alumínio, resina epóxi e vidro. . . . . . . . . . . . 100

6.4 Dimensões dos espelhos e resina epóxi usadas nas simulações. . . . 114

6.5 Discos e placas piezelétricas PZT-5A utilizados na caracterização. . 132

6.6 Propriedades do PZT-5A. . . . . . . . . . . . . . . . . . . 133

C.1 Especificações da sonda à fibras ópticas. . . . . . . . . . . . . . . . . 161 


\section{Lista de Abreviaturas}

A atenuador óptico

A1 analisador 1 - polarizador óptico

A2 analisador 2 - polarizador óptico

BS Divisor de feixes (do inglês beam-splitter)

CC corrente contínua

D fotodetector

DOF graus de liberdade (do inglês degrees of freedom)

FO sensor a fibras ópticas

GPIB General-Purpose Interface Bus (IEEE488)

KLM comportamento de um transdutor piezelétrico baseado em modelo elétrico de Krimholt, Leedon e Matthaei

L lente convergente

laser light amplification by stimulated emission of radiation

$\mathrm{L}_{R} \quad$ comprimento do braço de referência do interferômetro (do inglês reference length)

$\mathrm{L}_{S} \quad$ comprimento do braço da amostra do interferômetro (do inglês sample length)

L1 lente convergente 1

L2 lente convergente 2

M Espelho do inglês mirror)

M1 Espelho 1

M2 Espelho 2

MEF Método de Elementos Finitos

MEMS Microelectrical Mechanical System

O objetiva de microscópio 
PBS Divisor de feixes polarizador

(do inglês polarizer beam-splitter)

PBS1 Divisor de feixes polarizador 1

PBS2 Divisor de feixes polarizador 2

PD fotodetector

PDA fotodetector pré-amplificado

PDA1 fotodetector pré-amplificado 1

PDA2 fotodetector pré-amplificado 2

piezoatuador atuador piezelétrico

piezocerâmica cerâmica piezelétrica

PMN Metaniobato de Chumbo

PVC Policloreto de Vinil

PVDF Polifluoreto Vinilideno

PZT Titanato Zirconato de Chumbo

R Espelho de referência

S Espelho da amostra analisada

u.a. unidades arbtrárias

$\lambda / 2 \quad$ Retardador de $1 / 2$ comprimento de onda

$\lambda / 4 \quad$ Retardador de $1 / 4$ de comprimento de onda 


\section{Lista de Símbolos}

\begin{tabular}{|c|c|c|}
\hline Símbolo & Significado & Unidades S \\
\hline$u_{i}$ & componente do deslocamento & {$[\mathrm{m}]$} \\
\hline$r_{i}$ & componente cartesiana & {$[\mathrm{m}]$} \\
\hline$S_{i j}$ & componente da deformação mecânica & \\
\hline$T_{i j}$ & componente da tensão mecânica & {$\left[N . m^{-2}\right]$} \\
\hline$\rho$ & densidade do material & {$\left[\mathrm{kg} \cdot \mathrm{m}^{-3}\right]$} \\
\hline$v_{i}$ & componente da velocidade & {$\left[\mathrm{m} . \mathrm{s}^{-1}\right]$} \\
\hline$c_{i j k l}$ & componente elástica de rigidez & {$\left[\mathrm{N} . \mathrm{m}^{-2}\right]$} \\
\hline$s_{i j k l}$ & componente elástica de flexibilidade & {$\left[\mathrm{m}^{2} \cdot \mathrm{N}^{-1}\right]$} \\
\hline$\lambda$ е $\boldsymbol{\mu}$ & constantes de Lamé & {$\left[\mathrm{N} \cdot \mathrm{m}^{-2}\right]$} \\
\hline$E$ & módulo de Young & {$\left[\mathrm{N} . \mathrm{m}^{-2}\right]$} \\
\hline$\sigma$ & coeficiente de Poisson & \\
\hline$G_{x}$ & constante elástica de cisalhamento & {$\left[N . m^{-2}\right]$} \\
\hline$c_{l}$ & velocidade da onda elástica longitudinal no meio & {$\left[\mathrm{m} \cdot \mathrm{s}^{-1}\right]$} \\
\hline$c_{s}$ & velocidade da onda elástica de cisalhamento no meio & {$\left[\mathrm{m} \cdot \mathrm{s}^{-1}\right]$} \\
\hline$c_{e}$ & velocidade da onda elástica extensional no meio & {$\left[\mathrm{m} \cdot \mathrm{s}^{-1}\right]$} \\
\hline$D_{i}$ & componente do deslocamento elétrico & {$\left[\right.$ C.m $\left.{ }^{-2}\right]$} \\
\hline$E_{i}$ & componente do campo elétrico & {$\left[\mathrm{V} \cdot \mathrm{m}^{-1}\right]$} \\
\hline$\epsilon_{i j}$ & componente da constante dielétrica relativa & {$\left[\mathrm{F} \cdot \mathrm{m}^{-1}\right]$} \\
\hline$e_{i j k}$ & $\begin{array}{l}\text { constante piezelétrica, } \\
\text { tensão mecânica/campo elétrico }\end{array}$ & {$\left[\mathrm{C} . \mathrm{m}^{-2}\right]$} \\
\hline$E$ (sobrescrito) & a campo elétrico constante & {$[\mathrm{V} / \mathrm{m}]$} \\
\hline$S$ (sobrescrito) & a deformação mecânica constante & \\
\hline$D$ (sobrescrito) & a deslocamento elétrico constante & \\
\hline$T$ (sobrescrito) & a tensão mecânica constante & \\
\hline$d_{i j k}$ & $\begin{array}{l}\text { constante piezelétrica, } \\
\text { deformação mecânica/campo elétrico }\end{array}$ & $\begin{array}{l}{\left[\mathrm{m} . \mathrm{V}^{-1}\right] \mathrm{ou}} \\
{\left[\mathrm{C} \cdot \mathrm{N}^{-1}\right]}\end{array}$ \\
\hline
\end{tabular}




\begin{tabular}{|c|c|c|}
\hline Símbolo & Significado & Unidades SI \\
\hline \multirow[t]{2}{*}{$h_{i j k}$} & constante piezelétrica, & {$\left[\mathrm{V} \cdot \mathrm{m}^{-1}\right] \mathrm{ou}$} \\
\hline & campo elétrico/deformação & {$\left[\mathrm{N} . \mathrm{C}^{-1}\right]$} \\
\hline \multirow[t]{2}{*}{$g_{i j k}$} & constante piezelétrica, & {$\left[\mathrm{V} \cdot \mathrm{m} \cdot \mathrm{N}^{-1}\right] \mathrm{ou}$} \\
\hline & campo elétrico/tensão mecânica & {$\left[\mathrm{m}^{2} \cdot \mathrm{C}^{-1}\right]$} \\
\hline$\beta$ & impermeabilidade elétrica & {$\left[\mathrm{m} . \mathrm{F}^{-1}\right]$} \\
\hline$l$ & comprimento & {$[\mathrm{m}]$} \\
\hline$w$ & largura & {$[\mathrm{m}]$} \\
\hline$t$ & espessura & {$[\mathrm{m}]$} \\
\hline$d$ & diâmetro & {$[\mathrm{m}]$} \\
\hline$m$ & massa do corpo & {$[\mathrm{kg}]$} \\
\hline$V$ & volume do corpo & {$\left[\mathrm{m}^{-3}\right]$} \\
\hline$A$ & área da superfície da piezocerâmica & {$\left[\mathrm{m}^{2}\right]$} \\
\hline$C$ & capacitância elétrica & {$[\mathrm{F}]$} \\
\hline$Y$ & admitância elétrica & {$[\mathrm{S}]$} \\
\hline$Z$ & impedância elétrica & {$[\Omega]$} \\
\hline$i$ & $\sqrt{-1}$ & \\
\hline$f$ & freqüência & {$[\mathrm{Hz}]$} \\
\hline$\omega$ & freqüência angular $(2 \pi f)$ & {$[\mathrm{Hz}]$} \\
\hline$R$ & resistência elétrica & {$[\Omega]$} \\
\hline$X$ & reatância elétrica & {$[\Omega]$} \\
\hline$G$ & condutância elétrica & {$[\mathrm{S}]$} \\
\hline$B$ & susceptância elétrica & {$[\mathrm{S}]$} \\
\hline$f_{p}$ & freqüência da resistência elétrica máxima & {$[\mathrm{Hz}]$} \\
\hline$f_{s}$ & freqüência da condutância elétrica máxima & {$[\mathrm{Hz}]$} \\
\hline$k_{33}$ & coeficiente de acoplamento da espessura & \\
\hline$k_{31}$ & coeficiente de acoplamento longitudinal & \\
\hline$k_{p}$ & coeficiente de acoplamento planar & \\
\hline$k_{15}$ & coeficiente de acoplamento de cisalhamento & \\
\hline$k_{t}$ & coeficiente de acoplamento da espessura & \\
\hline$Q_{m}$ & fator de qualidade mecânico & \\
\hline$F$ & força & {$[\mathrm{N}]$} \\
\hline$k$ & rigidez & {$\left[\mathrm{N} . \mathrm{m}^{-1}\right]$} \\
\hline
\end{tabular}




\begin{tabular}{|c|c|c|}
\hline Símbolo & Significado & Unidades SI \\
\hline$\eta$ & fator de perdas (ligada ao amortecimento) & \\
\hline$c_{c}$ & amortecimento crítico & {$[\mathrm{kg} \cdot \mathrm{Hz}]$} \\
\hline$\zeta$ & coeficiente de amortecimento & \\
\hline$\alpha$ & constante multiplicadora da & \\
\hline$\beta$ & $\begin{array}{l}\text { matriz massa } \\
\text { constante multiplicadora da } \\
\text { matriz de rigidez }\end{array}$ & \\
\hline$Q$ & cargas elétricas & {$[\mathrm{C}]$} \\
\hline$\left[\mathbf{M}_{\mathbf{U U}}\right]$ & matriz massa & {$[\mathrm{kg}]$} \\
\hline$\left[\mathbf{C}_{\mathbf{U U}}\right]$ & matriz de amortecimento mecânico & \\
\hline$\left[\mathbf{K}_{\mathbf{U U}}\right]$ & matriz de rigidez elástica & {$\left[\mathrm{N} . \mathrm{m}^{-1}\right]$} \\
\hline$\left[\mathbf{K}_{\mathbf{U} \Phi}\right]$ & matriz de rididez piezelétrica & \\
\hline$\left[\mathbf{K}_{\Phi \Phi}\right]$ & matriz de rigidez dielétrica & {$[\mathrm{C}]$.} \\
\hline$\beta_{j}$ & constante multiplicadora da matriz rigidez & \\
\hline$\beta_{c}$ & variável multiplicadora da matriz rigidez & \\
\hline $\mathbf{C}_{\zeta}$ & matriz amortecimento dependente da freqüência & \\
\hline $\mathbf{C}_{k}$ & matriz amortecimento do elemento & \\
\hline$\left[\mathbf{C}_{\Phi \Phi}\right]$ & matriz de amortecimento dielétrico & \\
\hline$I$ & corrente elétrica & {$[\mathrm{A}]$} \\
\hline$\phi$ & fase & $\mathrm{rad}$ \\
\hline$\lambda$ & comprimento de onda & {$[\mathrm{m}]$} \\
\hline$\vec{k}$ & vetor de onda $(2 \pi / \lambda)$ & {$\left[\mathrm{m}^{-1}\right]$} \\
\hline$I$ & intensidade da luz & {$\left[\mathrm{W} \cdot \mathrm{m}^{-2}\right]$} \\
\hline$V_{x}$ & tensão elétrica & {$[\mathrm{V}]$} \\
\hline
\end{tabular}




\section{Capítulo 1}

\section{Introdução}

A utilização conjunta de técnicas ópticas, elétricas e numéricas, permite uma melhor compreensão do comportamento de transdutores piezelétricos e a determinação de vários fatores que influenciam em seu comportamento. Estes fatores são, por exemplo, amortecimento da estrutura, resposta do deslocamento em freqüência, resposta a uma excitação transiente, resposta em freqüência da admitância elétrica, frequiência de ressonância e anti-ressonância, acoplamento entre as estruturas do transdutor piezelétrico etc.

Técnica ópticas são muito utilizadas em análises de transdutores piezelétricos [1, 2,3] na freqüência do ultra-som (de alguns $\mathrm{MHz}$ até $\mathrm{GHz}$ ) em baixas freqüências (alguns $\mathrm{kHz}$ ) ou em regime estático (abaixo de $1 \mathrm{~Hz}$ ou sob corrente contínua). As técnicas são empregadas em medição de amplitude de vibração e geração de ultrasom a laser [1]. Em análises de amplitude de vibração as medições podem atingir uma precisão de subangströms [4]. Porém, para atingir essa precisão há necessidade de minimizar a influência dos ruídos ambientes de baixa freqüência (menores que $1 \mathrm{kHz}$ ) do sinal de resposta. O ruído ambiente tem amplitude de vibração na ordem

de alguns nanômetros [5], e modula em amplitude o sinal de resposta das análises, em medições na ordem de alguns nanômetros. Esse ruído, por ser aditivo (soma-se ao sinal de resposta) não pode ser eliminado através de filtragens no sinal adquirido, ele necessita ser separado, do sinal de resposta do transdutor, durante o processo de aquisição do sinal.

Os sistemas ópticos mais utilizados em medições de deslocamento, da faixa de 
alguns nanômetros até subangströms, são os interferômetros heteródinos ${ }^{1}[4,6,7,8]$, que utilizam um laser Zeeman ou um modulador acusto-óptico em um dos feixes laser, dessa forma é possível separar a freqüência do ruído ambiente da freqüência de resposta do transdutor analisado, através de análises no espectro de freqüências do sinal detectado.

Interferômetros em quadratura ${ }^{2}$ também são bastante utilizados nas medições de deslocamento $[1,9,10]$. Através da subtração dos sinais, adquiridos simultaneamente, obtém-se a resposta livre do ruído ambiente. Estes dois sistemas interferométricos são utilizados em medições de deslocamento estático até amplitudes de vibração na ordem de alguns MHz. Os arranjos padrões dos interferômetros em quadratura utilizam montagem tipo-Michelson $[1,9,10]$. A sugerida por VILKOMERSON [9] utiliza o menor número de componente ópticos, no entanto, não há controle de intensidade entre os feixes sinal e referência (capítulo 5), e há perda de no mínimo $50 \%$ da energia luminosa do laser nas reflexões no divisor de feixes. Na montagem utilizada por ZHANG et al. [10] há pouca perda de energia luminosa nas reflexões dos feixes laser, no divisor de feixes, no entanto, não há controle sobre a intensidade dos feixes sinal e referência.

O sistema interferométrico montado em regime de quadratura, utiliza um arranjo modificado do interferômetro de Mach-Zehnder. A montagem sugerida neste trabalho utiliza um número maior de componentes ópticos, porém propicia um maior controle das intensidades dos feixes laser, sinal e referência, que é importante em análises interferométricas, como está explicado na seção 5.5.1. Esse sistema interferométrico permite realizar medições com as amostras piezelétricas submetidas a tensões elétrica CC até a freqüência de aquisição limite dos fotodetectores. Arranjos similares a esse são utilizados por ROYER [4] e POLYTEC [11] em configuração heteródina, porém esses sistemas interferométricos não possuem controle de intensidade dos feixes referência e sinal, havendo múltiplas reflexões nos divisores de feixe, que são indesejáveis, porque isso acarreta em perda da energia luminosa dos feixes laser. Outro motivo para adotar a configuração desse interferômetro, é a possibil-

\footnotetext{
${ }^{1}$ interferometria heteródina: interferência entre feixes laser com freqüências ópticas ligeiramente distintas (em torno de $60 \mathrm{MHz}$ ), tal que a interferência entre esses feixes produz uma modulação em freqüência (batimento).

2 interferômetros em quadratura possuem dois fotodetectores, que detectam os sinais de interferência defasados de $\pi / 2$.
} 
idade de torná-lo heteródino apenas acrescentando, entre os componentes ópticos, um modulador acusto-óptico, com está descrito na seção 5.5.3.

Uma outra forma de minimizar a influência dos ruídos ambientes do sinal de resposta, é utilizar interferômetros controlados eletronicamente com filtros passabaixas, que compensam a vibração ambiente através de dispositivos eletro-mecânicos ou eletro-ópticos [1]. A compensação eletro-mecânica é realizada fixando o espelho de referência em um atuador piezelétrico [12], mas essa compensação pode apresentar muita instabilidade mecânica nos dispositivos, e não podem ser realizadas medições de amplitudes de vibração abaixo da freqüência máxima do filtro passa-baixas. A compensação eletro-óptica é realizada sem movimentos mecânicos dos dispositivos de controle, pois a estabilização do interferômetro é realizada através da variação do índice de refração de cristais eletro-ópticos [1], como por exemplo o niobato de lítio $\left(\mathrm{LiNbO}_{3}\right)$, o fosfato de hidrogênio e potássio (KDP) etc., que apresentam efeito eletro-óptico linear (Pockels) ou quadrático (Kerr) [13] quando aplicado um campo elétrico. No entanto, a compensação eletro-óptica máxima é dois comprimentos de onda do laser utilizado, que normalmente está dentro da faixa de amplitude do ruído apresentado.

O interferômetro tipo-Michelson montado, não possui controle de vibração ambiente. Porém pode ser utilizado com precisão de $1 \mathrm{~nm}$ nas análises, através da monitoração contínua do sinal de resposta. Pois, como está descrito na seção 5.4.1, o sinal de resposta passará por um máximo, quando a sensibilidade do interferômetro for máxima, e este deve ser o sinal a ser adquirido. Os resultado experimentais obtidos com essa técnica (ver seção 6.2.4), são comparados aos resultados obtidos pela análise numérica e apresentam boa concordância.

Além do ruído ambiente, outra dificuldade encontrada em análises de deslocamento, utilizando técnicas ópticas, está relacionada com a medição em superfícies ásperas ou o espelhamento da superfície analisada. A partir da década de 90, alguns autores iniciaram a mescla das técnicas interferométricas convencionais com holografia em cristais foto-refrativos para medição de movimentos ultra-sônicos em superfícies ásperas $[14,15,16,17]$. Os resultados apresentados por POUET et al. [17] mostram que deslocamentos na ordem de poucos nanômetros podem ser medidos com boa precisão. No entanto, dos trabalho publicados até agora, apenas 
ING e MONCHALIN [14], os precursores da técnica, relatam a possibilidade de utilizar esse tipo de sistema interferométrico em medições de amplitudes de vibração desde $1 \mathrm{kHz}$ e $20 \mathrm{MHz}$, embora nenhum trabalho mostre resultados experimentais na faixa de alguns quilohertz. Provavelmente essas análises dependam do tempo de resposta dos cristais foto-refrativos [16, 18]. Por esses motivos, não há possibilidade de utilizar os interferômetros foto-refrativos em medições de deslocamento estático

Soluções, para análise interferométrica de superfícies ásperas, são normalmente a fixação de espelhos ou polimento óptico nas superfícies analisadas [10]. A fixação de espelhos introduz modificações no comportamento das cerâmicas piezelétricas, pois há alterações na freqüência de ressonância devido ao acréscimo de massa e modificação na rigidez, como é mostrado na seção 6.3. O polimento óptico é uma boa opção, porém nem sempre é possível, como por exemplo no caso do atuador piezelétrico flextensional mostrado na Figura 1.1, devido a sua forma complexa. Uma solução que apresenta bons resultados, não influenciando no comportamento das cerâmicas piezelétricas e dos atuadores é a fixação de adesivos de poliéster metalizado nas superfícies analisadas. A focalização do feixe laser na superfície do poliéster reduz o espalhamento da luz refletida $[1,2]$.

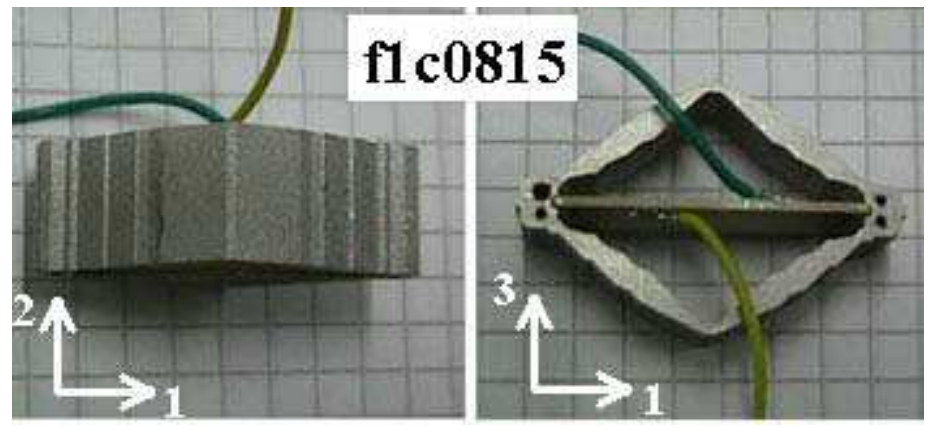

Figura 1.1. Visão frontal e lateral de um atuador piezelétrico flextensional projetado por otimização topológica e denominado f1c0815.

Na análise estática das cerâmicas piezelétricas ou dos atuadores piezelétricos flextensionais, não há influência do amortecimento [19], porém, em análises harmônica (senoidal contínua) ou transiente (um ciclo de seno, por exemplo) há influência do amortecimento. O amortecimento é um parâmetro importante na análise vibracional de uma estrutura, e no tratamento do amortecimento devem ser levados em conta as contribuições da massa e da rigidez da estrutura analisada, pois esses três 
parâmetros estão diretamente ligados (seção 2.4). A literatura clássica sobre vibração e amortecimento de estruturas [19, 20] não apresenta de forma satisfatória o tratamento e como determinar o amortecimento de uma estrutura. Os softwares de elementos finitos, tal como o ANSYS, permitem a modelagem e análise vibracional de uma estrutura, porém há diversas formas de inserir (entradas) o valor do amortecimento [21]. Os valores de amortecimento, de metais ou polímeros, fornecidos [22] apresentam valores altos para serem inseridos no ANSYS, e ao comparar os resultados experimentais e numéricos há uma grande diferença. Por esse motivo, desenvolver uma técnica de determinar o amortecimento é muito importante para o projeto e modelagem de transdutores piezelétricos.

As melhores considerações sobre amortecimento são relatadas em artigos na área de elementos finitos, devido a necessidade de inserir os amortecimentos nas simulações das estruturas, para uma aproximação da realidade. A formulação vibracional piezelétrica, para elementos finitos, foi inicialmente desenvolvida por ALLIK e HUGHES [23], sem considerar o amortecimento. Os primeiros a considerarem o amortecimento, na formulação piezelétrica do método de elementos finitos (MEF), foram NAILLON et al. [24], e até hoje este é um dos melhores trabalhos sobre o assunto, embora o resultado da impedância elétrica, obtida por esses autores, utilizando o MEF não considere o amortecimento. Algumas considerações sobre os coeficientes de amortecimento também são relatadas por $[25,26]$. Em seu trabalho, LERCH [26] atribui valores às constantes multiplicadoras da matriz massa e da matriz rigidez (seção 3.2), de forma a casar os resultados experimentais e simulados da impedância elétrica. No entanto, para o caso de um transdutor piezelétrico vibrando, o amortecimento considerado é o viscoso. Dessa forma, a constante multiplicadora da matriz massa deve ser nula, de acordo com o próprio autor [26]. Trabalhos mais recentes sobre amortecimento no $\operatorname{MEF}[27,28]$ apresentam maiores detalhes sobre as considerações no ANSYS, no entanto também não apresentam o processo de determinação do amortecimento.

A forma de determinação do amortecimento proposta, consiste na utilização em conjunto das técnicas ópticas, elétricas e numéricas. Através da análise elétrica da impedância e admitância elétrica, é possível calcular diretamente o amortecimento da cerâmica piezelétrica, através do fator de qualidade mecânico (seção 2.4.1). Os 
amortecimentos da estrutura flexível de alumínio, utilizadas nos transdutores flextensionais, e do vidro, utilizado como espelho nas cerâmicas piezelétricas, são determinados através da comparação entre os resultados experimentais e simulados obtidos nas análises da impedância elétrica e da análise transiente do comportamento vibracional do transdutor. Os resultados obtidos mostram uma boa concordância, como descrito no capítulo dos resultados experimentais e numéricos (capítulo 6).

Uma cerâmica piezelétrica tem seu comportamento influenciado pelas constantes dielétricas, das constantes piezelétricas e das constantes de rigidez mecânica, além da densidade que influencia na freqüência de ressonância. Os valores dessas constantes são fornecidos pelos fabricantes, e podem apresentar erro de até 20\%. O amortecimento não é fornecido pelos fabricantes, e este varia com a freqüência, assim como os valores das constantes dielétricas também variam com a freqüência. Dessa forma, desenvolver uma técnica de determinação, ou verificação, dos valores das constantes dielétrica, piezelétricas e mecânicas de uma cerâmica piezelétrica permite que as modelagens sejam realizadas com maior aproximação da realidade. A determinação do valor dessas constantes é realizada com um analisador de impedâncias de acordo com vários autores [29, 30, 31, 32, 33, 34].

As análises numéricas, utilizando o software ANSYS, de elementos finitos, permitem uma modelagem com todos os componentes mecânicos das estruturas analisadas. Assim, é possível inserir espelhos, adesivos, formas de fixação da estrutura, entre outros, e verificar a influência de cada um desses parâmetros no comportamento do transdutor piezelétrico. Pois, nas análises experimentais esses componentes, que em princípio teriam sua influência desprezada, contribuem no comportamento dos transdutores piezelétricos.

Este trabalho salienta a importância de se trabalhar em conjunto com técnicas experimentais e numéricas. Pois uma complementa a outra. Durante os anos em que esse trabalho foi desenvolvido, muitas análises apresentaram resultados experimentais e numéricos muito distintos. Isso ocorria devido às condições de contorno experimentais e numéricas serem diferentes, ou então, ao valor das constantes dos materiais serem diferentes dos valores fornecidos pelos fabricantes. As condições de contorno, às quais a amostra analisada está submetida, muitas vezes não são consideradas em sua totalidade. Mas, ao comparar os resultados experimentais e 
numéricos, verifica-se a importância de cada grau de liberdade de um sistema e de vários fatores externos ao meio em consideração.

Ao longo deste texto, principalmente no capítulo 6, denominado Resultados Experimentais e Numéricos, é mostrada a importância em se trabalhar em conjunto com as técnicas ópticas, elétricas e numéricas. Principalmente nas análises da influência de espelhos, adesivos e condições de restrição mecânicas que influenciam o comportamento das piezocerâmicas.

\subsection{Motivação}

A motivação desse trabalho surgiu através da necessidade da análise de transdutores piezelétricos flextensionais, e validação do método de otimização topológica utilizado para projetá-los [35]. Esses materiais são projetados como amplificadores acústicos e de deslocamento da cerâmica piezelétrica na direção 3, como mostra a Figura 1.1. A proposta desses dispositivos é de uso como atuadores [36, 37, 38, 39, 40], sonares [41] e hidrofones [42]. Por isso, neste trabalho serão chamados de atuadores piezelétricos flextensionais, ou simplesmente piezoatuadores flextensionais.

As análises desses materiais envolvem a determinação das freqüências de ressonância; o deslocamento por campo elétrico do ponto projetado para maior deslocamento; e também da taxa de amplificação do deslocamento. Para essas análises foram desenvolvidos sistemas os ópticos para medição pontual do deslocamento, descritos anteriormente. Esses sistemas ópticos permitem também a determinação das freqüências de ressonância, porém, as análises elétricas, utilizando um analisador de impedância e fase, fornecem esses valores com maior precisão. As análises numéricas são utilizadas para a comparação com os resultados experimentais e para determinar a influência das condições de contorno.

Nas análises numéricas é utilizado o método de elementos finitos (MEF). Esse método computacional permite obter resultados muito próximos à realidade $[43,44$, 45, 46], para isso há necessidade de conhecer o valores das constantes dielétricas, mecânicas e piezelétricas dos materiais que fazem parte do atuador piezelétrico. Essas propriedades são as utilizadas nas equações constitutivas piezelétricas e nãopiezelétricas (ver capítulo 2) que o software de MEF utiliza. 
Na próxima seção são descritas algumas aplicações de transdutores piezelétricos e a metodologia empregada neste trabalho, incluindo as dificuldades de implementação.

\subsection{Materiais e Métodos}

Transdutores piezelétricos são utilizados em aplicações em baixas freqüências (na faixa de $\mathrm{Hz}$ a poucos $\mathrm{kHz}$ ) como posicionadores de peças mecânicas; em sistemas de varredura de microscópios de força atômica; em controle de vibração em interferômetros a laser, como motores piezelétricos, como hidrofones etc. Em aplicações a altas freqüências (na ordem de alguns $\mathrm{MHz}$ ) são utilizados em aplicações de imagens ultra-sônicas, em ensaios não-destrutivos, em aplicações médicas como diagnóstico, uso terapêutico etc. E na faixa do $\mathrm{GHz}$ em microscopia e holografia acústica.

As técnicas ópticas possuem muitas aplicações na indústria e seu uso é crescente nesse setor. As técnicas ópticas de interferometria apresentam grande sensibilidade, resolução, precisão, acurácia e não têm contato mecânico com o objeto em análise. Essas técnicas, que podem ser tanto interferométricas quanto não-interferométricas, são utilizadas para medições de deslocamento desde subangströms até uma dezena de metros. As técnicas ópticas também são utilizadas na medição de velocidade, deformação, forma, planicidade e esfericidade, tensão e pressão mecânica, sinais de ultra-som, reconhecimento de padrões, visualização de campo acústico ou fluxo etc.

Com o desenvolvimento do sistema óptico de interferometria a laser, para caracterização de transdutores piezelétricos [45, 47, 48, 49, 50], o Grupo de Sensores e Atuadores da EPUSP/Mecatrônica, que atua na área de transdutores piezelétricos, tem à sua disposição mais uma importante ferramenta de análise de transdutores piezelétricos. Atualmente são realizadas pelo grupo: medição de densidade e viscosidade de líquidos [51, 52]; transmissão acústica de dados [53]; formação de imagem através de ondas acústicas na freqüência do ultra-som; pig ultra-sônico [54]; otimização topológica aplicada ao projeto de transdutores piezelétricos flextensionais [35] e cerâmicas piezelétricas [55]; também estão sendo projetados: motores piezelétricos [56]; mecanismos flexíveis [57]; nanoposicionadores; e MEMS (microelectro mechanical systems). 
Projetos de transdutores piezelétricos podem ser realizados através de modelos de circuitos elétricos equivalentes aos piezelétricos, como o KLM, o de Mason e de Redwood [58, 59], que são unidimensionais. Porém alguns autores [35, 38, 60] realizam os projetos de transdutores piezelétricos de forma bidimensional, através de técnicas computacionais, baseadas no método de elementos finitos. As análises por elementos finitos mostram-se uma ferramenta de simulação de transdutores piezelétricos com resultados muito próximos à realidade [43].

Nas análises elétricas é utilizado um analisador de impedâncias (HP4194A). Nestas análises são obtidas as curvas de admitância elétrica dos atuadores piezelétricos, para verificar a resposta em freqüência e também se estes foram bem montados. A caracterização das cerâmicas é realizada através de informações obtidas das curvas de resistência, reatância, capacitância e susceptibilidade elétricas.

As técnicas experimentais, utilizadas neste trabalho, são bem conhecidas na literatura, bons textos sobre a interferometria são encontrados em $[1,2,3]$, sobre as técnicas elétricas de caracterização das piezocerâmicas em [29, 30, 31, 32, 33, 34]. No entanto, a implementação de interferômetros, com a resolução desejada neste trabalho, apresenta muitas dificuldades. Principalmente com relação aos efeitos da vibração ambiente (ruídos de baixa freqüência, menores que $1 \mathrm{kHz}$ ) sobre o sinal de resposta adquirido. Pois o ruído aditivo possui uma amplitude na mesma ordem ou superior à amplitude de deslocamento das amostras piezelétricas analisadas. Outro fator importante e de difícil contorno nas análises interferométricas é o espelhamento da superfície analisada. Neste trabalho são apresentadas soluções simples à esses problemas.

A caracterização elétrica dos materiais piezelétricos é dominada há anos. Porém, muitas cerâmicas piezelétricas ainda não possuem todas as suas constantes determinadas, e aquelas que possuem os valores das constantes fornecidas pelos fabricantes, como por exemplo, o PZT-5A, podem apresentar diferenças entre os valores tabelados e os medidos experimentalmente. Uma variação nos valores da massa e/ou rigidez e/ou fator de qualidade influenciam na freqüência de ressonância, amplitude de deslocamento e amortecimento. Por isso, buscou-se desenvolver neste trabalho, uma técnica experimental de caracterização de materiais piezelétricos, e no futuro, de materiais não-piezelétricos. Para que os resultados numéricos e experimentais 
sejam cada vez mais próximos.

\subsection{Objetivos}

\subsubsection{Desenvolvimento de Sistemas Ópticos de Medição}

- Desenvolvimento de sistemas ópticos interferométricos, para análises precisas de amostras piezelétricas sob regime de excitação harmônico, transiente e estático. A meta é desenvolver sistemas interferométricos com alta resolução (1 $\mathrm{nm}$ ou menor) e que os sinais de resposta possam ser adquiridos livres do ruído ambiente.

\subsubsection{Determinação das Propriedades dos Materiais Piezelétricos e Não-piezelétricos}

- Combinação das técnicas ópticas, elétricas e numéricas para determinação do amortecimento de materiais piezelétricos e não-piezelétricos, que fazem parte de um transdutor piezelétrico;

- Medição das propriedades eletro-piezo-mecânicas, a partir das curvas de resposta elétrica dos materiais piezelétricos.

\subsubsection{Análise de Atuadores Piezelétricos}

- Análise e validação dos modelos dos atuadores flextensionais projetados por otimização topológica.

- As análises experimentais são realizadas por sistemas ópticos, com os quais são feitas as medições de amplitude de deslocamento, amplificação, resposta do deslocamento pela freqüência, resposta no domínio do tempo e das freqüências a uma excitação senoidal e o amortecimento. Também são realizadas análises experimentais da admitância elétrica, através da qual determinam-se as freqüências de ressonância dos piezoatuadores flextensionais.

- As análises numéricas são realizadas pelo MEF, através da qual são obtidas as 
amplitudes de deslocamento, amplificação, resposta em freqüência do deslocamento, curvas de impedância elétrica e freqüências de ressonância.

- Determinação da influência dos espelhos fixados às piezocerâmicas e piezoatuadores, assim como a influência dos engastes no comportamento desses materiais.

\subsection{Organização da Tese}

Este trabalho está dividido em 7 capítulos, sendo o primeiro a introdução, no qual são descritos brevemente a contribuição deste trabalho, os materiais analisados, a motivação e as técnicas experimentais e numéricas empregadas nas análises. Os capítulos 2, 3, 4 e 5 contêm teorias e métodos empregados, resumidos a seguir.

O capítulo 2 apresenta a teoria de ondas elásticas em meios não-piezelétricos e piezelétricos. Esse capítulo é desenvolvido para a apresentação das equações constitutivas piezelétricas e não-piezelétricas na forma matricial e das equações de equilíbrio, as quais são resolvidas pelo software de elementos finitos, o ANSYS, para o comportamento de um transdutor piezelétrico. A técnica elétrica de determinação dos valores das constantes piezelétricas, também é descrita nesse capítulo. Através da técnica elétrica determina-se também o fator de qualidade mecânico, através do qual obtém-se o amortecimento dos materiais, que está relacionado com perdas mecânicas, dissipação de energia sob forma de calor etc. Por esse motivo, e pela importância do amortecimento no comportamento de sistemas, é descrito o amortecimento viscoso, considerado nas análises dos transdutores piezelétricos vibrando.

No capítulo 3 há uma breve introdução ao método de elementos finitos e às equações de movimento piezelétricas. Nesse capítulo também é discutido o amortecimento e como empregá-lo no MEF. No complemento desse capítulo é apresentada uma breve descrição das inversões de base no ANSYS, devido à mudança da direção de polarização, as considerações dos modelos bidimensionais, e as considerações de modelos planos e axi-simétricos.

No capítulo 4 é realizada uma apresentação aos atuadores piezelétricos analisados: flextensional, bilaminar, unilaminar e em pilhas piezelétricas. Também é 
descrita algumas possíveis aplicações destes em interferômetros a laser.

O capítulo 5 apresenta a teoria sobre medição de deslocamento por sistemas ópticos interferométricos baseado no deslocamento de fase do sinal de interferência. Neste capítulo são mostrados também os interferômetros desenvolvidos, que são o interferômetro de Michelson, no qual pretende-se utilizar um sistema de estabilização, e um interferômetro de Mach-Zehnder em quadratura, com o qual podem ser realizadas medições tanto em regime estático quando na freqüência do ultra-som, eliminando o ruído ambiente através de subtração de sinais de interferência.

O capítulo 6 apresenta as análises experimentais e numéricas dos piezoatuadores e piezocerâmicas.

No capítulo 7 são apresentadas uma discussão e as conclusões sobre os resultados obtidos e as perspectivas futuras. 


\section{Capítulo 2}

\section{Propriedades dos Materiais Piezelétricos e Não-piezelétricos}

Transdutores piezelétricos são dispositivos eletro-mecânicos que convertem energia elétrica em mecânica e vice-versa. Na montagem de transdutores piezelétricos são utilizados materiais piezelétricos e não-piezelétricos, os quais, durante o processo de excitação elétrica do transdutor, produzem vibração mecânica. Um meio material quando sofre deformações ou vibrações está sujeito a forças atuando em seus átomos. Essas são forças elásticas que tendem a restaurar a posição de equilíbrio dos átomos. O comportamento macroscópico desses corpos é explicado pela teoria da elasticidade quando considera-se um meio contínuo [58, 59, 61, 62].

Piezocerâmicas, como os tipos de titanato zirconato de chumbo (PZT-4, PZT-5, PZT-7 e PZT-8) possuem suas propriedades dielétricas, piezelétricas e mecânicas geralmente fornecidas pelos fabricantes, com pequenas variações de um fabricante para outro (em torno de 5\%), porém os erros nos valores fornecidos podem chegar a 20\%. No entanto, materiais piezelétricos como o metaniobato de chumbo (PMN), o polifluoreto vinilideno (PVDF), um tipo de policloreto de vinil (PVC), que apresenta piezeletricidade, entre outros materiais piezelétricos, não possuem todas as suas constantes fornecidas pelos fabricantes. Além disso, dos materiais nãopiezelétricos (isotrópicos), usados na fabricação de transdutores piezelétricos (resina epóxi, metais etc.), podem ser obtidos valores tabelados do módulo de elasticidade, da densidade, do coeficiente de Poisson, do coeficiente de expansão térmica. No entanto, há necessidade de desenvolver uma técnica de medição de uma impor- 
tante propriedade mecânica, que é o amortecimento, tanto dos materiais piezelétricos (anisotrópicos), quanto dos materiais não-piezelétricos. O amortecimento influencia em perdas mecânicas e consequentemente em produção de calor. Dessa forma, conhecer o amortecimento dos componentes de um transdutor piezelétrico, permite uma modelagem mais precisa desses transdutor.

Com o conhecimento de todas as propriedades das piezocerâmicas e dos outros materiais que fazem parte de um transdutor piezelétrico, pode-se, através do método de elementos finitos, projetar transdutores piezelétricos com o comportamento desejado antes de fabricar os protótipos. Assim como permite também o projeto de transdutores e piezocerâmicas por otimização topológica [63, 64].

Neste capítulo são apresentadas as equações constitutivas e as equações de equilíbrio dos transdutores piezelétricos e a determinação das suas constantes experimentalmente. No próximo capítulo são apresentados os tipos de amortecimento e o método de elementos finitos. Esses dois capítulos estão diretamente relacionados pelo fato das constantes descritas aqui serem as utilizadas no software de elementos finitos.

\subsection{Equações Constitutivas da Elasticidade}

A teoria da elasticidade é descrita considerando um meio contínuo [58, 59, 61]. Esta seção trata de sólidos isotrópicos, não-piezelétricos. São apresentadas a lei de Hooke generalizada e as constantes físicas relacionadas com a deformação mecânica $(S)$ e a tensão mecânica $(T)$ sofridas por um corpo. A notação utilizada é a tensorial [65], na forma matricial reduzida.

\subsubsection{Deformação Mecânica}

A deformação mecânica é uma variação do deslocamento numa determinada direção. Em geral, o deslocamento é um vetor $\{\mathbf{u}\}$ com três componentes cartesianas $u_{i}$, com $i=1,2,3$. Cada qual pode ser uma função das três componentes cartesianas do vetor $\{\mathbf{r}\}$, que são $x_{i}$, para $i=1,2,3$.

As deformações de um corpo podem ser longitudinal ou de cisalhamento, como mostra a Figura 2.1. Uma deformação unidimensional longitudinal terá uma com- 
ponente

$$
S_{i i}=\frac{\partial u_{i}}{\partial x_{i}}
$$

Enquanto que, uma deformação unidimensional de cisalhamento terá uma componente

$$
S_{i j}=\frac{1}{2}\left(\frac{\partial u_{i}}{\partial x_{j}}+\frac{\partial u_{j}}{\partial x_{i}}\right) .
$$

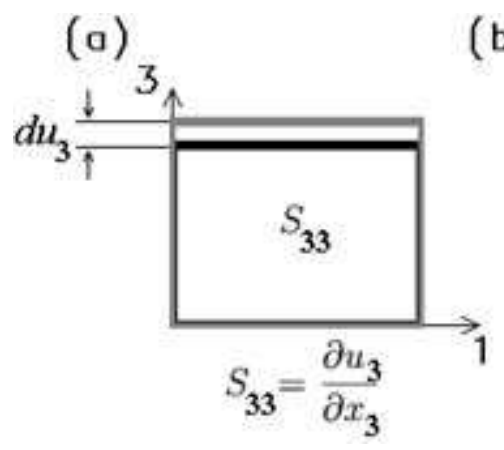

(b)

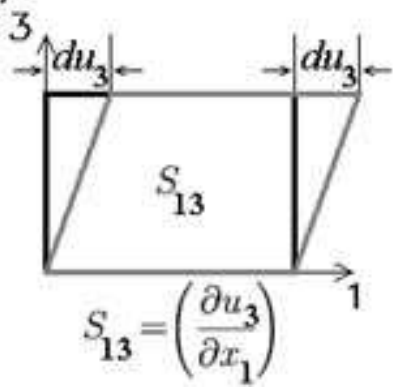

(c)

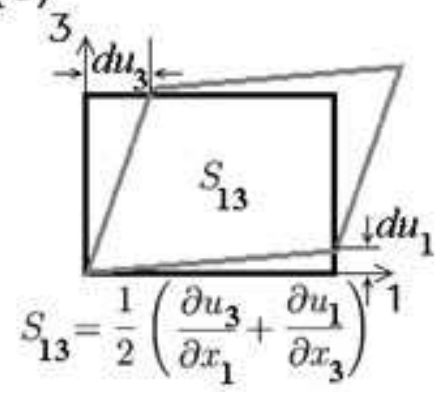

Figura 2.1. (a) deformação longitudinal, (b) deformação de cisalhamento simples e (c) deformação de cisalhamento puro.

Considerando a deformação com as componentes $x, y$ e $z$, pode-se escrever o tensor deformação $S_{i j}$, que é de segunda ordem [65], na seguinte forma matricial:

$$
[\mathbf{S}]=\left[\begin{array}{ccc}
S_{x x} & S_{x y} & S_{x z} \\
S_{y x} & S_{y y} & S_{y z} \\
S_{z x} & S_{z y} & S_{z z}
\end{array}\right] .
$$

O tensor deformação mecânica é simétrico, pois $S_{y x}=S_{x y}, S_{z x}=S_{x z}$ e $S_{z y}=S_{y z}$. Dessa forma, o tensor de nove componentes pode ser escrito na notação reduzida [58, $59,65]$ com apenas seis componentes:

$$
[\mathbf{S}]=\left[\begin{array}{llllll}
S_{x x} & S_{y y} & S_{z z} & S_{y z} & S_{x z} & S_{x y}
\end{array}\right]^{t}
$$

O sobrescrito ${ }^{t}$ indica matriz transposta. A notação da eq.(2.4) utiliza os termos longitudinais da deformação correspondendo aos índices:

$$
x x=1, \quad y y=2, \quad z z=3 .
$$

Os termos de cisalhamento da deformação correspondem aos índices

$$
y z=4, \quad x z=5, \quad x y=6 .
$$




\subsubsection{Tensão Mecânica}

Tensão mecânica é a força por unidade de área aplicada a um sólido. A variação das forças elásticas que atuam em um corpo, fazem este vibrar. Essas forças podem decompor-se em forças de volume e forças de superfície. As forças de volume são, por exemplo, o campo gravitacional que produz um força estática no volume e a força sobre uma distribuição volumétrica de cargas sob um campo elétrico. As forças de superfície são as de contanto direto entre os corpos, considerando situações macroscópicas, ou a força sobre um meio eletricamente condutor, submetido a um campo elétrico.

Uma força aplicada à superfície de um corpo produz três componentes de tensão mecânica. Tomando como exemplo a força aplicada na direção $z$ da superfície, estas componentes são $T_{z z}, T_{z x} e T_{z y}$. O termo $\left(T_{z z}\right)$ é a tensão mecânica longitudinal, a qual atua produzindo uma deformação na direção $z$. Os outros dois termos $\left(T_{z x} \mathrm{e}\right.$ $T_{z y}$ ) são as tensões mecânicas de cisalhamento que produzem distorções na superfície do corpo.

O tensor $T_{i j}$ também é simétrico e pode ser escrito na notação reduzida da seguinte forma:

$$
[\mathbf{T}]=\left[\begin{array}{llllll}
T_{x x} & T_{y y} & T_{z z} & T_{y z} & T_{x z} & T_{x y}
\end{array}\right]^{t}
$$

Considerando uma tensão mecânica variando continuamente sobre um ponto no material, pode-se escrever a equação do movimento [58, 59] através da segunda lei de Newton:

$$
\nabla \cdot[\mathbf{T}]=\rho \frac{\partial^{2}\{\mathbf{u}\}}{\partial t^{2}}=\rho \frac{\partial\{\mathbf{v}\}}{\partial t},
$$

na qual $\rho$ é a densidade do material e $\{\mathbf{v}\}$ é o vetor velocidade.

A eq.(2.8) é a equação de equilíbrio resolvida pelos software de elementos finitos $[24,26]$, como por exemplo o ANSYS, que é utilizado neste trabalho. Tanto o comportamento vibracional dos materiais piezelétricos, assim como dos não-piezelétricos, são resolvidos através dessa equação.

\subsubsection{Coeficientes Mecânicos}

As equações constitutivas para um sólido elástico linear [58, 59, 62] relacionam as componentes da tensão mecânica $T_{i j}$ e da deformação $S_{k l}$ através da lei de Hooke 
generalizada

$$
T_{i j}=c_{i j k l} S_{k l}
$$

ou

$$
S_{i j}=s_{i j k l} T_{k l}
$$

onde $c_{i j k l}$ são as componentes da constante elástica de rigidez e $s_{i j k l}$ as constantes elástica de flexibilidade, que é inversa da matriz rigidez. A rigidez é definida como a força necessária para produzir uma unidade de deslocamento na direção especificada. A flexibilidade é a recíproca da rigidez.

Corpos que são elasticamente equivalentes em todas as direções são chamados isotrópicos. Neste caso, o número de constantes elásticas independentes reduz-se a apenas duas [58, 59, 61], que são as constantes de Lamé $\boldsymbol{\lambda}$ e $\boldsymbol{\mu}$. A eq.(2.9) pode ser escrita na forma matricial, seguindo a notação dos índices dada pelas eqs.(2.5) e (2.6)

$$
\left[\begin{array}{c}
T_{1} \\
T_{2} \\
T_{3} \\
T_{4} \\
T_{5} \\
T_{6}
\end{array}\right]=\left[\begin{array}{cccccc}
c_{11} & c_{12} & c_{12} & 0 & 0 & 0 \\
c_{12} & c_{11} & c_{12} & 0 & 0 & 0 \\
c_{12} & c_{12} & c_{11} & 0 & 0 & 0 \\
0 & 0 & 0 & c_{44} & 0 & 0 \\
0 & 0 & 0 & 0 & c_{44} & 0 \\
0 & 0 & 0 & 0 & 0 & c_{44}
\end{array}\right]\left[\begin{array}{c}
S_{1} \\
S_{2} \\
S_{3} \\
S_{4} \\
S_{5} \\
S_{6}
\end{array}\right]
$$

onde

$$
c_{12}=\boldsymbol{\lambda}, \quad c_{44}=\boldsymbol{\mu}, \quad c_{11}=\boldsymbol{\lambda}+2 \boldsymbol{\mu} .
$$

A eq.(2.11) define as propriedades de conexão elástica entre as moléculas do material. Para uma determinada componente de tensão mecânica, se o corpo possuir alta rigidez, a deformação é relativamente pequena. Por outro lado, se o corpo possuir alta flexibilidade a deformação será grande.

A maioria dos cristais têm simetrias, o que reduz o número de constantes necessárias. Um material isotrópico com simetria cúbica apresenta a mesma relação de cisalhamento em todas as direções assim como as mesmas condições de deformação linear, por isso o tensor de rigidez possui forma descrita na eq.(2.11). 
Para materiais isotrópicos, a relação entre a tensão mecânica longitudinal e a deformação é dada pela eq.(2.9). Da qual obtém-se

$$
T_{I}=\boldsymbol{\lambda} \Delta+2 \boldsymbol{\mu} S_{I}
$$

onde $\Delta=S_{1}+S_{2}+S_{3}$ é definido com a dilatação do corpo [59] ou a fração da variação do seu volume.

Para o cisalhamento [58, 61], pode-se escrever a partir da eq.(2.11)

$$
T_{I}=\boldsymbol{\mu} S_{I}
$$

Para um material unidimensional sob tensão mecânica na direção $x$ pode-se introduzir as constantes conhecidas como modulo de Young $(E)$, que é a rigidez do material, e o coeficiente de Poisson $(\sigma)[58,61]$ através das relações:

$$
E=\frac{S_{1}}{T_{1}}
$$

$\mathrm{e}$

$$
\sigma=-\frac{S_{2}}{S_{1}}=-\frac{S_{3}}{S_{1}}
$$

Dessas relações obtém-se $c_{11}$ e $c_{44}$. O módulo de Young é um pouco menor que $c_{11}$, pois

$$
c_{11}=\frac{E(1-\sigma)}{(1+\sigma)(1-2 \sigma)} .
$$

A constante elástica de cisalhamento quase puro $c_{44}$ é também escrita como $G_{x}$, a qual relaciona o cisalhamento com as componentes de deformação e tensão mecânicas [58, 61]. Seu valor é obtido de

$$
c_{44}=G_{x}=\frac{E}{2(1+\sigma)} .
$$

Para os materiais isotrópicos também é possível obter a constante $c_{12}$ a partir dos valores conhecidos de $c_{11}$ e $\sigma$ :

$$
\sigma=\frac{c_{11}}{c_{11}+c_{12}}
$$

Uma onda acústica propagando-se em um sólido isotrópico, possui componentes logitudinais e transversais (de cisalhamento). As velocidades dessas ondas elásticas são dadas, respectivamente, por:

$$
c_{l}=\sqrt{\frac{c_{11}}{\rho}},
$$


e

$$
c_{s}=\sqrt{\frac{c_{44}}{\rho}},
$$

Se a onda elástica propaga-se numa barra muito fina, não há onda transversal e a onda longitudinal é chamada onda extensional, a sua velocidade é dada por:

$$
c_{e}=\sqrt{\frac{E}{\rho}},
$$

onde $c_{e}$ é a velocidade da onda elástica extensional. Através da relação entre as velocidades longitudinal e transversal de uma onda elástica em um sólido isotrópico, também é possível determinar o coeficiente de Poisson $\sigma$ [66], através de:

$$
\sigma=\frac{1-2 X}{2(1-X)}
$$

considerando $X=\left(c_{s} / c_{l}\right)$.

\subsection{Equações Constitutivas Piezelétricas}

A piezeletricidade pode ser definida como a polarização elétrica produzida por uma deformação mecânica em certos tipos de cristais. Um material piezelétrico, quando submetido a um campo elétrico, sofre alteração em suas dimensões. O inverso também vale, ou seja, quando um material piezelétrico sofre uma deformação, um campo elétrico é gerado. Por esse motivo a lei de Hooke [eq.(2.9)] não descreve completamente a relação entre deformação e tensão mecânica de um material piezelétrico, pois este também está sujeito a um campo elétrico, tal que:

$$
\begin{aligned}
D_{i} & =\epsilon_{i j} E_{i}, \quad \text { ou } \quad\{\mathbf{D}\}=[\epsilon]\{\mathbf{E}\} \\
\nabla \cdot \mathbf{D} & =0
\end{aligned}
$$

onde $D_{i}$ é o vetor deslocamento elétrico. $\epsilon_{i j}$ são as componentes do tensor dielétrico; e $E_{i}$ é o vetor campo elétrico.

Os materiais ferrelétricos são piezelétricos. O fenômeno da ferreletricidade, é similar ao fenômeno do ferromagnetismo. Essa similaridade é principalmente fenomenológica, pois os materiais ferromagnéticos exibem magnetização espontânea e efeito de histerese na relação entre a magnetização e o campo magnético. Enquanto que, os materiais ferrelétricos apresentam polarização espontânea e efeito de histerese entre o deslocamento dielétrico e o campo elétrico [67, 68, 69]. 
O efeito piezelétrico aparece espontaneamente em cristais naturais que não apresentam centro de simetria, como o quartzo, a turmalina, a calcita, a pirita, entre outros $[67,68]$. Porém, nestes o efeito piezelétrico é muito pequeno e as propriedades piezelétricas são determinadas de acordo com as características cristalográficas. Por outro lado, cerâmicas ferrelétricas apresentam piezeletricidade após serem polarizadas. Assim, a piezeletricidade pode ser induzida em materiais cerâmicos que apresentam ferreletricidade através do processo de polarização elétrica [59]. Alguns dos materiais cerâmicos ferrelétricos policristalinos são o titanato de bário $\left(\mathrm{BaTiO}_{3}\right)$, o PZT e o PMN. Outros materiais que apresentam piezeletricidade quando polarizados são os polímeros à base de PVDF.

Quando um campo elétrico é aplicado na direção da polarização (direção 3) de um material piezelétrico, os dipolos elétricos aumentam o alinhamento proporcionalmente à voltagem aplicada $[67,68,70]$. O resultado é uma mudança nas dimensões: expansão na direção do campo elétrico, quando este possui sentido inverso ao da polarização [Figura 2.2(a)], e contração na direção do campo elétrico, quando este possui o mesmo sentido da polarização [Figura 2.2(b)]. Quando o campo elétrico é aplicado perpendicular à direção da polarização, há um cisalhamento do material piezelétrico, como mostrado na Figura 2.2(c).

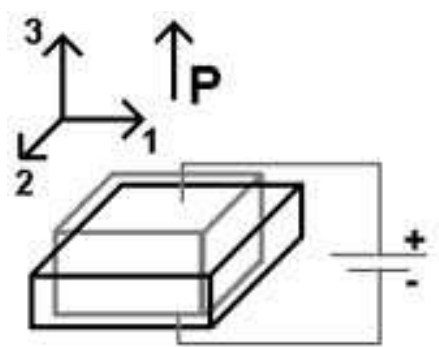

(a)

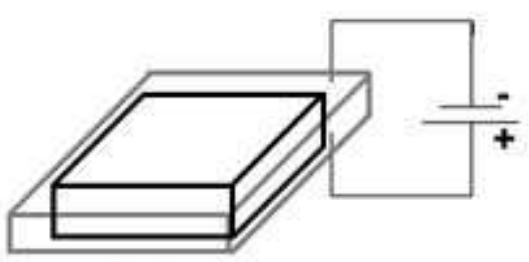

(b)

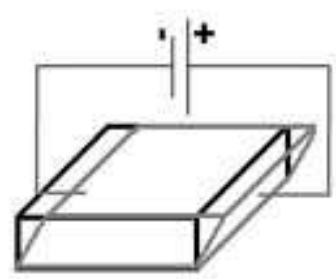

(c)

Figura 2.2. Piezocerâmica polarizada: (a) campo elétrico aplicado em sentido oposto ao da polarização; (b) campo elétrico aplicado no mesmo sentido da polarização; e (c) campo elétrico aplicado perpendicular à direção da polarização.

Uma característica essencial num material piezelétrico é a validade de relações lineares entre o campo elétrico aplicado e a tensão mecânica ou deformação mecânica produzida [70]. Pelo fato de um material piezelétrico apresentar propriedades elétricas 
e mecânicas, as equações constitutivas são expressas em termo dos tensores

$$
\begin{aligned}
T_{i j} & =c_{i j k l}^{E} S_{k l}+e_{k i j}\left(-E_{k}\right), \\
D_{i} & =e_{i k l} S_{k l}+\left(-\epsilon_{i k}^{S}\right)\left(-E_{k}\right)
\end{aligned}
$$

onde $e_{i k l}$ é tensor piezelétrico de tensão mecânica/campo elétrico, e o sobrescrito ${ }^{E}$ significa: a campo elétrico constante e o sobrescrito ${ }^{S}$ significa: a deformação mecânica constante.

As componentes do campo elétrico $\left(E_{i}\right)$ e do deslocamento elétrico $\left(D_{i}\right)$ são:

$$
\{\mathbf{E}\}=\left\{\begin{array}{c}
E_{x} \\
E_{y} \\
E_{z}
\end{array}\right\} \quad \text { e } \quad\{\mathbf{D}\}=\left\{\begin{array}{c}
D_{x} \\
D_{y} \\
D_{z}
\end{array}\right\} .
$$

Os materiais analisados e utilizados neste trabalho são cerâmicas da classe de simetria hexagonal da família $6 \mathrm{~mm}$, como os diversos tipos de PZT. De acordo com as normas do IEEE standards [29], a direção da polarização, é a direção z. Porém neste trabalho, a direção da polarização também será assumida na direção y, pois essa é a direção da polarização que o software ANSYS, de elementos finitos, considera nos modelos bidimensionais. Por isso, de uma forma geral será assumida como direção da polarização a direção 3, independente desta ser a direção $z$ ou $y$.

Os materiais piezelétricos são, elasticamente e piezeletricamente, anisotrópicos na direção 3 e isotrópicos no plano 12 [58]. Para os materiais das classes hexagonais [58, $59,70]$ com anisotropia na direção $z$ são mostrados a seguir o tensor elástico $\left(c_{i j k l}\right)$, o tensor dielétrico $\left(\epsilon_{i j}\right)$ e o tensor piezelétrico $\left(e_{i k l}\right)$ na forma matricial. As constantes de rigidez elástica $\left(c_{i j k l}\right)$ são:

$$
[\mathbf{c}]=\left[\begin{array}{cccccc}
c_{11} & c_{12} & c_{13} & 0 & 0 & 0 \\
c_{12} & c_{11} & c_{13} & 0 & 0 & 0 \\
c_{13} & c_{13} & c_{33} & 0 & 0 & 0 \\
0 & 0 & 0 & c_{44} & 0 & 0 \\
0 & 0 & 0 & 0 & c_{44} & 0 \\
0 & 0 & 0 & 0 & 0 & c_{66}
\end{array}\right],
$$


As componentes do tensor dielétrico $\left(\epsilon_{i j}\right)$ são:

$$
[\epsilon]=\left[\begin{array}{ccc}
\epsilon_{11} & 0 & 0 \\
0 & \epsilon_{11} & 0 \\
0 & 0 & \epsilon_{33}
\end{array}\right] .
$$

E as constantes piezelétricas de tensão mecânica $\left(e_{i k l}\right)$ são:

$$
[\mathbf{e}]=\left[\begin{array}{cccccc}
0 & 0 & 0 & 0 & e_{15} & 0 \\
0 & 0 & 0 & e_{15} & 0 & 0 \\
e_{31} & e_{31} & e_{33} & 0 & 0 & 0
\end{array}\right]
$$

onde a componente $i=1,2,3$ e as componentes $k l=1,2,3,4,5,6$. A componente $i$ indica a direção do campo elétrico aplicado e as componentes $k l$ a direção da tensão mecânica produzida (1,2,3 longitudinal, 4,5,6 cisalhamento) [70], que segue a notação das eqs.(2.5) e (2.6) . Os materiais piezelétricos da classe $6 \mathrm{~mm}$, quando expandem na direção 3, apresentam compressão nas direções 1 e 2 e vice-versa ${ }^{1}$, como ilustrado na Figura 2.2. Por isso, os valores das constantes $e_{31}$ possuem o sinal negativo.

Utilizando a notação tensorial reduzida, para representar as eq.(2.25), montase o seguinte tensor, que representa um material piezelétrico da classe de simetria $6 \mathrm{~mm}$, como o PZT-5A:

$$
\left[\begin{array}{c}
T_{x x} \\
T_{y y} \\
T_{z z} \\
T_{y z} \\
T_{x z} \\
T_{x y} \\
D_{x} \\
D_{y} \\
D_{z}
\end{array}\right]=\left[\begin{array}{cccccc|ccc}
c_{11}^{E} & c_{12}^{E} & c_{13}^{E} & 0 & 0 & 0 & 0 & 0 & e_{31} \\
c_{12}^{E} & c_{11}^{E} & c_{13}^{E} & 0 & 0 & 0 & 0 & 0 & e_{31} \\
c_{13}^{E} & c_{13}^{E} & c_{33}^{E} & 0 & 0 & 0 & 0 & 0 & e_{33} \\
0 & 0 & 0 & c_{44}^{E} & 0 & 0 & 0 & e_{15} & 0 \\
0 & 0 & 0 & 0 & c_{44}^{E} & 0 & e_{15} & 0 & 0 \\
0 & 0 & 0 & 0 & 0 & c_{66}^{E} & 0 & 0 & 0 \\
\hline 0 & 0 & 0 & 0 & e_{15} & 0 & -\epsilon_{11}^{S} & 0 & 0 \\
0 & 0 & 0 & e_{15} & 0 & 0 & 0 & -\epsilon_{11}^{S} & 0 \\
e_{31} & e_{31} & e_{33} & 0 & 0 & 0 & 0 & 0 & -\epsilon_{33}^{S}
\end{array}\right]\left[\begin{array}{c}
S_{x x} \\
S_{y y} \\
S_{z z} \\
S_{y z} \\
S_{x z} \\
S_{x y} \\
-E_{x} \\
-E_{y} \\
-E_{z}
\end{array}\right] .
$$

As características de um transdutor piezelétrico dependem das constantes ilustradas na eq.(2.30), para um material piezelétrico e do módulo de Young $(E)$, coeficiente

\footnotetext{
${ }^{1}$ devido às propriedades anisotrópicas no plano 12, as constantes da direção 1 e da direção 2 possuem os mesmos valores.
} 
de Poisson $(\sigma)$ e a densidade $(\rho)$ para um material sólido isotrópico. Além desses parâmetros, o amortecimento de todos os materiais que compõem um transdutor piezelétrico também é de fundamental importância, pois os transdutores piezelétricos podem ser modelados por um oscilador harmônico. Por isso, é importante determinar os valores dessas propriedades, pois os valores fornecidos pelos fabricantes podem apresentar um erro de até $20 \%$ em relação ao valor tabelado. Enquanto que o valor dos amortecimentos mecânicos não são fornecidos, pois não há interesse dos fabricantes nessa característica.

Neste trabalho, a determinação dos valores dessas constantes obedeceu à forma padrão descrita em diversos trabalhos. Os mais importantes são os do IEEE standards [29], IRE standards [30, 31, 32], HOLLAND e EERNISSE [33] e SMITS [34]. A seguir são descritos processos elétricos de determinação das constantes dos materiais piezelétricos. A esses métodos podem ser adicionados os métodos acústicos, obtendo-se os valores das constantes através das eqs.(2.16) a (2.22), e os métodos ópticos, os quais permitem também a medição das constantes dos materiais nãopiezelétricos.

\subsection{Caracterização Elétrica dos Materiais Piezelétricos}

Através de métodos elétricos, utilizando um analisador de impedâncias complexa (módulo e fase), é possível obter todas as constantes piezelétricas, elásticas e dielétricas de um material piezelétrico $[29,30,31,32,33,34,71]$. Neste trabalho foram caracterizadas piezocerâmicas hexagonais da classe de simetria $6 \mathrm{~mm}$. Inicialmente são obtidas as constantes citadas, nas direções 3 e 1 . As constantes na direção 2 são iguais às da direção 1, pois esses materiais são isotrópicos no plano 12 [58].

De acordo com os processos descritos a seguir, não é possível determinar diretamente os valores das constantes da equação constitutiva dada pela eq.(2.30). As constantes dessa equação são as inseridas no software ANSYS, de elementos finitos. 
Por isso, são introduzidas outras três equações constitutivas:

$$
\begin{aligned}
T_{i j} & =c_{i j k l}^{D} S_{k l}-h_{k i j} D_{k}, \\
E_{i} & =-h_{i k l} S_{k l}+\beta_{i k}^{S} D_{k}, \\
S_{i j} & =s_{i j k l}^{E} T_{k l}+d_{k i j} E_{k}, \\
D_{i} & =d_{i k l} T_{k l}+\epsilon_{i k}^{T} E_{k}, \\
S_{i j} & =s_{i j k l}^{D} T_{k l}+g_{k i j} D_{k}, \\
E_{i} & =-g_{i k l} T_{k l}+\beta_{i k}^{T} D_{k} .
\end{aligned}
$$

As relações dos termos dessas equações com os da eq.(2.25) são introduzidas no texto à medida que forem necessárias. No conjunto de eqs.(2.31) os novos termos são as constantes piezelétricas: $h_{i j k}$, campo elétrico/deformação; $d_{i j k}$, deformação/campo elétrico e $g_{i j k}$, campo elétrico/tensão mecânica. $\beta_{i k}$ é a impermeabilidade dielétrica. Os sobrescritos designam: ${ }^{D}$, a deslocamento elétrico constante; ${ }^{E}$, a campo elétrico constante; ${ }^{T}$, a tensão mecânica constante e ${ }^{S}$, a deformação mecânica constante.

\subsubsection{Condições para Determinação das Constantes Piezelétricas}

Para minimizar os erros e melhorar a acurácia na determinação das propriedades dos materiais piezelétricos, torna-se necessário utilizar esses materiais em formas diferentes e com distintas orientações de polarização, para a determinação dos valores de suas constantes. Cada forma permite determinar um conjunto de constantes. Em geral, as formas dos transdutores utilizados não são apropriadas para a medição de todas as constantes.

Para a determinação exata das constantes, várias influências devem ser levadas em conta. As condições sob as quais barras, placas ou discos piezelétricos são caracterizados devem concordar com as condições nas quais as formulações teóricas foram baseadas $[68,72]$. As Figuras 2.3 e 2.4 mostram as diferentes configurações das cerâmicas piezelétricas para a caracterização. A Tabela 2.1 mostra a relação mínima entre as dimensões das piezocerâmicas, para que estas possam ser caracterizadas eletricamente $[33,72]$. 
Tabela 2.1. Relações mínimas entre as dimensões dos materiais piezelétricos, para a caracterização elétrica.

\begin{tabular}{lccc}
\hline \hline & discos & placas & barras \\
\hline comprimento $(l)$ & - & 1 & 1 \\
diâmetro $(d)$ & 1 & - & $1 / 4$ \\
largura $(w)$ & - & $2 / 7$ & $1 / 4$ \\
espessura $(t)$ & $1 / 10$ & $2 / 7$ & $1 / 4$ \\
\hline \hline
\end{tabular}

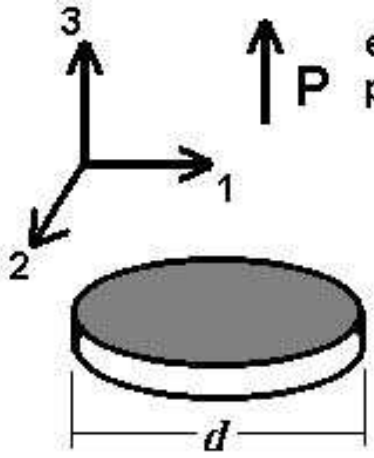

(a) disco

eletrodos nas superficies perpendiculares à direçao 3 .

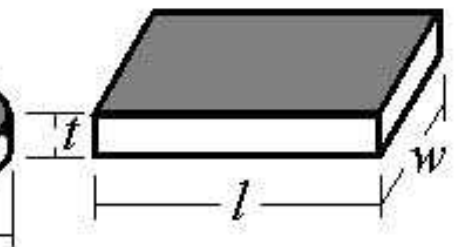

(b) placa

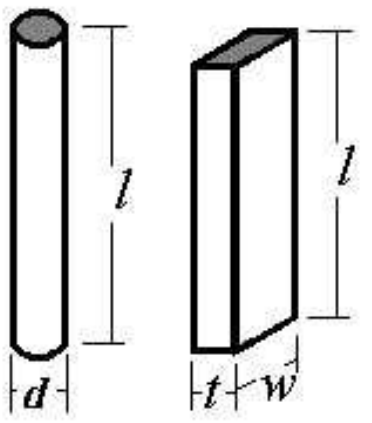

(c) barra

Figura 2.3. Dimensões e condições das cerâmicas piezelétricas para a determinação das diferentes constantes longitudinais e transversais. (a) disco piezelétrico; (b) placa piezelétrica; (c) barra piezelétrica. Nestas os eletrodos são perpendiculares à direção da polarização.

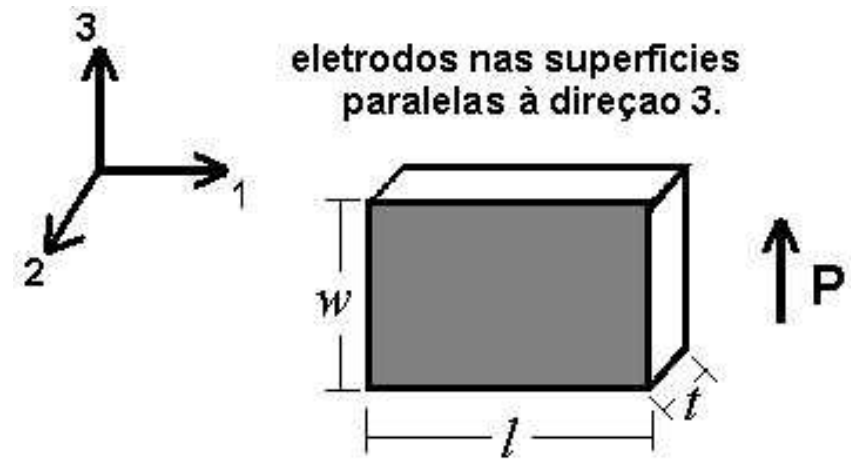

Figura 2.4. Condição de determinação das constantes de cisalhamento.

Eletrodos paralelos à direção da polarização.

Os testes devem ser feitos para garantir que não haja freqüências espúrias, as quais podem influenciar os resultados. As dimensões lineares da amostras, devem ser tais que não haja freqüências de ressonância vizinhas. 


\subsubsection{Medições em Regime Estático e Semi-estático}

A primeira constante a se determinar, para o cálculo das outras desejadas, é a densidade da piezocerâmica $\rho$. Esta é obtida a partir de sua massa $m$ e volume $V$.

A medição das constantes dielétricas são realizadas em $1 \mathrm{kHz}[29,32,72]$. Essa propriedade varia à medida que a freqüência se altera. No entanto, para efeito de comparação com os resultados tabelados, há necessidade de obtê-las a $1 \mathrm{kHz}$. No caso de um PZT-5A as constantes dielétricas a serem determinadas são as $\epsilon_{11}^{T}$ e $\epsilon_{33}^{T}$; $\epsilon_{11}^{S}$ e $\epsilon_{33}^{S}$. As constantes dielétricas determinadas experimentalmente estão à tensão mecânica constante.

Para a condição da direção da polarização estar na mesma direção do campo elétrico, ou seja, com os eletrodos da cerâmica perpendiculares à polarização (Figura 2.3), obtém-se:

$$
\epsilon_{33}^{T}=\frac{t C}{A}
$$

onde $C$ é a capacitância da piezocerâmica e $A$ a área da superfície da mesma e $t$ a espessura.

Para obter $\epsilon_{11}^{T}$, é necessário aplicar o campo elétrico perpendicular à direção da polarização (Figura 2.4). A equação é similar à anterior:

$$
\epsilon_{11}^{T}=\frac{t C}{A}
$$

As outras constantes são obtidas através do método da ressonância e estão descritos a seguir.

\subsubsection{Método da Ressonância}

O método para a determinação dos valores das constantes elástica e piezelétrica das cerâmicas devem ser simples e confiáveis. Para determinar as constantes elásticas e piezelétricas, o mais simples é o da método ressonância [29, 31, 72].

As principais propriedades de um oscilador piezelétrico, como por exemplo a freqüência e os parâmetros do circuito elétrico equivalente são expressas em termos das constantes elásticas, piezelétricas e dielétricas. Dessa forma, os valores para essas constantes podem ser obtidos de medições na freqüência de ressonância, parâmetros do circuito elétrico equivalente, das dimensões e densidade da amostra analisada, que deve ser convenientemente orientada, quando a teoria dos modos de vibração 
da amostra é conhecido. A admitância elétrica $Y$ de uma piezocerâmica retangular (placa) polarizada na direção da espessura e com o campo elétrico aplicado na mesma direção [Figura 2.3(b)] é dada de acordo com o IRE standards [31] e SMITS [34], e está relacionada com as constantes da direção longitudinal da cerâmica piezelétrica, ou seja, as direções 1 e 2. Sua expressão é:

$$
Y=i \omega\left(\epsilon_{33}^{T}-\frac{d_{31}^{2}}{s_{11}^{E}}\right) \frac{l w}{t}+i\left(\frac{1}{\rho s_{11}^{E}}\right)^{\frac{1}{2}} \frac{2 w d_{31}^{2}}{s_{11}^{E} t} \tan \left[\frac{1}{2} \omega l\left(\rho s_{11}^{E}\right)^{\frac{1}{2}}\right],
$$

onde $\omega=2 \pi f$ é a freqüência angular. A impedância elétrica $Z$, de uma cerâmica piezelétrica, na mesma configuração anterior, está relacionada com as constantes da direção da espessura, ou seja a direção 3, de acordo com SMITS [34], e é dada por:

$$
Z=-i \frac{t}{\omega l w} \beta_{33}^{S}+i\left(\frac{1}{\rho c_{33}^{D}}\right)^{\frac{1}{2}} \frac{h_{33}^{2}}{\omega^{2} l w} \tan \left[\frac{1}{2} \omega t\left(\frac{c_{33}^{D}}{\rho}\right)^{\frac{1}{2}}\right]
$$

Ao utilizar uma cerâmica piezelétrica na configuração da Figura 2.3(c), na qual o campo elétrico e a polarização estão na direção do comprimento $l$, a impedância elétrica é escrita [34]

$$
Z=-i\left(\beta_{33}^{T}-\frac{g_{33}^{2}}{s_{33}^{D}}\right) \frac{l}{\omega t w}+i\left(\frac{1}{\rho s_{33}^{D}}\right)^{\frac{1}{2}} \frac{2 g_{33}^{2}}{s_{33}^{D} w t \omega^{2}} \tan \left[\frac{1}{2} \omega l\left(\rho s_{33}^{D}\right)^{\frac{1}{2}}\right]
$$

enquanto que, para uma cerâmica piezelétrica na configuração de cisalhamento, como mostrada na Figura 2.4, a impedância elétrica é dada pelos coeficientes de cisalhamento [34]:

$$
Z=-i \frac{t \beta_{11}^{S}}{\omega l w}+i\left(\frac{1}{\rho c_{55}^{D}}\right)^{\frac{1}{2}} \frac{h_{15}^{2}}{w l \omega^{2}} \tan \left[\frac{1}{2} \omega t\left(\frac{c_{55}^{D}}{\rho}\right)^{\frac{1}{2}}\right]
$$

As freqüências de ressonância que devem ser determinadas são as $f_{s}$ e $f_{p}$, respectivamente freqüência de ressonância do circuito equivalente [33, 34, 70, 73] em série e em paralelo. A freqüência $f_{p}$ corresponde à resistência elétrica $R$ máxima $\left(|Z|=\sqrt{|R|^{2}+|X|^{2}} \longrightarrow X\right.$ é a reatância elétrica), enquanto que a freqüência $f_{s}$ corresponde à condutância elétrica $G$ máxima $\left(|Y|=\sqrt{|G|^{2}+|B|^{2}} \longrightarrow B\right.$ é a susceptância elétrica), como mostra as Figuras 2.5(a) e (b). Nesta figura também são ilustradas as freqüências relacionadas com a largura de banda, $f_{+1 / 2}$ e $f_{-1 / 2}$, que podem ser medidas também nos valores mínimo e máximo de $X$, respectivamente. 


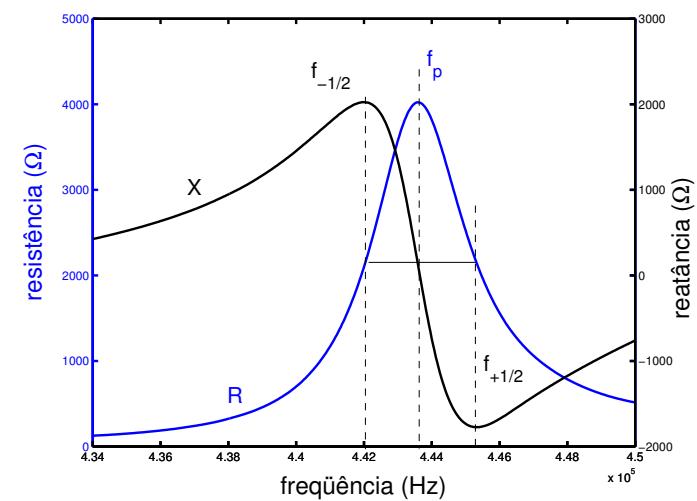

(a)

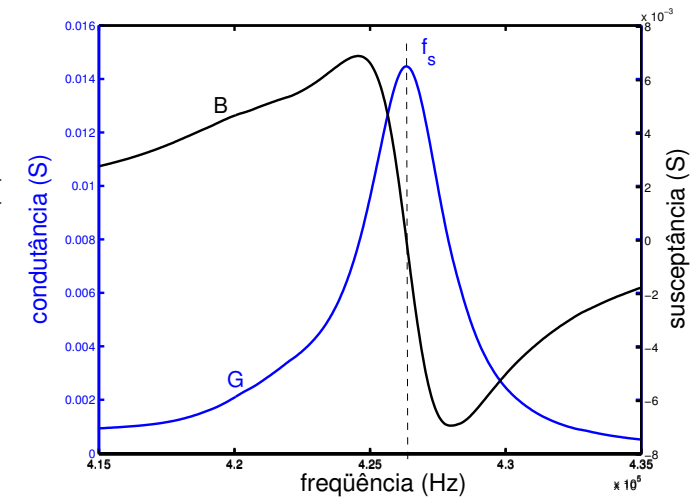

(b)

Figura 2.5. (a) curva da resistência $(R)$ e reatância elétricas $(X)$ indicando a freqüência $f_{p}, f_{+1 / 2}$ e $f_{-1 / 2}$. (b) curva da condutância $(G)$ e susceptância $(B)$ elétricas indicando a freqüência $f_{s}$.

\section{Coeficientes de Acoplamento}

Utilizando uma barra piezelétrica, com a polarização na direção do comprimento [Figura 2.3(c)], determina-se o coeficiente de acoplamento a partir das freqüências $f_{p}$ e $f_{s}$ do modo fundamental da direção do comprimento.

$$
k_{33}=\sqrt{\frac{\pi}{2} \frac{f_{s}}{f_{p}} \tan \left(\frac{\pi}{2} \frac{f_{p}-f_{s}}{f_{p}}\right)} .
$$

A utilização da barra deve-se ao fato da frequiência de ressonância do modo espessura ser baixa e bem distante das freqüências de ressonância do modo radial ou espessura da barra piezelétrica (Figura 2.3). Porém há grande dificuldade em realizar a polarização de uma barra piezelétrica comprida, pois pode haver o rompimento dielétrico da piezocerâmica durante esse processo. Portanto, na ausência de barras piezelétricas, pode-se utilizar um disco piezelétrico [Figura 2.3(a)] para a determinação do coeficiente de acoplamento $k_{33}$, desde que não haja outros modos de ressonância sobrepostos ao modo fundamental da espessura do disco. No caso da utilização do disco piezelétrico, as freqüências $f_{p}$ e $f_{s}$ são as do modo fundamental da direção da espessura.

O coeficiente de acoplamento transversal $k_{31}$ está relacionado com as direções 1 e 2 e é obtido utilizando uma barra piezelétrica ou um disco piezelétrico fino, aplicando o campo elétrico na direção da polarização. Para isso, deve-se obter as freqüências $f_{p}$ e $f_{s}$ do modo fundamental da espessura do disco piezelétrico, ou da 
direção do comprimento da barra piezelétrica. [Figura 2.3(b) e (c)].

$$
\frac{k_{31}^{2}}{1-k_{31}^{2}}=\frac{\pi}{2} \frac{f_{p}}{f_{s}} \tan \left(\frac{\pi}{2} \frac{f_{p}-f_{s}}{f_{s}}\right)
$$

fazendo

$$
U_{i}=\frac{\pi}{2} \frac{f_{p}}{f_{s}} \tan \left(\frac{\pi}{2} \frac{f_{p}-f_{s}}{f_{s}}\right)
$$

pode-se escrever:

$$
k_{31}=\sqrt{\frac{U_{i}}{1+U_{i}}} .
$$

A determinação do coeficiente de acoplamento planar $k_{p}$ de uma cerâmica piezelétrica é realizada utilizando um disco piezelétrico. O termo planar é usado porque a tensão mecânica é isotrópica no plano 12. As freqüências $f_{p}$ e $f_{s}$ são também determinadas para o modo fundamental da espessura do disco piezelétrico. O coeficiente de acoplamento $k_{p}$ está relacionado com a razão das freqüências. Primeiro deve-se obter a valor da relação $\frac{f_{p}-f_{s}}{f_{s}}$. O valor obtido dessa fração dá o valor de $k_{p}$ através da Figura 2.6. Este gráfico é obtido através do modelo do IRE standards [32] e vale para materiais piezelétricos que possuem o coeficiente de Poisson entre 0,27 e 0,35, como no caso dos PZTs.

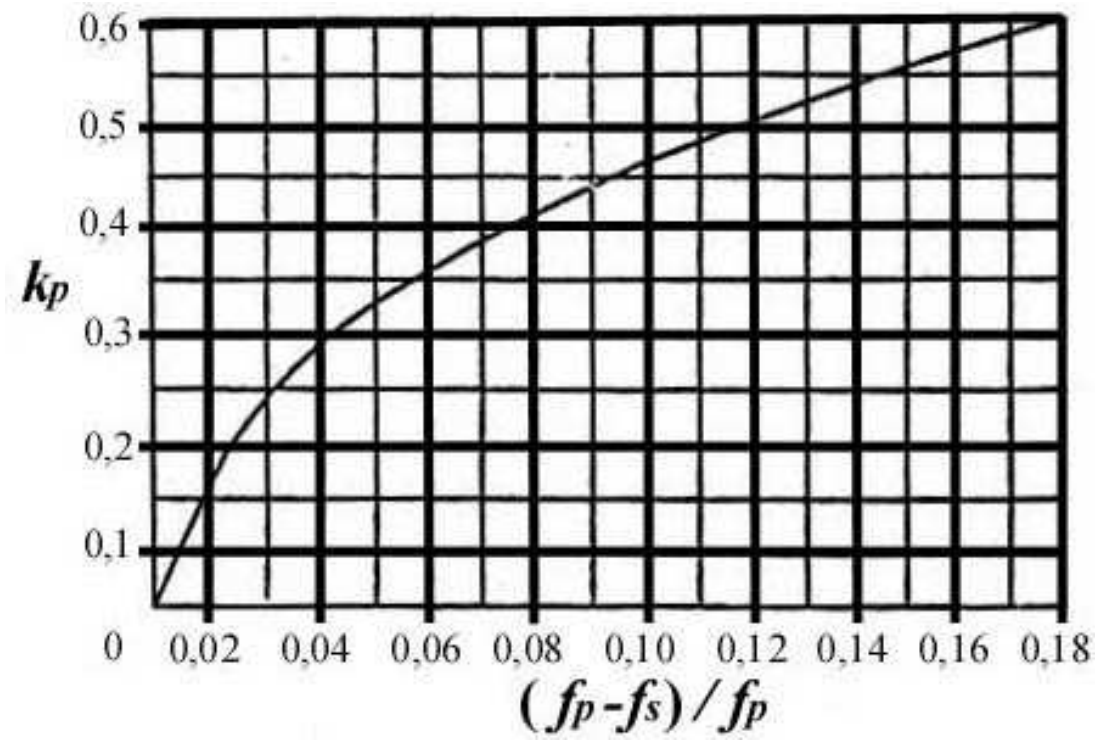

Figura 2.6. Relação entre $\frac{f_{p}-f_{s}}{f_{s}}$ e $k_{p}$.

O coeficiente de acoplamento de cisalhamento $k_{15}$ é obtido através de cálculos envolvendo outras constantes previamente determinadas. Os cálculos das constantes de cisalhamento são realizados com uma cerâmica piezelétrica na configuração mostrada 
na Figura 2.4. A configuração ideal para que haja modos de ressonância de cisalhamento, sem interferências de outros modos de ressonância, é $l / w / t=14 / 7 / 1$ [33]. A determinação das constantes de cisalhamento são obtidas a partir da largura de banda do ganho com a cerâmica piezelétrica na configuração paralela dada por:

$$
g_{p}=Z_{p}\left(\omega_{+1 / 2}-\omega_{-1 / 2}\right)
$$

onde $Z_{p}$ é o valor da impedância na freqüência $f_{p} ; \omega_{+1 / 2}$ e $\omega_{-1 / 2}$ são respectivamente as freqüências do valor máximo e mínimo de $X$ (Figura 2.5). A partir desse valor é determinado o parâmetro $G_{i}$ :

$$
G_{i}=\frac{g_{p} l w(\nu \pi)^{2} \epsilon_{11}^{T}}{8 t}
$$

onde $\nu$ é o número de harmônicos da direção na espessura $t$ na freqüência $f_{p}$. O coeficiente de acoplamento de cisalhamento é:

$$
k_{15}=\sqrt{\frac{G_{i}}{1+G_{i}}} .
$$

As constantes dielétricas a deformação constante são calculadas a partir de:

$$
\begin{aligned}
& \epsilon_{11}^{S}=\epsilon_{11}^{T}\left(1-k_{15}^{2}\right), \\
& \epsilon_{33}^{S}=\epsilon_{33}^{T}\left(1-k_{33}^{2}\right) .
\end{aligned}
$$

\section{Constantes Elásticas}

Utilizando uma placa piezelétrica, pode ser obtida a constante elástica de flexibilidade a campo elétrico constante:

$$
s_{11}^{E}=\frac{1}{4 \rho f_{s}^{2} l^{2}} .
$$

A partir das eqs.(2.41) e (2.47) obtém-se a constante elástica a deslocamento elétrico constante:

$$
s_{11}^{D}=s_{11}^{E}\left(1-k_{31}^{2}\right)
$$

Utilizando uma barra piezelétrica determina-se a seguinte constante elástica a deslocamento elétrico constante:

$$
s_{33}^{D}=\frac{1}{4 \rho f_{p}^{2} l^{2}} .
$$


Pode-se utilizar, no lugar da barra piezelétrica um disco piezelétrico. Nesse caso, o comprimento $l$ na eq.(2.49) é substituído pela espessura $t$. Através das eqs.(2.49) e (2.38) determina-se a constante de flexibilidade a campo elétrico constante:

$$
s_{33}^{E}=\frac{s_{33}^{D}}{1-k_{33}^{2}} .
$$

O coeficiente $c_{33}^{D}$ é determinado utilizando uma placa piezelétrica quadrada com $l>15 t$

$$
c_{33}^{D}=\frac{4 \rho f_{p}^{2} t^{2}}{\nu^{2}}
$$

O coeficiente de cisalhamento $s_{55}^{D}$ é determinado utilizando uma cerâmica piezelétrica na configuração ilustrada na Figura 2.4:

$$
s_{55}^{D}=\frac{\nu^{2}}{4 \rho f_{p}^{2} t^{2}} .
$$

A constante $s_{12}^{E}$ é determinada através da relação do raio do disco piezelétrico com a constante elástica $s_{11}^{E}$ previamente determinada. A relação mínima ideal entres as dimensões é $d=30 t$. Assim, primeiro determina-se o coeficiente de Poisson $\sigma$ através do valor obtido para $p$ :

$$
p=2 \pi f_{s} \frac{d}{2} \sqrt{s_{11}^{E} \rho}
$$

A relação entre $p$ e $\sigma$ é mostrada na Tabela 2.2 [33]. A partir desse valor, determinase $s_{12}$ :

$$
s_{12}^{E}=-\sigma s_{11}^{E}
$$

Tabela 2.2. Relações entre $p$ e $\sigma$.

\begin{tabular}{cccccc}
\hline \hline$\sigma$ & $p$ & $\sigma$ & $p$ & $\sigma$ & $p$ \\
\hline 0,20 & 2,02533 & 0,30 & 2,14777 & 0,40 & 2,30131 \\
0,21 & 2,03646 & 0,31 & 2,16154 & 0,41 & 2,31888 \\
0,22 & 2,04781 & 0,32 & 2,17562 & 0,42 & 2,33691 \\
0,23 & 2,05940 & 0,33 & 2,19004 & 0,43 & 2,35544 \\
0,24 & 2,07124 & 0,34 & 2,20479 & 0,44 & 2,37448 \\
0,25 & 2,08332 & 0,35 & 2,21991 & 0,45 & 2,39405 \\
0,26 & 2,09566 & 0,36 & 2,23539 & 0,46 & 2,41419 \\
0,27 & 2,10826 & 0,37 & 2,25125 & 0,47 & 2,43492 \\
0,28 & 2,12114 & 0,38 & 2,26752 & 0,48 & 2,45626 \\
0,29 & 2,13431 & 0,39 & 2,28420 & 0,49 & 2,47825 \\
\hline \hline
\end{tabular}


As outras constantes elásticas podem ser determinadas das seguintes relações:

$$
\begin{aligned}
& s_{12}^{D}=s_{12}^{E}-\frac{d_{31}^{2}}{\epsilon_{33}^{T}} \\
& s_{13}^{D}=-\left[\left(\frac{s_{11}^{D}+s_{12}^{D}}{2}\right)\left(s_{33}^{D}-\frac{1}{c_{33}^{D}}\right)\right]^{\frac{1}{2}}, \\
& s_{13}^{E}=s_{13}^{D}+\frac{d_{31} d_{33}}{\epsilon_{33}^{T}} \\
& s_{55}^{E}=\frac{s_{55}^{D}}{1-k_{15}^{2}} \\
& s_{66}^{E}=s_{66}^{D}=2\left(s_{11}^{E}-s_{12}^{E}\right) .
\end{aligned}
$$

As constantes piezelétricas de deformação mecânica $d_{i k l}$ são determinadas por métodos ópticos ou por métodos elétricos através das relações descritas na próxima seção. As constantes de rigidez elástica $c_{i j k l}$ são determinados da matriz inversa das constantes de flexibilidade elástica $s_{i j k l}\left([\mathbf{c}]=[\mathbf{s}]^{-\mathbf{1}}\right)$. Os valores de $c_{i j k l}^{E}$ são calculados utilizando o software MATLAB.

\section{Constantes Piezelétricas}

As constantes piezelétricas de deformação por campo elétrico $d_{33}$ e $d_{31}$ são obtidas das relações

$$
\begin{aligned}
& d_{33}=k_{33} \sqrt{\epsilon_{33}^{T} s_{33}^{E}}, \\
& d_{31}=k_{31} \sqrt{\epsilon_{33}^{T} s_{11}^{E}},
\end{aligned}
$$

as quais se relacionam com os tensores piezelétricos de tensão mecânica/campo elétrico $e_{i j k}$ [34], da seguinte forma:

$$
\begin{aligned}
e_{31} & =d_{31}\left(c_{11}^{E}+c_{12}^{E}\right)+d_{33} c_{13}^{E}, \\
e_{33} & =2 d_{31} c_{13}^{E}+d_{33} c_{33}^{E}, \\
e_{15} & =k_{15}\left[\frac{\epsilon_{11}^{T}\left(1-k_{15}^{2}\right)}{s_{55}^{D}}\right]^{\frac{1}{2}} .
\end{aligned}
$$

\section{Fator de qualidade}

O fator de qualidade mecânico, o qual está relacionado com as perdas mecânicas, tais como dissipação de calor é dado por:

$$
Q_{m}=\frac{\omega_{r}}{2\left(\omega_{+1 / 2}-\omega_{-1 / 2}\right)}
$$


O fator de qualidade mecânico também está relacionado com o amortecimento mecânico. Os tipos de amortecimento, sua influência no MEF e como inseri-los no software de elemento finitos, o ANSYS, está descrito a seguir e no capítulo 3.

\subsection{Amortecimento}

O tratamento do amortecimento de um material é uma medida importante para controle de vibração em engenharia. Os resultados das simulações das análises vibracionais e acústicas são bastante sensíveis a esse parâmetro.

Para o tratamento do amortecimento em uma estrutura $[19,27,74]$ é fundamental considerar a variação de três parâmetros:

- Amortecimento;

- Massa;

- Rigidez.

Nas considerações do comportamento vibracional de um transdutor piezelétrico, tanto em modelagens numéricas, quanto no projeto de transdutores, devem ser otimizados todos esses três parâmetros, e não apenas um deles. Pois todos contribuem nas respostas dinâmicas dos transdutores piezelétricos.

Com relação à dissipação de energia, a maioria dos sistemas que dissipam energia através da vibração são não-lineares e não obedecem a amortecimentos lineares viscosos nem amortecimentos lineares com histerese $[19,27,74]$. No entanto, modelos de amortecimento ideal podem ser concebidos, os quais frequentemente permitem uma aproximação satisfatória.

\subsubsection{Tipos de Amortecimento}

Os vários tipos de amortecimento são: o amortecimento viscoso, que é causado pela dissipação de energia; o amortecimento estrutural, que está ligado às propriedades do material; e o amortecimento por atrito, devido ao contato mecânico entre duas superfícies [19, 27]. Neste trabalho é analisada a influência do amortecimento viscoso no comportamento dos transdutores piezelétricos e as perdas mecânicas, assim como a forma de trabalhar com esse tipo de amortecimento no MEF. 


\section{Amortecimento Viscoso}

Quando sistemas mecânicos vibram em um meio fluido, como por exemplo ar, gas, água e óleo, a resistência do fluido ao movimento do corpo causa dissipações de energia. A quantidade de energia dissipada depende de vários fatores, tais como o tamanho e forma do corpo vibrante, a viscosidade do fluido, a freqüência de vibração e a velocidade da vibração do corpo. No amortecimento viscoso, as forças de amortecimento podem ser expressas em termos da equação

$$
F=-c \dot{u},
$$

onde $c$ é uma constante de proporcionalidade e $\dot{u}$ é a velocidade do corpo de massa $m$, como mostra a Figura 2.7.

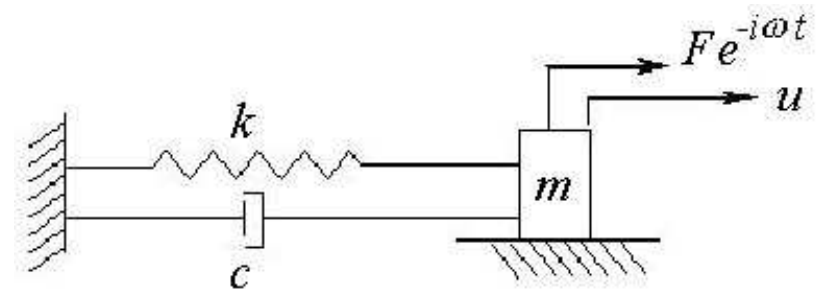

Figura 2.7. Vibração amortecida forçada.

Quando um sistema massa-mola simples está vibrando livremente, a equação do movimento é

$$
m \ddot{u}+c \dot{u}+k u=0,
$$

onde $\ddot{u}$ é aceleração do corpo e $k$ é a constante da mola, ou rigidez modal. Essa equação apresenta uma solução do tipo

$$
\begin{aligned}
u= & {\left[A \exp \left(i \sqrt{\frac{k}{m}-\left(\frac{c}{2 m}\right)^{2}} t\right)+\right.} \\
& \left.B \exp \left(-i \sqrt{\frac{k}{m}-\left(\frac{c}{2 m}\right)^{2}} t\right)\right] \exp \left(-\frac{c}{2 m} t\right),
\end{aligned}
$$

onde $A$ e $B$ são constantes arbitrárias dependentes de como o movimento se iniciou. Uma análise com relação à influência da rigidez, massa e amortecimento, na freqüência de ressonância $\omega_{r}$ do sistema revela que a partir do radical da exponencial da eq.(2.68)

$$
\omega_{r}=\sqrt{\frac{k}{m}-\left(\frac{c}{2 m}\right)^{2}},
$$


a contribuição de cada termo na curva de resposta do material piezelétrico e nãopiezelétrico, em função da freqüência é:

- massa diminui $\rightarrow$ freqüência de ressonância aumenta [Figura 2.8(a)];

- rigidez aumenta $\rightarrow$ freqüência de ressonância aumenta [Figura 2.8(b)];

- amortecimento aumenta $\rightarrow$ há uma pequena diminuição na freqüência de ressonância e a amplitude do deslocamento diminui [Figura 2.8(c)].

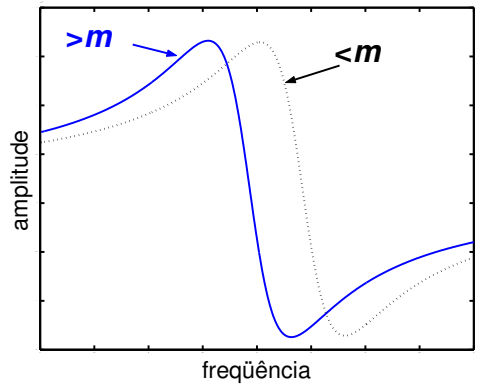

(a)

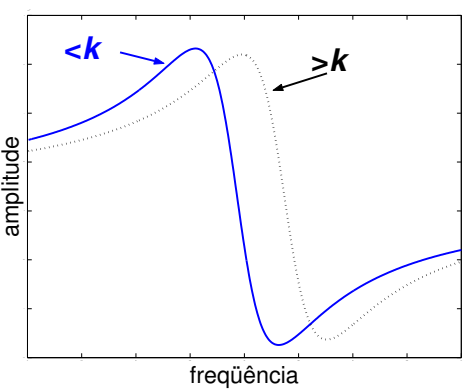

(b)

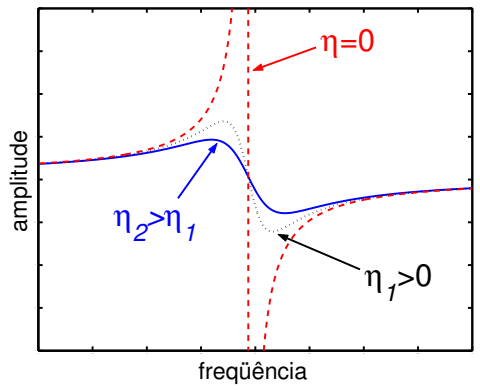

(c)

Figura 2.8. Curva da amplitude de deslocamento por freqüência. A freqüência de ressonância corresponde ao ponto de amplitude de deslocamento máximo. (a) influência da variação da massa $(m)$; influência da variação da rigidez $(k)$; influência da variação do amortecimento, o símbolo $(\eta)$ é o fator de perdas. Nesta figura, o símbolo $>$ significa maior e o símbolo < significa menor.

Pode ser observado que o comportamento do sistema amortecido depende dos valores numéricos da eq.(2.69). Na freqüência de ressonância $\left(\omega_{n}=\sqrt{k / m}\right)$ obtém-se o amortecimento crítico $c_{c}$ :

$$
\left(\frac{c_{c}}{2 m}\right)^{2}=\frac{k}{m}
$$

que pode ser escrito como

$$
c_{c}=2 m \omega_{n}
$$

Um parâmetro importante para descrever as propriedades do amortecimento é o coeficiente de amortecimento mecânico:

$$
\zeta=\frac{c}{c_{c}}=\frac{c}{2 m \omega_{n}}
$$

Baseado no valor da razão de amortecimento, o movimento do corpo de massa $m$ da Figura 2.7 pode ser dividido nos três seguintes casos: 
1. $\zeta<1$ - movimento oscilatório;

2. $\zeta>1$ - movimento não-oscilatório;

3. $\zeta=1$ - movimento com amortecimento crítico.

A mudança da freqüência natural de ressonância de um sistema com amortecimento nulo, no qual a amplitude do deslocamento é infinita, e a freqüência de ressonância do sistema com amortecimento é obtida a partir das eqs.(2.69) e (2.72):

$$
\omega_{r}=\omega_{n} \sqrt{1-\zeta^{2}}
$$

A forma mais comum de tratar o amortecimento é através da equação de Rayleigh:

$$
c=\alpha m+\beta k
$$

onde $\alpha$ é o fator de multiplicação da massa e $\beta$ o fator de multiplicação da constante elástica, ou rigidez do material.

Dessa forma, diferentes amortecimentos físicos podem ser modelados de acordo com os valores de $\alpha$ e $\beta$ [26]. Estas relações são:

- caso não-amortecido $(\alpha=0$ e $\beta=0)$;

- amortecimento viscoso $(\alpha=0$ e $\beta>0)$;

- amortecimento proporcional à massa $(\alpha>0$ e $\beta=0)$;

- amortecimento de Rayleigh $(\alpha>0$ e $\beta>0)$.

Os valores de $\alpha$ e $\beta$ dependem das características de dissipação de energia da estrutura e normalmente não podem ser calculados diretamente, mas são calculados pela razão do amortecimento modal $\left(\zeta_{m r}\right)$. Essa é a razão do amortecimento efetivo pelo amortecimento crítico para um modo particular de vibração $r$ e pode ser escrito como

$$
\zeta_{m r}=\frac{\alpha}{2 \omega_{r}}+\frac{\beta}{2} \omega_{r}
$$

O amortecimento viscoso é normalmente o que ocorre nas vibrações dos transdutores piezelétricos, dessa forma, $\alpha=0$ e o amortecimento $\beta$ pode ser calculado a partir de valores conhecidos de $\zeta_{r m}$ e $\omega_{r}$ que representam o amortecimento estrutural mecânico. Quando a estrutura que apresenta amortecimento está sujeita a uma excitação harmônica, esta pode ser tratada como sujeita a um amortecimento viscoso com coeficiente $[24,75]$

$$
\beta=\frac{1}{\omega Q_{m}},
$$


onde $Q_{m}$ é o fator de qualidade mecânico, que para um material piezelétrico pode ser determinado experimentalmente através da análise da impedância elétrica.

Ao utilizar um polímero em uma estrutura, como por exemplo, fixando os materiais do transdutor piezelétrico com resina epóxi, o amortecimento de toda estrutura é influenciado tanto pela rigidez do polímero, quanto pelo seu amortecimento. Estas duas propriedades são convenientemente quantificadas pelo módulo de Young complexo $E\left(1-i \eta_{S}\right)$ ou o módulo de cisalhamento puro complexo $G_{x}\left(1-i \eta_{G}\right)$. Onde os fatores de perda $\eta_{S}$ e $\eta_{G}$ têm valores iguais para um mesmo material.

A rigidez complexa pode ser expressa como $k(1-i \eta)$. O valor do fator de perdas $\eta$ pode variar de $2 \times 10^{-5}$, para o alumínio puro até 1,0 para borracha. O fator de perdas é o termo usado para quantificar a performance do amortecimento.

\subsection{Discussão}

Neste capítulo foi realizada uma introdução ao comportamento de transdutores piezelétricos. Para isso foram apresentadas as equações de equilíbrio mecânica e elétrica, as quais governam o movimento de um transdutor piezelétrico. Essas equações são dependentes das constantes elétricas, piezelétricas e mecânicas dos materiais que compõem um transdutor piezelétrico, sejam eles materiais piezelétricos ou não-piezelétricos. Também foi apresentado como determinar o valor de cada constante de um material piezelétrico através de análises elétricas. Dos parâmetros determinados, o fator de qualidade mecânico está relacionado com as perdas mecânicas, e consequentemente com o amortecimento. Por isso, o amortecimento, que é um parâmetro importante no comportamento dos transdutores piezelétricos, assim como nos projetos destes, e também nas análises computacionais, foi apresentado aqui na principal forma em que aparece nos sistemas considerados. No próximo capítulo são apresentados os conceitos básicos sobre MEF envolvidos neste trabalho e como utilizar o amortecimento nas simulações. 


\section{Capítulo 3}

\section{Método de Elementos Finitos}

Neste trabalho as análises numéricas dos transdutores piezelétricos são realizadas

utilizando o método de elementos finitos (MEF) através do software comercial ANSYS. Esse pacote permite modelar e simular com boa aproximação da realidade todos os transdutores piezelétricos utilizados neste trabalho. A teoria apresentada no capítulo 2 aplica-se ao comportamento de materiais piezelétricos e nãopiezelétricos. O ANSYS resolve as equações de equilíbrio desses materiais, e para isso é necessário inserir os valores das constantes das equações constitutivas apresentadas no capítulo 2. As simulações são realizadas em sua maioria em duas dimensões, devido ao alto custo computacional dos modelos tridimensionais. Dessa forma, dependendo de cada caso, são realizadas simulações considerando o estado plano de tensões mecânicas, o estado plano de deformações mecânicas e os modelos axi-simétricos. Por isso, neste capítulo também são apresentadas as equações constitutivas na forma matricial, considerando esses modelos bidimensionais. Também é discutido o amortecimento, que está relacionado com perdas mecânicas e elétricas, sua importância no ANSYS e como utilizá-lo.

A importância do amortecimento nas análises numéricas pelo MEF e como ele é considerado no ANSYS estão descritos na próxima seção, a qual trata de uma introdução ao MEF, equações piezelétricas e o amortecimento.

Neste capítulo, os termos em negrito entre parêntesis ou em tabelas, são as entradas no ANSYS. 


\subsection{Introdução ao MEF}

$\mathrm{O}$ método de elementos finitos $(\mathrm{MEF})$ permite modelar o comportamento físico de sistemas, estruturas e meios contínuos genéricos de maneira eficaz. O software utilizado neste trabalho é o ANSYS, que é aplicado em estática, dinâmica, fluxo de calor, fluidos, eletromagnetismo e piezeletricidade $[21,24,46]$. O ANSYS é capaz de resolver problemas lineares e não-lineares em engenharia, quando nãolinearidades estruturais podem ocorrer devido ao comportamento não-linear dos materiais, grandes deformações ou condições de contorno de contato.

Elementos finitos assemelham-se a fragmentos de uma estrutura, e são compostos por linhas, áreas e pontos que definem os elementos discretizados, como ilustra a Figura 3.1. Os elementos possuem áreas triangulares ou quadrilaterais [Figura 3.1(a)], os nós são pontos [Figura 3.1(b)] que servem como conectores para fixar os elementos adjacentes. Todos os elementos que compartilham um nó têm uma mesma componente de deslocamento. As linhas indicam os contornos entre os elementos [Figura 3.1(a)].

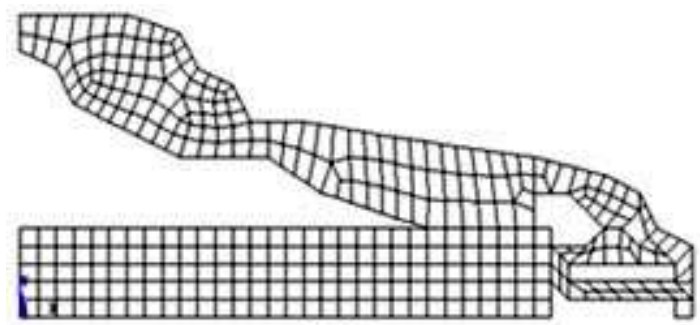

(a)

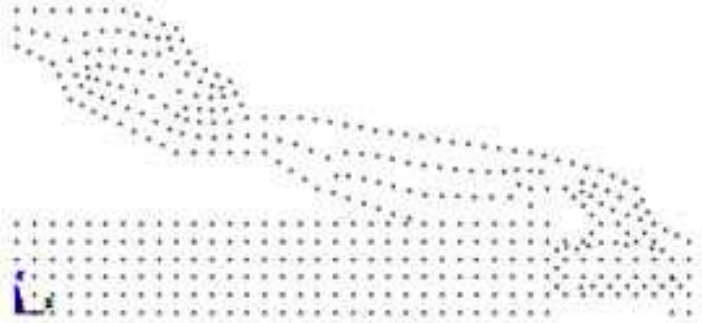

(b)

Figura 3.1. Modelo discretizado em vários elementos finitos: (a) indicando linhas, e áreas; (b) indicando os nós.

O uso do MEF depende basicamente da divisão da estrutura analisada em elementos discretos e do princípio variacional, que estabelece em cada instante o equilíbrio das energias cinética e potencial em todos os pontos do volume considerado [24].

No MEF, a modelagem de um material piezelétrico ou não-piezelétrico, obedece inicialmente às equações de equilíbrio [eqs.(2.8) e (2.24)]. As constantes inseridas no ANSYS para um sólido não-piezelétrico são as relacionadas com a lei de Hooke, dada pela eq.(2.9) e para um sólido piezelétrico são das equações constitutivas da 
eq.(2.25).

\subsection{Equações Piezelétricas do Movimento com Amortecimento}

As equações piezelétricas do movimento podem ser mostradas a partir do princípio da mínima energia por meio do princípio variacional [23, 24, 25]. As equações resultantes podem ser representadas na forma matricial pela montagem de todas as equações individuais de elementos finitos. As equações são escritas em termos do deslocamento $\{\mathbf{u}\}$ e potencial elétrico $\{\boldsymbol{\Phi}\}$ nos pontos nodais. As funções são escritas em termos das forças mecânicas $\{\mathbf{F}\}$ e cargas elétricas $\{\mathbf{Q}\}$ :

$$
\begin{aligned}
{\left[\mathbf{M}_{\mathbf{U U}}\right]\{\ddot{\mathbf{u}}\}+\left[\mathbf{C}_{\mathbf{U U}}\right]\{\dot{\mathbf{u}}\}+\left[\mathbf{K}_{\mathbf{U U}}\right]\{\mathbf{u}\}+\left[\mathbf{K}_{\mathbf{U} \Phi}\right]\{\boldsymbol{\Phi}\}=\{\mathbf{F}\}, } \\
{\left[\mathbf{K}_{\mathbf{U} \Phi}\right]^{t}\{\mathbf{u}\}+\left[\mathbf{K}_{\boldsymbol{\Phi} \Phi}\right]\{\boldsymbol{\Phi}\}=\{\mathbf{Q}\}, }
\end{aligned}
$$

onde

$$
\begin{aligned}
{\left[\mathbf{M}_{\mathbf{U U}}\right] } & =\rho \int_{V}\left[\mathbf{N}_{\mathbf{U}}\right]^{t}\left[\mathbf{N}_{\mathbf{U}}\right] d V & & \text { matriz massa; } \\
{\left[\mathbf{K}_{\mathbf{U U}}\right] } & =\int_{V}\left[\mathbf{B}_{\mathbf{U}}\right]^{t}[\mathbf{C}]\left[\mathbf{B}_{\mathbf{U}}\right] d V & & \text { matriz de rigidez elástica; } \\
{\left[\mathbf{K}_{\mathbf{U} \boldsymbol{\Phi}}\right] } & =\int_{V}\left[\mathbf{B}_{\mathbf{U}}\right]^{t}[\mathbf{e}]^{t}\left[\mathbf{B}_{\boldsymbol{\Phi}}\right] d V & & \text { matriz de rigidez piezelétrica; } \\
{\left[\mathbf{K}_{\boldsymbol{\Phi} \Phi}\right] } & =-\int_{V}\left[\mathbf{B}_{\boldsymbol{\Phi}}\right]^{t}[\epsilon]\left[\mathbf{B}_{\boldsymbol{\Phi}}\right] d V & & \text { matriz de rigidez dielétrica; }
\end{aligned}
$$

No conjunto de eqs.(3.2) a (3.5) os termos $\left[\mathbf{B}_{\mathbf{U}}\right],\left[\mathbf{B}_{\boldsymbol{\Phi}}\right]$ e $\left[\mathbf{N}_{\mathbf{U}}\right]$ são, respectivamente, matriz deformação-deslocamento, matriz campo-deslocamento elétrico e função de interpolação de deslocamento.

O termo $\left[\mathbf{C}_{\mathbf{U U}}\right]$ é a matriz amortecimento dada por:

$$
\begin{aligned}
{\left[\mathbf{C}_{\mathbf{U U}}\right]=} & \alpha\left[\mathbf{M}_{\mathbf{U U}}\right]+\left(\beta+\beta_{c}\right)\left[\mathbf{K}_{\mathbf{U U}}\right]+ \\
& \sum_{j=1}^{N_{M A T}} \beta_{j} \mathbf{K}_{\mathbf{j}}+\sum_{k=1}^{N_{E L E}} \mathbf{C}_{\mathbf{k}}+\mathbf{C}_{\zeta} .
\end{aligned}
$$

No ANSYS, a matriz amortecimento $\left[\mathbf{C}_{\boldsymbol{U} U}\right]$ pode ser montada através das propriedades de amortecimento da estrutura, que geralmente são dependentes da freqüência. A forma mais geral da matriz amortecimento $[21,27,28,74]$ é dada pela eq.(3.6).

Os termos dessa equação e como são inseridos no ANSYS são descritos a seguir: 
símbolo significado

$\alpha \quad$ constante multiplicadora da matriz massa

$\beta \quad$ constante multiplicadora da matriz rigidez

$\beta_{j} \quad$ constante multiplicadora da matriz rigidez

$\beta_{c} \quad$ variável multiplicadora da matriz rigidez

$\mathbf{C}_{\zeta} \quad$ matriz amortecimento dependente da freqüência

$\mathbf{C}_{\mathbf{k}} \quad$ matriz amortecimento do elemento

$N_{M A T}$ número de materiais com entradas DAMP

$N_{E L E} \quad$ número de elementos com amortecimento entrada no ANSYS

ALPHAD

BETAD

MP,DAMP

O termo $\beta_{j}$ é o valor do amortecimento de cada material usado nas modelagens no ANSYS. Pode-se trabalhar ou utilizando um valor de amortecimento para cada material (entradas em MP,DAMP) ou então usar o amortecimento do conjunto $\beta$ (entrada em BETAD).

O termo $\beta_{c}$ é utilizado em análises de resposta harmônica. Este é usado para dar a razão do amortecimento [eq.(2.72)], independente da freqüência. O multiplicador da matriz rigidez $\beta_{c}$ está relacionado $\operatorname{com} \zeta$ por:

$$
\beta_{c}=\frac{\zeta}{\pi f}
$$

A entrada de $\zeta$ no ANSYS é DMPRAT. Nessa equação, $f$ é a freqüência no

intervalo $f_{i}$ (freqüência inicial) e $f_{f}$ (freqüência final), definidas para a análise de resposta harmônica.

O termo $\mathbf{C}_{\zeta}$ é a matriz amortecimento dependente da freqüência. Este efeito ocorre apenas nas análises espectrais, análises de resposta harmônica com superposição de modos, e análises transiente com superposição de modos, as quais não são realizadas neste trabalho.

\subsubsection{Amortecimento Estrutural Mecânico}

Na prática é conveniente aproximar o amortecimento pela expressão de Rayleigh, que relaciona a matriz $\left[\mathbf{C}_{\mathbf{U U}}\right]$ com as matrizes de rigidez $\left[\mathbf{K}_{\mathbf{U U}}\right]$ e de massa $\left[\mathbf{M}_{\mathbf{U U}}\right]$ através das constantes $\alpha$ e $\beta[21,27,28,74]$ pela seguinte equação:

$$
\left[\mathbf{C}_{\mathbf{U U}}\right]=\alpha\left[\mathbf{M}_{\mathbf{U U}}\right]+\beta\left[\mathbf{K}_{\mathbf{U U}}\right]
$$

Na seção 2.4 é discutido que para o amortecimento viscoso $\alpha=0$, dessa forma, 
a matriz amortecimento torna-se

$$
\left[\mathbf{C}_{\mathbf{U U}}\right]=\frac{1}{\omega Q_{m}}\left[\mathbf{K}_{\mathbf{U U}}\right]
$$

onde $Q_{m}$ é o fator de qualidade mecânico do material piezelétrico, que pode ser determinado experimentalmente utilizando análises elétricas, como descrito no capítulo 2.

\subsubsection{Amortecimento Dielétrico}

Além do amortecimento estrutural mecânico, pode-se considerar também a matriz de amortecimento dielétrica, que caracteriza as perdas dielétricas e é dado pela equação:

$$
\left[\mathbf{C}_{\boldsymbol{\Phi} \boldsymbol{\Phi}}\right]=\frac{1}{\omega} \int_{V}\left[\mathbf{N}_{\boldsymbol{\Phi}}\right]^{t}\left[\epsilon^{d}\right]\left[\mathbf{N}_{\boldsymbol{\Phi}}\right] d V
$$

onde $\left[\mathbf{N}_{\boldsymbol{\Phi}}\right]$ é a função de interpolação de potencial elétrico e a matriz $\left[\epsilon^{d}\right]$ está relacionada com a matriz $\left[\epsilon^{S}\right]$ através de:

$$
\left[\epsilon^{d}\right]=-\tan \delta_{E}\left[\epsilon^{S}\right]
$$

O fator de perda dielétrica é

$$
h^{d}=-\tan \delta_{E}
$$

e obtém-se como solução para a eq.(3.10):

$$
\mathbf{C}_{\boldsymbol{\Phi} \boldsymbol{\Phi}}=-\frac{h^{d}}{\omega} \mathbf{K}_{\boldsymbol{\Phi} \boldsymbol{\Phi}}
$$

Essas perdas dielétricas provocam uma alteração de fase entre tensão e corrente elétricas.

\subsection{Solução das Equações Piezelétricas}

Três tipo de soluções são possíveis no ANSYS para as equações piezelétricas. Essas soluções incluem: análise estática, usada para a determinação de deslocamento ou potencial elétrico; análise dinâmica, usada para a determinação da resposta do sistema a excitações harmônica ou transiente; análise modal, usada para determinação das freqüências naturais e modos de vibração. 


\subsubsection{Análise Estática}

$\mathrm{Na}$ análise estática, os efeitos inerciais (massa) e do amortecimento são ignorados, com exceção dos efeitos de aceleração estática, como a ação da gravidade. Nestes casos as eqs.(3.1) reduzem-se a:

$$
\begin{aligned}
& {\left[\mathbf{K}_{\mathbf{U U}}\right]\{\mathbf{u}\}+\left[\mathbf{K}_{\mathbf{U} \boldsymbol{\Phi}}\right]\{\boldsymbol{\Phi}\}=\{\mathbf{F}\}} \\
& {\left[\mathbf{K}_{\mathbf{U} \boldsymbol{\Phi}}\right]^{t}\{\mathbf{u}\}+\left[\mathbf{K}_{\boldsymbol{\Phi \Phi} \boldsymbol{\Phi}}\right]\{\boldsymbol{\Phi}\}=\{\mathbf{Q}\} .}
\end{aligned}
$$

No entanto, podem ser aplicadas forças mecânicas e cargas elétricas. Também podem ser impostas condições de contorno impedindo o deslocamento ou aplicação de potencial elétrico. Por exemplo, a Figura 3.2(a) mostra cargas impondo deslocamento nulo em alguns elementos $(\mathbf{U X}=0$ e $\mathbf{U Y}=0)$ e tensão elétrica nos eletrodos superiores e inferiores (VOLT). Neste trabalho, normalmente é aplicada tensão elétrica no eletrodo inferior (por exemplo, VOLT $=1$ ) e aterrado o superior $(\mathbf{V O L T}=0)$. A solução da eq.(3.13) dá o deslocamento e o potencial elétrico em todos os graus de liberdade, para cada elemento.
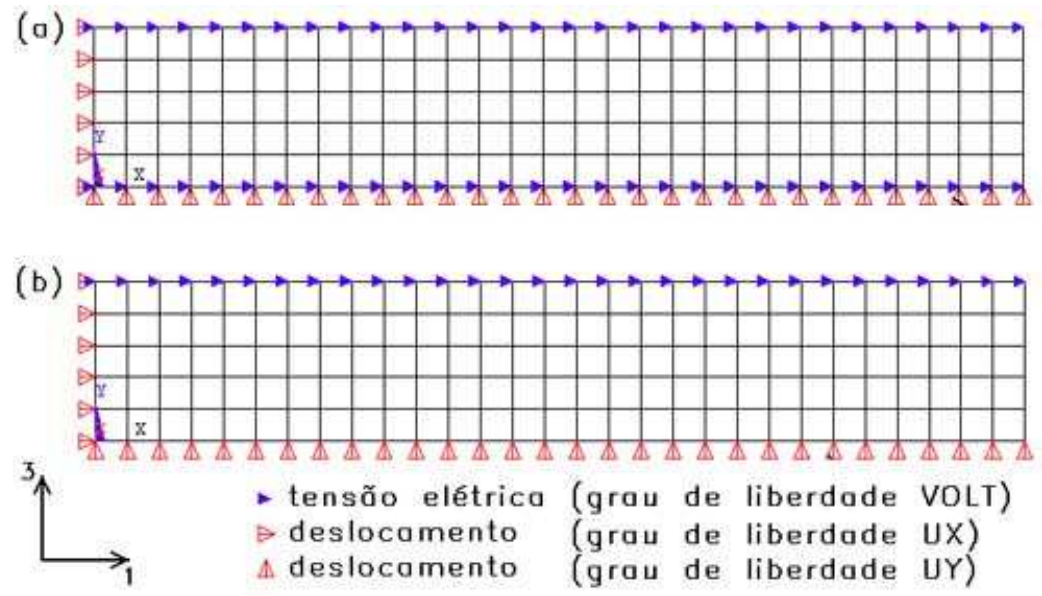

Figura 3.2. (a) cargas mecânicas e tensão elétrica em ambos eletrodos. (b) o eletrodo superior aterrado e inferior removido.

\subsubsection{Análise Dinâmica}

A resposta dinâmica de um material piezelétrico é obtida quando este é submetido a excitação harmônica (senoidal contínua) ou transiente (um ciclo de seno, por exemplo), nas quais as cargas aplicadas podem ser tensão elétrica, correntes elétricas, 
deslocamentos e forças mecânicas. A Figura 3.2(a) ilustra uma situação padrão de cargas aplicadas ao material piezelétrico para uma análise dinâmica.

Na análise harmônica, o deslocamento e a tensão elétrica, por exemplo, podem estar fora de fase, mas necessariamente possuem a mesma freqüência. O deslocamento elétrico, o potencial elétrico, a força mecânica e as cargas elétricas são dados, respectivamente, por

$$
\begin{aligned}
\{\mathbf{u}(\mathbf{t})\} & =\left\{u_{0}\right\} e^{-i \omega t+\phi_{1}} \\
\Phi(t) & =\Phi_{0} e^{-i \omega t+\phi_{2}} \\
\{\mathbf{F}(\mathbf{t})\} & =\left\{F_{0}\right\} e^{-i \omega t+\phi_{3}}, \\
Q(t) & =Q_{0} e^{-i \omega t+\phi_{4}} .
\end{aligned}
$$

Onde $\phi_{i}$, para $i=1,2,3,4$, é o deslocamento de fase. A carga elétrica é relacionada com a corrente elétrica no eletrodos através de

$$
\begin{aligned}
I(t) & =\frac{d Q(t)}{d t}, \\
Q(t) & =\frac{I}{i \omega} e^{-i \omega t+\phi_{4}} .
\end{aligned}
$$

Através da análise harmônica é possível determinar a resposta em freqüência do material piezelétrico. Essas respostas em freqüência podem ser, por exemplo, o deslocamento, admitância e impedância elétrica. Essas respostas elétricas são dadas por:

$$
\begin{aligned}
Z & =\frac{V}{I}=\frac{V_{0}}{i \omega Q_{0}} \\
Y & =\frac{1}{Z} .
\end{aligned}
$$

Nestas equações $V$ é a diferença de potencial elétrico e $V_{0}$ sua amplitude, $Y$ é a admitância elétrica e $Z$ a impedância elétrica, $\omega$ é a freqüência de excitação e $t$ o tempo, $i$ é a indicação de número imaginário $(i=\sqrt{-1})$ e $Q_{0}$ é a amplitude da carga elétrica. No modelo de MEF, a carga elétrica no eletrodo, no qual é aplicada tensão elétrica, é obtida somando-se as cargas elétricas nodais dos nós do eletrodo da cerâmica ( $V_{0}$ é a tensão elétrica aplicada e conhecida), ou seja:

$$
Q_{0}=\sum_{i=1}^{n e} Q_{0}^{i} .
$$


A Figura 3.3(a) ilustra uma curva de resposta em freqüência da admitância elétrica de um transdutor piezelétrico, obtida através da análise harmônica, destacando os pontos das freqüências de ressonância e anti-ressonância [75]. A Figura 3.3(b) mostra a curva da fase elétrica pela freqüência, para o mesmo transdutor.
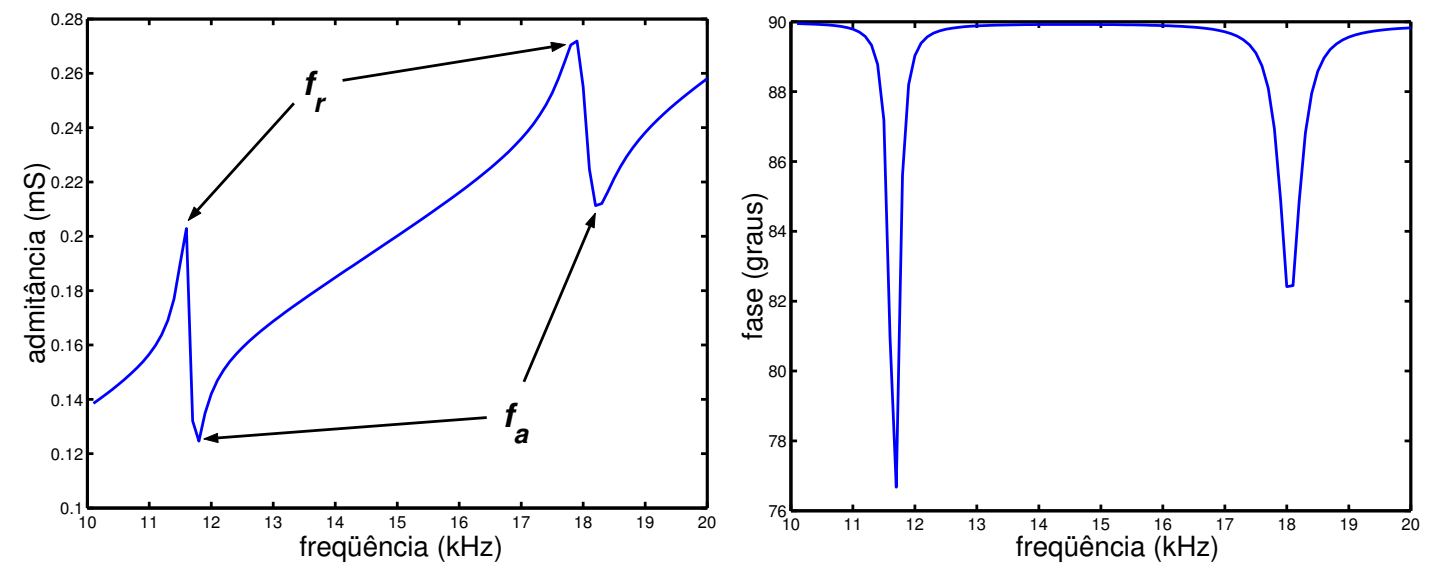

Figura 3.3. (a) Curva de resposta em freqüência da admitância elétrica, $f_{r}$ indica os pontos das freqüências de ressonância e $f_{a}$ os pontos das freqüências de anti-ressonância. (b) curva da fase elétrica.

$\mathrm{Na}$ análise transiente, o deslocamento e a tensão elétrica podem estar fora de fase e também possuir freqüências distintas, pois o material analisado tenderá a responder em suas freqüências naturais de ressonância. Nessa análise é necessário acoplar os nós que receberão o sinal de excitação, assim como os nós aterrados, pois o sinal elétrico é aplicado em um único nó do eletrodo inferior [Figura 3.2(a)], assim como o terra é aplicado em um único nó do eletrodo superior. Esses nós, que recebem a tensão elétrica e o terra, são denominados nós principais (Master DOF), e são aqueles que possuem o menor número do conjunto de nós selecionados.

\subsubsection{Análise Modal}

Os modos de vibração e as freqüências naturais também podem ser obtidos através da análise modal. Problemas típicos resolvidos por essa análise incluem a determinação das freqüências de ressonância ou anti-ressonância dos modos de vibração. As freqüências de ressonância são obtidas realizando um curto-circuito nos eletrodos. Isso é realizado aplicando tensão elétrica nula em ambos eletrodos do material piezelétrico, como ilustrado na Figura 3.2(a). As freqüências de anti-ressonância são 
obtidas aterrando um dos eletrodos e removendo a tensão elétrica do outro eletrodo, como mostra a Figura 3.2(b).

\subsection{Modelagem no ANSYS}

Ao realizar simulações pelo método de elementos finitos (MEF), é comum que esta seja em duas dimensões, não apenas para reduzir o tempo de processamento, mas também devido a limitações de memória com as quais os softwares de MEF trabalham. Entretanto, muitos problemas de elasticidade podem ser tratados satisfatoriamente em duas dimensões, pela teoria da elasticidade plana $[21,61,74,76]$.

Nos modelos bidimensionais, o ANSYS considera a polarização na direção $y$, enquanto que nos modelos tridimensionais a polarização pode ser considerada na direção z. No capítulo 2 a equação constitutiva [eq.(2.30)] segue a definição das direções do IEEE [29], no qual a polarização está na direção z. Dessa forma, para realizar uma simulação bidimensional há necessidade de inversão de base da matriz das equações constitutivas [eqs.(2.30)]. O ANSYS apresenta ainda uma outra diferença em relação à nomenclatura clássica utilizada nos livros de materiais piezelétricos $[58,59]$, os tensores de cisalhamento possuem outra ordem na notação reduzida.

Os materiais isotrópicos não sofrem alterações nas componentes matriciais, devido à simetria. Porém, um material piezelétrico da classe de simetria $6 \mathrm{~mm}$ possui a seguinte equação constitutiva no ANSYS (polarização eixo y), na notação matricial:

$$
\left[\begin{array}{c}
T_{x x} \\
T_{y y} \\
T_{z z} \\
T_{x y} \\
T_{y z} \\
T_{x z} \\
D_{x} \\
D_{y} \\
D_{z}
\end{array}\right]=\left[\begin{array}{cccccc|ccc}
c_{11}^{E} & c_{13}^{E} & c_{12}^{E} & 0 & 0 & 0 & 0 & e_{31} & 0 \\
c_{13}^{E} & c_{33}^{E} & c_{13}^{E} & 0 & 0 & 0 & 0 & e_{33} & 0 \\
c_{12}^{E} & c_{12}^{E} & c_{11}^{E} & 0 & 0 & 0 & 0 & e_{31} & 0 \\
0 & 0 & 0 & c_{44}^{E} & 0 & 0 & e_{15} & 0 & 0 \\
0 & 0 & 0 & 0 & c_{44}^{E} & 0 & 0 & 0 & e_{15} \\
0 & 0 & 0 & 0 & 0 & c_{66}^{E} & 0 & 0 & 0 \\
\hline 0 & 0 & 0 & e_{15} & 0 & 0 & -\epsilon_{11}^{S} & 0 & 0 \\
e_{31} & e_{33} & e_{31} & 0 & 0 & 0 & 0 & -\epsilon_{33}^{S} & 0 \\
0 & 0 & 0 & 0 & e_{15} & 0 & 0 & 0 & -\epsilon_{11}^{S}
\end{array}\right]\left[\begin{array}{c}
S_{x x} \\
S_{y y} \\
S_{z z} \\
S_{x y} \\
S_{y z} \\
S_{x z} \\
-E_{x} \\
-E_{y} \\
-E_{z}
\end{array}\right] .
$$

O apêndice A mostra alguns detalhes do processo de inversão de bases, assu- 
mindo a polarização na direção $y$ e também na direção $x$, que em alguns casos faz-se necessária, como por exemplo ao utilizar duas piezocerâmica em configuração perpendicular.

Nas modelagens bidimensionais devem ser inseridas as constantes dos materiais piezelétricos na ordem apresentada na eq.(3.23), como se fosse uma modelagem tridimensional. O ANSYS pode realizar as seguintes considerações bidimensionais:

- Estado plano de tensões mecânicas (plane stress);

- Estado plano de deformações mecânicas (plane strain);

- Axi-simétrica, para o caso de modelos cilíndricos.

O uso do estado plano de tensões mecânicas ou de deformações mecânicas depende das dimensões dos materiais, conforme descrito na seção 3.4.1. O uso do modelo axi-simétrico é possível com elementos cilíndricos. As considerações para esse modelo são descritas na seção 3.4.2. Para cada consideração bidimensional assumida, o ANSYS faz automaticamente as modificações na matriz tridimensional [eq.(3.23)].

\subsubsection{Estados Planos}

Os problemas envolvidos nas análises de estados planos podem ser definidos por um determinado número de restrições e suposições nos campos de tensão mecânica e deformação mecânica. A solução pode ser obtida através das considerações: de estado plano de tensões mecânicas (plane stress) e do estado plano de deformações mecânicas (plane strain). Esses estados planos são descritos em termos dos protótipos físicos da estrutura analisada.

- Estado Plano de Tensões Mecânicas (EPTM): esta consideração é utilizada em corpos que possuem uma geometria com a largura (direção 2) e o comprimento (direção 1) em dimensões comparáveis, como mostra a Figura 3.4(a). As cargas são aplicadas uniformemente sobre a espessura da placa.

- Estado Plano de Deformações Mecânicas (EPDM): esta consideração é utilizada em corpos que possuem a largura (direção 2) em dimensões muito superiores ao comprimento (direção 1) e à espessura (direção 3), como mostra a 
Figura 3.4(b). As cargas são distribuídas uniformemente em relação à largura e atuam perpendicular a esta.

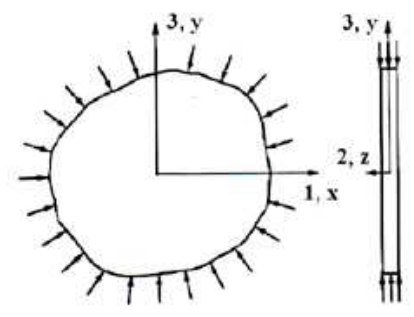

(a)

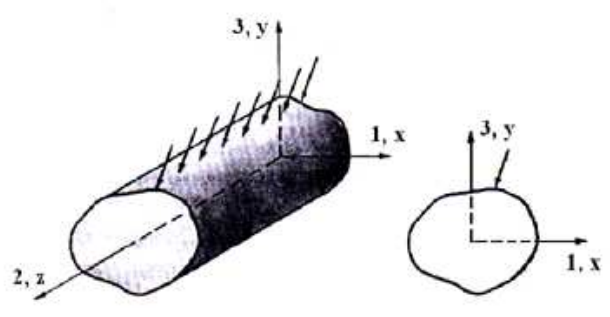

(b)

Figura 3.4. (a) estado plano de tensões mecânicas; (b) estado plano de deformações mecânicas. A polarização de um material piezelétrico é considerada na direção 3 .

As alterações realizadas pelo ANSYS são mostradas a seguir, de acordo com as condições assumidas: estado plano de tensões mecânicas; estado plano de deformações mecânicas; e axi-simétrico.

\section{Estado Plano de Tensões Mecânicas}

No caso dos materiais isotrópicos, o estado plano de tensões mecânicas da Figura 3.4(a) apresenta as componentes

$$
T_{z z}=0, \quad T_{y z}=0 \quad \text { e } \quad T_{x z}=0
$$

Essa forma a matriz da lei de Hooke torna-se [74, 76]:

$$
\left[\begin{array}{c}
T_{x x} \\
T_{y y} \\
T_{x y}
\end{array}\right]=\frac{E}{1-\sigma^{2}}\left[\begin{array}{ccc}
1 & \sigma & 0 \\
\sigma & 1 & 0 \\
0 & 0 & \frac{1-\sigma}{2}
\end{array}\right]\left[\begin{array}{c}
S_{x x} \\
S_{y y} \\
S_{x y}
\end{array}\right]
$$

No caso dos materiais piezelétricos com simetria hexagonal do grupo $6 \mathrm{~mm}$ no estado plano de tensões mecânicas, a componente do deslocamento elétrico na direção $z$ é nula:

$$
D_{z}=0
$$

Após as modificações na matriz das equações constitutivas piezelétrica [eq.(3.23)], realizada pelo ANSYS, esta assume a seguinte forma: 


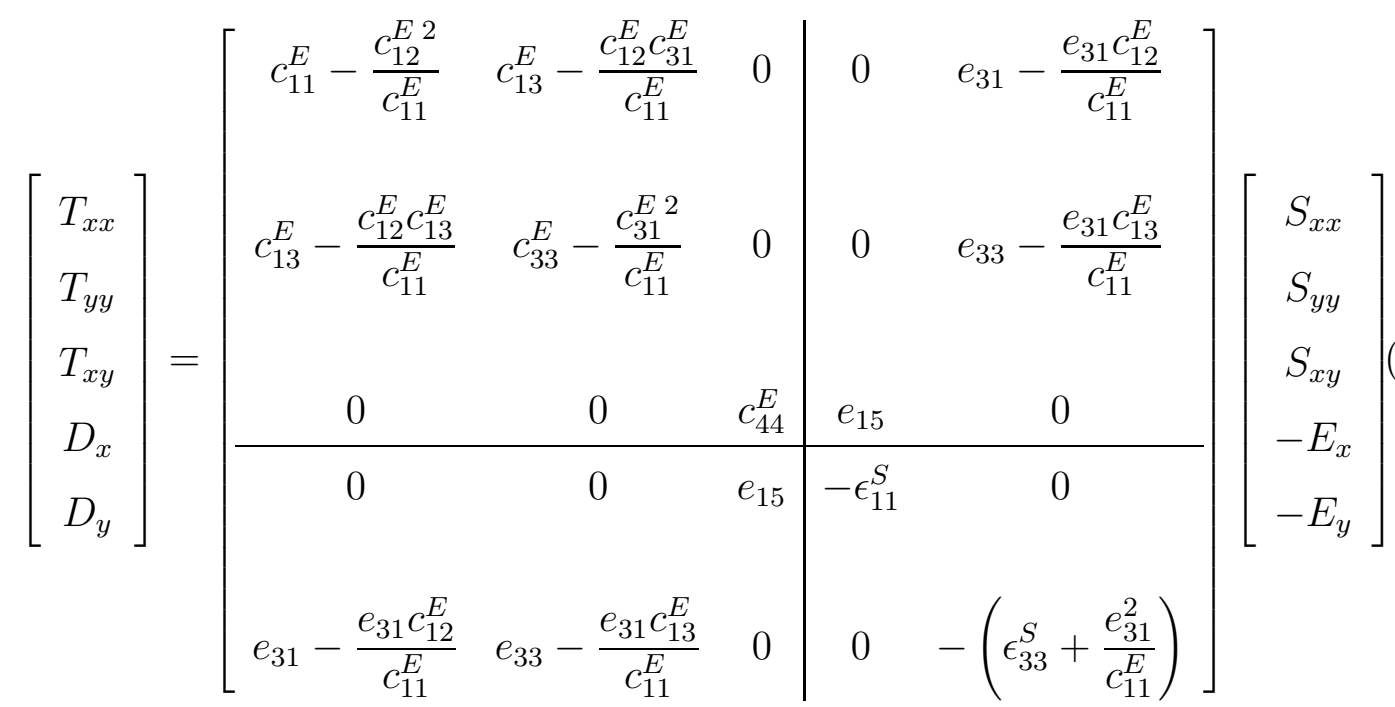

No caso do estado plano de tensões mecânicas há contribuição dos termos da rigidez na direção 2, pois nessas considerações assume-se a estrutura analisada possui dimensões finitas e a largura (direção 2) influencia no comportamento da estrutura.

\section{Estado Plano de Deformações Mecânicas}

O problema do estado plano de deformações mecânicas [Figura 3.4(b)] apresenta a componente do deslocamento na direção $z$ nula:

$$
u_{z}=0 .
$$

Dessa forma, as deformações:

$$
S_{z z}=0, \quad S_{y z}=0, \quad \text { e } \quad S_{x z}=0 .
$$

Nessa consideração, o ANSYS modifica a matriz da lei de Hooke para a seguinte forma:

$$
\left[\begin{array}{c}
T_{x x} \\
T_{y y} \\
T_{x y}
\end{array}\right]=\frac{E}{(1+\sigma)(1-2 \sigma)}\left[\begin{array}{ccc}
1-\sigma & \sigma & 0 \\
\sigma & 1-\sigma & 0 \\
0 & 0 & \frac{1-2 \sigma}{2}
\end{array}\right]\left[\begin{array}{c}
S_{x x} \\
S_{y y} \\
S_{x y}
\end{array}\right] .
$$

Na simulação de um material piezelétrico em estado plano de deformações mecânicas, a componente do campo elétrico da direção $z$ é nula:

$$
E_{z}=0
$$


O ANSYS modifica a matriz das equações constitutivas piezelétricas para a forma:

$$
\left[\begin{array}{c}
T_{x x} \\
T_{y y} \\
T_{x y} \\
D_{x} \\
D_{y}
\end{array}\right]=\left[\begin{array}{ccc|cc}
c_{11}^{E} & c_{13}^{E} & 0 & 0 & e_{31} \\
c_{13}^{E} & c_{33}^{E} & 0 & 0 & e_{33} \\
0 & 0 & c_{44}^{E} & e_{15} & 0 \\
\hline 0 & 0 & e_{15} & -\epsilon_{11}^{S} & 0 \\
e_{31} & e_{33} & 0 & 0 & -\epsilon_{33}^{S}
\end{array}\right]\left[\begin{array}{c}
S_{x x} \\
S_{y y} \\
S_{x y} \\
-E_{x} \\
-E_{y}
\end{array}\right]
$$

No estado plano de deformações mecânicas, não há contribuição dos termos da direção 2, pois assume-se que a estrutura analisada é infinita na direção da largura, ou que está rigidamente fixada nessa direção.

\subsubsection{Modelo Axi-simétrico}

A transformação das propriedades do material do sistema tridimensional para um modelo bidimensional axi-simétrico, ou seja do sistema de coordenadas cartesianas $x y z$ para os sistema de coordenadas cilíndricas $r \theta z$, se dá como mostra a Figura 3.5.

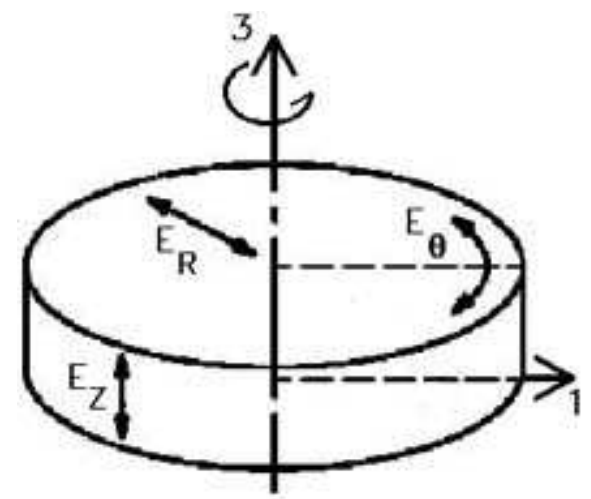

(a)

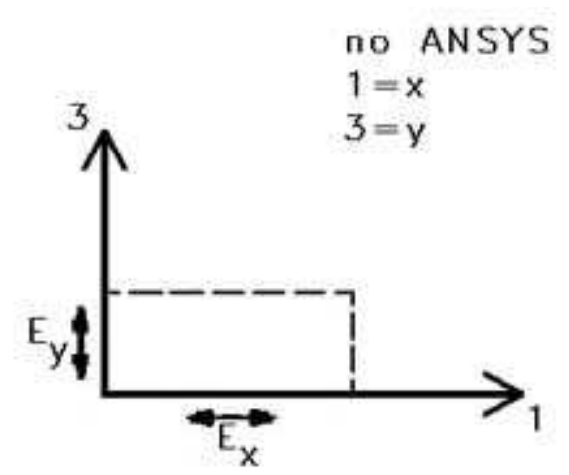

(b)

Figura 3.5. (a) sistema axi-simétrico em coordenadas cilíndricas; (b) sistema em coordenadas cartesianas.

Considerando um sólido isotrópico, para o qual o módulo de Young E é idêntico em todas as direções, e o mesmo vale para o coeficiente de Poisson $\sigma$, a matriz de rigidez na condição axi-simétrica é muito similar a uma matriz do estado plano de deformações mecânicas, com exceção da deformação circunferencial $S_{\theta}$ [74].

O cisalhamento puro $G_{i}$ não sofre alterações. A matriz é escrita com as coorde- 
nadas cilíndricas [74] da seguinte forma:

$$
\left[\begin{array}{c}
T_{r} \\
T_{\theta} \\
T_{z} \\
T_{z r}
\end{array}\right]=\left[\begin{array}{cccc}
(1-\sigma) c_{i} & \sigma c_{i} & \sigma c_{i} & 0 \\
\sigma c_{i} & (1-\sigma) c_{i} & \sigma c_{i} & 0 \\
0 & 0 & 1-\sigma & 0 \\
0 & 0 & 0 & G_{i}
\end{array}\right]\left[\begin{array}{c}
S_{r} \\
S_{\theta} \\
S_{z} \\
S_{z r}
\end{array}\right]
$$

onde:

$$
c_{i}=\frac{E}{(1+\sigma)(1-2 \sigma)} \quad \text { e } \quad \mathrm{G}_{\mathrm{i}}=\frac{\mathrm{E}}{2(1+\sigma)} .
$$

Não será feito aqui o tratamento do modelo axi-simétrico para materiais piezelétricos (sólido anisotrópico). Para um sólido de revolução, o software pode necessitar que as propriedades do material não tenham dependência em $\theta$ e que $\theta$ seja a principal direção de um material ortotrópico [21].

\subsection{Discussão}

Neste capítulo foi realizada uma introdução ao MEF e também às equações do movimento piezelétricas, que são consideradas pelos softwares de elementos finitos. A ênfase ao amortecimento foi novamente dada neste capítulo. Pois, assim como discutida no capítulo 2 a sua influência nos transdutores piezelétricos, aqui foi apresentada a equação matricial do amortecimento e como utilizar cada termo e suas contribuições no ANSYS, para os transdutores piezelétricos analisados e nas faixas de freqüência de interesse. Também foi discutida que devido ao alto custo computacional das modelagens tridimensionais, opta-se por realizar modelagens bidimensionais nos estados planos de tensão e deformação mecânicas e também axi-simétrica. Cada consideração bidimensional depende das formas ou das condições de contorno dos transdutores modelados. No próximo capítulo são apresentados os transdutores piezelétricos analisados neste trabalho e suas aplicações. 


\section{Capítulo 4}

\section{Atuadores Piezelétricos}

Os transdutores piezelétricos flextensional (flextensional), unilaminar (unimorph), bilaminar (bimorph) e multicamadas em pilha (stack), são normalmente utilizados como atuadores piezelétricos. Um atuador é um dispositivo capaz de produzir uma ação, como por exemplo, mover um corpo. Esses dispositivos são aplicados em diversos campos, tais como, na óptica, na micro-eletrônica, na medicina, na mecânica etc. Dentre as aplicações, podem ser destacadas: estabilização de interferômetros, posicionadores $X Y Z$ de espelhos ou para varredura em microscópios atômicos, manipulação de células ou genes etc. Por isso, os atuadores necessitam ter grande precisão e resolução. Em algumas aplicações, esses dispositivos precisam produzir força, serem compactos e robustos. Devem também apresentar respostas aos estímulos em um curto intervalo de tempo, além de consumir pouca energia elétrica. Devem apresentar baixa interferência eletromagnética e múltiplos graus de liberdade.

As análises experimentais e numéricas, dos atuadores piezelétricos, são realizadas em conjunto apenas na faixa linear do deslocamento pelo campo elétrico, com o intuito de verificar a deformação máxima, limites de tensão elétrica e para obter os limites lineares do deslocamento pelo campo elétrico.

Os atuadores piezelétricos, ou simplesmente piezoatuadores, são utilizados sob excitação elétrica em regime estático, quando submetidos à variação da tensão elétrica em corrente contínua (CC) ou em regime de excitação quasi-estático, quando submetidos a excitação harmônica, que são ondas senoidais contínuas, a freqüências abaixo de sua primeira freqüência de ressonância. 
O princípio de operação de um piezoatuador é produzir pequenas variações de deslocamentos quando submetido a pequenas variações de voltagem elétrica. Esse movimento não é influenciado pela estricção/fricção. Várias aplicações para os piezoatuadores são descritas em [77].

Um sistema piezelétrico de posicionamento apresenta uma resolução de subnanômetros, podendo posicionar peças em intervalo de atuação maior que $100 \mu \mathrm{m}$. Um piezoatuador bilaminar pode chegar a deformações superiores a $1 \mathrm{~mm}$ [5], no entanto produz pouca força [78], enquanto que os piezoatuadores flextensional e de multicamadas cerâmicas em pilha são capazes de deformarem-se na mesma ordem e também produzirem força [37, 79], ou seja, movem cargas.

Nas seções seguintes são apresentados os piezoatuadores analisados neste trabalho.

\subsection{Atuador Piezelétrico Flextensional}

Uma boa revisão dos primeiros transdutores flextensionais é realizada por ROLT [41]. Os primeiros transdutores eram dispositivos eletro-acústicos utilizados imersos em água atuando como sonares. A fabricação do primeiro modelo consta de 1929 [41] e utilizava uma membrana metálica revestindo uma barra magneto-estrictiva. A camada metálica tinha a função de amplificar as ondas acústicas geradas pela barra magneto-estrictiva. O nome atual destes dispositivos vem de Flexural-Extensional Electromechanical Transducer, ou abreviando o nome do dispositivo ficando apenas Flextensional Electromechanical Transducer. A combinação desse nome vem da produção de som através da flexão (flexural) da membrana metálica ao ser estendida (extensional) e contraída durante o movimento da barra magneto-estrictiva.

A partir de 1990 foram fabricados outros tipos de transdutores eletromecânicos flextensionais [36, 38]. Estes novos dispositivos utilizam uma piezocerâmica, como elemento ativo, colada a uma estrutura metálica flexível. A função desses novos transdutores é amplificar e mudar a direção dos pequenos deslocamentos mecânicos (deformação) da piezocerâmica e são utilizados como piezoatuadores. O esquema ilustrado na Figura 4.1 mostra em forma de diagrama a função de um piezoatuador flextensional. 


\begin{tabular}{|c|}
$\begin{array}{c}\text { Atuador } \\
\text { Flextensional }\end{array}$ \\
piezelétrica
\end{tabular}$\quad+$\begin{tabular}{l}
$\begin{array}{l}\text { Estrutura } \\
\text { Flexível }\end{array}$ \\
\hline
\end{tabular}

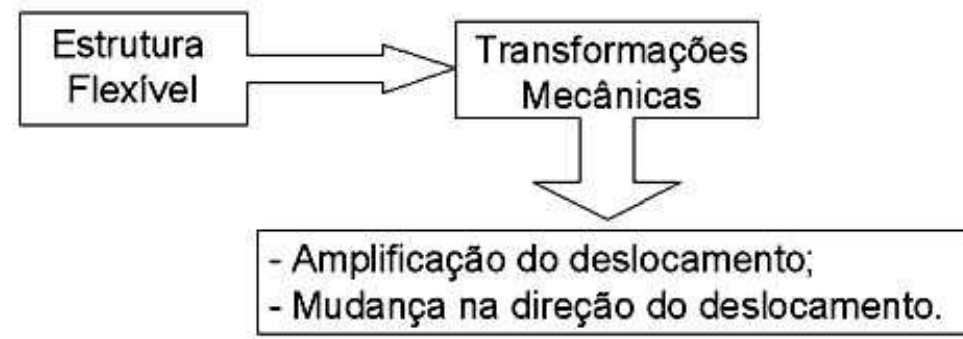

Figura 4.1. Diagrama da função da um transdutor piezelétrico flextensional.

Dois exemplos típicos de piezoatuadores flextensionais são os da primeira geração: moonies $^{T M}[36,42]$; e os da segunda geração: cymbals $^{T M}[38,80]$. Estes consistem num disco cerâmico piezelétrico montado entre duas estruturas de metal, também circulares, como ilustrado na Figura 4.2. Essas estruturas metálicas amplificam em mudam a direção do deslocamento gerado pela piezocerâmica, como ilustrado na Figura 4.3. Tanto a deformação no sentido do comprimento quanto da deformação no sentido da espessura (coeficientes piezelétricos $d_{31}$ e $d_{33}$, respectivamente) contribuem para a amplificação do deslocamento, no entanto, o coeficiente que apresenta uma grande contribuição é o $d_{31}$, pois um grande deslocamento longitudinal da piezocerâmica (direção 1) produz uma grande amplificação no deslocamento da estrutura metálica na direção 3 (Figura 4.3).

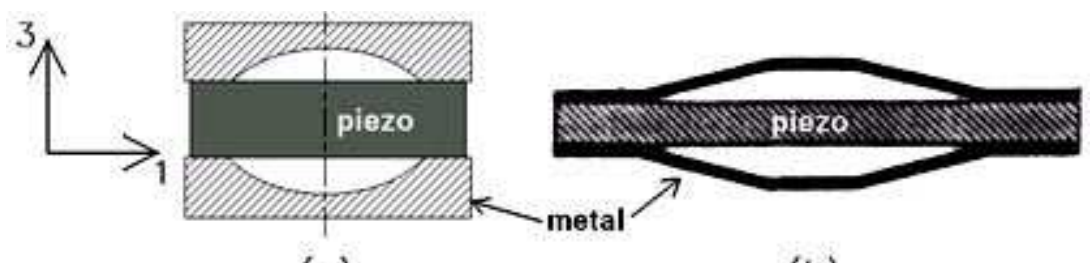

(a)

(b)

Figura 4.2. Primeira e segunda geração de piezoatuadores flextensionais: (a) moonies $^{T M}$; (b) cymbals $^{T M}$.

Um piezoatuador flextensional é projetado para trabalhar em regime de excitação estática, ou seja, alimentado por uma tensão elétrica constante, ou então em regime semi-estático, ou seja, alimentado por uma onda senoidal contínua a 
baixas-freqüências (menores que $10 \mathrm{kHz}$ ). Algumas das aplicações de um piezoatuador flextensional são como nanoposicionador [39, 60], motores piezelétricos [40], hidrofones $[42,81]$ e sonares [41].

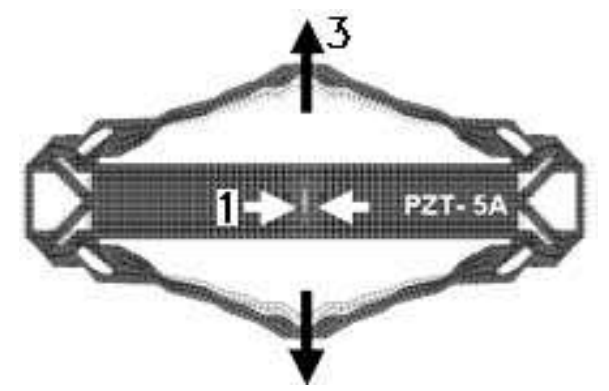

Figura 4.3. Esquema da amplificação gerada pela estrutura flexível. A contração da piezocerâmica na direção 1, produz um grande deslocamento da estrutura flexível na direção 3.

Ao projetar um transdutor piezelétrico flextensional, leva-se em conta o desempenho deste, medido pela razão de amplificação dos deslocamentos gerados pela cerâmica, e da força produzida ou da força de bloqueio, ou seja, a força máxima que um piezoatuador pode produzir se for bloqueado (não deformar) por um corpo rígido [38]. A rigidez e a flexibilidade da estrutura metálica acoplada à piezocerâmica é o que determina a taxa de amplificação de deslocamento e a força produzida.

A otimização da eficiência dos primeiros piezoatuadores flextensionais era realizada por tentativa e erro, como por exemplo produzido cortes em diferentes pontos da estrutura metálica [38], ou utilizando uma das estruturas metálicas de latão e a outra de aço [80]. Neste trabalho são caracterizados piezoatuadores flextensionais, que foram projetados por otimização topológica por SILVA et al. [35], para que possuíssem uma boa eficiência. Diferentes estruturas de transdutores piezelétricos flextensionais podem ser obtidas com maior eficiência para as mais variadas tarefas.

A validação do método de otimização topológica, desenvolvido por SILVA et al. [63, 64], para projeto dos piezoatuadores flextensionais, é a meta inicial desse trabalho. Algumas aplicações desses dispositivos são sugeridas para serem utilizadas em sistemas interferométricos, como ilustra a Tabela 4.1.

Dos vários protótipos, fabricados por eletro-erosão a fio, alguns são ilustrados nesta seção, na qual pretende-se mostrar os piezoatuadores flextensionais montados em placas cerâmicas de espessuras $1 \mathrm{~mm}, 3 \mathrm{~mm}$ e $5 \mathrm{~mm}$, assim como em uma pilha 
Tabela 4.1. Aplicações dos piezoatuadores flextensionais em sistemas interferométricos.

estabilização de interferômetros posicionamento nanométrico dos espelhos controle de inclinação dos espelhos

piezoatuadora (seção 4.3). Nesta seção também procura-se mostrar as diferentes e complexas formas das estruturas metálicas em alumínio, para amplificações máximas de deslocamento em pontos distintos.

Dois piezoatuadores flextensionais, projetados para utilizarem cerâmica de $5 \mathrm{~mm}$ de espessura, são mostrados na Figura 4.4. O superior é o f1a1025, projetado para obter um deslocamento máximo no centro, como ilustra a Figura 4.4. Enquanto que o inferior é o f2b0830, projetado como um protótipo de mecanismo flexível [57], dessa forma seu deslocamento máximo é nas extremidades, como ilustra a Figura 4.4.

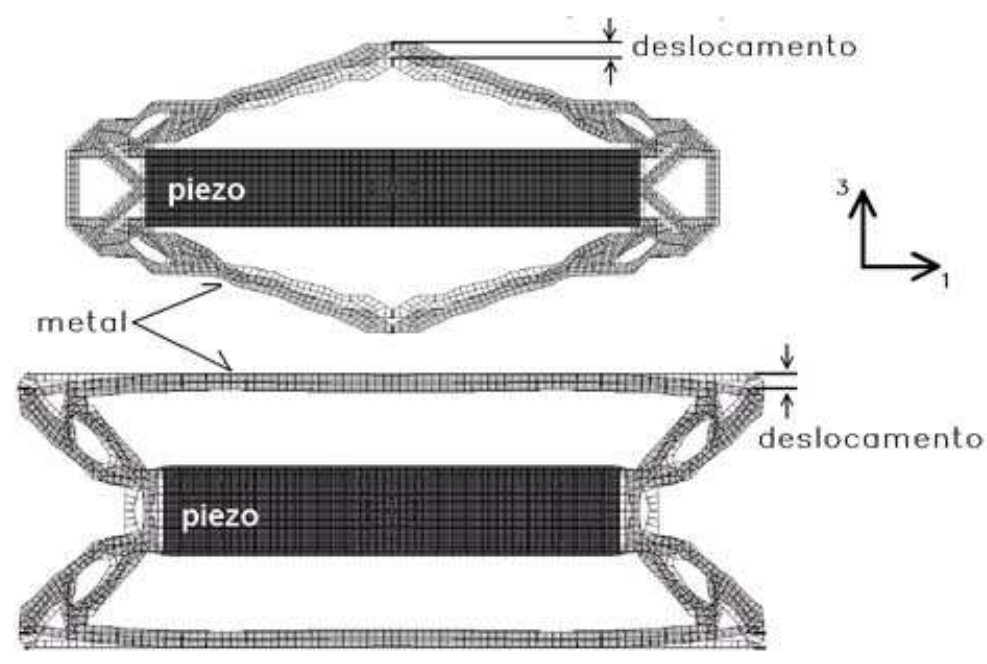

Figura 4.4. Piezoatuadores flextensionais ilustrando o deslocamento da piezocerâmica e da estrutura flexível. Superior f1a1025 e inferior f2b0830.

Piezoatuadores similares foram projetados para serem acoplados a piezocerâmicas de $1 \mathrm{~mm}$ e $3 \mathrm{~mm}$, pois com uma piezocerâmica mais fina, aplica-se uma tensão elétrica menor para obter um deslocamento maior. Nestes flextensionais, pode-se aplicar com segurança um campo elétrico de até $500 \mathrm{~V} / \mathrm{mm}$, no ar. A Figura 4.5 mostra dois piezoatuadores flextensionais com uma piezocerâmica retangular de 3 mm e de $1 \mathrm{~mm}$ de espessura. Também é ilustrado o ponto no qual deseja-se o 
deslocamento máximo desses atuadores. Na seção 4.3 é mostrado um piezoatuador flextensional projetado para utilizar como elemento ativo uma pilha piezoatuadora.

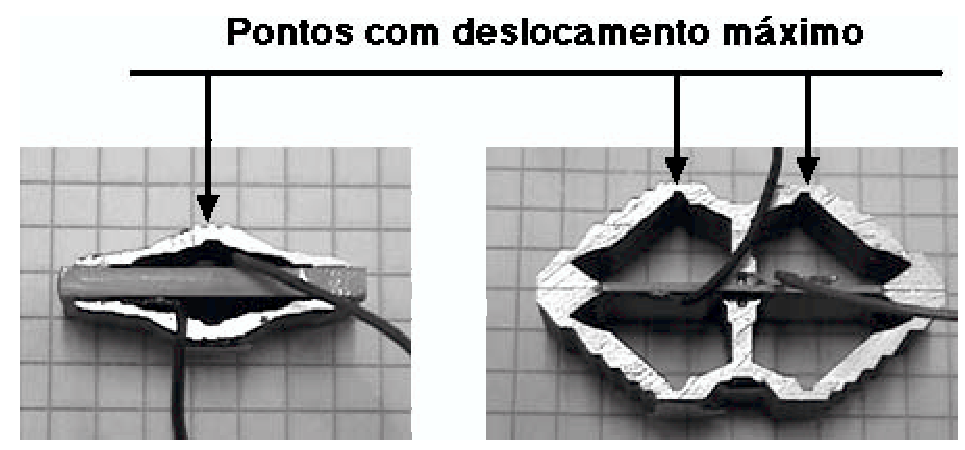

Figura 4.5. Flextensional com cerâmica de $3 \mathrm{~mm}$ de espessura e $1 \mathrm{~mm}$ de espessura.

Os piezoatuadores flextensionais, que utilizam piezocerâmicas, apresentam um deslocamento linear com o campo elétrico até aproximadamente $100 \mathrm{~V} / \mathrm{mm}$. Acima do valor desse campo elétrico, os flextensionais mostram uma resposta com histerese ferrelétrica [68].

\subsection{Atuadores Piezelétricos: Unilaminar e Bilam- inar}

\subsubsection{Unilaminar}

Os unilaminares e bilaminares também são utilizados como atuadores piezelétricos de grandes deslocamentos. Os unilaminares são fabricados colando uma piezocerâmica a um substrato inativo, como por exemplo uma chapa metálica [Figura 4.6(a)]. A deformação máxima do unilaminar é obtida no centro do atuador [Figura 4.6(b)]. Este tipo de atuador é muito utilizado em espelho de interferômetros a laser, para o controle de vibração ambiente [82].

O efeito similar ao de um atuador unilaminar foi obtido ao fixar um pequeno espelho nas piezocerâmicas analisadas no interferômetro. Por menor que fosse o espelho e a quantidade de resina epóxi utilizada na fixação, a cerâmica sofria curvaturas parecidas com a de um unilaminar. No entanto, esse é um efeito indesejável 


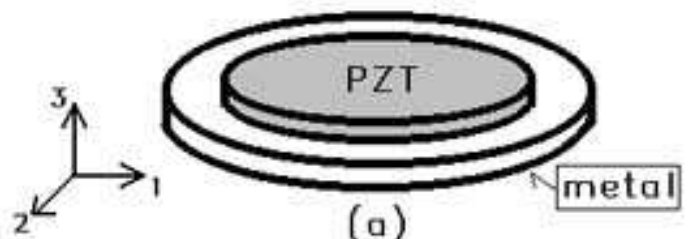

(a)

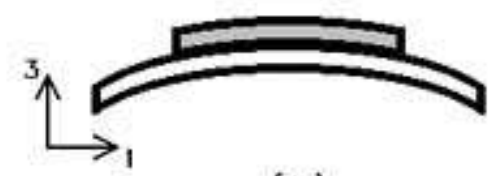

(b)

Figura 4.6. Atuador piezelétrico unilaminar: (a) vista frontal; (b) vista de perfil em repouso; (c) vista de perfil sob excitação.

ao experimento, pois o objetivo de obter o deslocamento da piezocerâmica na direção 3, é obter a taxa de amplificação que a estrutura flexível produziu nessa direção. Com a piezocerâmica curvando-se onde está fixado o espelho, o deslocamento medido é muito superior ao de uma cerâmica sem o espelho, dessa forma, não era possível obter a taxa de amplificação da estrutura flexível. A solução encontrada para realizar as medições de deslocamento da cerâmica, por sistemas ópticos, foi fixar uma fita de poliéster metalizada na superfície da piezocerâmica ou depositar ouro por vaporização em sua superfície com polimento óptico.

Devido ao surgimento desse problema, é analisada a influência da resina epóxi e do espelho no comportamento da piezocerâmica e projetado um engaste para estudo do comportamento dessa piezocerâmica com espelho fixado.

\subsubsection{Bilaminar}

Um piezoatuador bilaminar é um dispositivo eletromecânico com alto grau de flexão, também conhecido por cantiléver bilaminar, porque normalmente são montados como uma viga em balanço. O seu funcionamento é similar ao de um termostato bimetálico, no qual uma tira metálica é sanduichada entre duas tiras piezocerâmicas, normalmente um tipo de PZT. Quando é aplicado uma tensão elétrica nas piezocerâmicas o substrato metálico inclina-se com um movimento proporcional a voltagem aplicada. Um piezoatuador bilaminar pode mover-se pouco mais que $1 \mathrm{~mm}$ no entanto produz forças muito pequenas [78]. Um bilaminar possuiu uma resposta típica de deslocamento na ordem de $10 \mu \mathrm{m} / \mathrm{V}$ em regime de excitação estático. $\mathrm{Na}$ freqüência de ressonância pode atingir até $50 \mu \mathrm{m} / \mathrm{V}$, como é mostrado no capítulo 6 .

Estes dispositivos são utilizados em aplicações que exigem grandes deslocamentos, que não seriam possíveis de obter com piezocerâmicas ou flextensionais operando 
nos modos $d_{31}$ e $d_{33}$, pois as voltagens necessárias para obter um deslocamento nessa magnitude seriam muito altas, o que está limitado pelo rompimento dielétrico do material, além do fato do limite de operação no ar ser para um campo elétrico de $1000 \mathrm{~V} / \mathrm{mm}$.

A combinação de um bilaminar (PZT/metal/PZT), como ilustrado na Figura 4.7, possibilita esses grandes deslocamentos, pois as tiras piezelétricas operam em modos opostos, ou seja, enquanto uma das tiras é expandida a outra é contraída, produzindo uma inclinação do cantiléver bilaminar, como mostra a Figura 4.7. Um estudo sobre as equações constitutivas dos bilaminares piezelétricos é realizada por SMITS et al. $[83,84]$.

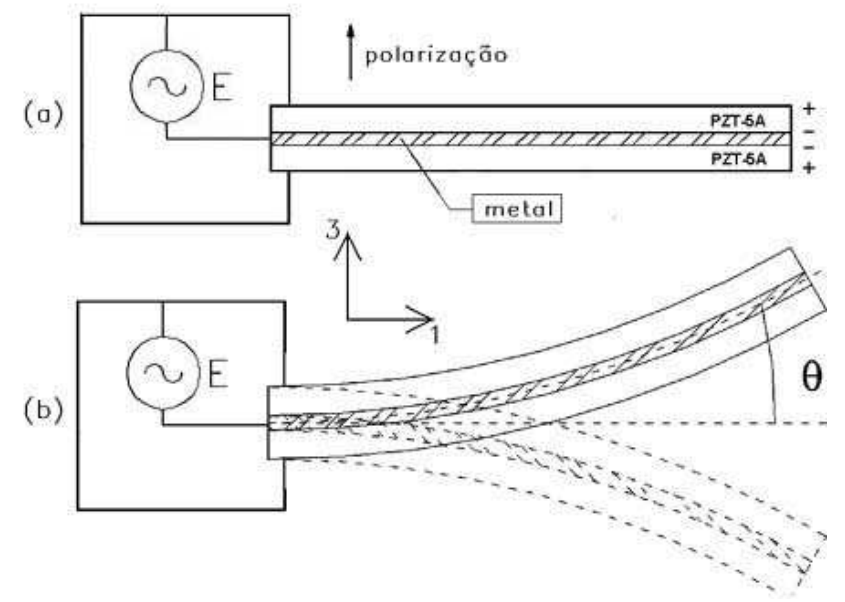

Figura 4.7. Modelo de um bilaminar cantiléver. (a) em repouso e (b) excitado por um campo elétrico alternado.

Os piezoatuadores bilaminar cantiléver estão disponíveis em duas configurações: em paralelo e em série. Na configuração em paralelo as tiras piezelétricas são individualmente conectados à fonte de tensão elétrica, e possuem um eletrodo de metal entre as tiras piezelétricas, como na Figura 4.8(a). Na configuração em série os eletrodos conectados à fonte de tensão elétrica são os superiores e inferiores e não há necessidade da tira metálica entes as tiras piezelétricas, como mostra a Figura 4.8(b).

No cantiléver bilaminar em série, uma das tiras piezelétricas estará sempre sujeita a uma voltagem em sentido oposto em relação a polarização elétrica, desse modo há sempre um risco de despolarização. Para evitar a despolarização o campo elétrico máximo é limitado a poucas centenas de volts por milímetros. Um cantilever bilaminar na configuração serial é largamente utilizado como um sensor de força [85]. 
Também há possibilidade de despolarização de uma das tiras piezelétricas na configuração paralela. Por isso, os mesmos cuidados com limite de campo elétrico devem ser tomados.

A espessura de cada tira piezelétrica de um cantiléver bilaminar varia entre $200 \mu \mathrm{m}$ e $250 \mu \mathrm{m}$, o que permite ser aplicada, com segurança, uma tensão elétrica máxima entre $50 \mathrm{~V}$ e $100 \mathrm{~V}$. Esses atuadores produzem um grande deslocamento, no entanto há diminuição de rigidez, força e velocidade.

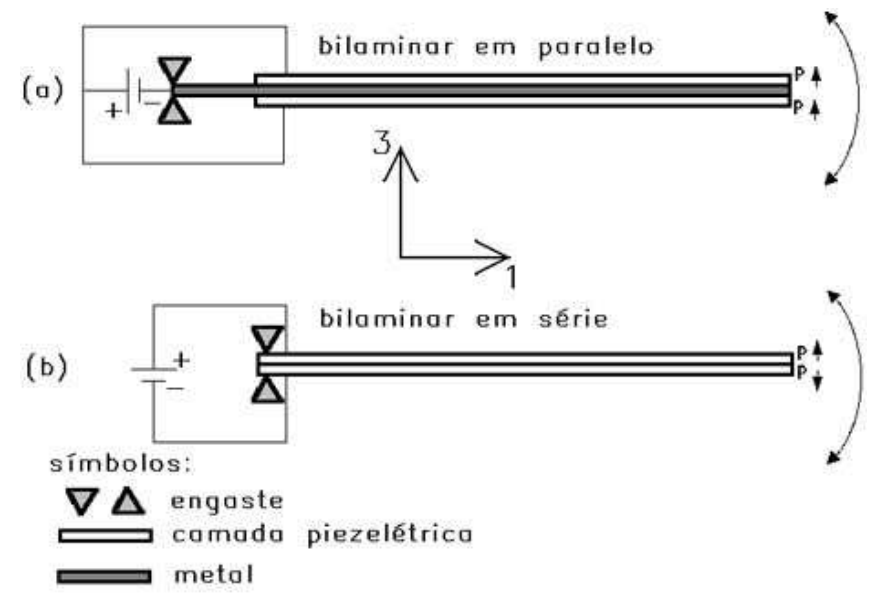

Figura 4.8. Bilaminar cantilever operando em: (a) paralelo; (b) série.

\subsection{Atuador Piezelétrico Multicamadas (Stack)}

A função de um transdutor piezelétrico multicamadas piezelétricas em pilha (stack) é produzir um grande deslocamento a baixas voltagens. Estes fazem uso de seu movimento axial (praticamente a contribuição piezelétrica é apenas do $d_{33}$ ), podendo chegar a uma deformação de até $2 \%$ de seu comprimento inicial. Isso é obtido porque as camadas piezelétricas são empilhadas e conectadas em paralelo, como mostra Figura 4.9. Dessa forma, há uma diminuição na impedância elétrica em relação a uma piezocerâmica inteiriça, de mesmo comprimento e espessura, tal que a uma tensão elétrica muito baixa (alguns poucos volts) o deslocamento é grande, pois somam-se as contribuições dos deslocamentos de cada camada piezelétrica.

Esse material piezelétrico possui uma grande força e é usado exclusivamente como atuador piezelétrico. Por isso, será denominado pilha piezoatuadora. As pilhas piezoatuadoras são normalmente feitas com um tipo de PZT. As propriedades 
desses atuadores são determinadas pelas dimensões da pilha, da estrutura da camada piezelétrica e do tipo de PZT utilizado.

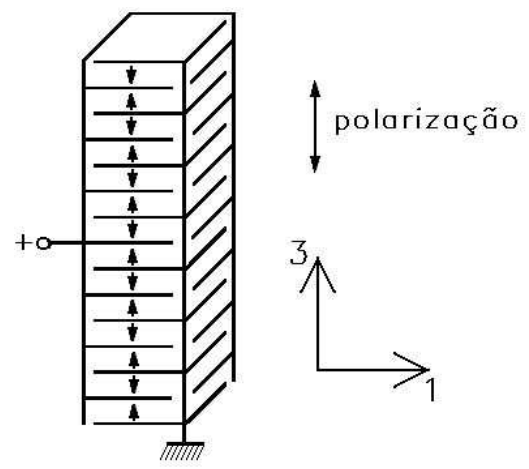

Figura 4.9. Pilha piezoatuadora.

Neste trabalho são analisados transdutores piezelétricos multicamadas acoplados à uma estrutura flexível, tornando-se um flextensional (Figura 4.10). Cada pilha piezoatuadora tem $18 \mathrm{~mm}$ de comprimento total, sendo compostos por várias camadas de 0,1 mm de espessura. Estes são usados em aplicações de condução a baixas voltagens, possuindo um deslocamento linear com a tensão elétrica até $10 \mathrm{~V}$.
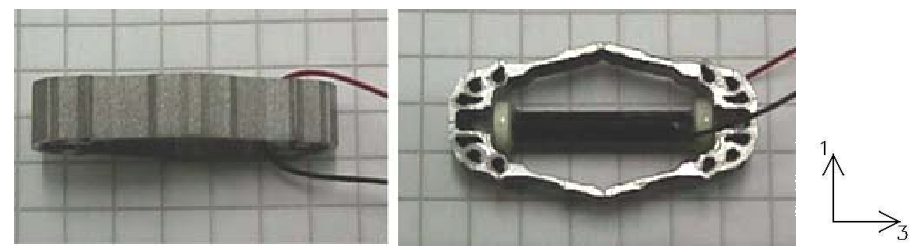

Figura 4.10. Pilha piezoatuadora em um flextensional.

\subsection{Discussão}

Ao analisar esses atuadores piezelétricos, há interesse em determinar o deslocamento por tensão elétrica e limites de operação, assim como validar os modelos projetados por otimização topológica. Nestas análises são utilizados métodos ópticos, que permitem o estudo do comportamento dos piezoatuadores em regime estático e dinâmico. O princípio de funcionamento das técnicas ópticas empregadas está descrito no próximo capítulo. 


\section{Capítulo 5}

\section{Métodos Ópticos}

Técnicas ópticas são aplicadas em diversos campos da pesquisa $[1,2,18,86,87]$ e da engenharia de precisão $[88,89,90]$. Elas são utilizadas em medições de deslocamento, deformação, planicidade, esfericidade, rugosidade, vibração, velocidade, visualização de campo acústico etc.

O interesse em medição de deslocamento de superfície de transdutores piezelétricos ou detecção de ondas elásticas em líquidos e sólidos levou à implementação de técnicas ópticas. Estas técnicas são amplamente exploradas, existindo uma quantidade significativa de publicações nessa área. Alguns dos importantes artigos e livros envolvendo o estudo de transdutores piezelétricos por técnicas ópticas são os de SCRUBY e DRAIN [1], MONCHALIN [2] e ROYER [3], que fazem uma descrição de todas as técnicas ópticas utilizadas para análise desses transdutores. Também podem ser destacados os trabalhos de ROYER [4, 6], STEGEMAN [91] e BABOUX [92].

Os métodos ópticos de medição utilizados neste trabalho são as técnicas interferométrica e não-interferométrica. As técnicas interferométricas baseiam-se na medição da fase do padrão de inteferência da onda de luz laser $[1,3,48,93]$ e as técnicas não-interferométricas baseiam-se na medição de deslocamento mediante a variação da intensidade da luz refletida pela superfície analisada [1, 2, 94]. 


\subsection{Técnica Interferométrica}

A interferometria óptica é um sistema muito sensível para medições de deslocamento. Porém, para que as medições sejam viáveis a fonte de luz deve possuir uma boa coerência (ver apêndice B), condição necessária para que haja interferência. Há dois tipos de coerência, a espacial e a temporal, que podem ser descritas sucintamente como: há boa coerência espacial quando as frentes de onda que interferem são planas e originárias de uma mesma fonte luminosa; e há boa coerência temporal quando a fonte luminosa é monocromática. Por isso o laser é a fonte de luz mais utilizada em interferometria.

Em uma medição de deslocamento num sistema interferométrico, a sonda óptica (feixe de luz laser) deve incidir normal a superfície analisada. Utilizando essa técnica, podem-se realizar medições com transdutores piezelétricos em regime estático, harmônico ou transiente.

As técnicas interferométricas, mais utilizadas atualmente, para medições de amplitudes de vibração em transdutores piezelétricos são a interferometria homódina [10, 95], que normalmente utiliza um interferômetro do tipo Michelson [13, 96, 97], e a interferometria heteródina [6, 98, 99], que normalmente utiliza um interferômetro de Mach-Zehnder [13, 96, 97].

Nos interferômetros homódinos os feixes laser que interferem possuem a mesma freqüência óptica, enquanto que nos interferômetros heteródinos a inteferência é realizada entre feixes laser com freqüências ópticas ligeiramente diferentes [3, 99, 100]. A interferometria heteródina possui a vantagem de filtrar as vibrações ambientes, através de uma modulação em freqüência, do sinal óptico. No entanto, esse tipo de interferômetro não foi implementado durante esse trabalho de doutorado.

Os interferômetros implementados são um do tipo-Michelson em regime homódino sem estabilização [50] e um Mach-Zehnder modificado em regime de quadratura [1, 10]. Na próxima seção são descritos os princípios básicos de interferometria e as técnicas de medição. 


\subsubsection{Interferômetro de Michelson}

Normalmente os interferômetros para medições de deslocamento são pequenas variações do interferômetro do Michelson, ilustrado por um modelo simplificado na Figura 5.1. O feixe de luz proveniente da fonte laser é monocromático e colimado, tal que a frente de onda é aproximadamente plana. Esse feixe laser é dividido em dois no divisor de feixes (BS), que é um espelho semitransparente, e direcionado em caminhos ortogonais, normalmente chamados braços do interferômetro. Um dos feixes é chamado feixe referência, este incide no espelho fixo (R), o outro é chamado feixe sinal e incide no espelho da amostra (S) em movimento, cujo deslocamento desejase medir. Os feixes são refletidos pelos espelhos, retornando ao divisor de feixes e interferindo-se no caminho em direção ao fotodetector (D). Duas observações importantes são necessárias aqui: se o laser não for perfeitamente monocromático, os caminhos ópticos referência $L_{R}$ e sinal $L_{S}$ têm que ser aproximadamente iguais, o erro tolerável é de poucos milímetros (menor que $2 \mathrm{~mm}$ ); deve-se incidir sobre o foto-diodo apenas o máximo central do sinal de inteferência. Para aumentar a sensibilidade do sistema interferométrico os feixes laser que interferem devem ser expandidos.

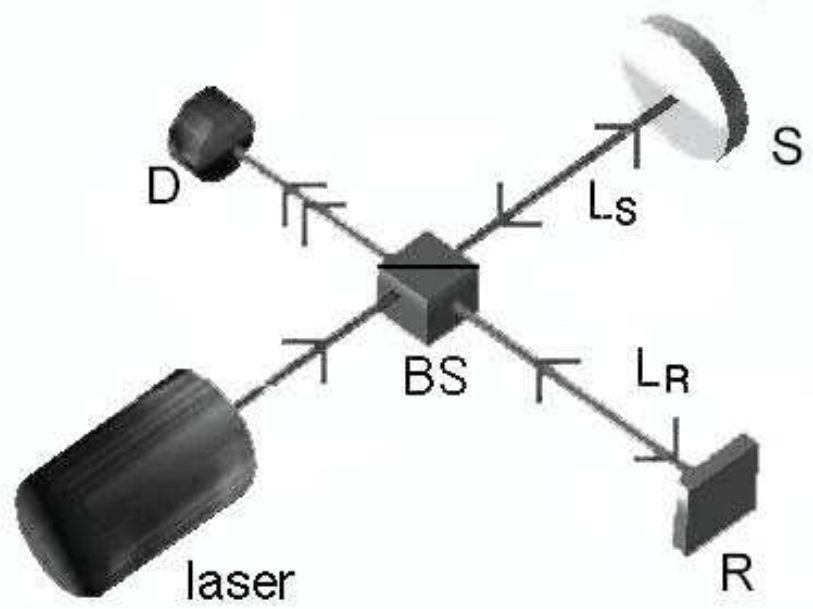

Figura 5.1. Interferômetro de Michelson.

O deslocamento da superfície analisada produz uma variação na intensidade da interferência, a qual passa por máximos e por mínimos. Isso ocorre porque a luz é uma onda de natureza eletromagnética, tal que quando a superfície analisada 
desloca-se é produzida uma variação na fase entre os feixe referência e o feixe sinal. A intensidade máxima é obtida quando a interferência é construtiva, isso ocorre quando a diferença de fase entre os feixes equivale a deslocamentos de $n \lambda$, onde $\lambda$ é o comprimento de onda do laser e $n$ é um número inteiro. A intensidade mínima é obtida quando a inteferência é destrutiva, isso ocorre quando a diferença de fase equivale a um deslocamento de $\left(n+\frac{1}{2}\right) \lambda$.

Através do princípio de superposição de ondas obtém-se o tratamento matemático da interferência. Apesar da luz ser uma onda eletromagnética, é comum realizar o tratamento matemático apenas considerando o campo elétrico $(\vec{E})$, principalmente porque a grandeza mensurável é a intensidade, que é proporcional ao módulo do quadrado do campo elétrico $\left(I=\left|\vec{E}^{2}\right|\right)$.

Em um interferômetro de Michelson homódino, as duas ondas eletromagnéticas, que somam-se, são provenientes da mesma fonte laser (Figura 5.1), e possuem a mesma freqüência $(\omega)$, no entanto as amplitudes podem ser distintas, pois o divisor de feixes pode não ser $50 \%{ }^{1}$. Além disso, os espelhos R e S podem possuir diferentes coeficientes de reflexão.

Por simplicidade matemática e aproximação a um sistema interferométrico real com a fonte laser verticalmente polarizada, o desenvolvimento teórico será ilustrado para ondas eletromagnéticas monocromáticas polarizadas verticalmente, tal que as ondas eletromagnéticas que se somam podem ser escritas na notação complexa como:

$$
\begin{aligned}
\vec{E}_{R} & =\vec{a} e^{i\left(\omega t-\vec{k} \cdot \vec{u}_{R}\right)}=\vec{A} e^{i \omega t} \\
\vec{E}_{S} & =\vec{b} e^{i\left(\omega t-\vec{k} \cdot \vec{u}_{S}\right)}=\vec{B} e^{i \omega t}
\end{aligned}
$$

com

$$
\vec{A}=\vec{a} e^{-i\left(\vec{k} \cdot \vec{u}_{R}\right)} \quad \vec{B}=\vec{b} e^{-i\left(\vec{k} \cdot \vec{u}_{S}\right)}
$$

Nestas equações a freqüência das ondas eletromagnéticas é $\omega$ propagando-se num tempo $t$ e o vetor de onda é $|\vec{k}|=2 \pi / \lambda$. Os vetores $\vec{u}_{R}$ e $\vec{u}_{S}$ representam o deslocamento das ondas, tal que a diferença entre esses termos dará a diferença de caminho óptico $(\Delta \vec{u})$, e consequentemente a diferença de fase $\phi$ entre as ondas.

A resultante da soma das ondas eletromagnéticas é

$$
\vec{E}=\vec{E}_{R}+\vec{E}_{S}
$$

\footnotetext{
${ }^{1} \mathrm{Um}$ divisor de feixes $50 \%$ transmite metade da luz incidente e reflete a outra metade.
} 
Escrevendo a eq.(5.3) em função da intensidade, obtém-se:

$$
\begin{aligned}
I & =\left|\vec{E}^{2}\right|=\left|\left(\vec{E}_{R}+\vec{E}_{S}\right) \cdot\left(\vec{E}_{R}+\vec{E}_{S}\right)\right| \\
& =\left|\vec{E}_{R}^{2}\right|+\left|\vec{E}_{S}^{2}\right|+2\left|\vec{E}_{R} \cdot \vec{E}_{S}\right|
\end{aligned}
$$

A intensidade resultante será

$$
I=I_{R}+I_{S}+2\left|\vec{E}_{R} \cdot \vec{E}_{S}\right|
$$

$I_{R}$ e $I_{S}$ são as intensidades do feixe referência e sinal, respectivamente, e $I$ é a intensidade resultante. Toda a informação sobre a interferência está contida no terceiro termo desta equação. Ele carrega informação da fase da onda ou se há coerência entre essas ondas [13]. Os termos da coerência não são tratados neste texto. Resolvendo o terceiro termo da eq.(5.5), obtém-se:

$$
\begin{aligned}
2\left|\vec{E}_{R} \cdot \vec{E}_{S}\right| & =\Re\left\{\vec{E}_{R} \cdot \vec{E}_{S}^{*}\right\} \\
& =\Re\left\{a b \exp \left[-i\left(k u_{R}-\omega t\right)+i\left(k u_{S}-\omega t\right)\right]\right\},
\end{aligned}
$$

com $\Re$ significando real. A parte real da eq.(5.6) é

$$
\Re\left\{\vec{E}_{R} \cdot \vec{E}_{S}^{*}\right\}=a b \cos \left(k u_{R}-k u_{S}\right) .
$$

De acordo com as eqs.(5.4) e (5.6) as intensidades $I_{R}$ e $I_{S}$ são da forma:

$$
\begin{aligned}
& I_{R}=\left|E_{R}^{2}\right|=\frac{1}{2} \Re\left\{\vec{E}_{R} \cdot \vec{E}_{R}^{*}\right\}=\frac{a^{2}}{2}, \\
& I_{S}=\left|E_{S}^{2}\right|=\frac{1}{2} \Re\left\{\vec{E}_{S} \cdot \vec{E}_{S}^{*}\right\}=\frac{b^{2}}{2},
\end{aligned}
$$

o que leva à

$$
2\left|\vec{E}_{R} \cdot \vec{E}_{S}\right|=a b \cos \left(k u_{R}-k u_{S}\right)=2 \sqrt{I_{R} I_{S}} \cos (\phi) .
$$

A intensidade mensurável é então

$$
I=I_{R}+I_{S}+2 \sqrt{I_{R} I_{S}} \cos (\phi)
$$

As fases correspondentes aos pontos de intensidade máxima $\left(I_{M A X}\right)$ e de intensidade mínima $\left(I_{M I N}\right)$ são obtidas da eq.(5.10). Esses pontos equivalem às seguintes fases:

$$
\begin{array}{rll}
I_{M A X}=I_{R}+I_{S}+2 \sqrt{I_{R} I_{S}}, & \text { para } \phi=0,2 \pi, \ldots 2 n \pi ; \\
I_{M I N}=I_{R}+I_{S}-2 \sqrt{I_{R} I_{S}}, & \operatorname{para} \phi=\pi, 3 \pi, \ldots(2 n-1) \pi
\end{array}
$$


das quais se obtém:

$$
\begin{aligned}
I_{R}+I_{S} & =\frac{I_{M A X}+I_{M I N}}{2}, \\
2 \sqrt{I_{R} I_{S}} & =\frac{I_{M A X}-I_{M I N}}{2},
\end{aligned}
$$

que permite reescrever a eq.(5.10) da seguinte forma:

$$
I=\frac{I_{M A X}+I_{M I N}}{2}+\frac{I_{M A X}-I_{M I N}}{2} \cos (\phi)
$$

A eq.(5.10), ou a eq.(5.13), traz informação da fase $(\phi)$, o que permite calcular o deslocamento. Essa fase deve-se a

$$
\phi=k u_{R}-k u_{S}
$$

A fase mostrada na eq.(5.14) aparece quando há diferença de caminho óptico na propagação de cada onda. Em um interferômetro de Michelson o caminho óptico de referência $\left(L_{R}\right)$, ilustrado na Figura 5.1, é duas vezes a distância do divisor de feixes (BS) ao espelho R, pois o feixe laser percorre essa distância na ida até o espelho e na volta após a reflexão. O mesmo vale para o caminho óptico do sinal $\left(L_{S}\right)$.

No caso do interferômetro de Michelson, as medições são realizadas considerando que o espelho de referência $(R)$ está fixo e a amostra espelhada $(S)$ está em movimento. No caso do interferômetro de Michelson, as distância referência $\left(u_{R}\right)$ e sinal $\left(u_{S}\right)$ são percorridas, pelo feixe laser, no caminho de ida e volta do divisor de feixes aos espelhos. Assim, a variação de caminho óptico é

$$
2 \Delta u=2\left(u_{R}-u_{S}\right)
$$

e a diferença de fase é

$$
\phi=2 k\left(u_{R}-u_{S}\right)=2 k \Delta u
$$

ou

$$
\phi=\frac{4 \pi}{\lambda} \Delta u
$$

tal que, para uma diferença de fase de $\pi$, a diferença de caminho óptico é

$$
\Delta u=\frac{\lambda}{4}
$$

Da eq.(5.16), a variação da intensidade será

$$
I=\frac{I_{M A X}+I_{M I N}}{2}+\frac{I_{M A X}-I_{M I N}}{2} \cos \left(\frac{4 \pi}{\lambda} \Delta u\right) .
$$




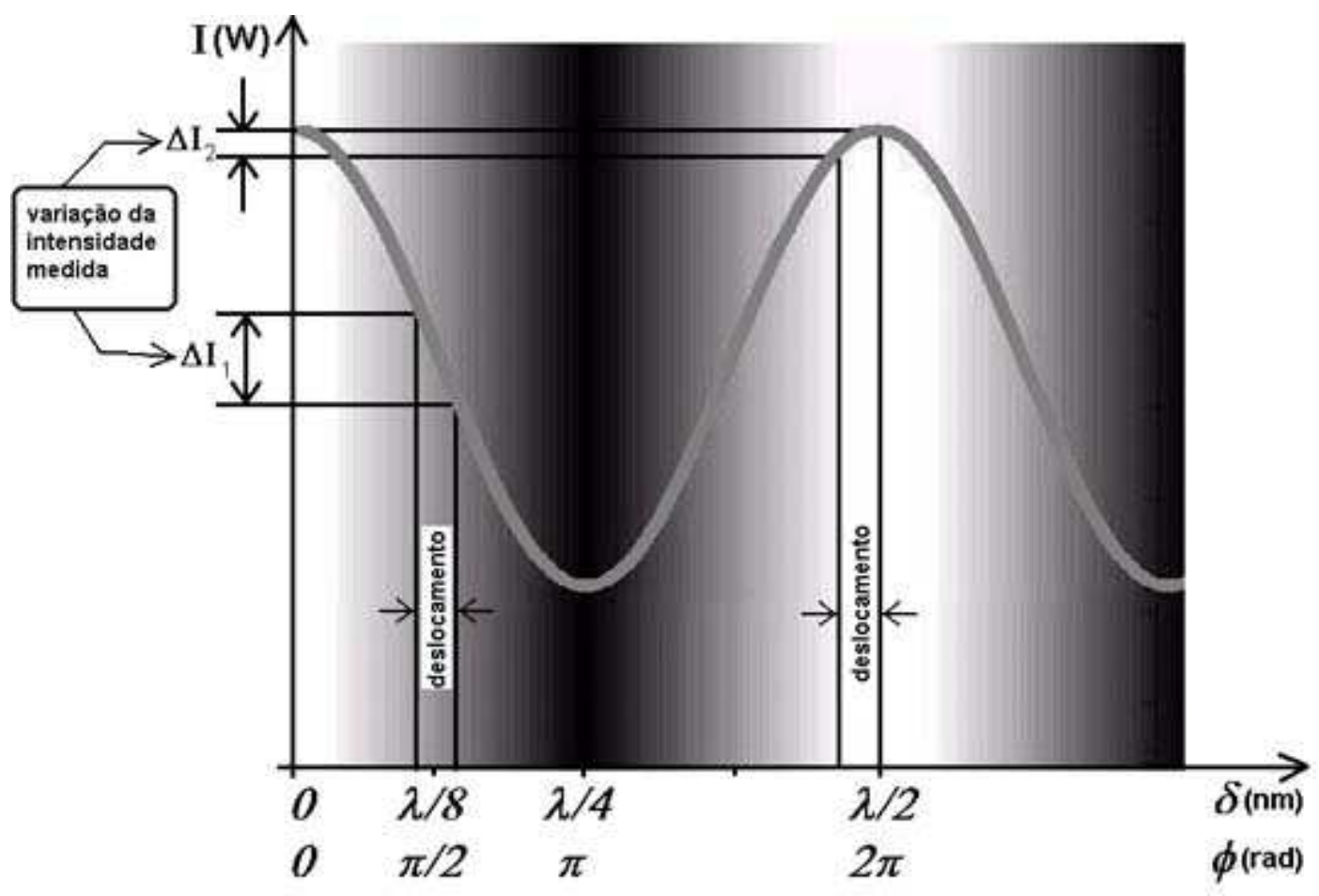

Figura 5.2. Variação da intensidade de acordo com a fase.

A Figura 5.2 mostra a relação entre a variação de intensidade, fase e deslocamento. As medições de deslocamento podem ser realizadas de duas formas, ambas baseadas na diferença de fase.

A primeira técnica é utilizada para medições de deslocamento superiores a $\lambda / 4$. Nesta é utilizada contagem de franjas de interferência. Essa técnica permite medir grandes deslocamentos, tanto na região linear quanto não-linear, do deslocamento por campo elétrico, dos transdutores piezelétricos. A resolução é de $\lambda / 8$ com um erro menor que 1\%. Esta técnica também é utilizada para caracterizar o comportamento eletro-estrictivo dos materiais piezelétricos [10].

Na segunda técnica descrita, as medições de deslocamento são realizadas na região linear do padrão de interferência (com resposta $\Delta I_{1}$ ilustrada na Figura 5.2). Através desta técnica são realizadas medições de deslocamento inferiores a $\lambda / 4$, utilizada em análises de resposta transiente, ou para pequenos deslocamentos nas análises estática e harmônica. A resolução do interferômetro de Michelson montado neste trabalho, possui uma resolução e $1 \mathrm{~nm}$, e o erro nas medições pode chegar a $5 \%$. 


\subsection{Medição de Deslocamentos Superiores a $\lambda / 4$}

As medições de deslocamentos superiores a $\lambda / 4$ são realizadas através de contagem de franjas. Ao deslocar a superfície analisada em alguns micrômetros, o fotodetector, sobre o qual o sinal de interferência incide, detecta a variação de intensidade. Esse fotodetector é conectado a um osciloscópio digital, através do qual a variação do sinal de interferência é adquirida. A forma do sinal adquirido é similar ao da Figura 5.3. Para facilitar o cálculo, o deslocamento deve ser ajustado para que haja um número inteiro de franjas. De modo que a cada defasagem de $2 \pi$ haverá um deslocamento de $\lambda / 2$.

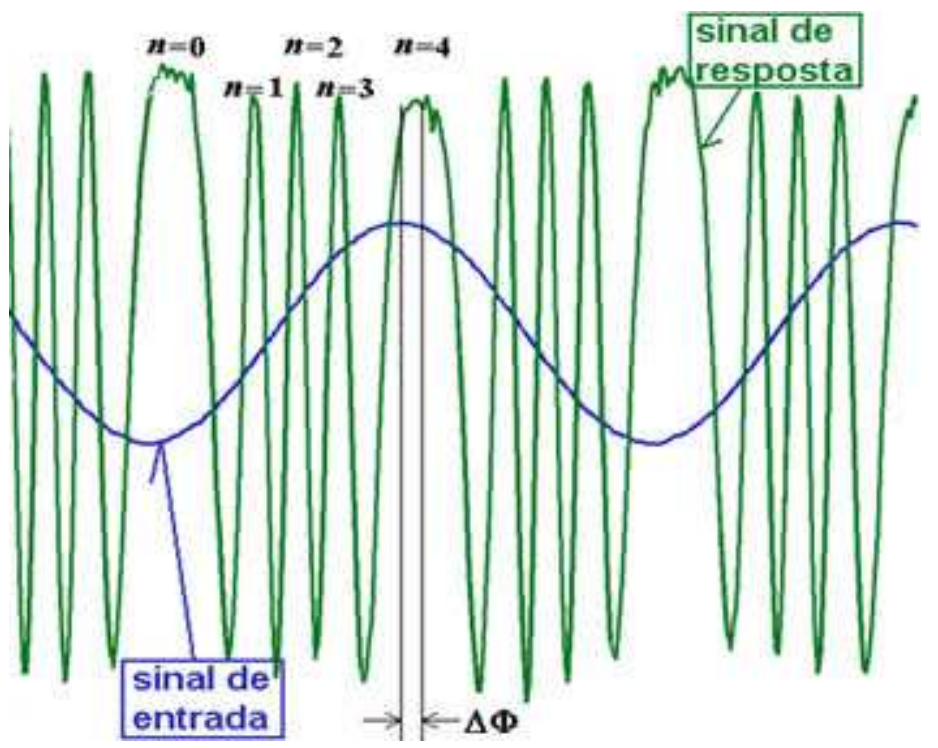

Figura 5.3. Medição por contagem de franjas. $n$ é o número de franjas relativas ao deslocamento pico-a-pico.

A Figura 5.3 mostra o sinal de entrada e a resposta do deslocamento. Note que as partes abauladas do sinal de resposta correspondem ao ponto no qual a amostra analisada inverte o sentido do deslocamento. Contando os picos entre os dois sinais abaulados, obtém-se o deslocamento pico-a-pico, através de:

$$
\Delta u=n \frac{\lambda}{2}
$$

sendo $n$ o número de picos de intensidade contados no intervalo.

Utilizando essa técnica, para medir o tempo de resposta entre o sinal de entrada e o sinal de resposta da amostra, mede-se a diferença de tempo ou a diferença de fase $(\Delta \Phi)$ entre o sinal de entrada e o sinal de resposta, como mostra a Figura 5.3. 
Medições de deslocamento na ordem de alguns micrômetros apresenta a vantagem de não ser necessária a calibração do sistema, pois trabalha-se sempre com o sinal entre $I_{M A X}$ e $I_{M I N}$.

Através de medições de grandes deslocamentos é possível determinar os intervalos de deslocamento linear, não-linear e o campo elétrico para o qual a piezocerâmica começa a apresentar um comportamento eletro-estrictivo.

A medição de deslocamento por contagem de franjas é utilizada para medição de grandes deslocamentos de transdutores piezelétricos excitados com sinal harmônico ou estático. Apenas recentemente BARRIÈRE e ROYER [101] mostraram a possibilidade de medição de respostas a sinais transientes com deslocamentos superiores a $\lambda / 4$. Para essas medições de deslocamentos, na ordem de alguns micrômetros, foi utilizado um interferômetro heteródino com detecção de sinais em quadratura e auto-calibrado.

\subsection{Medição de Deslocamentos Inferiores a $\lambda / 4$}

As medições de deslocamentos menores que $\lambda / 4$ são realizadas na faixa linear do padrão de interferência, indicado pela resposta $\Delta I_{1}$ na Figura 5.2, ou seja, próximo ao ponto de inflexão da curva. Este ponto de inflexão é obtido igualando a derivada segunda da eq.(5.18) a zero:

$$
\frac{d^{2} I}{d \phi^{2}}=-2 \sqrt{I_{R} I_{S}} \cos (\phi)=0 .
$$

A eq.(5.20) será nula quando a fase entre os feixes laser, referência e sinal, for $(n+\pi / 2)$, para $n$ inteiro. Dessa forma, as medições de deslocamento devem ser realizadas em torno desse ponto. Devido a periodicidade da variação da intensidade da interferência, pode-se escolher $n=0 \operatorname{assim} \phi=\pi / 2$, como ilustrado na Figura 5.2. Em função da posição, obtém-se a partir da eq.(5.16) que a essa diferença de fase corresponde a região em torno de

$$
\Delta u=\frac{\lambda}{8}
$$

Para trabalhar nessa região deve-se introduzir um acréscimo no caminho óptico 
do feixe sinal de $\lambda / 8$. A eq.(5.18) é reescrita para essa condição, assumindo a forma:

$$
\begin{aligned}
I & =\frac{I_{M A X}+I_{M I N}}{2}+\frac{I_{M A X}-I_{M I N}}{2} \cos \left\{\frac{4 \pi}{\lambda}\left[u_{R}-\left(u_{S}+\frac{\lambda}{8}\right)\right]\right\} \\
& =\frac{I_{M A X}+I_{M I N}}{2}+\frac{I_{M A X}-I_{M I N}}{2} \cos \left[\frac{4 \pi}{\lambda}\left(u_{R}-u_{S}\right)-\frac{\pi}{2}\right] \\
& =\frac{I_{M A X}+I_{M I N}}{2}+\frac{I_{M A X}-I_{M I N}}{2} \operatorname{sen}\left[\frac{4 \pi}{\lambda}\left(u_{R}-u_{S}\right)\right]
\end{aligned}
$$

Essa intensidade é detectada por um fotodetector pré-amplificado e o sinal é adquirido por um osciloscópio digital. Por isso, o sinal é lido em volts, tal que a partir da eq.(5.12) pode-se escrever $V_{C}=\frac{I_{M A X}+I_{M I N}}{2}$ relativo ao nível corrente contínua $(\mathrm{CC})$ e $V_{0}=\frac{I_{M A X}-I_{M I N}}{2}$ é a amplitude das franjas de interferência, como ilustra a Figura 5.4. Escrevendo a eq.(5.22) em função da tensão elétrica, chega-se ao sinal $V_{D}$ detectado pelo fotodetector:

$$
V_{D}=V_{C}+V_{0} \sin \left(\frac{4 \pi}{\lambda} \Delta u\right)
$$

A amplitude do deslocamento da superfície analisada é obtida de

$$
\Delta u=\frac{\lambda}{4 \pi} \sin ^{-1}\left(\frac{V_{D}-V_{C}}{V_{0}}\right) .
$$

Quando as amplitudes dos deslocamentos medidos são muito menores que o comprimento de onda do laser $(\Delta u<<\lambda)$ a eq.(5.24) pode ser aproximada à

$$
\Delta u=\frac{\lambda}{4 \pi}\left(\frac{V_{D}-V_{C}}{V_{0}}\right) .
$$

Através da eq.(5.25) obtém-se facilmente o deslocamento da superfície analisada. Para isso, primeiro deve-se calibrar o sistema fazendo a amostra analisada deslocarse distâncias maiores que $\lambda / 4$, dessa forma o padrão de interferência passará por máximos e mínimos de intensidade, como ilustra a Figura 5.4. Essa variação picoa-pico de intensidade é registrada como $2 V_{0}$. A amostra analisada deve ser posicionada no ponto onde a intensidade é a metade da intensidade pico-a-pico (em $V_{C}$ ), como mostra a Figura 5.4. Dessa forma, excita-se a amostra piezelétrica com sinais harmônico, transiente ou estático, tal que a amplitude do deslocamento não ultrapasse $\lambda / 20$. Adquire-se esse sinal senoidal e o valor pico-a-pico é $V_{D}$. Inserindo esses valores na eq.(5.25) e o valor do comprimento de onda do laser, obtém-se o deslocamento da amostra.

Efetivamente, o valor $V_{C}$ pode ser eliminado da equação, pois a função deste é fazer o offset zero do sinal. Assim, a equação final para determinação da amplitude 


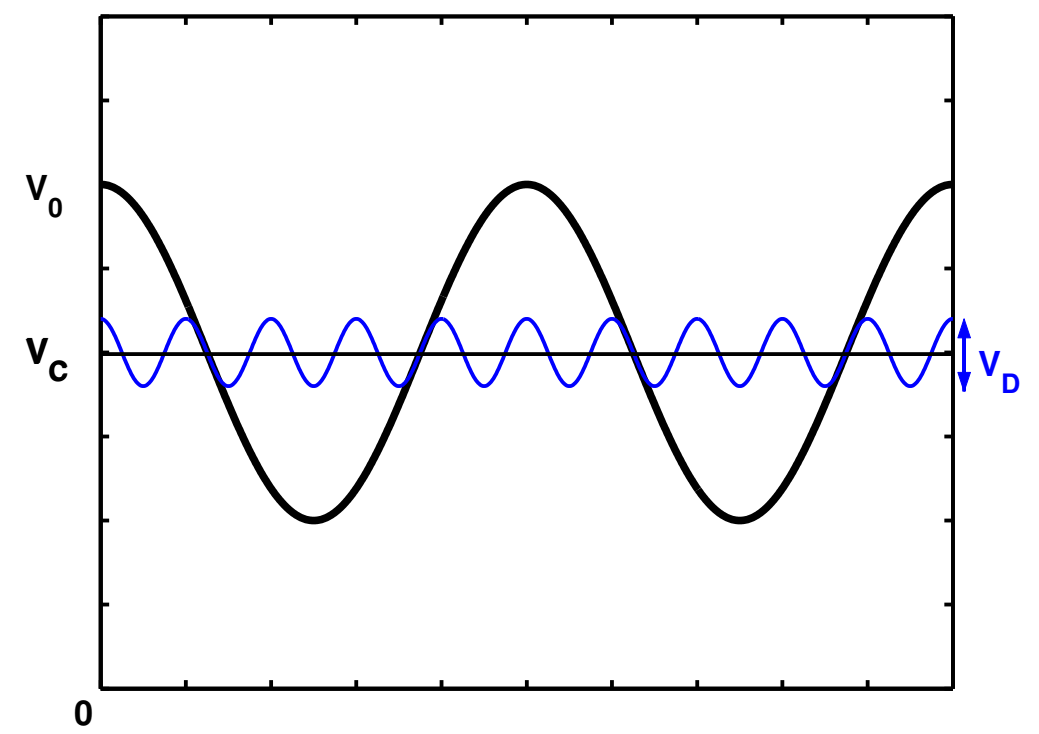

Figura 5.4. Calibração do interferômetro. $V_{0}$ é a amplitude do sinal de calibração. $V_{C}$ é o "nível CC" dos sinais, devido aos feixes de interferência não possuírem exatamente a mesma intensidade. $\mathrm{V}_{D}$ é a resposta pico-a-pico.

de deslocamento é

$$
\Delta u=\frac{\lambda}{4 \pi}\left(\frac{V_{D}}{V_{0}}\right) .
$$

Alguns cuidados importantes que devem ser tomados ao utilizar essa técnica são: utilizar a região linear do sinal de interferência para as medições e procurar utilizar o feixe suficientemente expandido sobre o fotodetector, para que mínimas variações de intensidade devido a variação de fase sejam detectadas. Ou seja, aumenta-se a sensibilidade do sistema interferométrico. Caso a medição de deslocamento não seja realizada na região linear do sinal de interferência, a resposta do deslocamento medida é menor que a correta. A Figura 5.2 mostra que para um mesmo deslocamento da superfície analisada, se a medição é realizada na parte linear (próximo a $\lambda / 8$ ), obtém-se a melhor resposta do deslocamento $\delta$ em função da variação da intensidade $\Delta I_{1}$. Por outro lado, se a leitura é realizada na região da intensidade máxima (próximo a $\pi / 2,3 \pi / 2 \ldots$ ), ou da intensidade mínima (próximo a $0,2 \pi \ldots$ ), a resposta do deslocamento em função da variação da intensidade $\Delta I_{2}$ apresenta valores mínimos.

Essas condições de medição de deslocamento por sistema interferométricos, são condições ideais. No entanto, durante as medições há um fator externo que influ- 
encia negativamente nas medições. Esse fator externo é o ruído ambiente de baixa freqüência, que está relacionado com vibrações ambientes, produzidas por maquinas, sons etc., outra contribuição para o ruído ambiente é a variação térmica sobre a montagem do sistema interferométrico. A seguir são apresentadas as contribuições negativas da vibração ambiente e como contorná-la.

\subsection{Vibração Ambiente}

As técnicas de medição descritas nas seções anteriores consideram que o espelho de referência não se move. No entanto isso não é possível na prática, pois há vibrações ambientes, variações de temperatura etc., que produzem variações em todos os braços do interferômetro. Muitas técnicas são utilizadas para eliminar ou minimizar as vibrações ambientes, no entanto, nenhuma é $100 \%$ eficaz. Dentre os recursos utilizados para minimizar as vibrações externas está a utilização de uma boa mesa óptica, com grande momento de inércia e amortecimento pneumático. A eliminação das vibrações ambientes, que normalmente são inferiores a $1 \mathrm{kHz}$, é realizada utilizando: interferômetros estabilizados eletronicamente por filtros passabaixas, que controlam um atuador piezelétrico no espelho de referência; sistema interferométricos em quadratura, que detectam a variação do padrão de interferência por dois fotodetectores, nos quais os sinais de interferência estão defasados de $\pi / 2$; e interferômetros heteródinos.

\subsubsection{Influência do Ruído Ambiente nas Resposta do Deslo- camento}

Muitos dos problemas no uso de interferometria a laser estão relacionados com a presença de ruídos de fundo nos laboratórios, que são vibrações à baixas freqüências (abaixo de $1 \mathrm{kHz}$ ). Essas vibrações ambientes influenciam nas medições de deslocamento muito pequenos, como os da superfície de transdutores piezelétricos. Nesse nível de ruído, a resposta do interferômetro não pode ser simplesmente filtrada, deixando somente o sinal sem distorções. A Figura 5.5 mostra um exemplo da resposta do interferômetro ao deslocamento do transdutor piezelétrico com a presença do ruído ambiente de baixa freqüência. Na Figura 5.5(a) são mostrados separada- 
mente o ruído ambiente de baixa freqüência e o sinal de resposta esperado. No entanto, a influência do ruído ambiente produz uma modulação em amplitude no sinal de resposta, tal que se ambos forem observados na escala de tempo do ruído ambiente, na tela do osciloscópio será visto uma modulação como a mostrada na Figura 5.5(b). Finalmente, a Figura 5.6 mostra a evolução no tempo do sinal de resposta observado na tela do osciloscópio. Nessa evolução, o sinal de resposta passa por máximos e mínimos, além de inverter a fase. O sinal a ser adquirido deve ser o de maior amplitude, como é descrito na seção 5.5.1.

O ruído de baixa freqüência atrapalha muito as medições de deslocamentos pequenos, pois a resposta do deslocamento do transdutor piezelétrico passa por amplitudes máximas e mínimas, e periodicamente inverte o sinal do deslocamento.

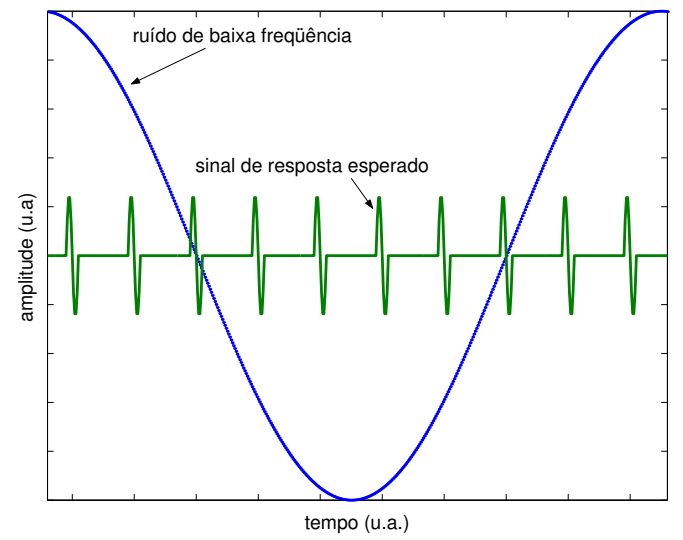

(a)

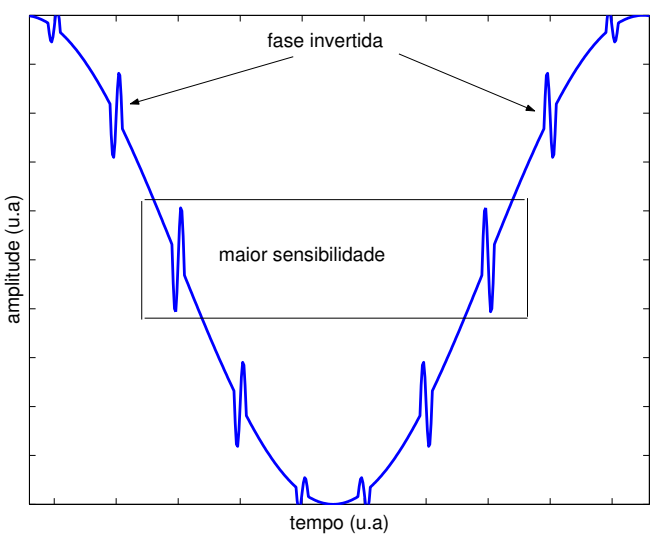

(b)

Figura 5.5. (a) ruído ambiente de baixa freqüência e sinal transiente esperado na resposta; (b) sinal observado no osciloscópio, o de baixa freqüência modula em amplitude o sinal de resposta. A notação (u.a.) significa unidades arbitrárias.

A vibração ambiente produz uma variação no tempo dos caminhos ópticos referência e sinal, de modo que a eq.(5.23) pode ser reescrita da seguinte forma

$$
V_{D}=V_{C}+V_{0} \sin \left(\frac{4 \pi}{\lambda} \Delta u+\varepsilon(t)\right)
$$

a variável $\varepsilon(t)$ é a fase devida à vibração ambiente.

Neste trabalho são caracterizados piezoatuadores para serem utilizados no espelho de referência para estabilização eletrônica do interferômetro. A descrição de um sistema controlado eletronicamente é realizada na seção 5.5.2. Também é mon- 


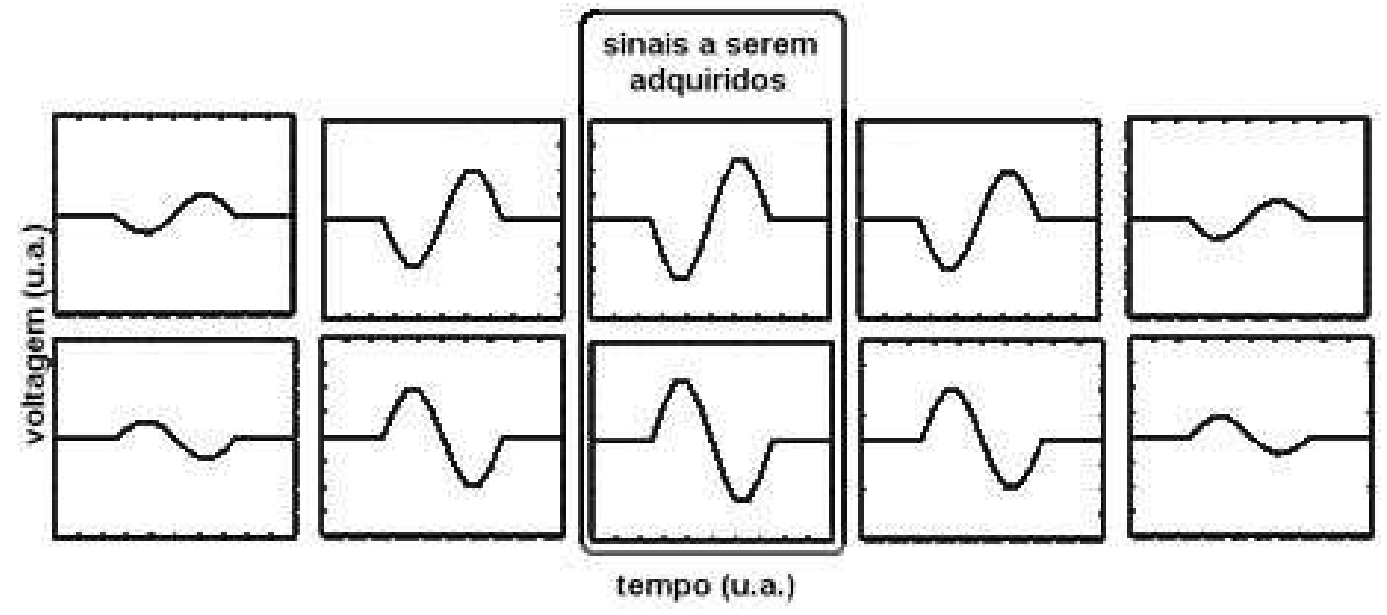

Figura 5.6. Evolução do sinal de resposta, observado em um osciloscópio. A aquisição deve ser realizada quando a resposta passa por um valor máximo. A notação (u.a.) significa unidades arbitrárias.

tado um sistema interferométrico em quadratura, descrito na seção 5.5.3. No entanto, o que funciona com maior eficiência são os interferômetros heteródinos $[1,6]$. Esses serão implementados em um projeto futuro do grupo.

Uma forma alternativa e simples para realização das medições de deslocamento pelo sistema interferométrico é descrita a seguir. O interferômetro montado é um tipo-Michelson na sua configuração mais simples. Porém, a alternativa encontrada apresenta a desvantagem de um considerável aumento no tempo da determinação do deslocamento correto.

\subsection{Sistemas Ópticos Utilizados nas Medições}

\subsubsection{Interferômetro de Michelson sem Controle de Vibração}

O interferômetro utilizado nessas medições é um tipo-Michelson na configuração ilustrada na Figura 5.7. A fonte de luz utilizada é um laser He-Ne $(\lambda=632,8 \mathrm{~nm})$ verticalmente polarizada, com potência nominal de saída de $10 \mathrm{~mW}$. No alinhamento deve ser tomado o cuidado para os feixes sinal e referência não retornem à cavidade laser, pois nesse caso, haveria flutuações na intensidade do laser, devido a realimentação da cavidade, o que causa instabilidade na fonte laser [1].

Fontes laser com intensidade $10 \mathrm{~mW}$, não possuem grande comprimento de 


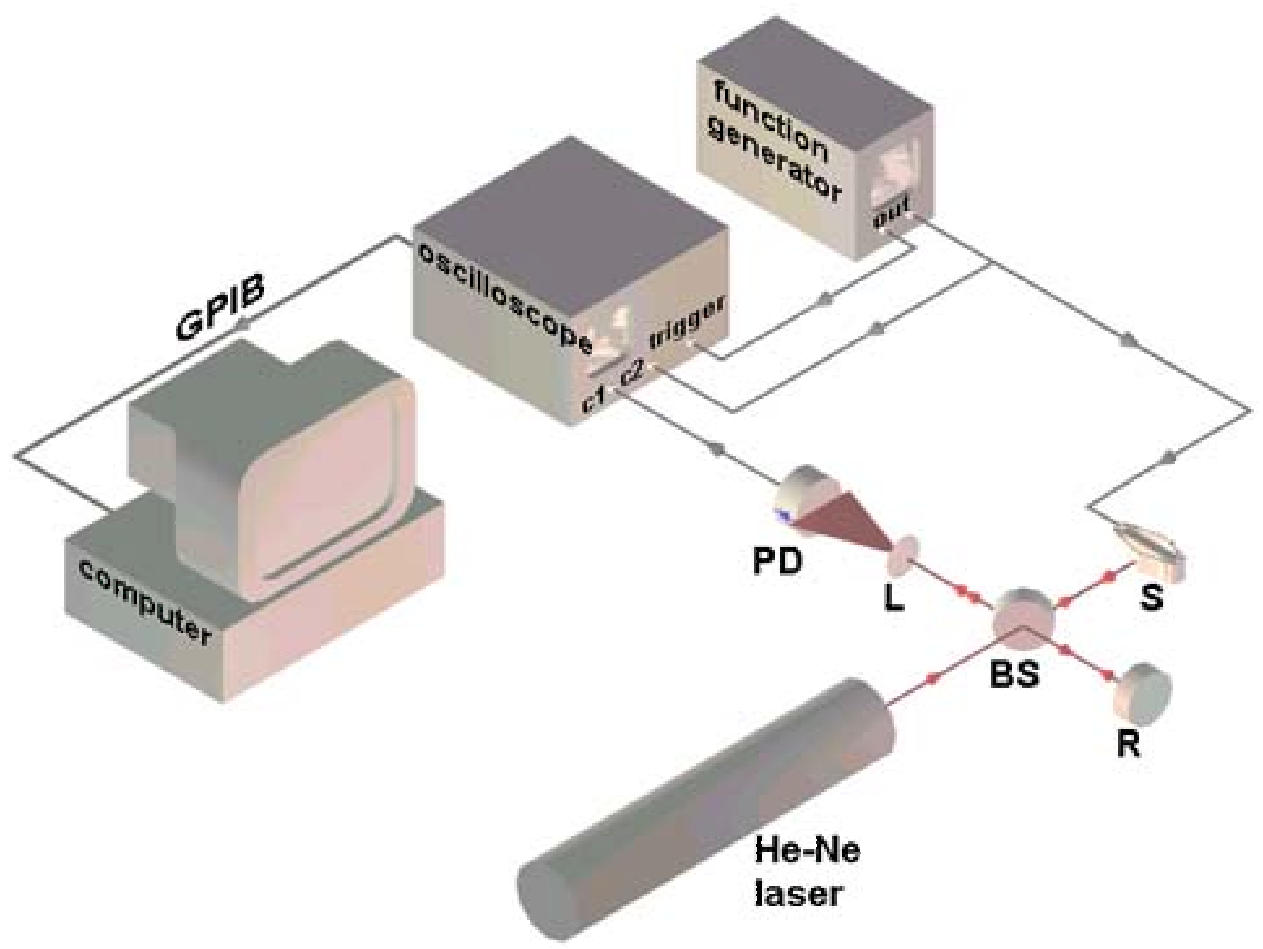

Figura 5.7. Montagem experimental do interferômetro de Michelson.

coerência [1]. Por isso, os braços do interferômetro devem possuir aproximadamente o mesmo comprimento (ver apêndice B), para que o padrão de interferência entre os feixes referência e sinal tenha uma única franja, a qual é expandida por uma lente convergente (L), garantido assim maior sensibilidade do interferômetro a laser, nas medições.

Outra consideração importante no alinhamento do sistema interferométrico, é a visibilidade das franjas de interferência. A visibilidade está relacionada com a diferença de intensidade entre a intensidade máxima da interferência $\left(I_{M A X}\right)$ e a intensidade mínima da interferência $\left(I_{M I N}\right)$, que dependem da intensidade dos feixes referência e sinal, que interferem [eqs.(5.11)].

Se $I_{R}$ e $I_{S}$ possuem praticamente a mesma intensidade há uma boa visibilidade das franjas. Se estes possuem intensidades distintas, a visibilidade diminui a medida que aumenta a diferença entre as intensidades sinal e referência. A visibilidade $\left(I_{V I S}\right)$ é dada por:

$$
I_{V I S}=\frac{I_{M A X}-I_{M I N}}{I_{M A X}+I_{M I N}}
$$

Dificilmente a intensidade mínima, do padrão de interferência, é nula. No entanto, deve-se procurar alinhar o interferômetro, para uma condição próxima à ideal, 
controlando a relação da intensidade dos feixes de luz que incidem no espelho de referência e na amostra espelhada, tal que os feixes refletidos tenham aproximadamente a mesma intensidade. Ao analisar os flextensionais, pode-se utilizar um BS com relação reflexão/transmissão da luz, igual a 50/50, ou seja, a luz refletida e a transmitida pelo BS, possuem a mesma intensidade, porque os pequenos espelhos fabricados, por deposição de alumínio em lamínula de microscópio, possuem uma taxa de reflexão próxima a do espelho $\mathrm{R}$.

O equipamento eletrônico utilizado (Figura 5.7) é composto por um gerador de funções, o qual envia sinais senoidais harmônicos ou um ciclo de seno (burst) para excitar a amostra piezelétrica $(\mathrm{S})$. O intervalo de voltagem utilizado é tal que os deslocamentos pico-a-pico não ultrapassem 1/10 do comprimento de onda do laser He-Ne utilizado $\left(\frac{\lambda}{10}=63,3 \mathrm{~nm}\right)$. Dessa forma, é garantido que após o alinhamento do sistema a medição será na região linear do padrão de interferência. Um osciloscópio digital monitora e adquire os sinais do gerador de funções e a resposta obtida pelo fotodetector, em seguida esses dados são exportados para um micro-computador através do protocolo de comunicação GPIB. O trigger do osciloscópio é realizado com o sinal de excitação.

Uma foto do interferômetro de Michelson, descrito nessa seção, é mostrada na Figura 5.8. O atenuador de intensidade da luz (A), é um polarizador. Há necessidade de atenuar a intensidade do padrão de interferência, que incide no fotodetector (PDA), pois este possui saturação para $0,16 \mathrm{~mW}$ de potência de luz.

A calibração, desse sistema interferométrico, é realizada fazendo a amostra piezelétrica vibrar com amplitude superior a $\frac{\lambda}{4}=158,2 \mathrm{~nm}$. A calibração é realizada frequentemente, pois esse sistema interferométrico não é estabilizado eletronicamente. Por isso, as vibrações ambiente, que são de baixa-freqüência (abaixo de $1 \mathrm{kHz}$ ), produzem um desalinhamento periódico do sistema interferométrico.

As medições são realizadas adquirindo o sinal quando a sensibilidade do interferômetro é máxima, ou seja, quando o sinal de resposta apresenta uma amplitude máxima, a qual deve ser monitorada continuamente, antes da aquisição. Isso é possível devido ao sinal de resposta variar continuamente entre um mínimo e um máximo de intensidade, como descrito na seção 5.4.1.

Com essa técnica, os resultados são obtidos com precisão de $1 \mathrm{~nm}$ e um erro 


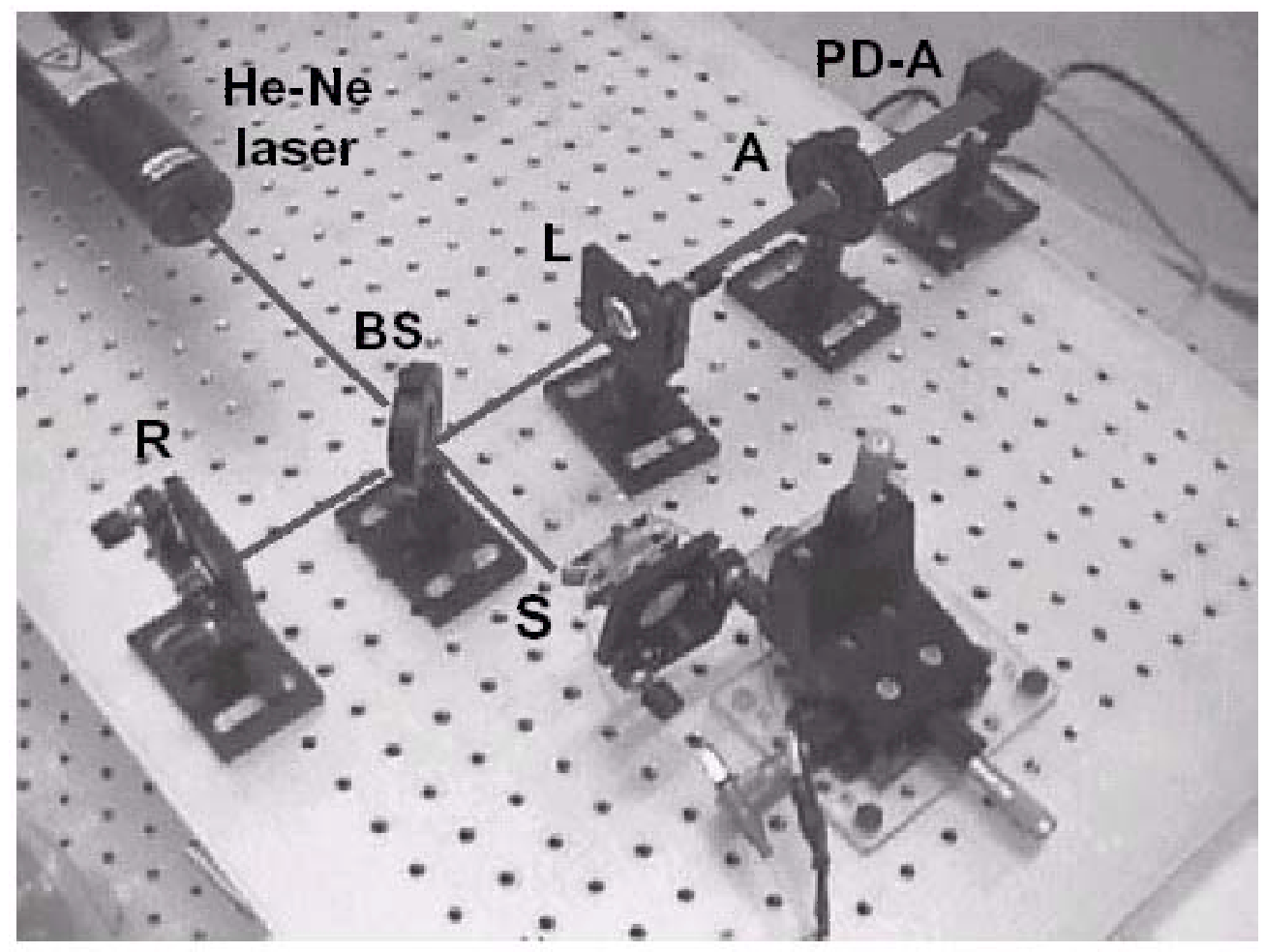

Figura 5.8. Foto do interferômetro de Michelson utilizado nas análises dos flextensionais.

máximo de 5\%. O que é um resultado satisfatório. A desvantagem desse sistema é o tempo de demanda entre as aquisições, pois sempre que altera-se a amostra piezelétrica ou a freqüência de excitação, há necessidade de nova calibração do sistema e um novo estudo para verificar qual a amplitude máxima do sinal de resposta, a qual deve ser adquirida.

Um sistema interferométrico capaz de medir deslocamentos nanométricos de transdutores piezelétricos a altas freqüências (acima de $10 \mathrm{kHz}$ ) é descrito na próxima seção.

\subsubsection{Interferômetro de Michelson Estabilizado}

Em um interferômetro estabilizado eletronicamente, é utilizado um filtro passabaixas, que controla um atuador piezelétrico no espelho de referência, tal que este compense a vibração ambiente em fase oposta. Ou seja, o atuador que comanda o espelho de referência deve vibrar periodicamente na freqüência de vibração do 
ambiente com uma defasagem de $\pi$ :

$$
\delta=\frac{\pi}{2}+\pi
$$

onde $\delta$ é a diferença de fase entre os feixes ópticos sinal e referência, os quais devem estar na condição de defasagem de $\pi / 2$ para que as medições sejam realizadas na região linear do padrão de interferência e $\pi$ é a fase em relação à posição da medição, com que o espelho de referência deve vibrar.

O esquema do interferômetro de Michelson com o filtro eletrônico passa-baixas controlando um atuador piezelétrico no espelho de referência é mostrado na Figura 5.9. A amplitude de vibração do ruído ambiente está em média próximo a $60 \mathrm{~nm}$ para uma freqüência de $300 \mathrm{~Hz}$. Uma piezocerâmica precisaria estar sob um campo elétrico de amplitude aproximadamente $200 \mathrm{~V} / \mathrm{mm}$ para produzir esse deslocamento na direção 3. No entanto, os piezoatuadores apresentam deslocamento por campo elétrico pelo menos 10 vezes superior ao da piezocerâmica, na mesma direção.

Os piezoatuadores, analisados neste trabalho, para serem utilizados no controle do espelho de referência, na faixa de freqüência entre $1 \mathrm{~Hz}$ e $300 \mathrm{~Hz}$, são: flextensional [40], que apresenta uma resposta de aproximadamente $10 \mathrm{~nm} /(\mathrm{V} / \mathrm{mm})$; um tipo de unilaminar, projetado neste trabalho após a verificação da influência de pequenos espelhos colados à superfície das piezocerâmicas. A resposta do tipounilaminar é de $5 \mathrm{~nm} /(\mathrm{V} / \mathrm{mm})$; bilaminar da APC [102], que apresenta uma resposta de aproximadamente $200 \mathrm{~nm} /(\mathrm{V} / \mathrm{mm})$. Cada um desses piezoatuadores apresenta deslocamento por campo elétrico distintos. No entanto há necessidade de levantar a curva de resposta do deslocamento em freqüência de cada um, para verificar qual melhor se aplica ao controle do interferômetro.

\subsubsection{Interferômetro de Mach-Zehnder em Quadratura}

Uma outra técnica interferométrica, utilizada para separar o ruído do sinal, é a interferometria em quadratura. Este é um interferômetro não-estabilizado, que permite obter a defasagem $(\phi=(4 \pi \Delta u) / \lambda)$, entre os feixes sinal e referência, na presença de flutuações aleatórias $(\varepsilon(t))$, graças à detecção dos sinais de interferência em quadratura, ou seja, são utilizados dois fotodetectores e os sinais de interferência são obtidos defasados de $\pi / 2$. 


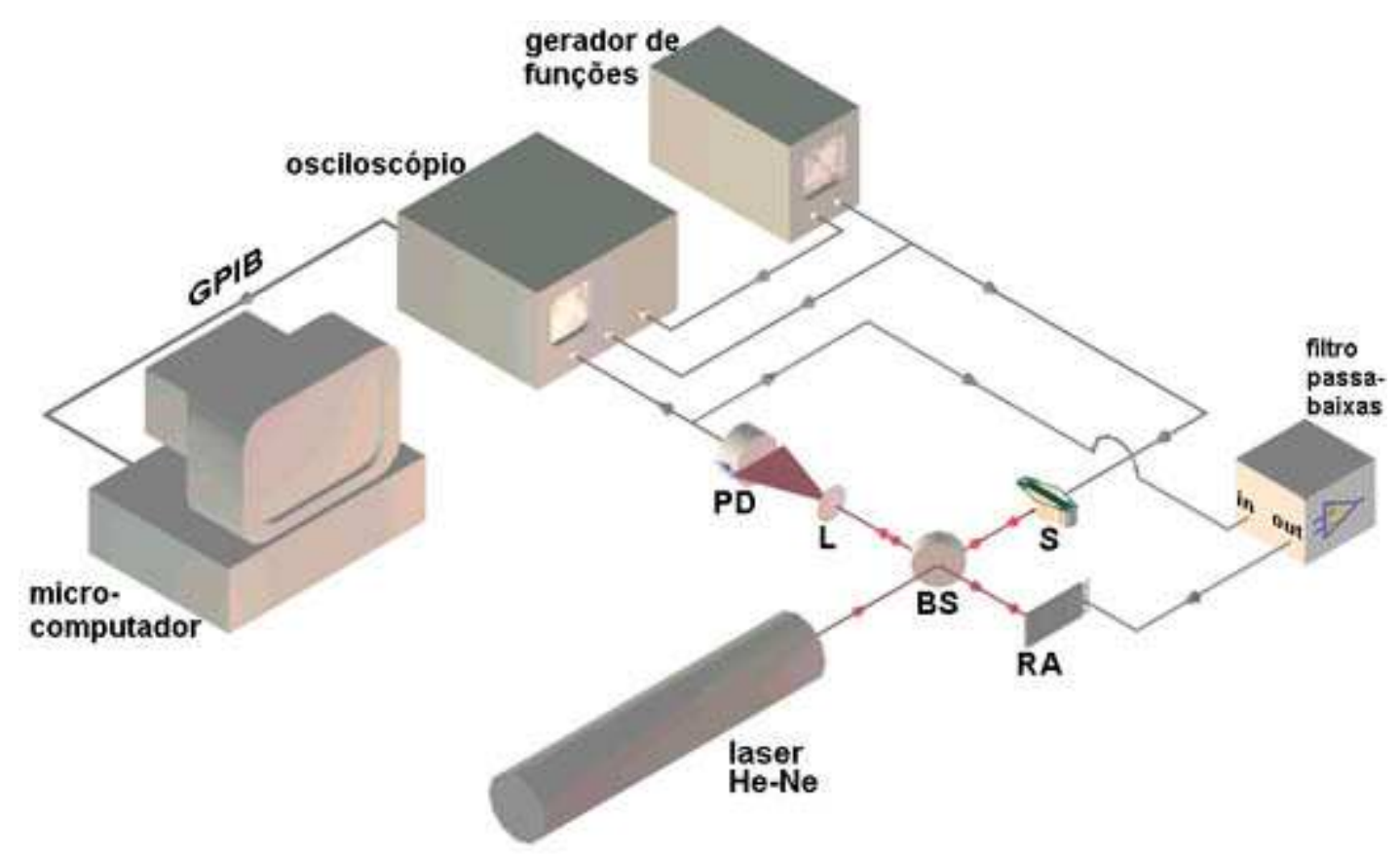

Figura 5.9. Interferômetro de Michelson estabilizado e controlado eletronicamente.

O interferômetro montado com esse propósito é um Mach-Zehnder modificado, como ilustra a Figura 5.10. O arranjo básico desse interferômetro é similar ao utilizado por ROYER [6] ou pela empresa POLYTEC [11]. No entanto, ambos utilizam um sistema de demodulação heteródina do sinal óptico e são vibrômetros Doppler, os quais realizam medições da velocidade de superfícies, e através da integração do sinal no tempo obtêm o deslocamento. Esses dois equipamentos também são indicados à medições de vibrações na freqüência do ultra-som.

Um sistema interferométrico em quadratura pode realizar medições de deslocamento tanto em regime estático, quasi-estático quanto na freqüência do ultra-som. O arranjo clássico dos interferômetros em quadratura é um tipo-Michelson com algumas variações $[1,9,10]$. No entanto, o Mach-Zehnder proposto neste trabalho apresenta vantagens em relação ao Michelson, que é um melhor controle das intensidades dos feixes referência e sinal, menor perda de energia, como conseqüência praticamente eliminam-se as reflexões parasitas dos divisores de feixe, que têm a tendência de realimentar a cavidade do laser produzindo flutuações na intensidade. Além disso, o arranjo utilizado permite que, num futuro projeto do grupo, seja introduzido um modulador acusto-óptico (célula de Bragg) entre os divisores de feixe 
polarizadores (PBS1 e PBS2), dessa forma, os ajustes necessários para a montagem de um interferômetro heteródino seriam mínimas. Por outro lado, este arranjo apresenta desvantagem em relação ao alinhamento dos componentes ópticos.

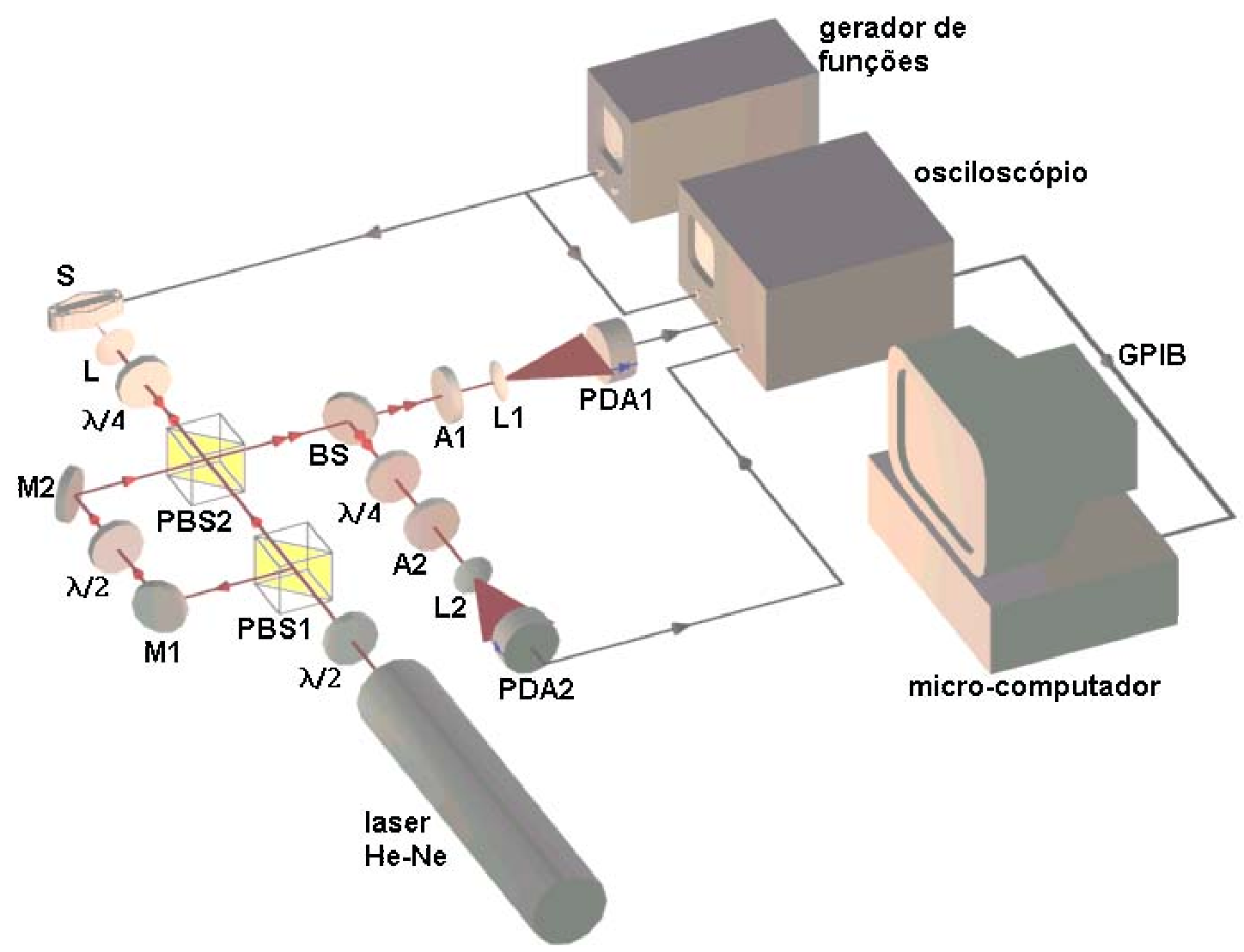

Figura 5.10. Interferômetro de Mach-Zehnder com dupla detecção de sinais ópticos defasados de $\pi / 2$.

O arranjo do interferômetro Mach-Zehnder modificado (Figura 5.10), utiliza uma fonte laser polarizada verticalmente. Para esse arranjo há necessidade da fonte laser ser linearmente polarizada. A Figura 5.11 mostra o comportamento do campo elétrico do feixe laser nesse interferômetro. Na saída do laser é utilizado um retardador de $1 / 2$ comprimento de onda $(\lambda / 2)$, o qual produz um giro na polarização linear do laser, tal que pode-se controlar a intensidade de luz que será refletida e transmitida pelo primeiro divisor de feixe polarizador (PBS1), que reflete a luz com polarização vertical e transmite a luz com polarização horizontal [103]. O controle das intensidades transmitida e refletida pelo PBS1 é importante para que os feixes sinal e referência que interferem tenham aproximadamente a mesma intensidade, como descrito mais a frente. 


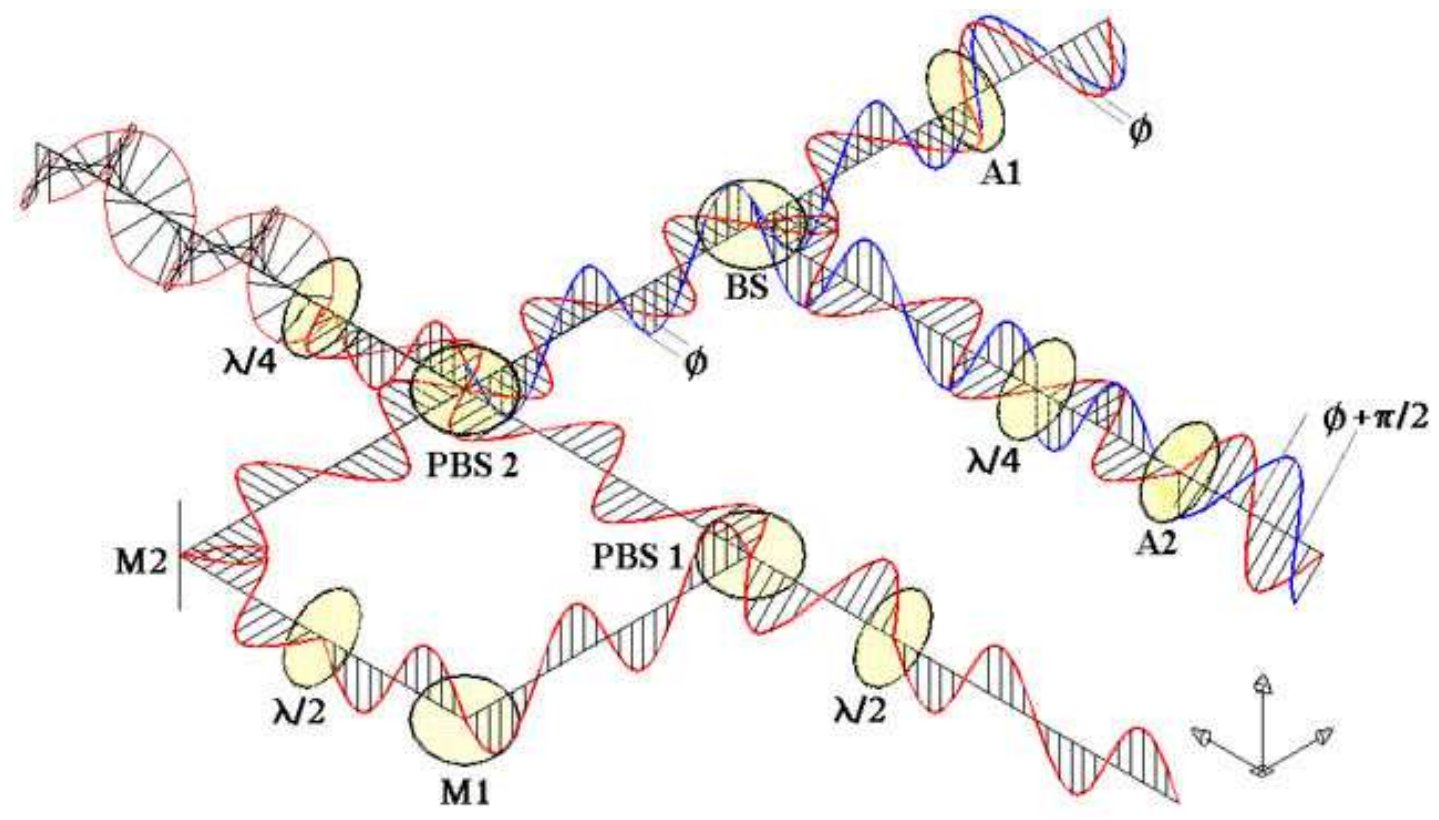

Figura 5.11. Esquema gráfico do comportamento da polarização no interferômetro montado.

O feixe de luz refletido pelo PBS1, que é verticalmente polarizado, é o feixe referência, o qual após refletir no espelho M1 atravessa um outro retardador $\lambda / 2$ configurado de forma a girar em $90^{\circ}$ a direção da polarização desse feixe. Isso é realizado para que o feixe de referência fique com polarização horizontal e assim, após refletir no espelho M2 possa ser transmitido pelo segundo divisor de feixes polarizador (PBS2).

O feixe de luz transmitido pelo PBS1 é o feixe sinal e possui polarização horizontal [103], dessa forma, também atravessa o PBS2. Após PBS2 o feixe sinal atravessa um retardador de $1 / 4$ de comprimento de onda $(\lambda / 4)$ com o eixo lento ${ }^{2}$ alinhado a $45^{\circ}$ com a direção da polarização [103] do feixe sinal. Assim, após atravessar este retardador o feixe sinal adquire polarização circular. Uma lente convergente é utilizada para focalizar o feixe sinal na superfície analisada, tal que superfícies refletoras, porém sem polimento óptico, possam ser analisadas. Pois dessa forma reduz-se o espalhamento e aumenta-se o ganho da intensidade da luz refletida $[1,2]$. Após a reflexão na superfície, o feixe atravessa novamente a lente convergente sendo colimado. Ao atravessar novamente o retardador $\lambda / 4$ a polarização do feixe sinal

\footnotetext{
${ }^{2} \mathrm{O}$ fabricante define os eixos ordinário e extra-ordinário, do retardador de onda, como eixos rápido e lento. Os retardadores utilizados neste trabalho possuem a forma circular e o eixo lento é identificado através de um corte secante na extremidade do retardador [103].
} 
torna-se vertical e assim é refletido pelo PBS2.

A relação entre as intensidades dos feixes referência e sinal deve ser tal que os feixes refletidos pela amostra $(\mathrm{S})$ e pelos espelhos de referência (M1 e M2) tenham aproximadamente a mesma intensidade. Para isso, após o alinhamento inicial com espelhos idênticos (M1, M2 e S), posiciona-se a amostra espelhada na posição correta e gira-se o retardador $\lambda / 2$ da saída do laser de modo a obter após PBS2 os feixes referência e sinal com intensidades aproximadamente iguais. O segundo retardador $\lambda / 2$, posicionado entre M1 e M2, também deve ser girado de modo a eliminar reflexões do feixe referência em PBS2. Com um bom alinhamento e o controle entre as polarizações, realizada pelos dois retardadores $\lambda / 2$, praticamente não existe perda de energia do feixe referência, evitando-se dessa forma reflexões indesejáveis no PBS2.

No caminho entre PBS2 e BS (Figura 5.11) os feixes referência e sinal possuem polarizações ortogonais, por isso não interferem. BS é um divisor de feixes 50/50, o qual transmite metade da intensidade incidente e reflete a outra metade, cada qual direcionada a um fotodetector. No caminho dos feixe transmitidos por BS é inserido

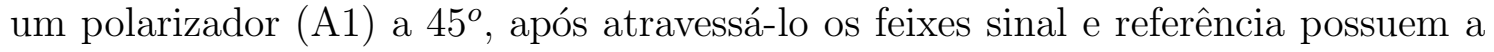
mesma polarização e interferem-se, em seguida são expandidos por uma lente L1 e incidem no fotodetector PDA1. No caminho dos feixes refletidos por BS é inserido um retardador $\lambda / 4$ configurado de forma a produzir um atraso de fase de $90^{\circ}$ no feixe sinal. Após o retardador há um polarizador (A2) a $45^{\circ}$ com a direção das polarizações dos feixes referência e sinal. Após atravessá-lo esses feixes possuirão a mesma polarização e irão interferir. Em seguida são expandidos por uma lente (L2) e incidem sobre um fotodetector PDA2.

O sinal de interferência detectado por PDA-1 tem uma defasagem de $\pi / 2$ em relação ao sinal detectado por PDA-2. A Figura 5.12(a) mostra uma simulação dos sinais adquiridos com ruído de baixa freqüência pelos dois fotodetectores. Estes sinais estão defasados de $\pi / 2$. Quando é realizada a subtração desses sinais, observase um sinal de resposta com amplitude constante, livre do ruído, como mostra a Figura 5.12(b).

Devido à defasagem de $\pi / 2$ entre os dois sinais adquiridos, o sinal $V_{D 1}$ detectado pelo fotodetector 1 (PDA-1) e o sinal $V_{D 2}$ detectado pelo fotodetector 2 (PDA-2) 


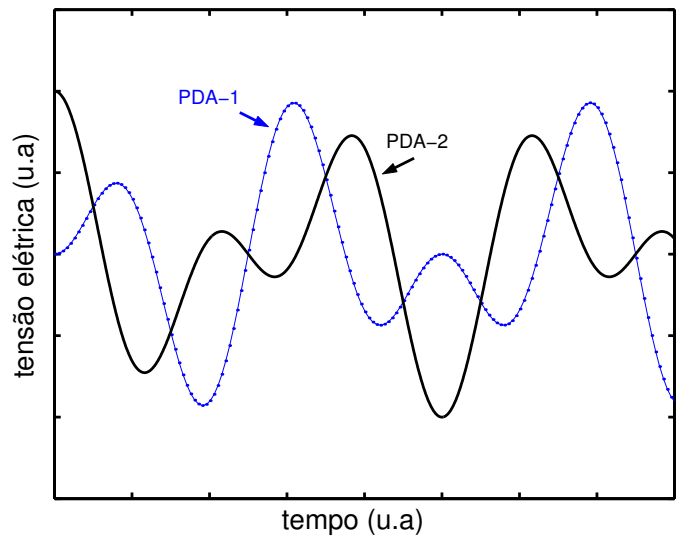

(a)

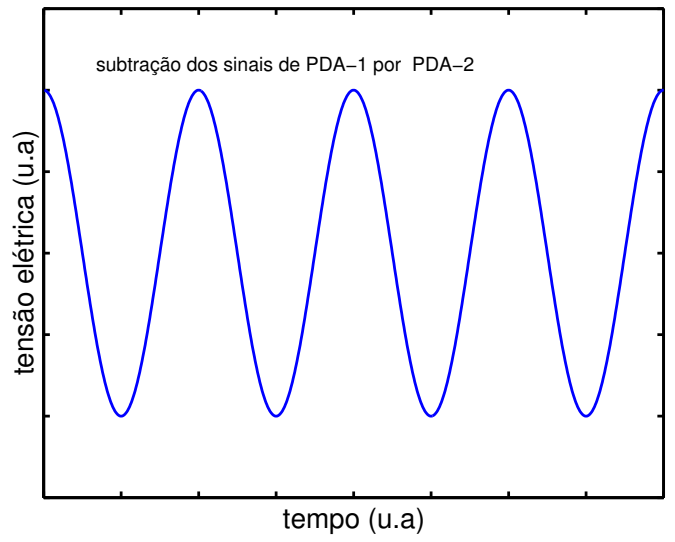

(b)

Figura 5.12. (a) Sinais de inteferência detectados em defasagem de $\pi / 2$. (b) Subtração dos sinais defasados, mostrando a resposta livre do ruído de baixas-freqüências.

podem ser escritos como:

$$
\begin{aligned}
& V_{D 1}=V_{C}+V_{0} \cos [\phi+\varepsilon(t)], \\
& V_{D 2}=V_{C}+V_{0} \sin [\phi+\varepsilon(t)] .
\end{aligned}
$$

Os sinais adquiridos em quadratura permitem o cálculo do deslocamento através da divisão das eq.(5.30) tal que:

$$
\phi=\tan ^{-1}\left(\frac{V_{D 2}}{V_{D 1}}\right)
$$

ou escrevendo em termos do deslocamento

$$
\Delta u=\frac{\lambda}{4 \pi} \tan ^{-1}\left(\frac{V_{D 2}}{V_{D 1}}\right)
$$

O deslocamento pode ser calculado a partir dessa condição, sem necessidade de calibração do sistema.

Uma foto do interferômetro de Mach-Zehnder modificado, desenvolvido neste trabalho, é mostrada na Figura 5.13. Nesta figura as abreviaturas são as mesmas descritas para a Figura 5.10.

\subsubsection{Sistema Óptico Não-Interferométrico}

Sistemas ópticos não-interferométricos também são utilizados em medições de deslocamentos e várias são as técnicas empregadas $[1,2,3]$. As medições de deslocamento dos atuadores piezelétricos sob excitação estática foram realizadas no Grupo 


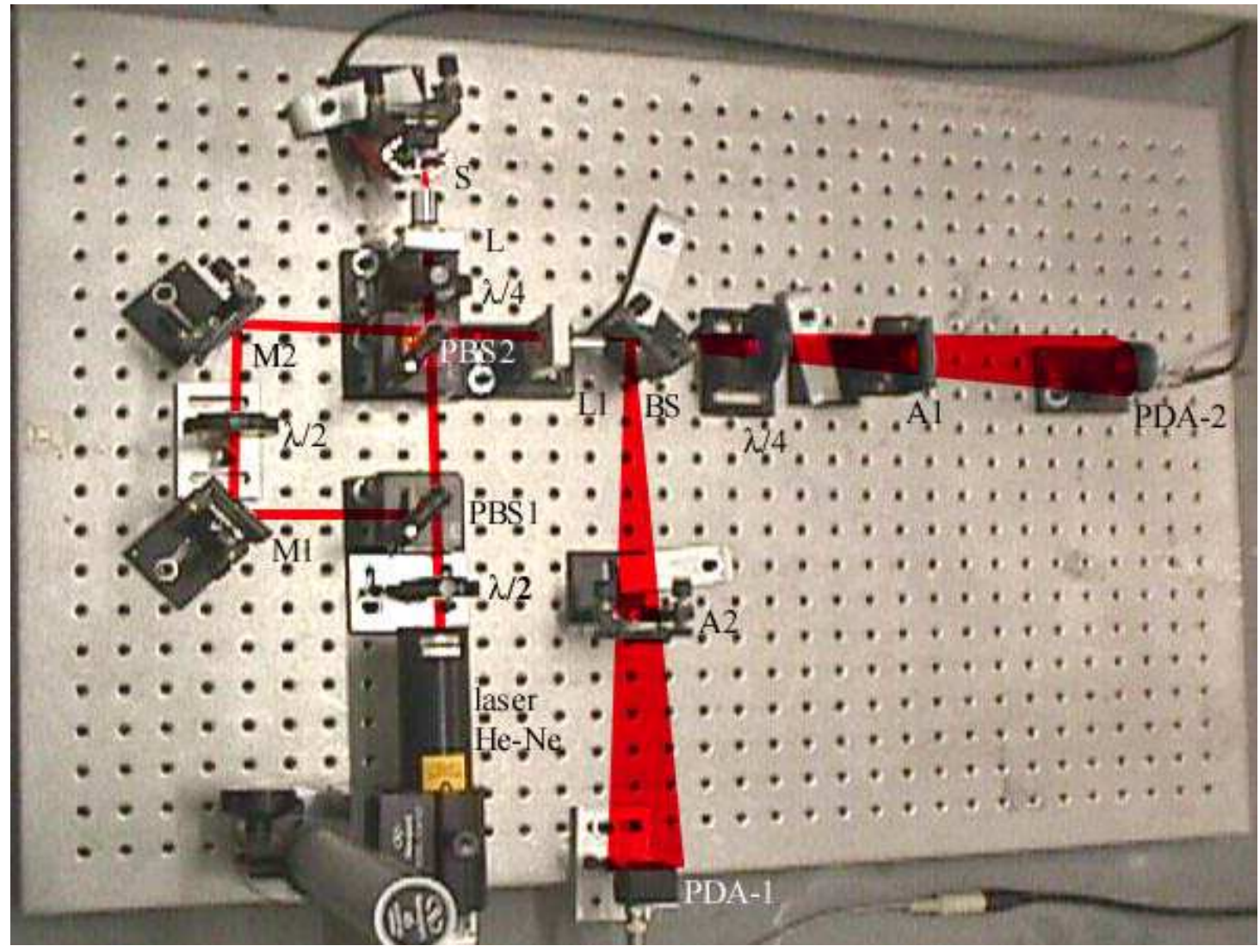

Figura 5.13. Foto do interferômetro de Mach-Zehnder modificado em regime de quadratura.

de Cerâmicas Ferroelétricas da UFSCar, utilizando o sistema a fibras ópticas MTI2000 [94]. O princípio de funcionamento desse equipamento está descrito no apêndice C. Este sistema realiza a medição de deslocamento através da detecção da variação da intensidade da luz refletida pela superfície analisada.

A Figura 5.14 mostra o arranjo experimental utilizado na análise dos materiais piezelétricos. A amostra piezelétrica analisada $(\mathrm{S})$ deve ser posicionada perpendicular à ponta sensora a fibras ópticas (FO). A calibração do sistema é realizada, no intervalo de medição desejado, como descrito no apêndice C. Um gerador de funções envia o sinal que é amplificado em 100 vezes para excitar a amostra piezelétrica (S). A amplificação do sinal de excitação, é realizada por uma fonte/amplificador estabilizado. Um osciloscópio monitora o sinal da fonte estabilizada com uma atenuação de 1000 vezes. O trigger é realizado com esse sinal. Um microcomputador adquire os sinais, de excitação e resposta, através da comunicação GPIB com o osciloscópio.

Esse sistema apresenta a vantagem de realizar facilmente análises estáticas do 


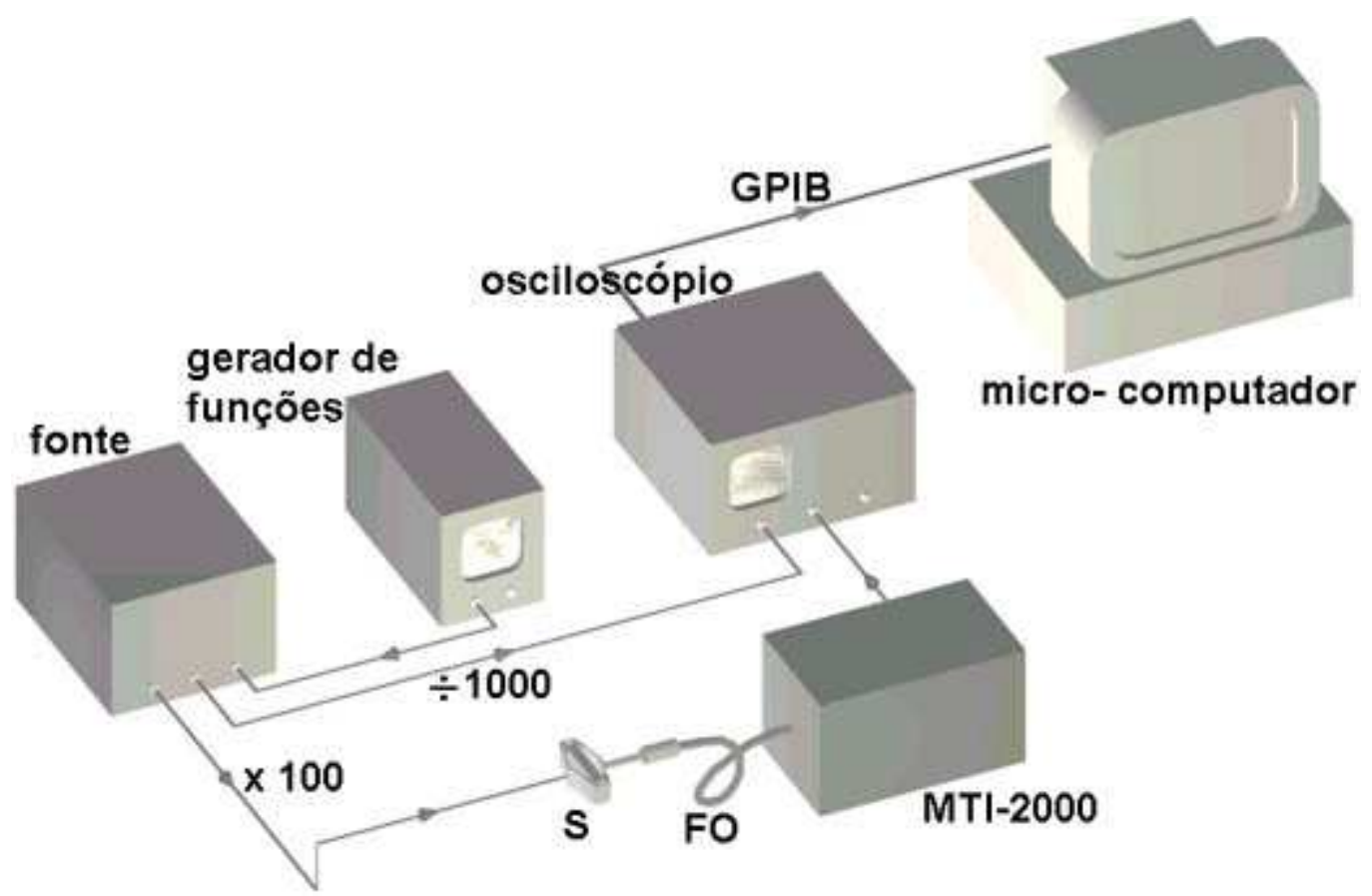

Figura 5.14. Esquema da montagem experimental utilizando o MTI2000 .

deslocamento da superfície do transdutor piezelétrico. Essas análises são realizadas com um sinal triangular de $1 \mathrm{~Hz}$. No entanto, análises harmônicas ou transientes estão limitadas 150 kHz [94], enquanto que, um sistema interferométrico pode realizar análises a freqüências de vibração, da amostra piezelétrica, até alguns $\mathrm{MHz}$ [1]. Esse sistema também está sujeito à vibrações ambientes e variações de temperatura, tal que, medições de deslocamento na ordem de dezenas de nanômetros apresentam muitos ruídos, e necessitam ser realizadas num ambiente com a temperatura estável. 


\section{Capítulo 6}

\section{Resultados Experimentais e}

\section{Numéricos}

Este capítulo divide-se em seções, que contêm análises das cerâmicas piezelétricas e de alguns tipos de piezoatuadores. A seção 6.1 mostra o processo de determinação experimental do amortecimento de diferentes cerâmicas piezelétricas PZT$5 \mathrm{~A}$, através da determinação do fator de qualidade mecânico $\left(Q_{m}\right)$. Para cada cerâmica é determinado um valor distinto de amortecimento. Esta seção mostra que no caso de cerâmicas vibrando, pode ser considerado apenas o amortecimento viscoso e o parâmetro a ser determinado é o valor da constante multiplicadora da matriz de rigidez. Os resultados obtidos são utilizados nas simulações, mostrando boa concordância entre os resultados experimentais e numéricos.

A seção 6.2 descreve a montagem e a análise dos piezoatuadores flextensionais. Estas análises foram utilizadas para validar o método de otimização topológica utilizado para projetar esses atuadores [35] e determinar o amortecimento do alumínio, material das estruturas flexíveis. Para isso, são realizadas análises em conjunto com as técnicas experimentais (ópticas e elétricas) e numéricas (MEF) os comportamentos desses atuadores e verificada a taxa de amplificação produzida pela estrutura flexível.

A seção 6.3 realiza uma análise sobre a influência do engaste das cerâmicas piezelétrica e da fixação de pequenos espelhos rígidos em sua superfície, fazendo-as curvarem-se como atuadores unilaminares onde o espelho é fixado.

Alguns piezoatuadores são analisados para verificar a viabilidade de aplicação na 
estabilização de interferômetros. A análise do atuador bilaminar e a determinação do melhor engaste para esse material é realizada na seção 6.4.

Por fim, na seção 6.5 são analisadas as pilhas piezoatuadoras. Estes materiais são compostos por múltiplas camadas piezelétricas de $100 \mu \mathrm{m}$ de espessura e por isso, ao aplicar poucos volts apresentam comportamento não-linear. Dessa forma, na análise destes também procura-se determinar a faixa linear do deslocamento por tensão elétrica e a tensão limite de operação destes materiais.

As medições experimentais são realizadas com um analisador de impedâncias (HP4194A), por interferômetros a laser (Michelson e Mach-Zehnder) e sistema óptico não interferométrico a fibras ópticas (MTI-2000). As análises numéricas são realizadas pelo método de elementos finitos, utilizando o software ANSYS.

\subsection{Determinação do Amortecimento das Piezo- cerâmicas}

As amostras piezelétricas analisadas apresentam pequenas variações nos valores do amortecimento e densidade, de uma para outra. Dessa forma, a simulação de cada cerâmica é realizada com o valor do amortecimento e da densidade determinados para cada uma. Nas simulações no ANSYS foi utilizado apenas a constante multiplicador da matriz de rigidez $\beta_{j}$ para cada material (MP,DAMP). O multiplicador da matriz massa $(\alpha)$ é considerado nulo.

\subsubsection{Modelagem no ANSYS}

A modelagem das piezocerâmicas no software ANSYS V5.7 é realizada em duas dimensões considerando a 1/4 da simetria das piezocerâmicas, pois estas são simétricas, e dessa forma o custo computacional é minimizado. Na análise elétrica das piezocerâmicas, estas estão livres de esforços mecânicos e podem vibrar em todas as direções. Dessa forma, nas simulações é assumido o estado plano de tensões mecânicas. Um modelo similar ao construído é ilustrado na Figura 3.2(a). As constantes eletropiezo-mecânicas utilizadas no ANSYS não podem ser determinadas diretamente através da caracterização elétrica (ver seção 2.3.3). Dessa forma, o valor das constantes obtidas experimentalmente apresentam uma diferença de valor em relação 
Tabela 6.1. Propriedades do PZT-5A usadas no ANSYS.

\begin{tabular}{lccl}
\hline \hline constantes elásticas & $c_{11}^{E}$ & 12,10 & $\times 10^{10} \mathrm{~N} \cdot \mathrm{m}^{-2}$ \\
& $c_{12}^{E}$ & 7,52 & $\times 10^{10} \mathrm{~N} \cdot \mathrm{m}^{-2}$ \\
& $c_{13}^{E}$ & 7,51 & $\times 10^{10} \mathrm{~N} \cdot \mathrm{m}^{-2}$ \\
& $c_{33}^{E}$ & 11,10 & $\times 10^{10} \mathrm{~N} \cdot \mathrm{m}^{-2}$ \\
& $c_{44}^{E}$ & 2,105 & $\times 10^{10} \mathrm{~N} \cdot \mathrm{m}^{-2}$ \\
& $c_{66}^{E}$ & 2,24 & $\times 10^{10} \mathrm{~N} \cdot \mathrm{m}^{-2}$ \\
constantes piezelétricas & $e_{31}$ & $-5,35$ & $\mathrm{C} \cdot \mathrm{m}^{-2}$ \\
& $e_{33}$ & 15,8 & $\mathrm{C} \cdot \mathrm{m}^{-2}$ \\
& $e_{15}$ & 12,3 & $\mathrm{C} \cdot \mathrm{m}^{-2}$ \\
constantes dielétricas & $\epsilon_{11}^{S} / \epsilon_{0}$ & 916 & \\
relativas* & $\epsilon_{22}^{S} / \epsilon_{0}$ & 916 & \\
\hline \hline
\end{tabular}

$(*) \quad \epsilon_{0}=8,85 \times 10^{-12} \mathrm{~F} . \mathrm{m}^{-1}$

Tabela 6.2. Dimensões das piezocerâmicas (PZT-5A).

\begin{tabular}{lccc}
\hline \hline & espessura (3) & largura (2) & comprimento (1) \\
\hline cerâmica 1 & $0,99 \mathrm{~mm}$ & $13,95 \mathrm{~mm}$ & $29,87 \mathrm{~mm}$ \\
cerâmica 2 & $2,95 \mathrm{~mm}$ & $13,95 \mathrm{~mm}$ & $29,95 \mathrm{~mm}$ \\
cerâmica 3 & $4,97 \mathrm{~mm}$ & $13,90 \mathrm{~mm}$ & $29,90 \mathrm{~mm}$ \\
\hline \hline
\end{tabular}

às tabeladas que varia de $0,3 \%$ a $26 \%$ (ver seção 6.6). Esta diferença afeta principalmente o valor da freqüência de ressonância, devido à variação das constantes elásticas de rigidez e a densidade. Por isso, a densidade utilizada é a medida experimentalmente e as outras constante usadas são ilustradas na Tabela 6.1.

Para a determinação da constante multiplicadora da matriz de rigidez $\beta_{j}$ e validação da técnica, são analisadas 3 cerâmicas piezelétricas retangulares, com as dimensões ilustradas na Tabela 6.2.

\section{Piezocerâmica de $5 \mathrm{~mm}$ de espessura}

A densidade da cerâmica piezelétrica de $5 \mathrm{~mm}$ de espessura é $\rho=7591 \mathrm{~kg} \cdot \mathrm{m}^{-3}$, a freqüência de ressonância do modo fundamental do comprimento (direção 1) é $f_{0}=46.600 \mathrm{~Hz}$ e o fator de qualidade mecânico determinado experimentalmente, 
utilizando a eq.(2.65), é $Q_{m}=69$, através desse valor determina-se o amortecimento para a freqüência de ressonância do modo comprimento $\beta_{j}=4,9 \times 10^{-8}$, utilizando a eq.(2.76). Os resultados da análise da admitância elétrica e da curva de fase, experimentais e simuladas, são mostradas nas Figuras 6.1(a) e (b), respectivamente.

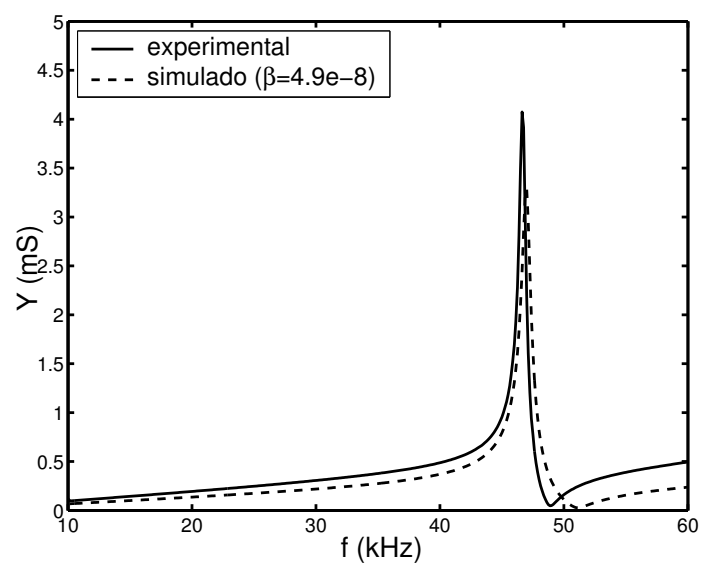

(a)

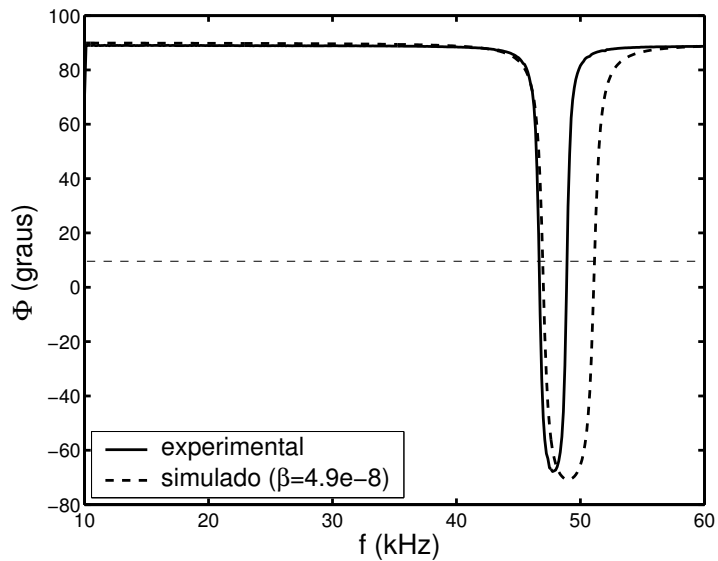

(b)

Figura 6.1. respostas elétricas da cerâmica de $5 \mathrm{~mm}$ de espessura na região da modo fundamental de vibração do comprimento. (a) curva da admitância elétrica e (b) curva da fase elétrica.

Através da curva de admitância elétrica (Figura 6.1(a)), nota-se que os valores experimentais e simulados até a freqüência de anti-ressonância (aproximadamente $50 \mathrm{kHz}$ ) estão próximos. Após esse valor há um aumento na diferença entre os valores da admitância elétrica experimental e simulado. Os resultados experimental e simulado apresentam uma boa concordância, mostrando que o valor determinado para o amortecimento é satisfatório.

A curva de fase também mostra resultados experimentais e simulados próximo [Figura 6.1(b)]. Porém, os resultados obtidos nas análises pelo ANSYS mostraram a fase variando entre $180^{\circ}$ e $0^{\circ}$, enquanto os resultados experimentais obtidos com o HP4191A sempre mostram a fase variando entre $90^{\circ}$ e $-90^{\circ}$. Dessa forma, o valor da fase obtida nas análises numéricas está subtraído de $90^{\circ}$, para que o patamar superior da curva simulada case com o da curva experimental. 


\section{Piezocerâmica de $3 \mathrm{~mm}$ de espessura}

As mesmas análises são realizadas para cerâmicas piezelétrica de $3 \mathrm{~mm}$ de espessura. O valor da densidade dessa cerâmica é $\rho=7680 \mathrm{~kg} \cdot \mathrm{m}^{-3}$, a freqüência de ressonância do modo fundamental do comprimento (direção 1) é $f_{0}=46.400 \mathrm{~Hz}$ o fator de qualidade mecânico é $Q_{m}=69$ e o o valor da constante multiplicadora da matriz de rigidez determinado para a freqüência de ressonância do modo comprimento é $\beta_{j}=5,0 \times 10^{-8}$.

As Figuras 6.2(a) e (b) mostram a comparação entre os resultados experimentais e simulados da curva de admitância elétrica e fase, respectivamente. As curvas de admitância elétrica obtidas na análise dessa cerâmica mostram uma boa concordância na faixa de $10 \mathrm{kHz}$ até $44 \mathrm{kHz}$ e uma pequena divergência a partir da freqüência de ressonância. A fase também apresenta uma boa concordância e assim como relatado anteriormente, houve uma correção na curva de fase subtraindo o valor obtido nas análises numéricas por $90^{\circ}$.

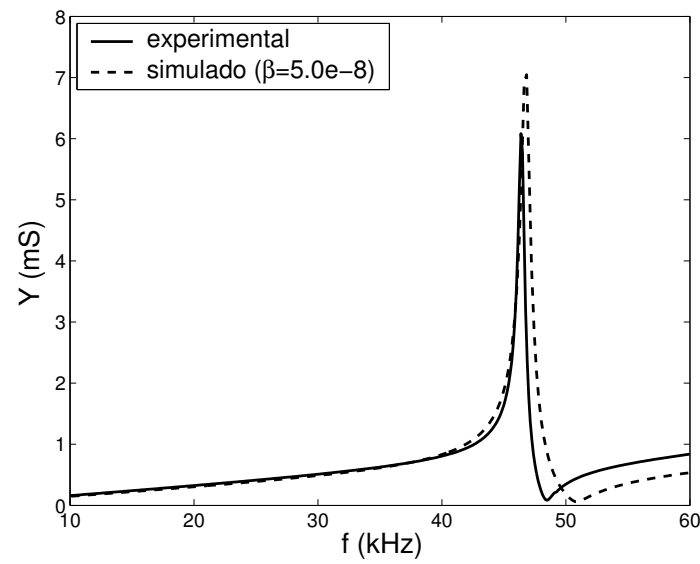

(a)

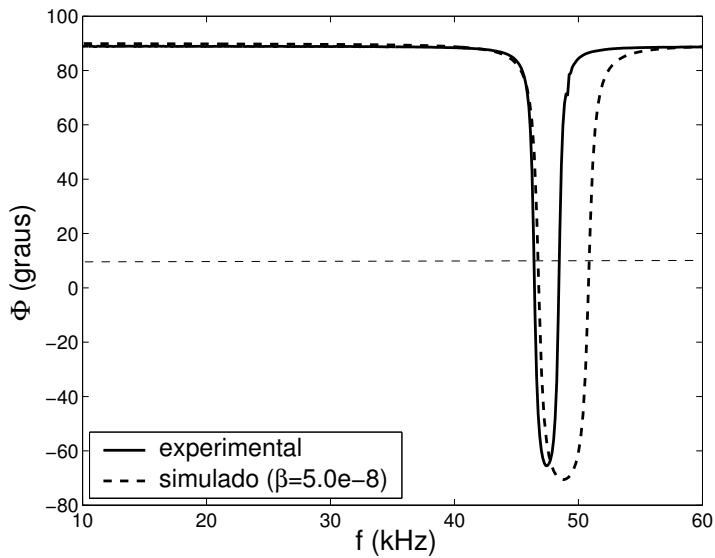

(b)

Figura 6.2. respostas elétricas da cerâmica de $3 \mathrm{~mm}$ de espessura na região da modo fundamental de vibração do comprimento. (a) curva da admitância elétrica e (b) curva da fase elétrica.

\section{Piezocerâmica de $1 \mathrm{~mm}$ de espessura}

Nas análises da cerâmica de $1 \mathrm{~mm}$ de espessura, verificou-se que o seu fator de qualidade mecânico é muito baixo para o modo de ressonância do comprimento $\left(Q_{m}=50\right)$. No entanto, a comparação entre os resultados experimentais e simulados 
da curva de impedância e fase (Figuras 6.3), mostram que esse valor poderia ser ainda menor, pois ao utilizar um fator de qualidade maior, há um decréscimo no valor de $\beta_{j}$ e o valor máximo da admitância aumenta. A densidade dessa cerâmica é $\rho=7674 \mathrm{~kg} \cdot \mathrm{m}^{-3}$, a freqüência de ressonância do modo fundamental do comprimento (direção 1) é $f_{0}=45.700 \mathrm{~Hz}$ e o amortecimento determinado para a freqüência de ressonância do modo comprimento é $\beta_{j}=7,0 \times 10^{-8}$.

As Figuras 6.3(a) e (b) mostram a comparação entre os resultados experimentais e simulados da curva de admitância elétrica e fase, respectivamente. Assim como no caso da cerâmica de $3 \mathrm{~mm}$ de espessura, os resultados da admitância elétrica obtidos para a cerâmica de $1 \mathrm{~mm}$ de espessura mostram uma boa concordância de $10 \mathrm{kHz}$ até $44 \mathrm{kHz}$, divergindo após a freqüência de ressonância. As curvas de fase mostram que as freqüências de ressonância estão deslocadas nessa comparação. No entanto, esses resultados são satisfatório mostrando a validade da determinação experimental do amortecimento para cerâmicas piezelétricas. Alguns comentários sobre os resultados obtidos são descritos a seguir.

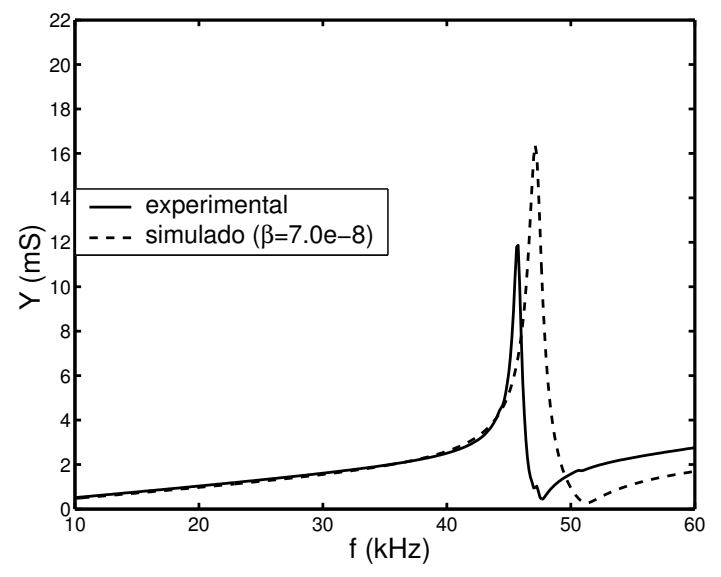

(a)

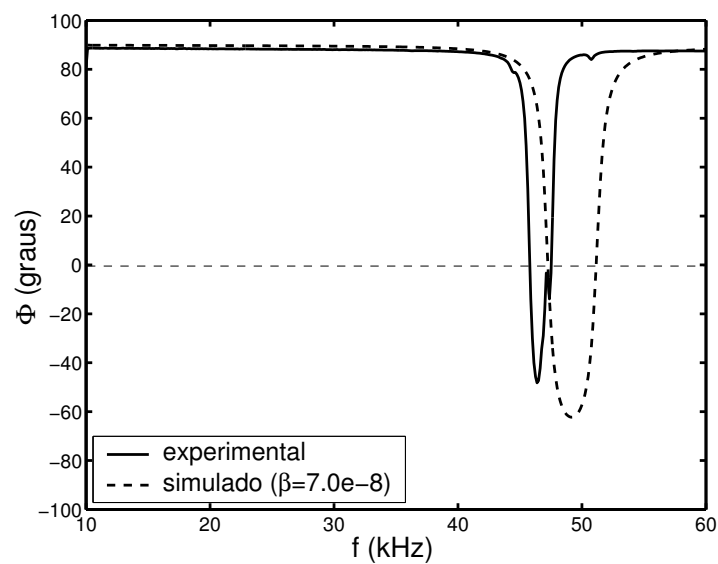

(b)

Figura 6.3. respostas elétricas da cerâmica de $1 \mathrm{~mm}$ de espessura na região da modo fundamental de vibração do comprimento. (a) curva da admitância elétrica e (b) curva da fase elétrica.

\section{Discussões}

Os resultados obtidos mostram que a técnica de determinação do multiplicador da matriz de rigidez $\left(\beta_{j}\right)$ é válido e que o multiplicador da matriz massa $(\alpha)$ pode ser 
desprezado nas análises vibracionais de transdutores piezelétricos em meios fluidos (ar, líquido), pois na consideração do amortecimento viscoso há apenas contribuição de $\beta_{j}$. A partir dos valores determinados experimentalmente para o amortecimento das piezocerâmicas, e checados através de analises numéricas, são determinados os amortecimentos $\beta_{j}$ do alumínio e vidro, através da comparação dos resultados experimentais e simulados, obtidos nas análises ópticas e elétricas dos piezoatuadores flextensionais e das cerâmicas com espelhos de vibro fixados em sua superfície.

\subsection{Piezoatuadores Flextensionais}

A análise dos piezoatuadores flextensionais tem por objetivos: verificar se estes foram montados sem falhas; o intervalo de resposta linear do deslocamento pela voltagem aplicada; as curvas de histerese; o tempo de resposta; verificar o valor amortecimento determinado para as piezocerâmicas e determinar o amortecimento para o alumínio; e verificar a influência da resina epóxi utilizada na fixação das estruturas flexíveis à piezocerâmica.

A determinação experimental das freqüências de ressonância é realizada, inicialmente, utilizando um analisador de impedância e fase. Dessa forma, é possível verificar, comparando as freqüências de ressonância da cerâmicas piezelétrica e do piezoatuador flextensional, se a montagem foi bem sucedida.

Cada protótipo piezoatuador flextensional foi projetado para possuir um deslocamento máximo em um ponto sobre sua superfície, como descrito na seção 4.1. Por isso, as medições de deslocamento são realizadas somente neste ponto.

Os flextensionais são projetados para trabalharem em regime estático ou quasiestático, como atuadores ou sensores. Dessa forma, as medições são realizadas com os flextensionais sob excitação:

- transiente, utilizando um ciclo de seno (burst) na freqüência central de $10 \mathrm{kHz}$. O objetivo principal da simulação transiente é a determinação do amortecimento assim como da influência do epóxi na rigidez ou acoplamento das estruturas do transdutor.

- harmônica, entre 10 kHz e a primeira freqüência de ressonância (condição quasi-estática). Abaixo de $10 \mathrm{kHz}$, o deslocamento cai linear e lentamente, 
por isso não foram realizadas medições em regime harmônico abaixo dessa freqüência.

- estática, utilizando um sinal triangular, de um gerador de funções, com freqüência igual ou inferior a $1 \mathrm{~Hz}$.

Os resultados experimentais e simulados, das análises, aparecem simultaneamente em cada seção, desde que os dois tenham sido obtidos.

\subsubsection{Montagem dos Piezoatuadores Flextensionais}

Os protótipos dos atuadores flextensionais são compostos por uma estrutura flexível em alumínio conectada a uma piezocerâmica retangular (placa). As piezocerâmicas utilizadas, na montagem dos piezoatuadores flextensionais, são PZT-5A com as dimensões ilustradas na Tabela 6.2. A direção 3 é a direção da polarização das piezocerâmicas. Os eletrodos estão depositados ortogonais à direção da polarização, ou seja, nas faces que estão nos planos 12 .

Os piezoatuadores flextensionais com cerâmica de $5 \mathrm{~mm}$ de espessura, e analisados neste trabalho, são mostrados na Figura 6.4. Estes são denominados: f1a1025, f1a0820, f1a20827 e f2b0830. A Figura 6.5 mostra o denominado f1b0820 que utiliza uma piezocerâmica de $3 \mathrm{~mm}$ de espessura. E finalmente, a Figura 6.6 mostra o flextensional denominado f1c0815, que utiliza uma piezocerâmica de $1 \mathrm{~mm}$ de espessura.

A estrutura flexível de alumínio foi cortada por eletro-erosão a fio e as piezocerâmicas foram fixadas usando resina epóxi. Também foi testado em alguns protótipos a fixação da piezocerâmica utilizando rosin, que é uma mistura de cera de abelha com breu. O rosin foi utilizado, porque além de fornecer uma fixação com rigidez semelhante a da resina epóxi, pode ser facilmente removido através de aquecimento a cerca de $80^{\circ} \mathrm{C}$, o que permite utilizar a mesma cerâmica para montagens com diferentes tipos de estruturas flexíveis.

Para isolar eletricamente os contatos entre os eletrodos da piezocerâmica e a estrutura flexível de alumínio, foi removida uma pequena parte dos eletrodos na região de contato entre a piezocerâmica e a estrutura flexível de alumínio constituídas por uma peça única, como o f1a1025, f2b0830, f1a20827 e f1c0815 (Figuras 6.4 e 6.6). 

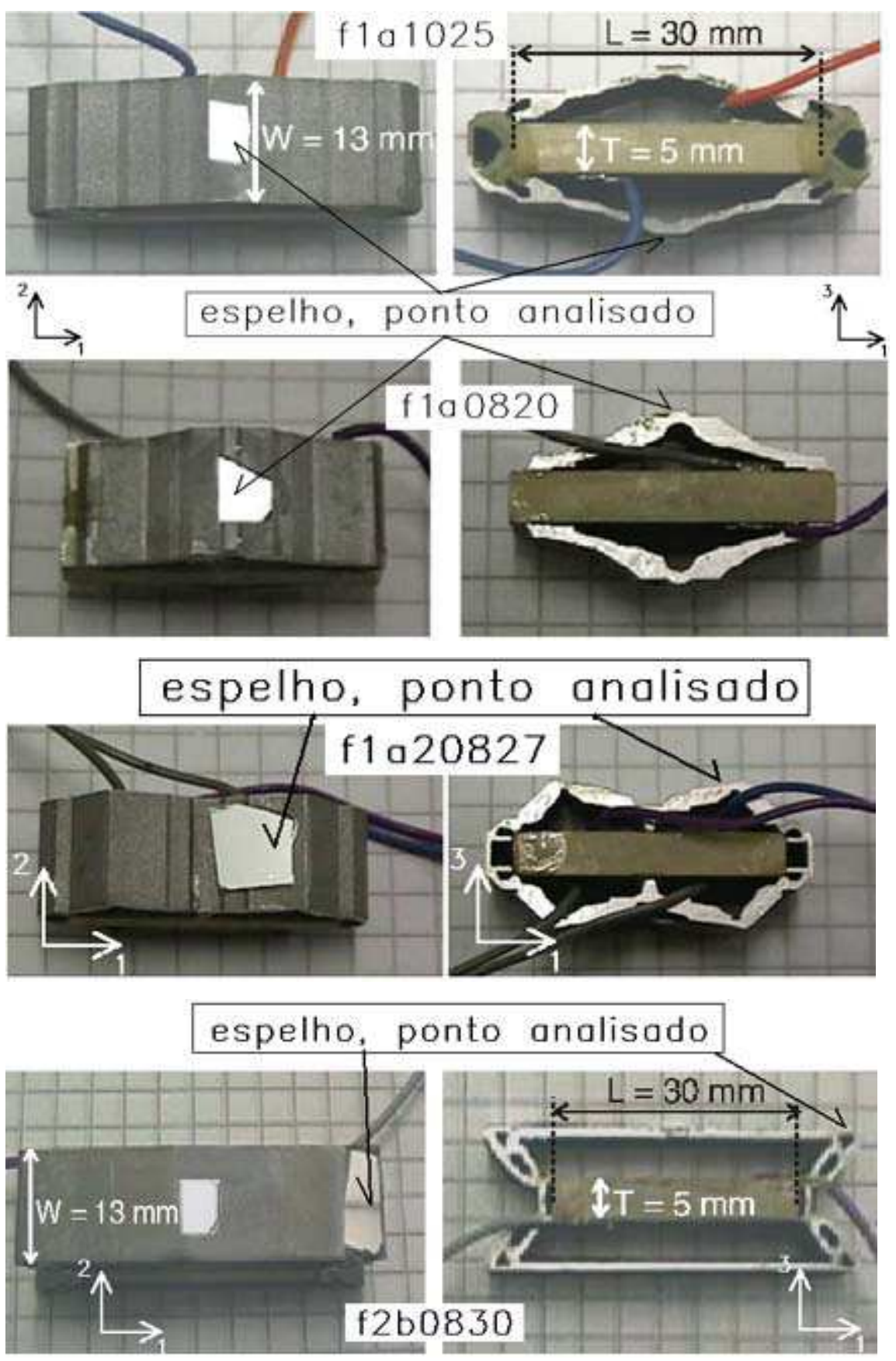

Figura 6.4. Piezoatuadores flextensionais com cerâmicas de $5 \mathrm{~mm}$ de espessura. As demais dimensões das piezocerâmicas estão ilustradas na própria figura. Estes são denominados f1a1025, f1a0820, f1a20827 e f2b0830. 


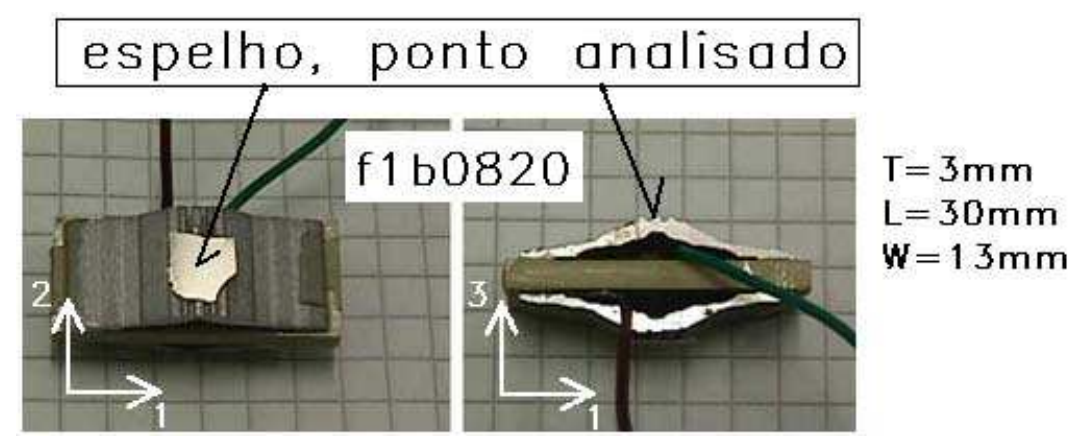

Figura 6.5. Piezoatuador flextensional f1b0820 com piezocerâmica de $3 \mathrm{~mm}$ de espessura.

Dessa forma, evita-se um curto-circuito. A remoção de parte dos eletrodos foi feita usando-se uma lixa. No entanto, uma melhor solução para a remoção dessa pequena parte dos eletrodos é através de corrosão química, como a realizada em chapas impressas de circuitos eletrônicos, utilizando o percloreto de ferro. Nos casos em que as estruturas flexíveis são bipartidas, como os f1a0820 e f1b0820 (Figuras 6.4 e 6.5), não há risco de curto-circuito e não há necessidade de remoção parcial dos eletrodos. Durante o processo de secagem da resina epóxi entre a piezocerâmica e a estrutura bipartida, estes foram mantidos firmemente fixados.

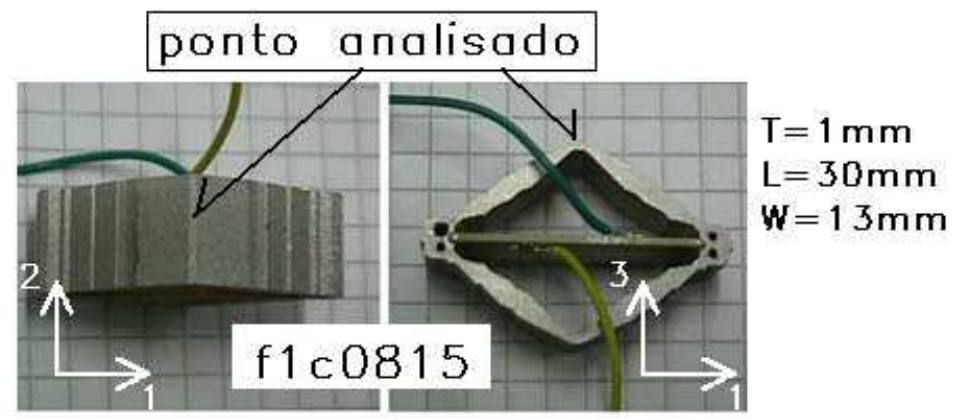

Figura 6.6. Piezoatuador flextensional f1c0815 com piezocerâmica de $1 \mathrm{~mm}$ de espessura.

\subsubsection{Método de Elementos Finitos (MEF)}

Os modelos dos piezoatuadores flextensionais são feitos em duas dimensões considerando a $1 / 4$ da simetria. A Figura 6.7(a) mostra o piezoatuador flextensional f1a1025 completo e a Figura 6.7(b) mostra o mesmo atuador modelado com 1/4 da simetria no ANSYS. 
Nesses análises as camadas de resina epóxi são consideradas apenas para os piezoatuadores flextensionais f1a0820 e f1b0820, que são os que possuem estruturas flexíveis bipartidas. Para os outros piezoatuadores flextensionais verificou-se que a influência da resina epóxi era desprezível.

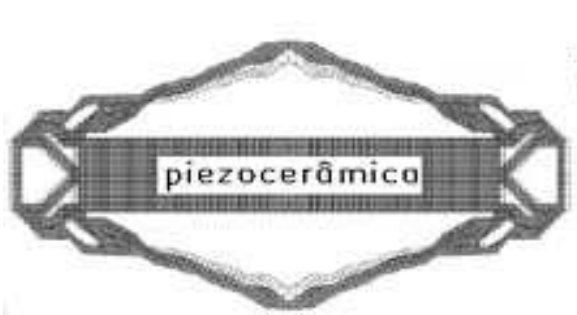

(a)

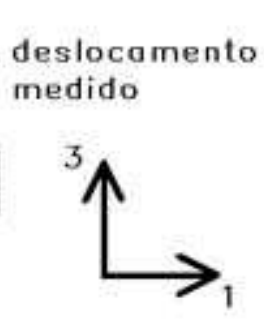

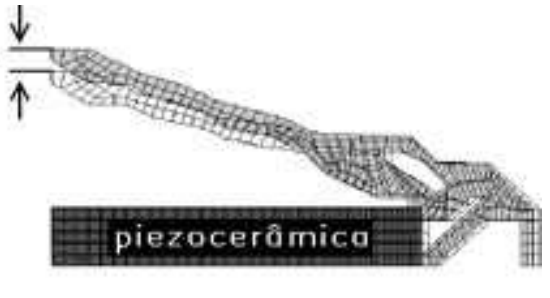

(b)

Figura 6.7. piezoatuador flextensional f1a1025 modelados por elementos finitos. (a) completo; (b) $1 / 4$ da simetria.

As condições experimentais de análise das piezocerâmicas e dos piezoatuadores flextensionais motiva a considerações distintas nas simulações. Essas condições são:

- Na análise da impedância elétrica, tanto a cerâmica piezelétrica quanto o piezoatuador flextensional estão livres, ou seja, sem tensões mecânicas aplicadas e podem deformar-se em todas as direções $(1,2,3)$. A largura $(w)$ da cerâmica é $1 / 3$ do comprimento $(l)$, por isso, nas simulações para obter as curvas de resposta da admitância elétrica foram assumidos o estado plano de tensões mecânicas (plane stress), tanto para a piezocerâmica quanto para o piezoatuador flextensional (ver seção 3.4.1).

- Na análise do deslocamento, a piezocerâmica é rigidamente presa na direção da largura $(w)$, não deformando-se ou deformando-se pouco nessa direção. Essa condição de não-deformação é melhor simulada bidimensionalmente quando assume-se o estado plano de deformações mecânicas (plane strain), como discutido na seção 3.4.1. A estrutura em alumínio não está presa na direção da largura. Para esta foi assumido o estado plano de tensões mecânicas.

Devido às simulações serem realizadas com 1/4 da simetria dos flextensionais, são impostas condições de deslocamento mecânico nulo nos nós e direções indicados na Figura 6.8. Os eletrodos da piezocerâmica são colocados nas linhas da direção 
1, ortogonais à direção da polarização (direção 3), como mostra a Figura 6.8. Ao utilizar 1/4 da simetria do piezoatuador flextensional, a piezocerâmica é modelada com metade de sua espessura verdadeira. Por isso, a tensão elétrica aplicada nas simulações, deve ser a metade da voltagem desejada.

As simulações são realizadas considerando as análises harmônica e transiente. A análise harmônica é realizada para determinação da resposta do deslocamento em freqüência, das curvas de admitância elétrica, e consequentemente das freqüências de ressonância considerando o amortecimento mecânico, que é o fator multiplicador $\beta$ da matriz de rigidez [eqs.(2.74) e (3.8)]. A análise transiente é realizada para verificar o amortecimento, influência da resina epóxi na fixação, tempo de resposta e espectro de freqüência das amostras piezelétricas utilizadas neste trabalho.

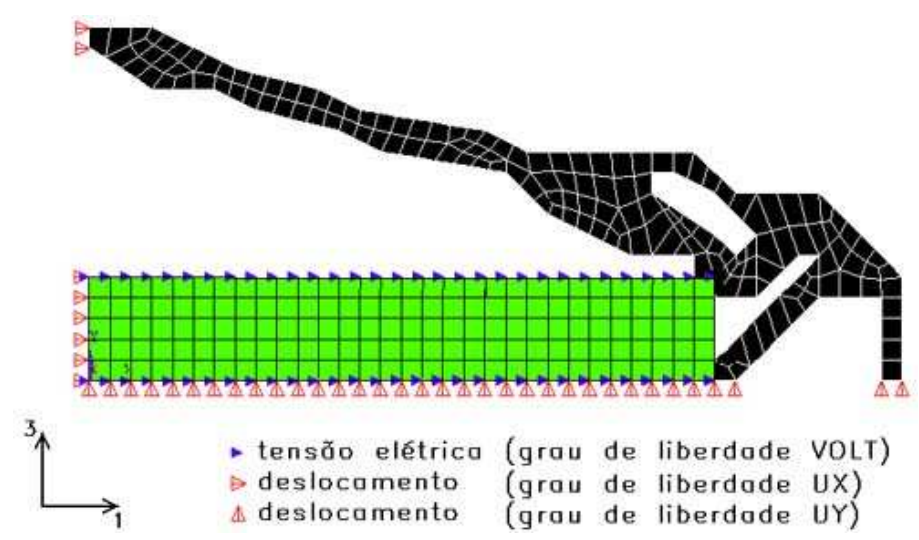

Figura 6.8. Cargas mecânica e elétrica aplicadas ao flextensional na simulação.

A Tabela 6.1 mostra as propriedades do PZT-5A usadas nas simulações. As propriedades do alumínio, resina epóxi e vidro usadas nas simulações são mostradas na Tabela 6.3.

Os valores do amortecimento do alumínio e do vidro, mostrados na Tabela 6.3 foram determinados através de comparação entre os resultados obtidos nas simulações e os resultados experimentais das análises da admitância elétrica e transiente dos piezoatuadores flextensionais e do tipo-unilaminar. O amortecimento da resina epóxi foi desprezado devido a espessura desse material nas simulações ter sido inferior a $100 \mu \mathrm{m}$. 
Tabela 6.3. Propriedades do alumínio, resina epóxi e vidro.

\begin{tabular}{lcccc}
\hline \hline & $E\left(\times 10^{9} \mathrm{~N}^{-\mathrm{m}^{-2}}\right)$ & $\rho\left(\mathrm{kg} \cdot \mathrm{m}^{-3}\right)$ & $\sigma$ & $\beta_{j}\left(\times 10^{-8}\right)$ \\
\hline alumínio & 70,0 & 2700 & 0,33 & 20 \\
epóxi & 4,5 & 1160 & 0,33 & - \\
vidro & 70,0 & 2510 & 0,29 & 40 \\
latão & 100,0 & 8400 & 0,34 & - \\
\hline \hline
\end{tabular}

\subsubsection{Análise da Admitância Elétrica}

As piezocerâmicas usadas na montagem dos protótipos são inicialmente caracterizadas em um analisador de impedâncias e fase (HP4194A), para a determinação das curvas de admitância elétrica e freqüências de ressonância. A curva de admitância elétrica da piezocerâmicas é comparada com a curva do piezoatuador flextensional, para verificar se o processo de fixação, dos elementos do piezoatuador, foi realizado com sucesso. Pois após a fixação da piezocerâmica na estrutura flexível novas freqüências de ressonância aparecem devido ao acréscimo de massa e acoplamento entre os elementos do piezoatuador. Simulações numéricas computacionais, utilizando o software de elementos finitos ANSYS são realizadas com o intuito de verificar se as freqüências de ressonância obtidas experimentalmente são similares às obtidas por simulações.

As curvas de admitância elétrica experimentais são adquiridas pelo HP4194A, no intervalo de freqüências entre $10 \mathrm{kHz}$ e $60 \mathrm{kHz}$. Estas curvas experimentais são comparadas com as curvas obtidas pela simulação no ANSYS, no mesmo intervalo de freqüência.

O resultado obtido para a cerâmica de 5 mm de espessura é mostrado na Figura 6.1(a) e Os resultados das análises da admitância elétrica dos piezoatuadores flextensionais f1a1025 e f2b0830 são mostrados na Figura 6.9. Essas curvas foram obtidas utilizando o valor do amortecimento da piezocerâmica determinado experimentalmente e assumindo valores para o amortecimento do alumínio. O valor utilizado é mostrado na Tabela 6.3. Verifica-se também que os valores utilizados para o amortecimento $\beta_{j}$ mostram-se satisfatórios.

Através das curvas de admitância elétrica determinam-se as freqüências de ressonância do modo comprimento da cerâmica piezelétrica e as primeiras freqüências de ressonância dos piezoatuadores flextensionais. Através dos resultados obtidos 

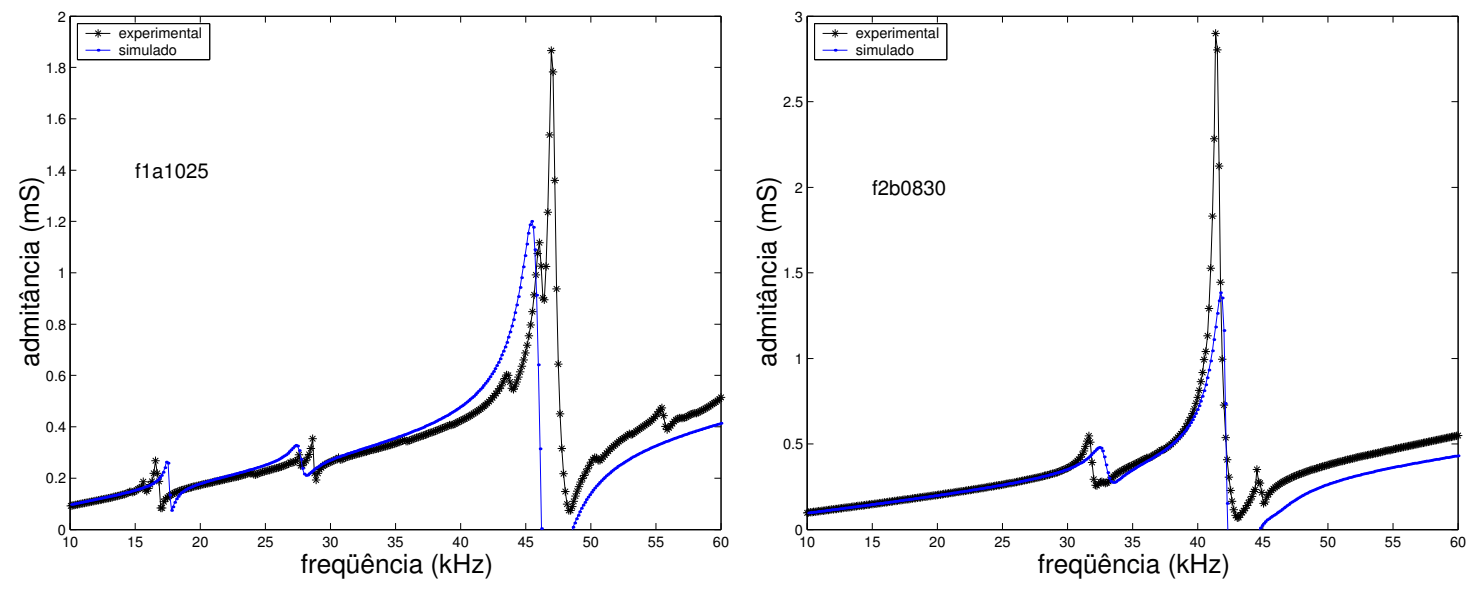

Figura 6.9. Curvas de admitância elétrica experimental de simulada dos piezoatuadores flextensionais f1a1025 e f2b0830.

para os flextensionais, é verificado se estes foram montados corretamente, através da verificação das novas freqüências de ressonância, que surgem no intervalo analisado. A Figura 6.9 mostra que as curvas experimentais e simuladas apresentam as novas freqüências de ressonância e esses resultados estão muito próximos. Nota-se também que há freqüências de ressonância que aparecem nas análises experimentais, mas não aparecem nas análises numéricas. Uma possível explicação está relacionada com as simulações terem sido realizadas em duas-dimensões, pois simulações realizadas em três dimensões por LERCH [43] mostram resultados experimentais e simulados com as freqüências espúrias. No entanto, análises tridimensionais têm um alto custo computacional de tempo e memória, tornando as análises dos piezoatuadores flextensionais inviáveis.

As mesmas análises são realizadas para a cerâmica de $3 \mathrm{~mm}$ de espessura [Figura 6.2(a)] e para o piezoatuador f1b0820, que utiliza essa piezocerâmica como elemento ativo. A Figura 6.10(a) mostra as curvas de admitância elétrica, experimental e simulada. Esse piezoatuador apresentou uma curva de admitância elétrica com valores de ressonância diferentes dos obtidos experimentalmente. Isso provavelmente ocorreu devido à quantidade de resina epóxi utilizada na montagem do flextensional f1b0820.

A análise da cerâmica de $1 \mathrm{~mm}$ de espessura [Figura 6.3(a)] e do flextensional f1c0815 também mostraram resultados satisfatórios e uma boa concordância, como pode ser observado pela Figura 6.10(b). 


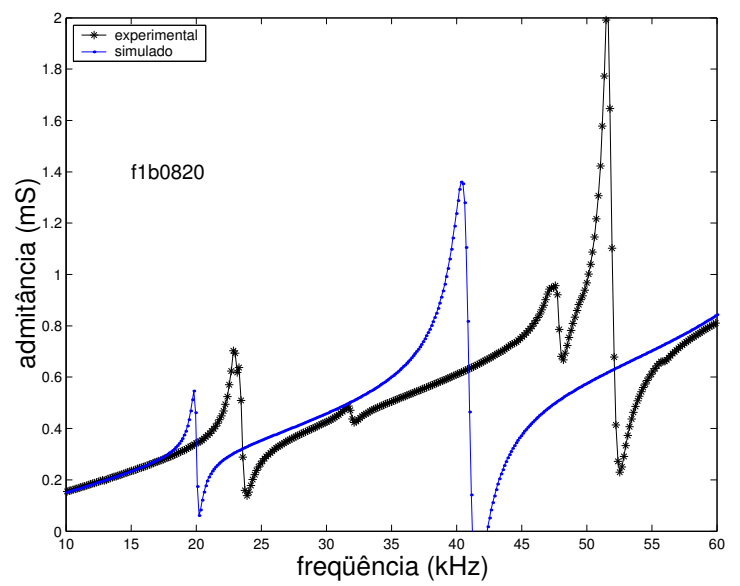

(a)

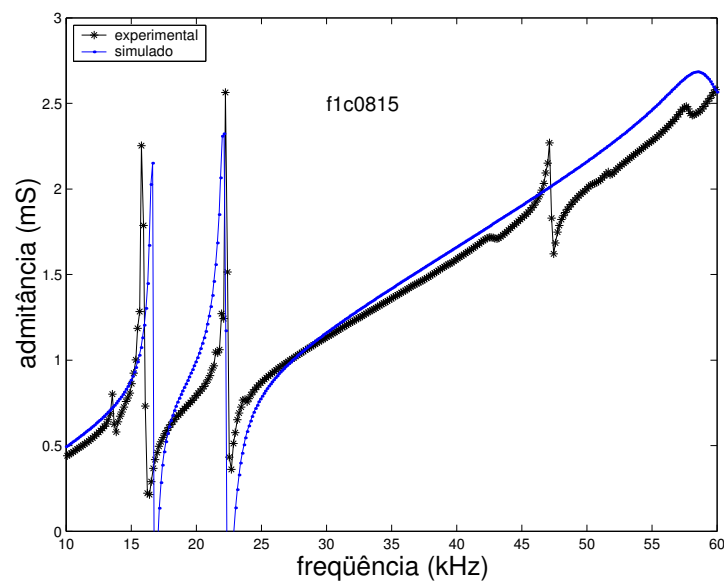

(b)

Figura 6.10. Curvas de admitância elétrica experimental de simulada dos piezoatuadores flextensionais: (a) f1b0820 e (b) f1c0815.

\subsubsection{Análises por Sistemas Ópticos}

Sistemas ópticos são utilizados na medição de deslocamento das piezocerâmicas e dos piezoatuadores flextensionais. Os objetivos dessas medições são:

- Obter a faixa de deslocamento linear e o comportamento não linear no flextensionais;

- Obter a taxa de amplificação de deslocamento na direção z que a estrutura flexível em alumínio produziu em relação à piezocerâmica nua;

- Obter a resposta do deslocamento em freqüência dos atuadores flextensionais até a primeira freqüência de ressonância;

- Obter o tempo de resposta dos atuadores flextensionais;

- Obter o amortecimento da piezocerâmica e do alumínio usado na estrutura flexível;

- Validar o método de otimização topológica, utilizado para projetar esses piezoatuadores.

Para realizar as medições é empregada a interferometria a laser nas análises das piezocerâmicas e dos flextensionais em regime harmônico, desde $10 \mathrm{kHz}$ até a primeira freqüência de ressonância, e em regime transiente com um ciclo de seno na 
freqüência central de $10 \mathrm{kHz}$. Nas análises com os materiais piezelétricos sob regime estático é utilizado um sistema óptico não-interferométrico. A interferometria a laser também pode realizar medições de deslocamento em regime estático.

Em análises por sistemas ópticos, há necessidade das amostras possuírem superfície reflexiva, para que haja reflexão da luz incidente. As soluções encontradas para espelhar os materiais piezelétricos para as análises ópticas foram:

- Fabricar pequenos espelhos, por vaporização de alumínio na superfície de lamínulas de microscópio;

- Colar fita de poliéster metalizada;

- Dar polimento óptico e depositar ouro por sputtering na superfície do material analisado.

As estrutura flexíveis, por serem fabricadas por eletro-erosão a fio, apresentam muita porosidade na superfície. Nestas foram fixados os pequenos espelhos ou a fita de poliéster reflexivo. No caso de utilizar a fita de poliéster é necessário trabalhar com o feixe laser focalizado, devido ao espalhamento da luz na reflexão $[1,2]$. Não é possível dar polimento óptico às estruturas flexíveis, devido às suas formas complexas e a deposição direta, de ouro em sua superfície não melhora a qualidade da luz refletida, como foi verificado.

Para espelhar piezocerâmicas foi colada a fita de poliéster reflexiva ou realizado um polimento quasi-óptico ${ }^{1}$ e depositando ouro ou alumínio em sua superfície. Como não foi possível dar um polimento realmente óptico, essa solução não se mostrou melhor que o uso da fita de poliéster reflexiva, pois em ambos casos há necessidade de trabalhar com o feixe laser focalizado no ponto de análise.

Também houve a tentativa de colar os pequenos espelhos na superfície das piezocerâmicas, porem houve problemas com essa solução. Esses problemas e sua análise, estão relatados na seção 6.3 .

A Figura 6.11(a) mostra uma foto do fixador do flextensional ou da piezocerâmica, para as análises no interferômetro. Essas análises são realizadas no ar,

\footnotetext{
${ }^{1}$ Um polimento óptico necessita ser, no mínimo, $1 / 5$ do comprimento de onda da luz incidente. No entanto, os polimentos realizados são da ordem de 1 comprimento de onda, por isso, há luz espalhada na reflexão.
} 
para evitar perdas mecânicas. Os materiais piezelétricos são presos apoiados por três pontos, como ilustra a Figura 6.11(b). Dois parafusos prendem a base inferior, para dar equilíbrio e um parafuso prende a parte superior. Dessa forma, a amostra piezelétrica analisada tem liberdade para deslocar-se nas direções 1 e 3 . O deslocamento na direção 2 é praticamente nulo, pois os parafusos são bem apertados, tal que, nessa condição há uma aproximação do estado plano de deformações mecânicas, que é assumido para a piezocerâmica nas análises de deslocamento.

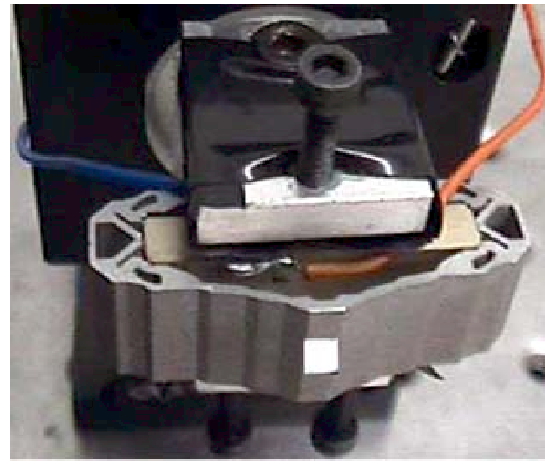

(a)

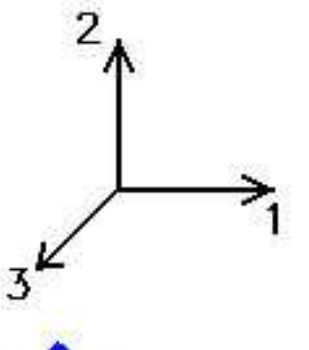

engaste

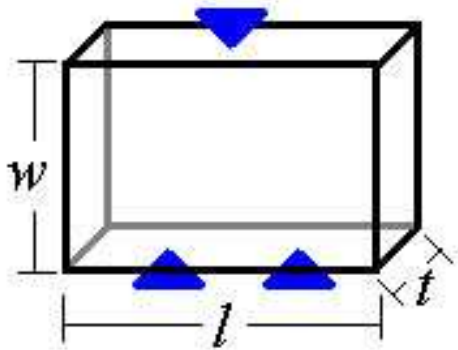

(b)

Figura 6.11. (a) Foto do fixador dos atuadores flextensionais ou piezocerâmicas na montagem no interferômetro laser. (b) esquema indicando o engaste dos três parafusos.

O feixe sinal do laser (sonda laser) é apontado na posição do flextensional, para a qual foi projetada para possuir deslocamento máximo. Estes pontos estão indicados nas Figuras 6.4, 6.5 e 6.6.

A seguir, são descritos os resultados do deslocamento e da taxa de amplificação do piezoatuadores flextensionais.

\section{Análise Transiente}

Os resultados das análises dos piezoatuadores flextensionais em regime de excitação transiente, realizada com o interferômetro laser [45, 47, 48, 49], são comparados com os resultados obtidos pelo ANSYS. O sinal de excitação transiente, com $30 \mathrm{~V}$ pico-a-pico, é mostrado na Figura 6.12.

A Figura 6.13 mostra os resultados experimental e simulado dos flextensionais que utilizam a piezocerâmica de 5 mm de espessura: f1a1025, f2b0830, f1a0820 e f1a20827. Nas simulações foi assumido o estado plano de deformações mecânicas 


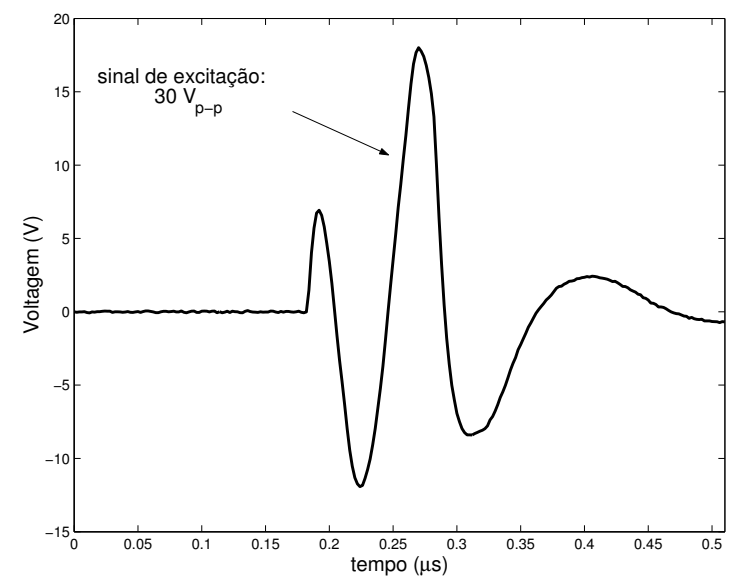

Figura 6.12. Sinal de excitação transiente dos atuadores flextensionais e cerâmicas piezelétricas. A voltagem é $30 \mathrm{~V}_{p-p}$.

para a piezocerâmica e estado plano de tensões mecânicas para a estrutura em alumínio. Também são utilizados os amortecimentos determinados experimentalmente para a piezocerâmica e o valor determinado pelas simulações, para o alumínio está listado na Tabela 6.3.

A Figura 6.13 mostra que para o piezoatuador flextensional f1a0820 há três curvas de resposta transiente: experimental, simulada com resina epóxi e simulada sem resina epóxi. Pois, este flextensional utiliza as estruturas metálicas bipartidas e o deslocamento longitudinal da piezocerâmica é transferido para a estrutura em alumínio através de cisalhamento na resina epóxi. Por isso, há influência da resina epóxi no comportamento do piezoatuador flextensional fla0820, como mostram os resultados da análise transiente (Figura 6.13). O resultado numérico, considerando a resina epóxi entre a piezocerâmica e a estrutura flexível, é obtido utilizado uma camada de $100 \mu \mathrm{m}$ de espessura de resina.

Os outros flextensionais analisados (f1a1025, f2b0830 e f1a20827) realizam a transferência do deslocamento longitudinal da piezocerâmica, através de compressão da cerâmica na parede interna da estrutura metálica flexível. Por esse motivo, a resina epóxi não influencia (ou tem pouca influência) no comportamento desses piezoatuadores flextensionais.

Os resultados experimentais e simulados no domínio do tempo são muito semelhantes, como mostra a Figura 6.13, demonstrando que as considerações utilizadas foram as que melhor se ajustavam as situações experimentais e que o método de 

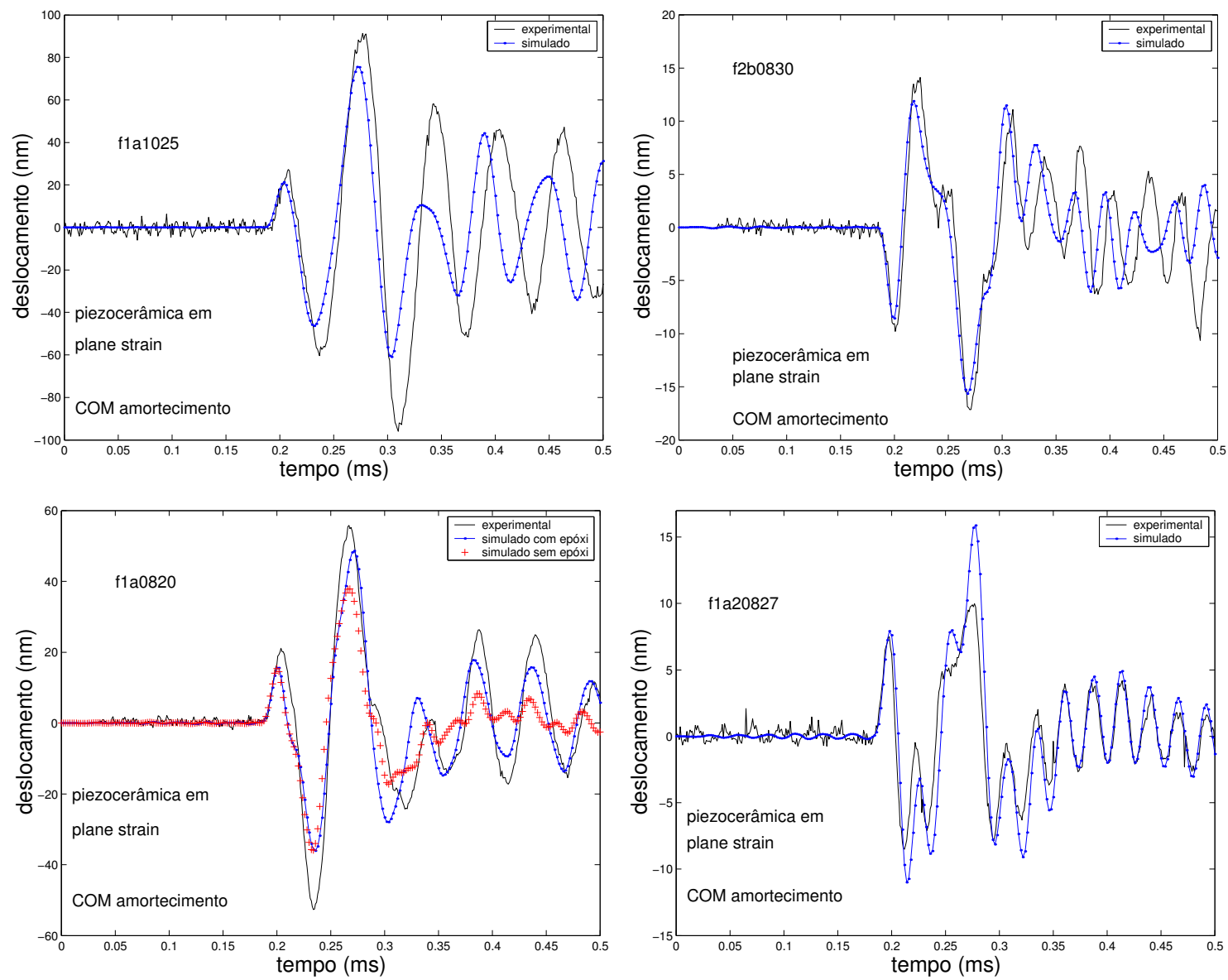

Figura 6.13. Resposta transiente do deslocamento dos piezoatuadores: f1a1025, f2b0830, f1a0820 e f1a20827, que utilizam uma cerâmica de 5 mm de espessura como elemento ativo.

elementos finitos está muito próximo da realidade, e por esse motivo é usado para projetos de estruturas otimizadas. No entanto, a comparação completa desses resultados é realizada no domínio da freqüência, através de transformada de Fourier do sinal transiente.

A Figura 6.14 mostra a transformada de Fourier do sinal de excitação transiente. Esse espectro de freqüências mostra a freqüência central de excitação em $10 \mathrm{kHz}$ e também é composto por freqüências em aproximadamente $25 \mathrm{kHz}, 35 \mathrm{kHz}, 45 \mathrm{kHz}$ e $55 \mathrm{kHz}$.

As respostas no domínio das freqüências dos flextensionais f1a1025, f2b0830, f1a0820 e f1a20827, são mostradas na Figura 6.15. Pelas figuras no domínio das freqüências das respostas dos piezoatuadores flextensionais pode ser observado que os resultados mostram uma boa concordância. Isso sugere que os resultados exper- 


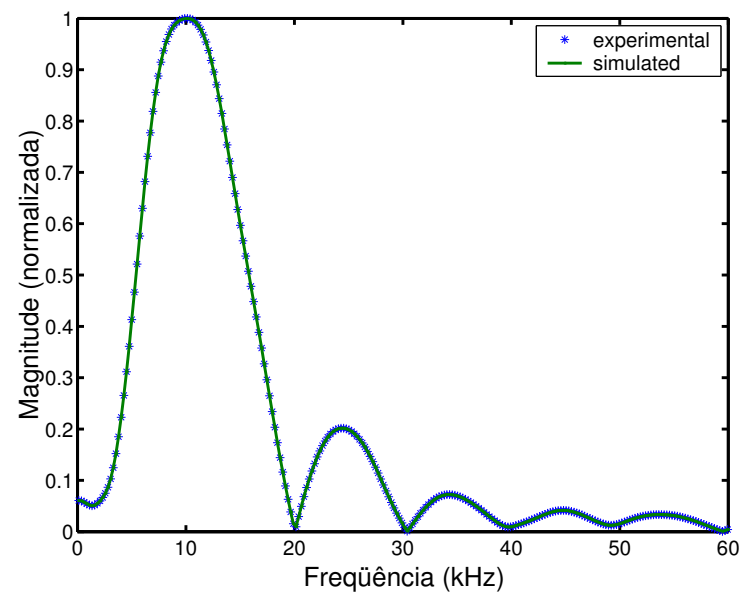

Figura 6.14. Espectro de magnitude do sinal de excitação transiente.

imental e simulados casam muito bem. Pode ser observado ainda que a condição de análise numérica que melhor se ajusta ao fla0820 é quando há consideração da resina epóxi nas simulações.

\section{Análise Harmônica}

Os atuadores flextensionais são projetados para aplicações estáticas ou quasi-estáticas (abaixo da primeira freqüência de ressonância). Por isso, a resposta do deslocamento dos atuadores flextensionais são obtidos excitando o atuador com um sinal senoidal contínuo, no intervalo de freqüência entre $10 \mathrm{kHz}$ e a primeira freqüência de ressonância, como mostra a Figura 6.16. Abaixo de $10 \mathrm{kHz}$ a resposta do decaimento decai lentamente, e em regime estático o deslocamento é menor 30\% para f1a1025 e menor $10 \%$ para o f2b0830 em relação ao deslocamento obtido a $10 \mathrm{kHz}$.

Os resultados experimental e simulado mostrados na Figura 6.16 estão normalizados para um campo elétrico de $1 \mathrm{~V} / \mathrm{mm}$. As taxas de amplificação dos resultados simulados e experimentais estão mostradas na Figura 6.17.

A taxa de amplificação é obtida para cada freqüência pela divisão do deslocamento gerado pelo atuador (no ponto ilustrado na Figura 6.4) e o deslocamento gerado pela piezocerâmica na direção 3 considerando um mesmo campo elétrico aplicado. 

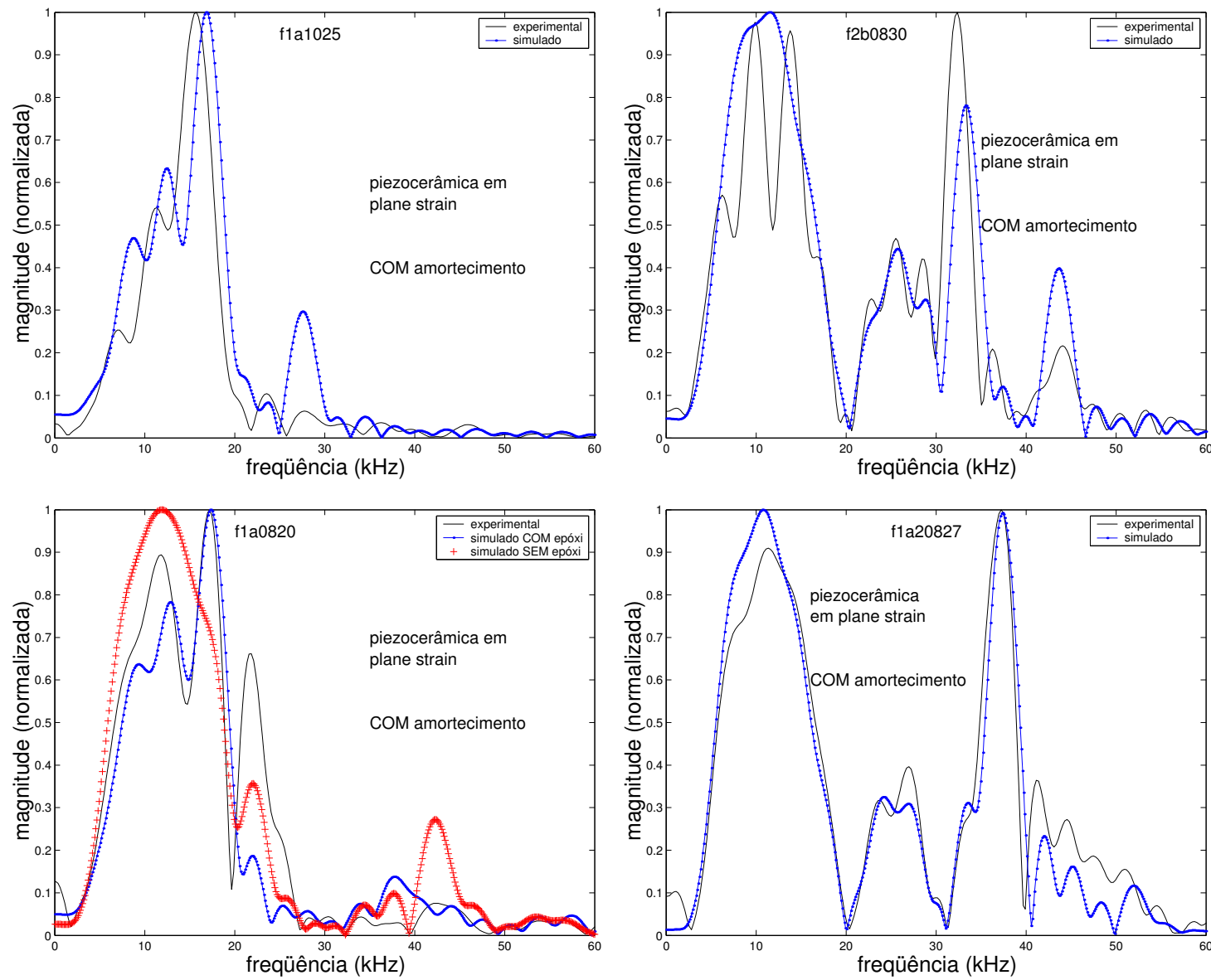

Figura 6.15. Espectro de magnitude do sinal de excitação transiente e das respostas do deslocamento sob essa excitação dos flextensionais f1a1025, f2b0830, f1a0820 e f1a20827.

\section{Análise Estática}

A análise estática experimental dos piezoatuadores e das piezocerâmicas, é realizada alimentando a amostra piezelétrica com um sinal triangular a $1 \mathrm{~Hz}$, enviado por um gerador de funções, e a leitura do deslocamento é realizada com o sensor a fibras ópticas MTI-2000, na configuração ilustrada na Figura 5.14. No ANSYS é realizada a análise estática e o valor obtido é comparado com uma análise transiente, inserindo um sinal triangular de $1 \mathrm{~Hz}$, com 20 pontos. Os resultados obtidos são iguais, pois um sinal de entrada, triangular, de $1 \mathrm{~Hz}$ equivale a uma análise estática. Por esse motivo, os resultados são mostrados sempre em função do sinal triangular.

A Figura 6.18(a) mostra o sinal triangular de excitação, com 100 V de amplitude, e o sinal de resposta, que é aproximadamente linear, nesse exemplo. Os piezoatuadores flextensionais, submetidos a excitações sob campos elétricos superiores a 


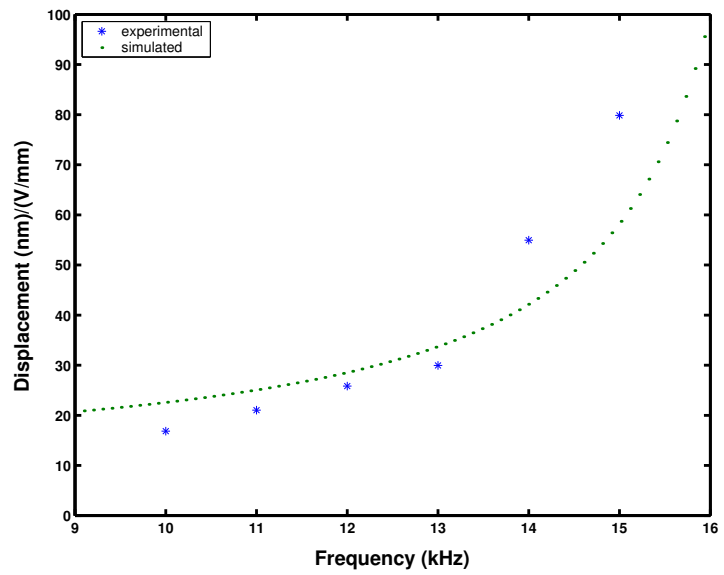

(a)

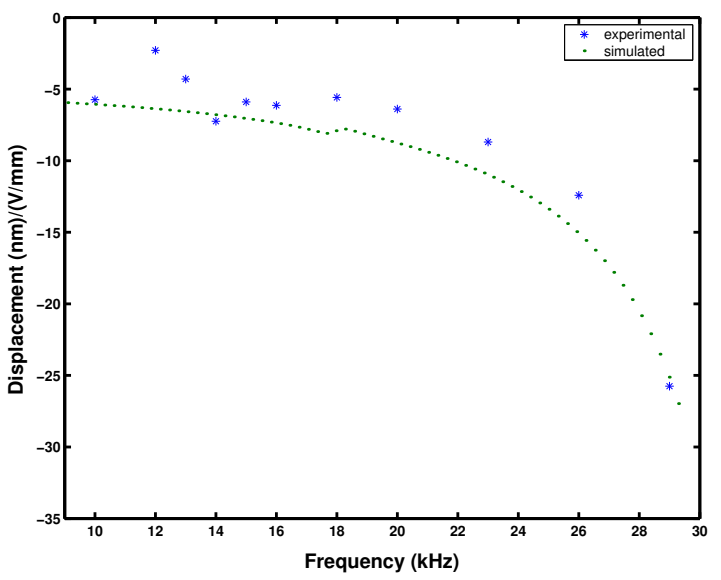

(b)

Figura 6.16. Resposta normalizada do deslocamento em freqüência do (a)f1a1025 e (b)f2b0830.

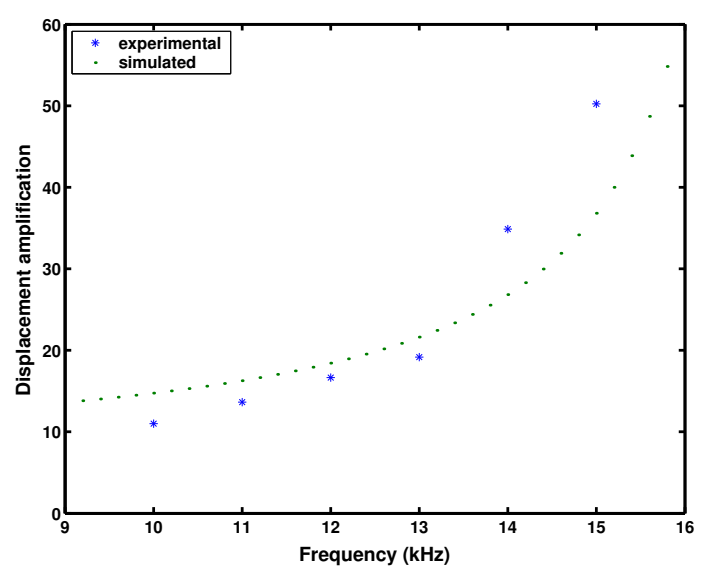

(a)

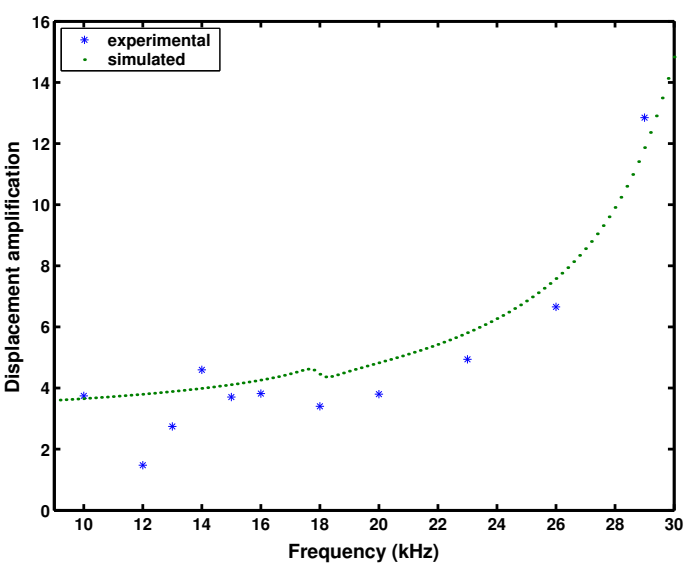

(b)

Figura 6.17. Taxa de amplificação dos deslocamentos (a)f1a1025 e (b)f2b0830.

$100 \mathrm{~V} / \mathrm{mm}$, apresentam uma resposta não-linear, como mostrado na Figura 6.18(b), na qual o flextensional estava submetido a uma tensão elétrica de 1000 V. Através dos resultados ilustrados, pode ser notado que a medição de deslocamentos, utilizando o MTI-2000, na ordem de alguns nanômetros apresentam ruídos [Figura 6.18(a)] devido à resolução mínima do sensor utilizado $(16 \mathrm{~nm})$. Por outro lado, nas medições na ordem de alguns micrômetros praticamente não há ruídos [Figura 6.18(b)].

Nas análises são comparados o deslocamento dos flextensionais na direção 3, com os deslocamentos das piezocerâmicas nas direções 3 e 1 (ver Figura 6.4). Outros autores fazem a comparação entre o deslocamento dos flextensionais e das piezo- 


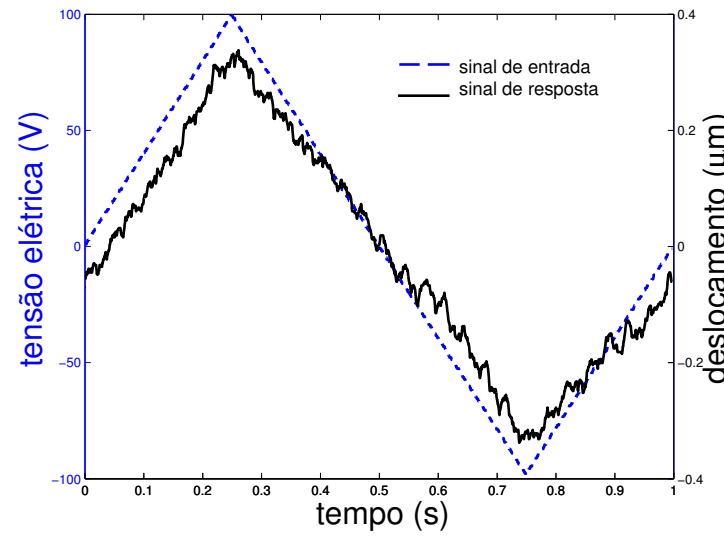

(a)

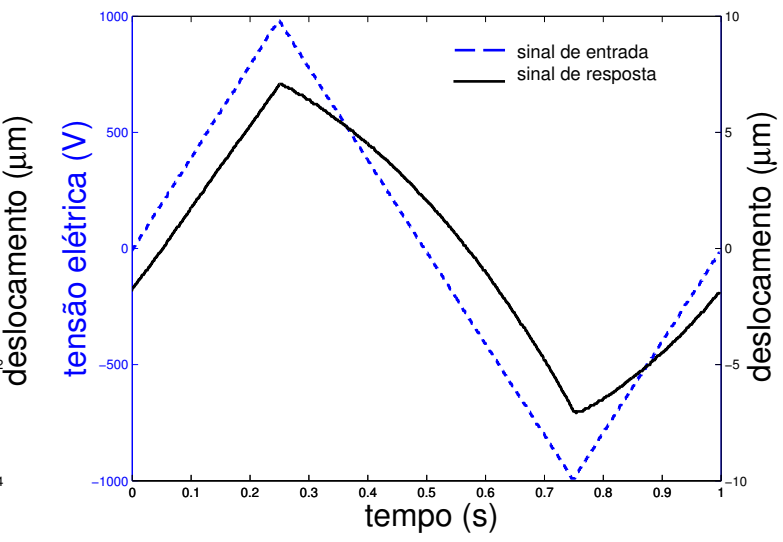

(b)

Figura 6.18. sinais de excitação e resposta dos atuadores flextensionais. (a)intervalo linear; (b) intervalo não-linear.

cerâmicas apenas na direção $3[37,36]$. No entanto, embora haja contribuição do coeficiente piezelétrico $d_{33}$ da piezocerâmica, na amplificação do deslocamento pela estrutura flexível, a maior contribuição é do coeficiente piezelétrico $d_{31}$. Por esse motivos será também verificada a amplificação da estrutura flexível em relação às contribuições $d_{33}$ e $d_{31}$ da piezocerâmica.

A Figura 6.19(a) mostra os resultados do deslocamento por tensão elétrica, obtidos através das análises estáticas, experimental e simulada, do flextensional f1a1025 e da cerâmicas de $5 \mathrm{~mm}$ de espessura. Pode ser observado que o fla1025 amplifica cerca de 9 vezes o deslocamento na em relação ao $d_{33}$ da piezocerâmica e em aproximadamente 3 vezes em relação ao $d_{31}$.

Os resultados da análise estática do flextensional f1b0820 e da piezocerâmica de $3 \mathrm{~mm}$ de espessura são mostrados na Figura 6.19(b). Nestes resultados notase que o deslocamento simulado do flextensional é muito superior ao experimental, provavelmente devido à influência da resina epóxi utilizada na fixação das estrutura metálicas bipartidas. Pode ser observado que o f1b0820 amplifica cerca de 10 vezes o deslocamento em relação ao $d_{33}$ da piezocerâmica e em aproximadamente 2 vezes comparado ao deslocamento longitudinal $d_{31}$ da mesma cerâmica.

A Figura 6.20(a) mostra os resultados experimentais e simulados do flextensional f1c0815 também no intervalo linear, ou seja, para um campo elétrico máximo de $100 \mathrm{~V} / \mathrm{mm}$. A piezocerâmica utilizada na montagem desse atuador possui $1 \mathrm{~mm}$ de espessura. Nesta figura não são mostrados os resultados experimentais do desloca- 


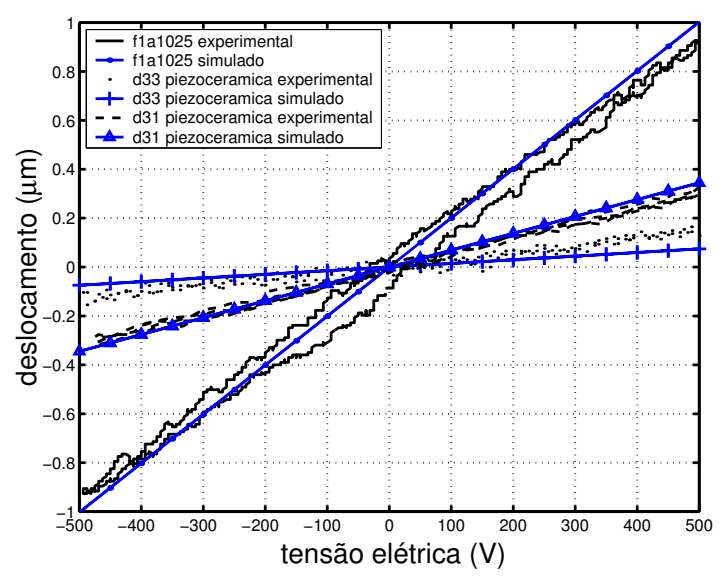

(a)

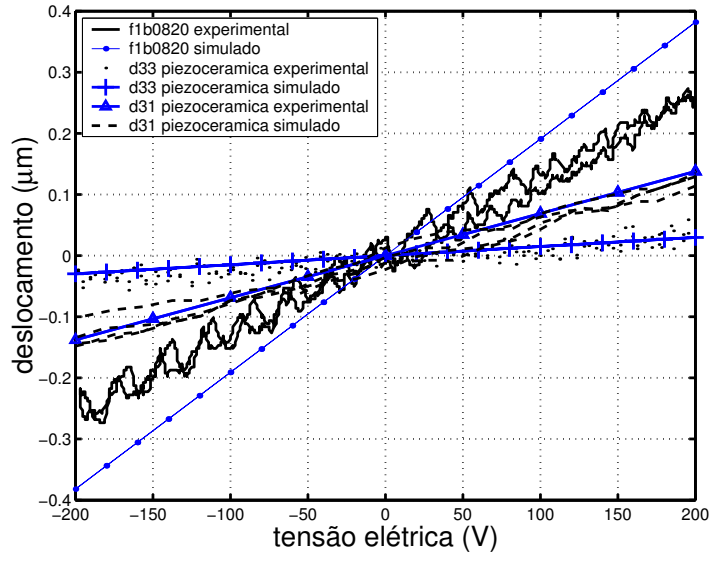

(b)

Figura 6.19. Resultados experimentais e simulados da análise estática do deslocamento dos piezoatuadores flextensionais: (a) f1a1025 e (b) f1b0820.

mento da piezocerâmica na direção 1, devido a dificuldade experimental de analisar uma superfície de $1 \mathrm{~mm}$ de espessura. Nota-se que a amplificação da estrutura flexível em relação ao $d_{33}$ também é de aproximadamente 10 vezes, e há uma pequena amplificação em relação ao deslocamento longitudinal.

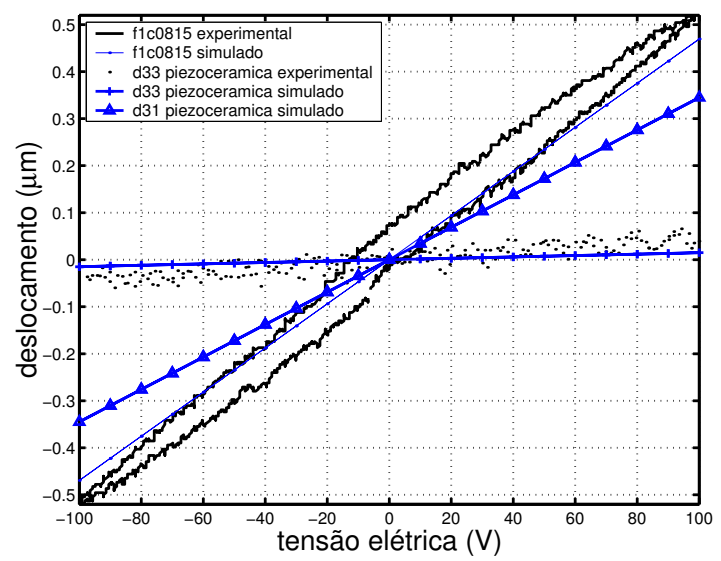

(a)

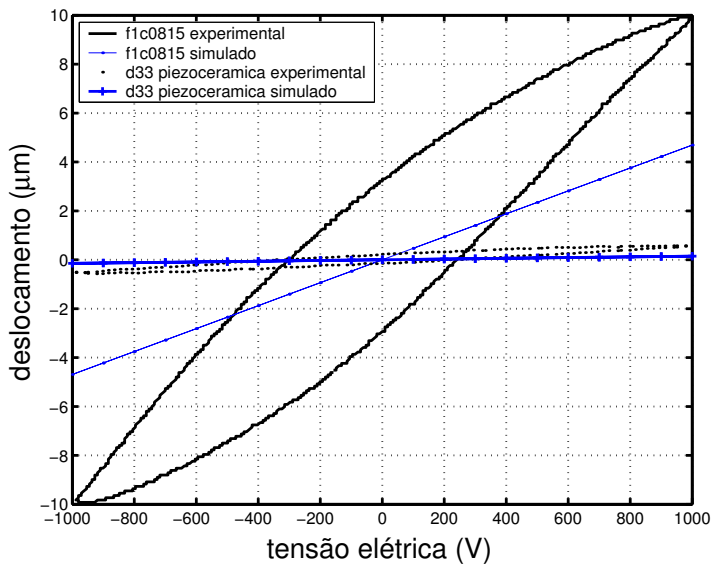

(b)

Figura 6.20. Resultados experimentais e simulados do deslocamento do piezoatuador flextensional f1c0815. (a) intervalo linear e (b) intervalo não-linear mostrando histerese ferrelétrica.

A Figura 6.20(b) mostra o comportamento não linear do flextensional f1c0815 para um campo elétrico de $1 \mathrm{kV} / \mathrm{mm}$. Para um campo elétrico alto como este, a não-linearidade do deslocamento da piezocerâmica ou do piezoatuador flexten- 
sional é bastante acentuada. O ANSYS não pode realizar simulações não-lineares de piezelétricos, por isso os resultados simulados apresentados nessa figura diferem muito dos resultados experimentais.

\subsection{Influência do Espelho no Comportamento das Piezocerâmicas}

As análises dos materiais piezelétricos, pelos métodos ópticos, exige que estes possuam superfície reflexiva. Várias técnicas de espelhamento dos materiais piezelétricos foram experimentadas, tais como fixar grandes e pequenos espelhos, fixar espelhos alumínio com polimento óptico, utilizar fitas de poliéster metalizadas, dar polimento óptico e depositar ouro por sputtering. Os grandes espelhos e os feitos com alumínio foram descartados, pois possuem grande massa em relação às amostras piezelétricas, e alteram as freqüências de ressonâncias das piezocerâmicas e piezoatuadores. As boas soluções são a utilização das fitas de poliéster metalizado e o sputtering, porém, nesses casos há necessidade de utilizar o feixe do laser focalizado na superfície analisada, como já discutido anteriormente. Outra boa opção é a fabricação de pequenos espelhos feitos por vaporização de alumínio na superfície de lamínulas de microscópio. Os resultados das análises ópticas dos piezoatuadores flextensionais apresentaram resultados muito bons, como pode ser observado nesse capítulo. No entanto, as cerâmicas piezelétricas tiveram o comportamento alterado por causa da fixação dos espelhos. Esta seção mostra a influência dos pequenos espelhos.

Na cerâmica de $1 \mathrm{~mm}$ de espessura é realizada a análise estática, utilizando o MTI-2000. Os resultados experimentais do deslocamento da piezocerâmica na direção 3, com e sem o espelho colado em sua superfície, são mostrados na Figura 6.21. Para a análise sem o espelho, a piezocerâmica recebeu um polimento quasi-óptico e em seguida foi depositado ouro por sputtering. O resultado mostra que o espelho produziu uma amplificação de aproximadamente 9 vezes no deslocamento na direção 3 .

A análise transiente também revela a influência do espelho colado à superfície das piezocerâmicas. Simulações realizadas no ANSYS das piezocerâmicas retangulares, com dimensões descritas na Tabela 6.2, sem espelho apresentam o mesmo resultado. 


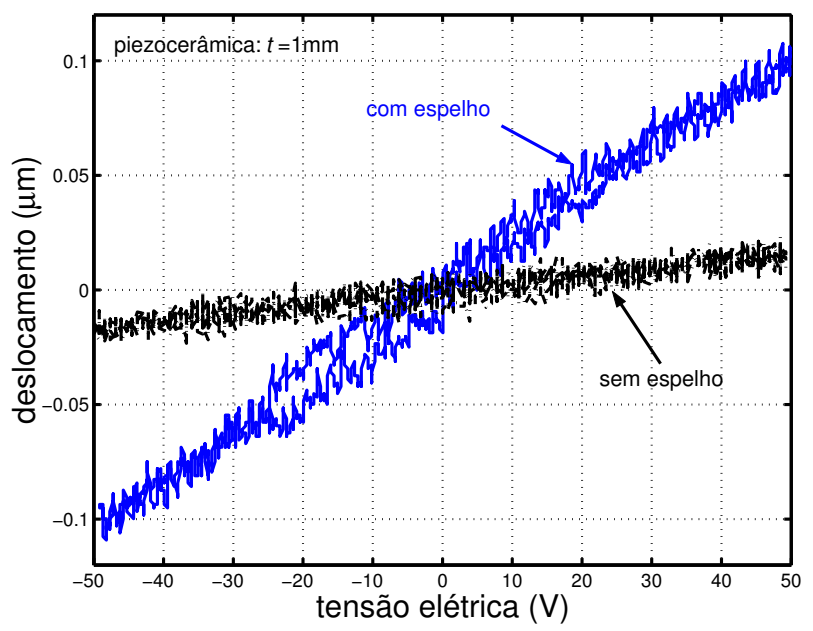

Figura 6.21. Resultados experimentais do deslocamento da cerâmica de $1 \mathrm{~mm}$ de espessura na direção 3, com e sem o espelho.

O sinal de excitação é mostrado na Figura 6.12 e as respostas das piezocerâmicas na Figura 6.22. Os resultados para todas as cerâmicas são idênticos, pois a espessura da cerâmica não influência no deslocamento da direção 3, como pode ser mostrado através de expressões analíticas simples [81].

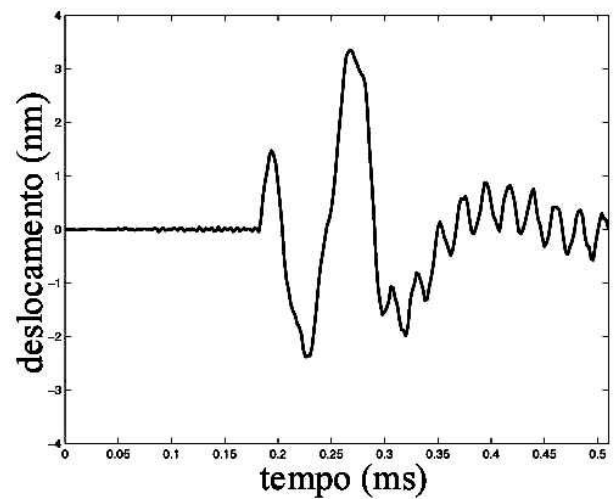

Figura 6.22. Resposta transiente das cerâmicas de $1 \mathrm{~mm}, 3 \mathrm{~mm}$ e $5 \mathrm{~mm}$ de espessura. Para todas essas, a resposta transiente simulada é idêntica.

Nas análises ópticas, as piezocerâmicas são fixadas através de três parafusos, como mostrado na Figura 6.11. Essa fixação deixa as piezocerâmicas praticamente livres para curvarem-se no centro e produzirem a amplificação do deslocamento, quando há em sua superfície pequenos espelhos de vidro. Por esse motivo, as análises numéricas do deslocamento precisam deixar o centro da cerâmica livre, e dessa forma não é possível aplicar a restrição de deslocamento similar a dos flex- 
tensionais, ilustrada na Figura 6.8. Inicialmente, a condição de contorno utilizada nas simulações foi modelar as cerâmicas sem restrição a deslocamento na direção 3. As dimensões dos espelhos e da resina epóxi usadas nas simulações estão ilustradas na Tabela 6.4. A resina epóxi tem o mesmo comprimento do espelho. Os valores da tabela são aproximadamente iguais aos experimentais.

Tabela 6.4. Dimensões dos espelhos e resina epóxi usadas nas simulações.

\begin{tabular}{cccc}
\hline \hline $\begin{array}{c}\text { espessura da } \\
\text { cerâmica }\end{array}$ & $\begin{array}{c}\text { comprimento do } \\
\text { espelho }(\mathbf{L})\end{array}$ & $\begin{array}{c}\text { espessura do } \\
\text { espelho }(\mathbf{T})\end{array}$ & $\begin{array}{c}\text { espessura da } \\
\text { resina epóxi (t) }\end{array}$ \\
\hline \hline $1 \mathrm{~mm}$ & $10 \mathrm{~mm}$ & $0,2 \mathrm{~mm}$ & $0,1 \mathrm{~mm}$ \\
$3 \mathrm{~mm}$ & $4 \mathrm{~mm}$ & $0,2 \mathrm{~mm}$ & $0,1 \mathrm{~mm}$ \\
$5 \mathrm{~mm}$ & $2 \mathrm{~mm}$ & $0,2 \mathrm{~mm}$ & $0,1 \mathrm{~mm}$ \\
\hline \hline
\end{tabular}

Os resultados obtidos nas análises transiente, para o mesmo sinal de excitação, centrado em 10 kHz (Figura 6.12), são mostrados na Figura 6.23(a) para a piezocerâmicas de $5 \mathrm{~mm}$ de espessura, na Figura 6.23(b) para a piezocerâmica de $3 \mathrm{~mm}$ de espessura e na Figura 6.23(c) para a piezocerâmica de $1 \mathrm{~mm}$ de espessura.

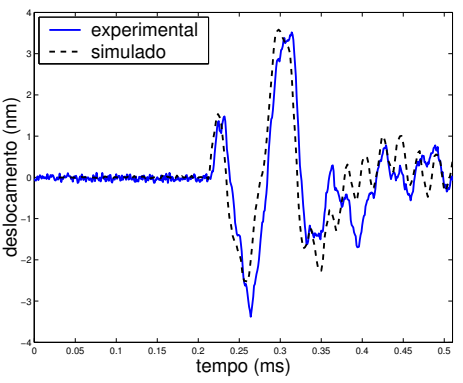

(a)

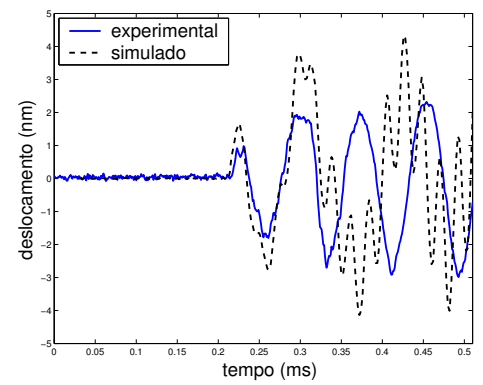

(b)

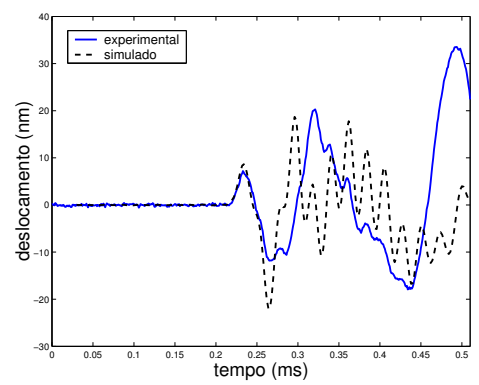

(c)

Figura 6.23. Resposta do deslocamento com as cerâmicas sob excitação transiente. A espessura das cerâmicas é:(a) $5 \mathrm{~mm}$; (b) $3 \mathrm{~mm}$ e (c) $1 \mathrm{~mm}$.

Para a cerâmica de $5 \mathrm{~mm}$ de espessura pode ser observado que os sinais, experimental e simulado, da resposta no tempo são muito similares, pois nessa, devido a grande massa de cerâmica em relação a do espelho, há pouca influência deste. No entanto, os resultados simulados obtidos para as piezocerâmicas de $3 \mathrm{~mm}$ e $1 \mathrm{~mm}$ de espessura apresentam uma concordância na amplitude do deslocamento, mas as simulações demostram haver uma resposta de alta freqüência, e os resultados ex- 
perimentais demonstram que há pouca resposta em alta freqüência. A análise no domínio das freqüências, ilustrada na Figura 6.24, mostra claramente que nos resultados simulados há uma freqüência de ressonância próxima a $46 \mathrm{kHz}$, enquanto que, nos resultados experimentais essa freqüência de ressonância é atenuada.

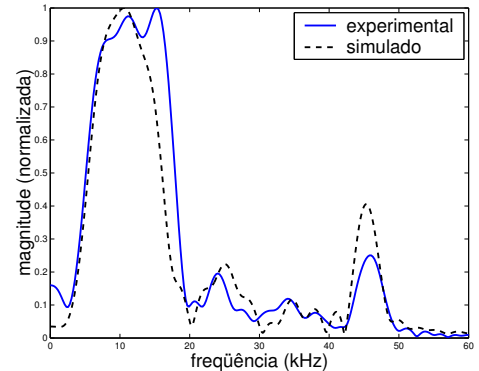

(a)

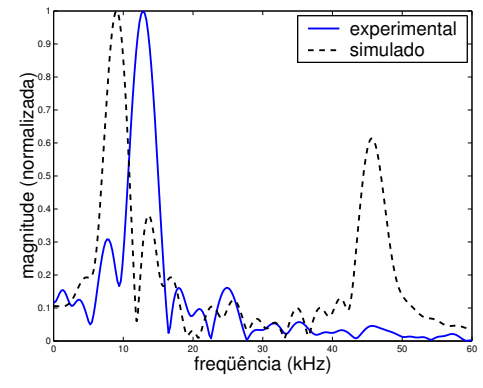

(b)

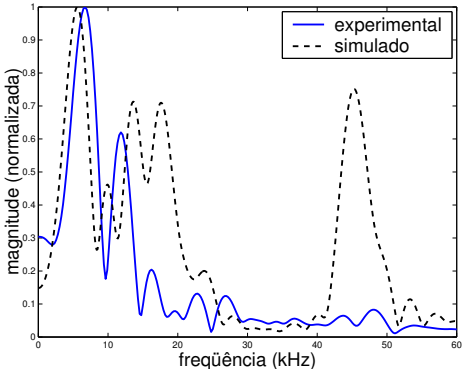

(c)

Figura 6.24. Análise no domínio das freqüências das respostas das piezocerâmicas de espessura:(a) $5 \mathrm{~mm}$; (b) $3 \mathrm{~mm}$ e (c) $1 \mathrm{~mm}$.

O surgimento da freqüência de resposta na análise simulada em aproximadamente $46 \mathrm{kHz}$ nas cerâmicas de $1 \mathrm{~mm}$ e $3 \mathrm{~mm}$ de espessura está relacionada com as condições de contorno e cargas mecânicas aplicadas às cerâmicas. A conclusão que chega-se sobre a condição de contorno é que as cerâmicas não podem ser simuladas como se estivessem rigidamente fixadas. Por outro lado, também não podem ficar sem restrição a deslocamento na direção 3 e 1. Dessa forma, a solução encontrada na modelagem no ANSYS, é fixar a piezocerâmica por três pontos, como na condição experimental. No entanto, os três parafusos que a prendem comportam-se como uma mola, pois o engaste não é suficientemente rígido, permitindo que cada parafuso tenha movimentos com fase aleatória em relação aos outros parafusos.

A utilização do elemento LINK1 no ANSYS, permite a modelagem da cerâmica piezelétrica com a condição de contorno próxima à experimental. Esse elemento é unidimensional e pode ser utilizado como mola ou treliça. A Figura 6.25 mostra a cerâmica de $1 \mathrm{~mm}$ de espessura modelada com elemento LINK1, criado entre um nó na piezocerâmica e um nó fora, o qual está indicado na Figura 6.25. A distância entre os elementos LINK1 equivale à distância dos parafusos nas condições experimentais.

Os parâmetros e condições de utilização do elemento LINK1 é descrita em [21]. Este elemento, apesar de ser unidimensional, simula a área de contanto entre ele e o outro elemento, no qual faz contato. O parafuso utilizado na fixação exper- 


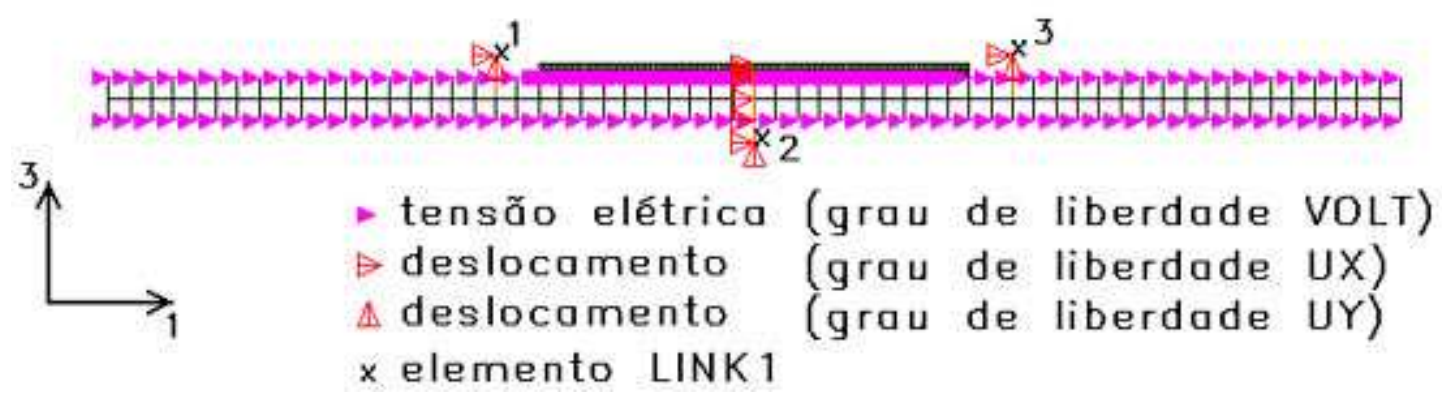

Figura 6.25. Condição de contorno para simular cerâmicas piezelétricas engastadas por três pontos. O elemento usando no engaste é o LINK1.

imental, possui uma área de contato de $7,0686 \mathrm{~mm}^{2}$. No entanto, o modelo no ANSYS é bidimensional o que dificulta a utilização dessa área de contato para todos os três parafusos, pois um dos parafusos fica do lado oposto da cerâmica, como mostrado na Figura 6.36. Dessa forma, a melhor relação entre as áreas de contato, utilizadas no modelo bidimensional é: 7,0686 $\mathrm{mm}^{2}$, no ponto 1 indicado na Figura $6.25 ; 1,7671 \mathrm{~mm}^{2}$, no ponto 2 , que é relativo ao parafuso que prende a piezocerâmica no centro e está no lado oposto ao dos dois parafusos; e $0,7854 \mathrm{~mm}^{2}$ no ponto 3. A diferença entre as áreas de contato do ponto 1 e 3 deve-se, provavelmente, a um dos parafusos estar mais apertado que o outro. A rigidez utilizada é a do alumínio.

Os resultados da análise transiente, da cerâmica de $1 \mathrm{~mm}$ de espessura, modelada como ilustrado na Figura 6.25, apresenta a resposta no tempo ilustrada na Figura 6.26(a) e a resposta no domínio das freqüências ilustrada na Figura 6.26(b).

A análise elétrica da resposta em frequência da admitância elétrica e da fase, na cerâmica de $1 \mathrm{~mm}$ de espessura com espelho fixado na superfície, no intervalo entre $10 \mathrm{kHz}$ e $40 \mathrm{kHz}$, mostra o surgimento de frequências de ressonância próximo a $17 \mathrm{kHz}, 23 \mathrm{kHz}$ e $27 \mathrm{kHz}$. A Figura 6.27(a), mostra os resultados experimentais da admitância elétrica e fase, obtidos nessas análises. A Figura 6.27(b), mostra os resultados das simulações no ANSYS. devidas à massa do espelho e da resina epóxi usada na fixação da superfície refletora. Uma análise na Figura 6.27 mostra que há coincidência dos resultados experimentais e simulados das freqüências de ressonância próximos a $17 \mathrm{kHz}, 23 \mathrm{kHz}$. Os valores experimentais da admitância elétrica são duas vezes maiores que os valores numéricos. Isso provavelmente ocorreu devido às dificuldades de utilizar as condições de contorno corretas. 


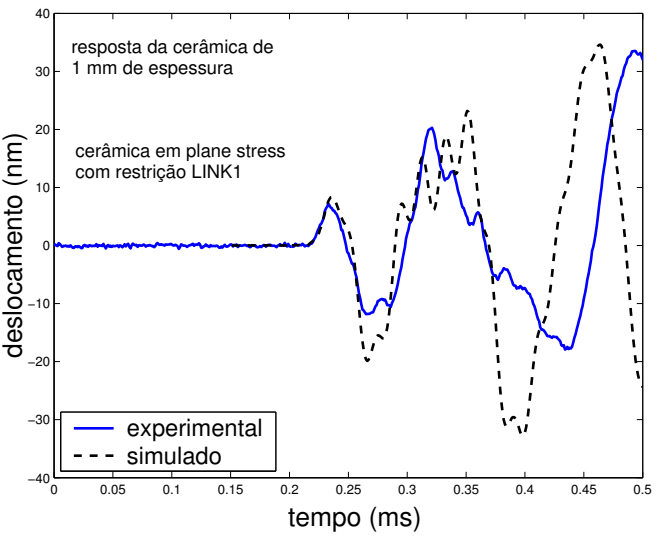

(a)

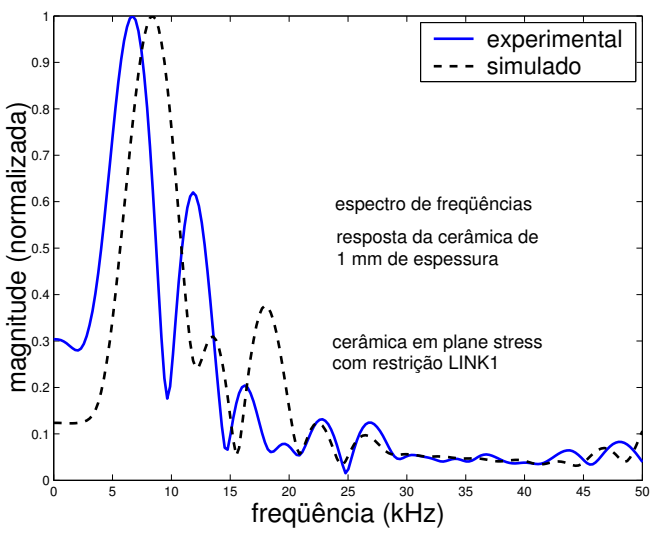

(b)

Figura 6.26. resultados da análise transiente da cerâmica de $1 \mathrm{~mm}$ de espessura, com espelho e com elemento LINK1. (a) resposta da análise transiente no domínio do tempo e (b) resposta no domínio das freqüências.

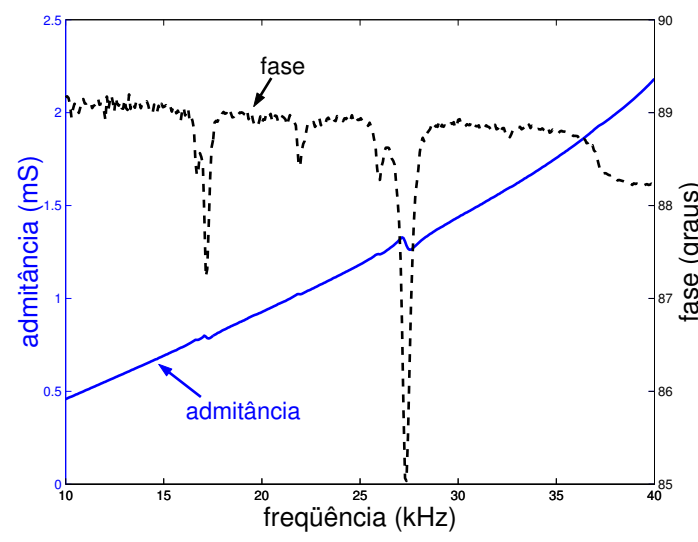

(a)

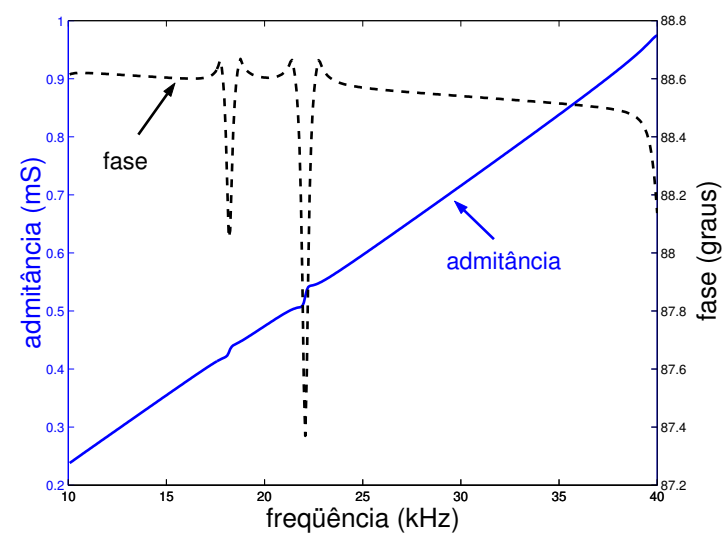

(b)

Figura 6.27. análise elétrica da cerâmica de $1 \mathrm{~mm}$ de espessura com espelho fixado em sua superfície. (a) resultados experimentais da admitância elétrica e fase e (b) resultados numéricos.

O resultado obtido para a curva da fase, através do ANSYS, apresenta a fase variando de $180^{\circ}$ até $-180^{\circ}$, enquanto nos resultados experimentais, a fase varia entre $90^{\circ}$ e zero. No caso dessa curva de fase, é usado um fator de correção de "2,03", apenas para manter o patamar superior, das curvas experimental e simulada, próximo.

O efeito que surge nessas cerâmicas, principalmente na de $1 \mathrm{~mm}$ de espessura, é similar ao de um atuador unilaminar, como pode ser observado pela Figura 6.28, na 
qual são comparados para os resultados das deformações em uma mesma freqüência. Nas duas situações ilustradas, a cerâmica piezelétrica está sob as condições de contorno ilustradas na Figura 6.25. Na Figura 6.28(a), não há o espelho e a resina epóxi, as deformações são apenas longitudinais para as freqüências ilustradas. Na Figura 6.28(b), há o espelho e a resina epóxi, as freqüências ilustradas foram obtidas por análise modal indicando ressonância. A piezocerâmica sofre curvaturas devido à rigidez do espelho.

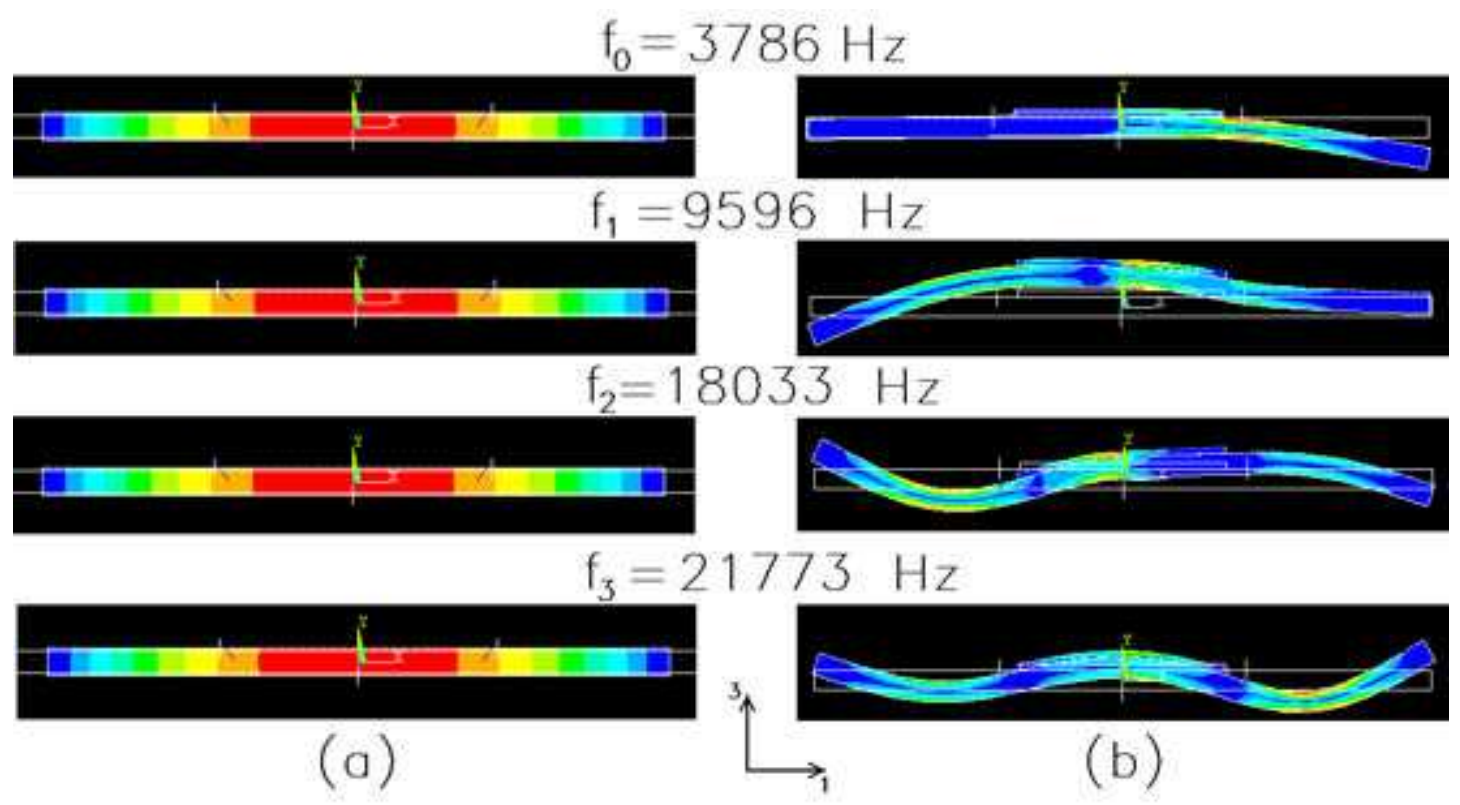

Figura 6.28. Deformação da cerâmica de $1 \mathrm{~mm}$ de espessura para um mesmo valor de campo elétrico e engastadas pelo elemento LINK1. (a) sem espelho e (b) com espelho colado.

A curvatura da piezocerâmica é independente da freqüência, como mostra o resultado obtido através da análise estática, ilustrado na Figura 6.29

Por causa desse comportamento, decidiu-se por projetar um engaste mecânico e fixar um espelho na superfície da piezocerâmica retangular, tal que esta possuísse um comportamento similar ao de um atuador unilaminar, com as condições de contorno previamente estabelecidas. Com este tipo-unilaminar, são obtidas as freqüências de ressonância e a resposta no domínio das freqüências. 


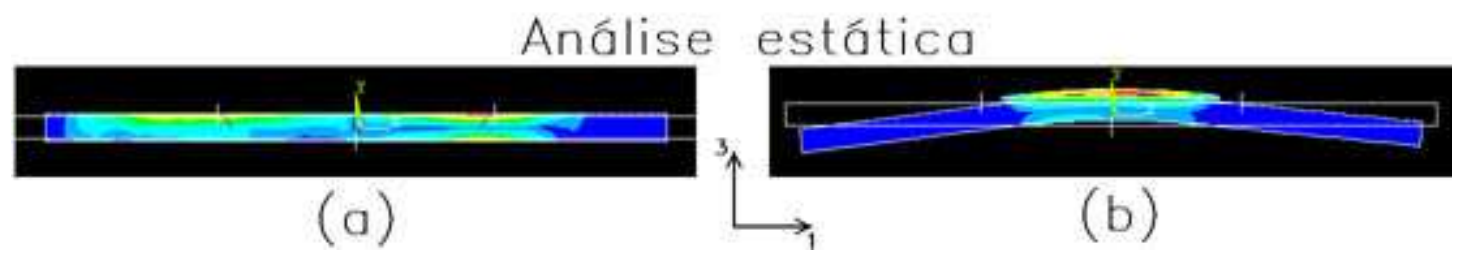

Figura 6.29. Resultado da deformação da cerâmica de $1 \mathrm{~mm}$ de espessura em análise estática, para um mesmo valor de campo elétrico e engastadas pelo elemento LINK1. (a) sem espelho e (b) com espelho colado.

\section{Análise da piezocerâmica sob condições de contorno controladas}

A piezocerâmica retangular, de $1 \mathrm{~mm}$ de espessura, é montada sobre uma estrutura em alumínio, como ilustrado na Figura 6.30, dessa forma tem um comportamento similar ao de um atuador unilaminar. Algumas dimensões são ilustradas nessa mesma figura.
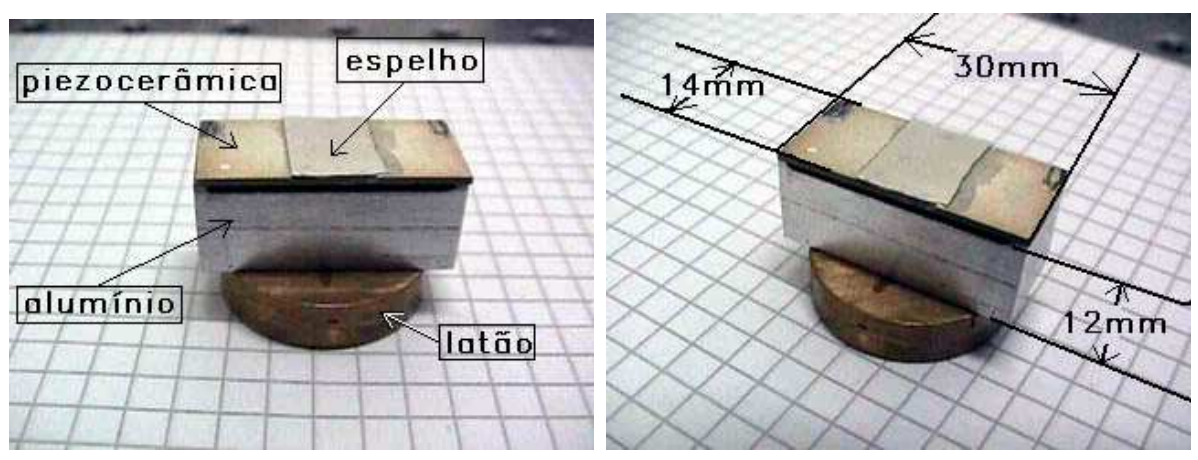

Figura 6.30. Foto da piezocerâmica com espelho engastada a uma estrutura em alumínio.

No ANSYS, o modelo é realizado com metade da simetria em duas-dimensões, assumindo o estado plano de tensões mecânicas. A Figura 6.31 mostra o modelo completo, ilustrando as dimensões de cada material. O espelho fixado sobre a piezocerâmica possui as seguintes dimensões: $l=100 \mathrm{~mm}, t=0,2 \mathrm{~mm}$ e a largura idêntica a da piezocerâmica $(w=13,95 \mathrm{~mm})$. A piezocerâmica pode oscilar livremente na direção 3, com curvatura máxima no centro (Figura 6.31).

A análise modal desta piezocerâmica mostra que a primeira freqüência de ressonância está em 3748 Hz, e o modo de vibração é ilustrado na Figura 6.32(a). Os modos de vibração da segunda e terceira freqüências de ressonância, assim como os 


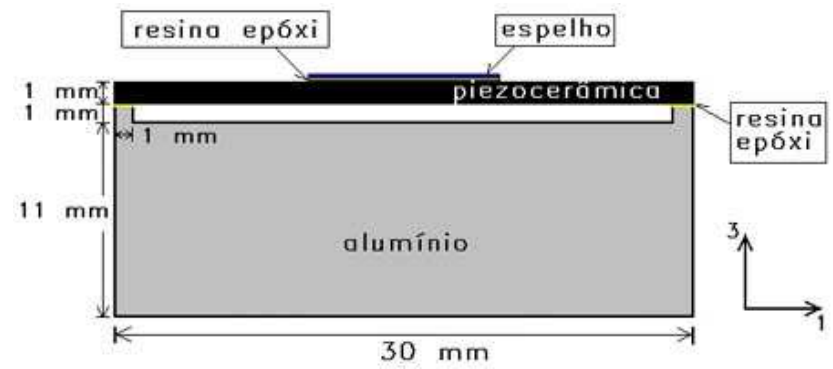

Figura 6.31. Modelo completo da piezocerâmica com espelho, montada sobre uma base de alumínio com.

valores destas, obtidos pela análise modal, são mostrados nas Figuras 6.32(b) e (c).

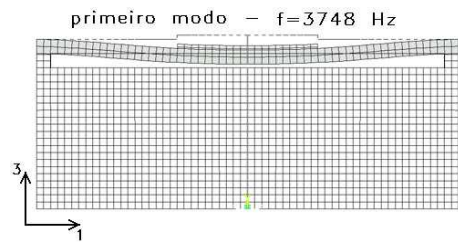

(a)

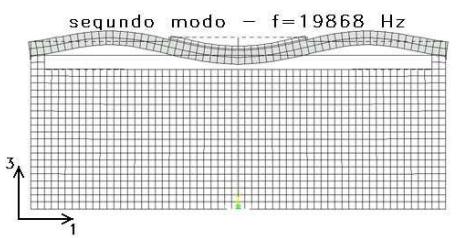

(b)

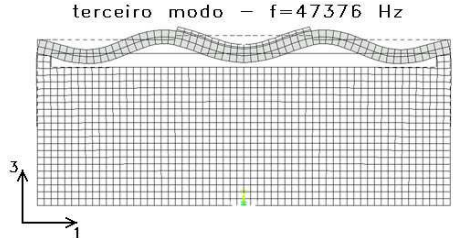

(c)

Figura 6.32. Análise modal da piezocerâmica: (a) primeira freqüência de ressonância, (b) segunda freqüência de ressonância e (c) terceira freqüência de ressonância.

Análises elétricas são realizadas para verificar se as freqüências de ressonância experimental e simuladas concordam com as obtidas pela análise modal. A Figura 6.33(a) mostra os resultados experimentais e simulados da resposta em freqüência da admitância elétrica, e a Figura 6.33(b) mostra a resposta da fase elétrica. Os resultados experimentais e simulados mostram uma boa concordância nos valores das freqüências de ressonância, e também são próximo as valores obtidos pela análise modal. No entanto, a admitância elétrica obtida através da análise numérica, tem um valor $50 \%$ menor que o obtido experimentalmente. Essa diferença no valor da admitância elétrica deve estar relacionada com a dificuldade em modelar perfeitamente um transdutor piezelétrico composto, como no caso desse unilaminar. Também é verificado na Figura 6.27 a diferença entre os valores experimentais e simulados da admitância elétrica.

Assim foi realizada uma correção por um fator 2,03 na curva de fase da Figura 6.27(b), também é utilizado esse recurso na Figura 6.33(b). 


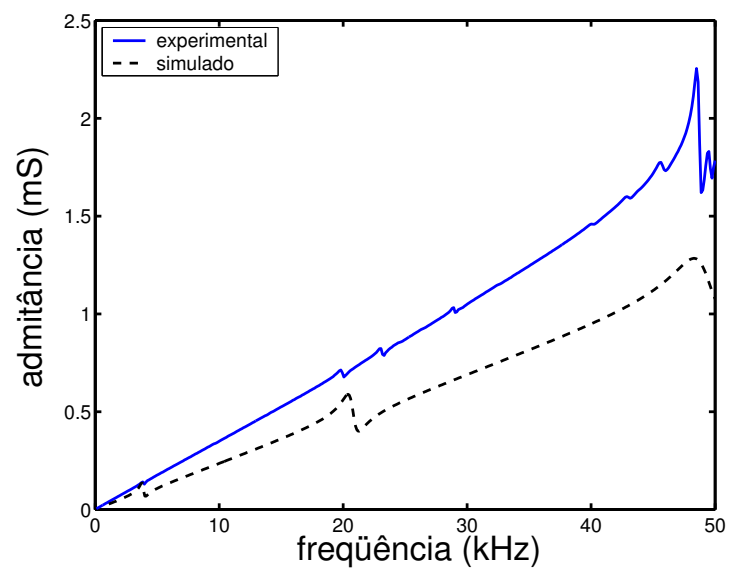

(a)

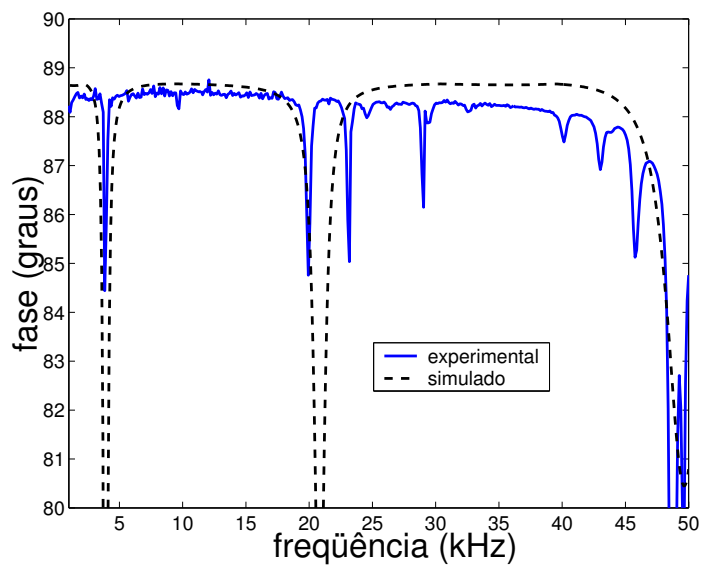

(b)

Figura 6.33. (a) Resposta em freqüência da admitância elétrica. (b) Resposta da fase.

Além da análise da admitância elétrica, para verificar as freqüências de ressonância dessa piezocerâmica, também é realizada uma análise transiente, com o sinal de excitação ilustrado na Figura 6.34(a). Essa análise tem apenas o intuito de verificar a resposta no domínio das freqüências desse dispositivo. A Figura 6.34(b) mostra a resposta do sinal de excitação no domínio das freqüências e a Figura 6.34(c) mostra a resposta da piezocêmica no domínio das freqüências, com uma boa concordância entre as resposta experimental e simulada, ambas com a freqüência de ressonância próxima a $4 \mathrm{kHz}$, como mostraram as análises modal e elétrica, ilustradas nas Figuras 6.32 e 6.33

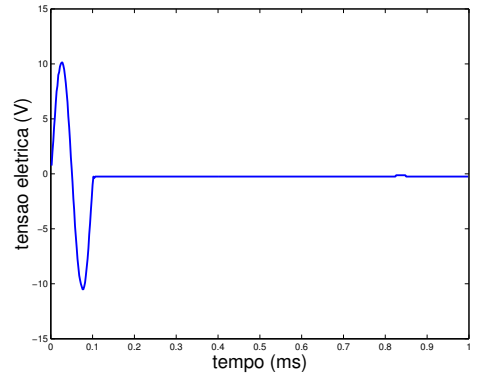

(a)

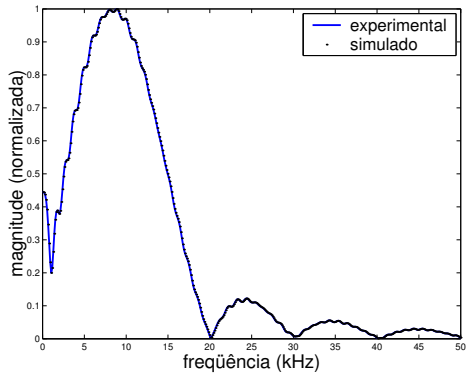

(b)

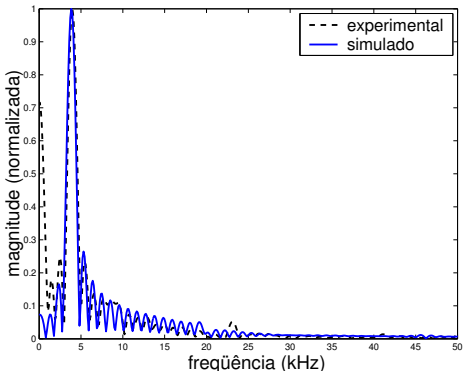

(c)

Figura 6.34. (a) Sinal senoidal de excitação transiente centrado em 10 kHz. (b) Espectro de freqüência do sinal de excitação. (c) Resposta da piezocerâmica ao sinal transiente. 


\subsection{Atuadores Piezelétricos Aplicados à Interfer- ometria}

A estabilização eletro-mecânica de interferômetros é realizada com atuadores piezelétricos [1, 3, 92] fixados ao espelho de referência. Para essa função é necessário um atuador com grande deslocamento (dezenas de nanômetros) a baixas voltagens (de milivolts a uma dezena de volts). Os atuadores caracterizados para essa função são um cantilever bilaminar e o flextensional f1c0815, analisado na seção 6.2.

\subsubsection{Bilaminar}

O bilaminar caracterizado é ilustrado na Figura 6.35. Cada camada piezelétrica e a placa de metal têm $200 \mu \mathrm{m}$ de espessura. As outras dimensões estão ilustradas na Figura 6.35. Para o uso com atuador piezelétrico em um interferômetro, é necessário um bom espelho na superfície do atuador. Por isso, foi colado à superfície do bilaminar um espelho de quartzo polido opticamente, com alumínio depositado em sua superfície por vaporização Figura 6.35. A fixação do espelho foi realizada com resina epóxi. O espelho possui $1 \mathrm{~mm}$ de espessura e $5 \mathrm{~mm}$ de diâmetro.

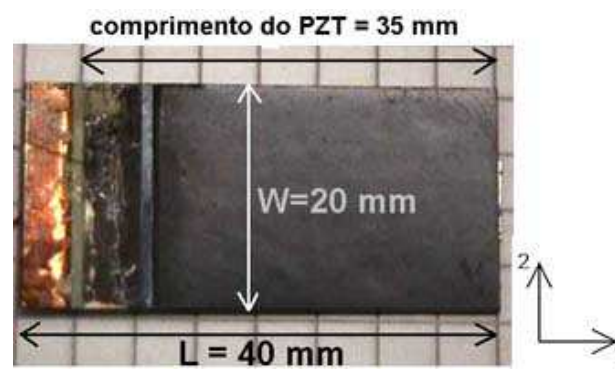

(a)

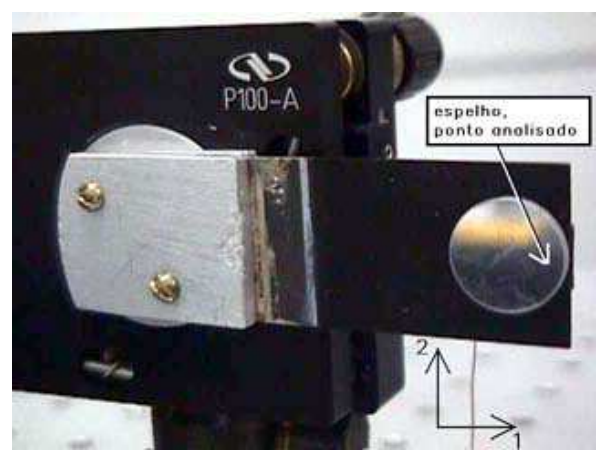

(b)

Figura 6.35. Atuador bilaminar: (a) foto com as escalas; (b) com o espelho e montado como uma viga em balanço.

As análises do bilaminar são realizadas por técnicas ópticas, interferométricas e não-interferométricas, e também pelo método de elementos finitos, para efeito de comparação dos resultados experimental/simulados [5].

Na condições experimentais de análise o cantiléver bilaminar está engastado com 
praticamente $40 \mathrm{~mm}$ livres e também na condição de $20 \mathrm{~mm}$ livres, como mostra em esquema a Figura 6.36.

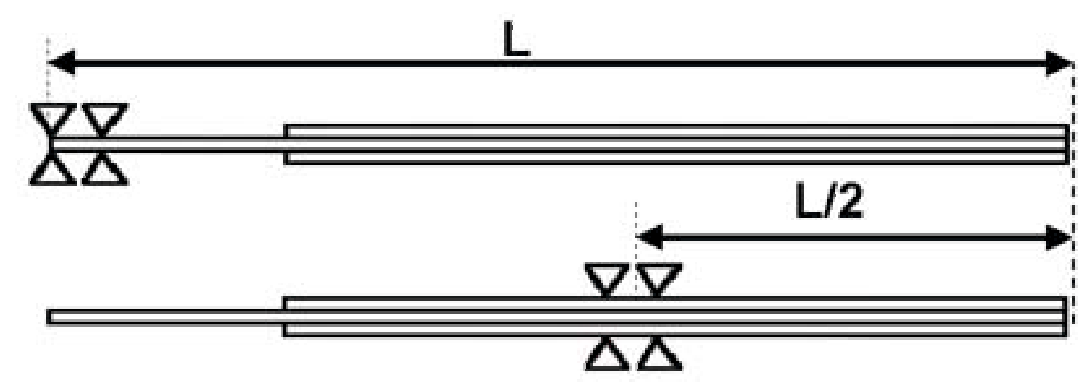

Figura 6.36. Cantiléver bilaminar engastado com $40 \mathrm{~mm}$ livres e com $20 \mathrm{~mm}$ livres.

$\mathrm{Na}$ condição do cantiléver com $40 \mathrm{~mm}$ livres, as análises experimentais por sistemas ópticos são realizadas com o interferômetro tipo-Michelson ilustrado na Figura 5.8, e o aparelho comercial MTI-2000 Fotonic Sensor ${ }^{T M}$ (Figura 5.14). O primeiro realizou as medições, pelo princípio do deslocamento de fase no intervalo entre $80 \mathrm{~Hz}$ e $1200 \mathrm{~Hz}$. O segundo realizou as medições pela variação de intensidade do feixe de luz refletido na superfície analisada, no intervalo entre $10 \mathrm{~Hz}$ e $1200 \mathrm{~Hz}$. As excitações foram com sinais harmônicos, no intervalo de freqüências mencionado.

Na condição do cantiléver com 20 mm livres as análises experimentais são realizadas com o interferômetro tipo-Michelson no intervalo de freqüências entre $10 \mathrm{~Hz}$ e $360 \mathrm{~Hz}$.

\section{Análises}

O piezoatuador cantiléver bilaminar é modelado usando o MEF pelo ANSYS. Os modelos bidimensionais são feitos baseados no estado plano de deformações mecânicas para o bilaminar, devido as suas formas retangulares, nas quais a espessura do piezoatuador é muito menor que sua largura. O espelho é modelado considerando o estado plano de tensões mecânicas.

Esses modelos são feitos considerando os eletrodos em ambas superfícies das camadas piezelétricas, e perpendiculares à direção de polarização. Na camada metálica é ligado o terra. Nas simulações, foram utilizados como material piezelétrico o PZT5A e como metal o latão, as propriedades usadas no ANSYS são mostradas nas 
Tabelas 6.1 e 6.3 , respectivamente.

As Figuras 6.37(a) e (b) mostram, respectivamente, o primeiro e segundo modos de vibração do cantilever com $40 \mathrm{~mm}$ livres. As freqüências obtidas pela análise modal são 57,18 Hz e 944,72 Hz. Os resultados experimentais obtidos pelas análises ópticas mostram freqüências de ressonância em aproximadamente 72 Hz e 1019 Hz e pelo analisador de impedâncias foi obtida apenas a do segundo modo, em $950 \mathrm{~Hz}$.

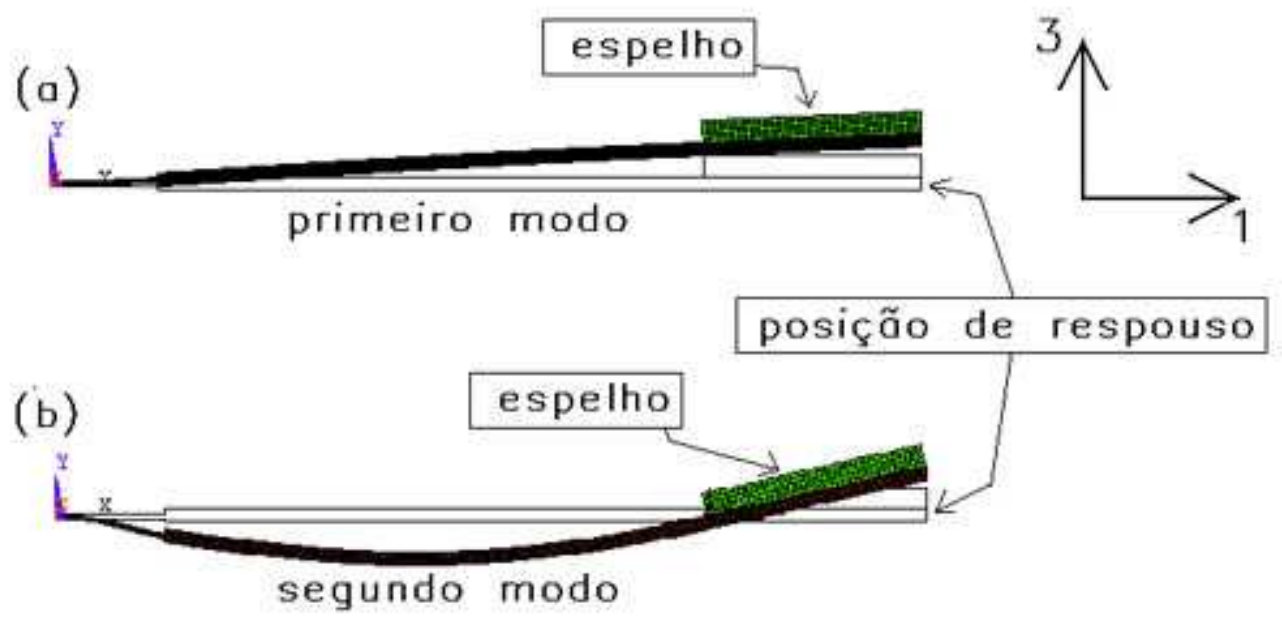

Figura 6.37. Atuador bilaminar simulado no ANSYS (a) 2D ilustrando o primeiro modo; (b) o segundo modo de vibração.

O piezoatuador cantiléver bilaminar possui um grande deslocamento próximo à primeira e a segunda freqüências de ressonância, como mostram os resultados experimentais e simulado ilustrados na Figura 6.38, a qual está normalizada para deslocamento por $1 \mathrm{~V}$ aplicado. Esses resultados foram obtidos numa faixa de freqüência entre $10 \mathrm{~Hz}$ e $1200 \mathrm{~Hz}$. Esses grandes deslocamentos na primeira e segunda freqüências de ressonância, são ilustrados quantitativamente na Figura 6.38 e de forma demonstrativa nas Figuras 6.37(a) e (b). Ao utilizar o bilaminar engastado com 40 mm livres, na primeira freqüência de ressonância, a amplitude do deslocamento pode atingir $50 \mu \mathrm{m} / \mathrm{V}$, ou, aplicando $20 \mathrm{~V}$ ele terá uma amplitude de deslocamento de $1 \mathrm{~mm}$. No entanto, para o propósito de utilizá-lo no controle de vibração do sistema interferométrico, o piezoatuador bilaminar deve operar abaixo da freqüência natural de vibração da viga, ou seja, abaixo de $60 \mathrm{~Hz}$. As freqüências dos ruídos ambientes estão em aproximadamente $1 \mathrm{~Hz}, 5 \mathrm{~Hz}, 10 \mathrm{~Hz}$ e $250 \mathrm{~Hz}$, o que inviabiliza o uso desse atuador, nessa condição, para estabilizar o interferômetro a 
laser. Por esse motivo, foi realizada uma análise do cantiléver com 20 mm e 14 mm livres.

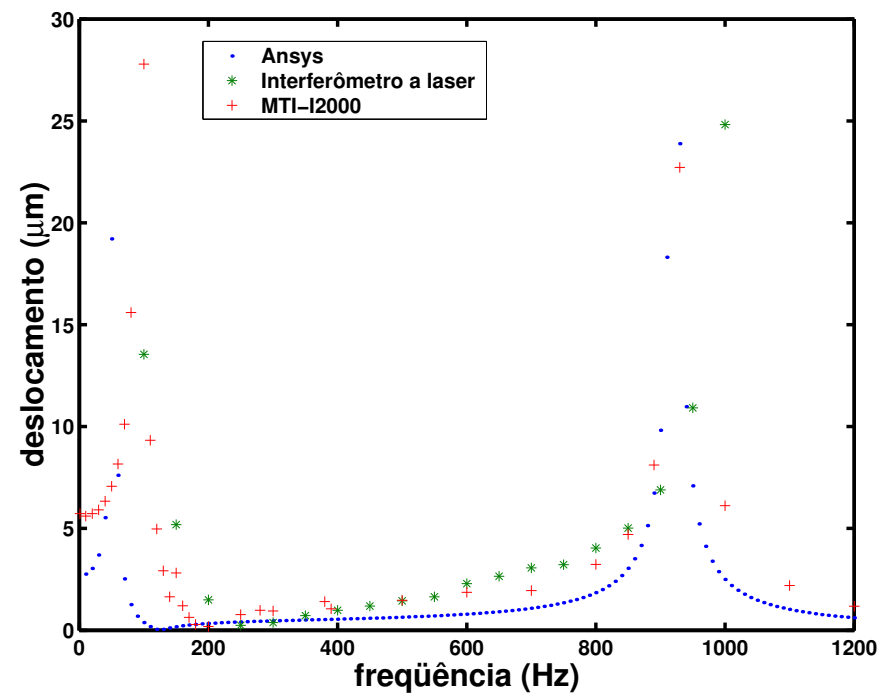

Figura 6.38. Resultados experimental e simulado da resposta do deslocamento em freqüência.

O modo de vibração do cantiléver bilaminar engastado com $20 \mathrm{~mm}$ livres é mostrado na Figura 6.39. Os resultados experimentais e simulados do cantiléver

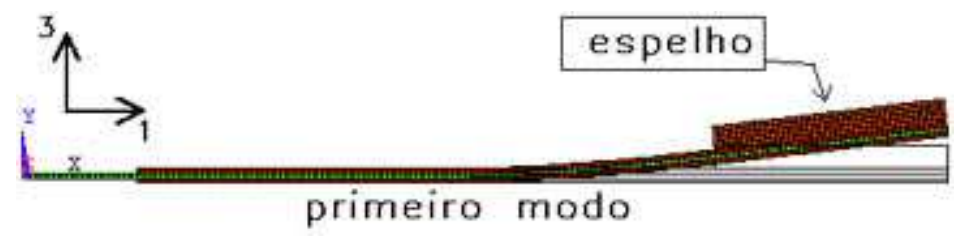

Figura 6.39. Primeiro modo de vibração do atuador cantiléver bilaminar simulado no ANSYS com 20 mm livres.

nessa condição são mostrados na Figura 6.40. Estes resultados são obtidos de análises pelo ANSYS e pelo interferômetro. A freqüência de ressonância do primeiro modo obtida pela análise modal no ANSYS é 576,99 Hz. Através dos resultados mostrados na Figura 6.40 nota-se que o cantiléver nessa condição pode ser usado para estabilizar o interferômetro até a faixa linear de $250 \mathrm{~Hz}$. O ideal é obter uma faixa linear acima de $500 \mathrm{~Hz}$. Para obter esse intervalo linear, foi determinado através das análises pelo MEF que o cantiléver com 14 mm livres apresentaria uma boa solução. Os resultados obtidos para esse comprimento livre da viga são satisfatório, como mostra a Figura 6.40, pois a resposta do deslocamento por freqüência 


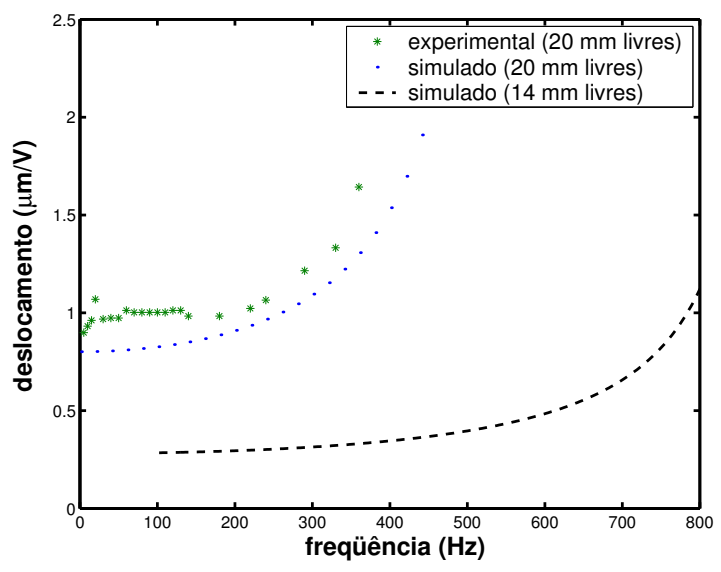

Figura 6.40. Resultados experimental e simulados do cantiléver engastado com $20 \mathrm{~mm}$ livres e $14 \mathrm{~mm}$ livres.

é praticamente plana até a freqüência de $400 \mathrm{~Hz}$.

No entanto, experimentalmente surgiram outras freqüências de ressonância, a primeira em aproximadamente $360 \mathrm{~Hz}$. Esta freqüência surgia devido ao modo de vibração natural da estrutura fixadora do cantiléver. Por esse motivo, uma outra estrutura para o engaste do bilaminar foi usinada. A Figura 6.41 mostra o cantiléver, com 14 mm livres, engastado por dois paralelepípedo de alumínio com as dimensões ilustradas na mesma figura.
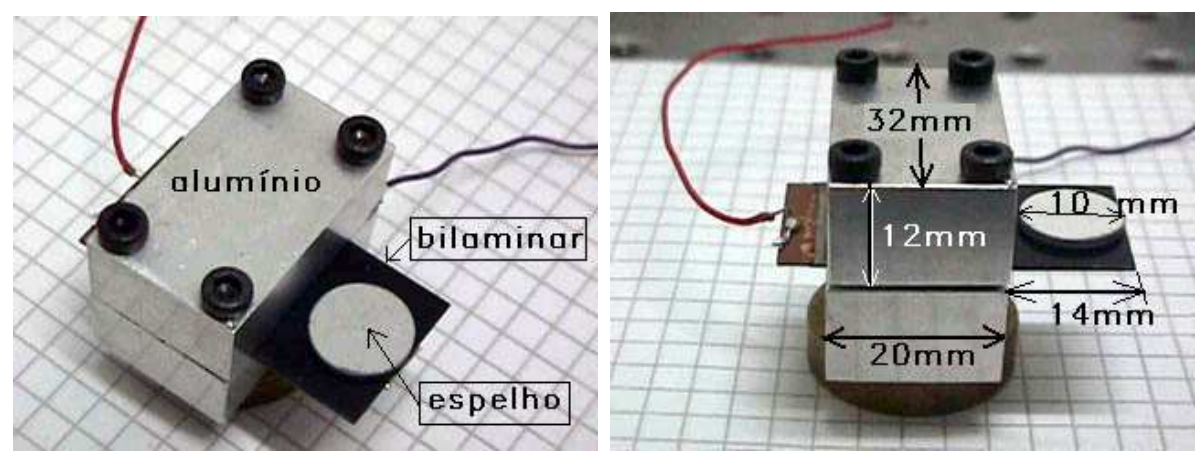

Figura 6.41. Foto em duas perspectivas e as dimensões do engaste, do bilaminar e do espelho.

Os resultados experimental e simulado da análise da admitância elétrica [Figuras 6.42(a) e (b), respectivamente] com o cantilever engastado com $14 \mathrm{~mm}$ livres, como na Figura 6.41, mostram a freqüência de ressonância fundamental do cantilever próxima a $900 \mathrm{~Hz}$, que está de acordo com o projeto do engaste.

O cantiléver bilaminar, fixado com $14 \mathrm{~mm}$ livres entre os paralelepípedos de 


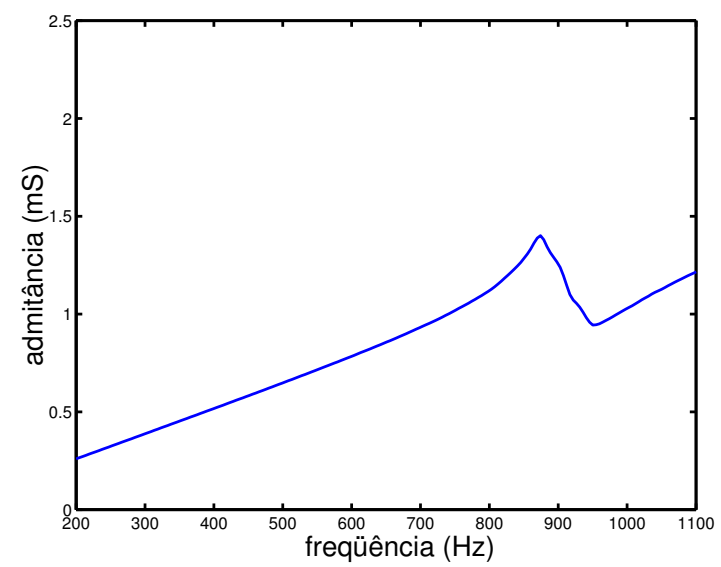

(a)

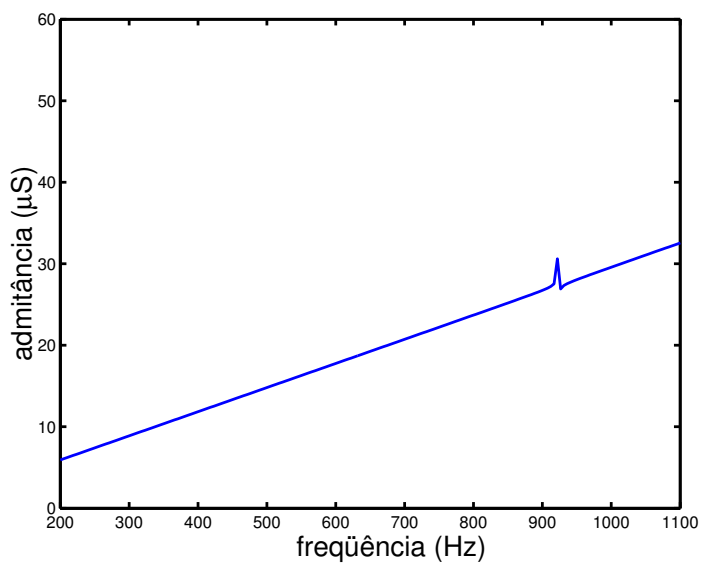

(b)

Figura 6.42. (a) Curva de admitância elétrica experimental. (b) Curva de admitância elétrica experimental.

alumínio, apresentar um bom comportamento para ser utilizado como compensador de variação de caminho óptico em sistemas interferométricos. Para atingir uma amplitude de vibração de 60 nm entre 100 Hz e 300 Hz é necessário que o filtro passabaixas forneça uma tensão elétrica de saída em torno de $160 \mathrm{mV}$. A estabilização do interferômetro será implementada num trabalho futuro.

\subsection{Pilhas Piezoatuadoras}

A medição de deslocamento desses piezoatuadores é realizada com o MTI-2000 apenas em análise estática. Os objetivos são obter o intervalo de resposta linear do deslocamento por tensão elétrica e também o intervalo não-linear, mas que pode ser utilizado no posicionamento de pecas, porém sem precisão ou controle. A essas análises é adicionada a tensão limite de operação limite dos atuadores, pois acima dessa tensão produz-se danos irreversíveis nos atuadores. O sinal de alimentação dos piezoatuadores é triangular em $1 \mathrm{~Hz}$, similar ao ilustrado na Figura 6.18.

Nas pilhas piezoatuadores há praticamente apenas a contribuição do coeficiente piezelétrico $d_{33}$, pois praticamente não há deformações na direção 1. A Figura 6.43 mostra os dois atuadores flextensionais que utilizam uma pilha piezoatuadora como elemento ativo. Estes piezoatuadores são denominados f3a0930 e f3a1030.

Inicialmente é analisado a pilha piezoatuadora antes de ser fixada à estrutura flexível de alumínio. O objetivo é verificar o deslocamento do flextensional na 


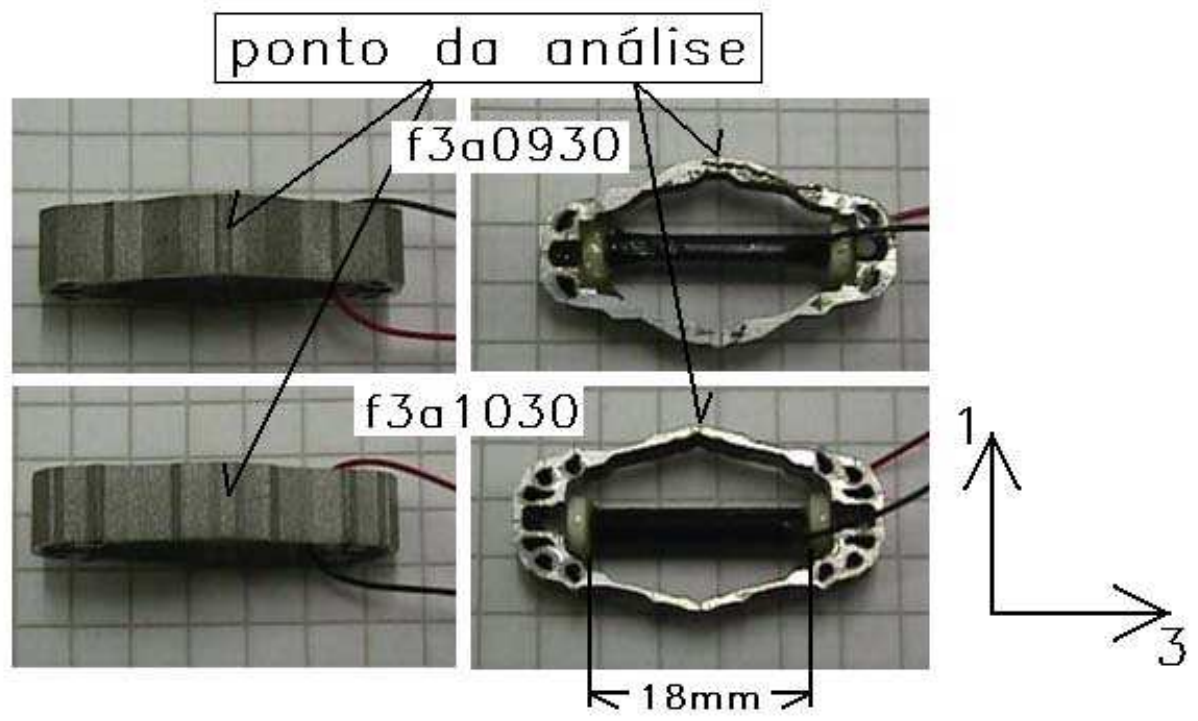

Figura 6.43. Piezoatuadores flextensionais, com pilhas piezoatuadoras, denominados f3a0930 e f3a1030.

direção 1, pois a pilha piezoatuadora desloca-se na direção 3 (Figura 6.43).

A pilha piezoatuadora é fixada ao suporte para a análise utilizando a cera de abelha com breu derretida, na base de acrílico, inferior. Este material foi escolhido para a fixação, por ser de fácil remoção, bastando aquecer até temperatura aproximadamente $80^{\circ} \mathrm{C}$. Na outra base de acrílico da pilha piezoatuadora é fixado o poliéster metalizado, para tornar a superfície reflexiva.

As Figuras 6.44(a) e (b) mostram, respectivamente, os resultados experimentais do deslocamento por tensão elétrica no intervalo linear e não-linear. Pode ser notado através da Figura 6.44(a) que o intervalo linear é obtido até uma tensão elétrica de $10 \mathrm{~V}$ de amplitude, produzindo um deslocamento de $1 \mu \mathrm{m}$. Esta mesma figura mostra que para uma tensão elétrica de $15 \mathrm{~V}$ o comportamento começa a tornar-se não-linear. A Figura 6.44(b) mostra o intervalo não-linear que ainda pode-se utilizar esse atuador. Este intervalo vai até $30 \mathrm{~V}$ de amplitude. Por essa figura, pode ser observado que para uma tensão elétrica de $35 \mathrm{~V}$ a curva de histerese do deslocamento apresenta deformações nas extremidades.

A deformação apresentada está relacionada com o campo elétrico aplicado ser alto $^{2}$, dessa modo, a cerâmica esta sob um campo coercitivo. A Figura 6.45 ilustra melhor esse comportamento, pois esses resultados são obtidos aplicando de $70 \mathrm{~V}$ a

\footnotetext{
${ }^{2}$ Cada camada da pilha piezoatuadora possui $100 \mu \mathrm{m}$ de espessura. Dessa forma, uma tensão elétrica de $100 \mathrm{~V}$ equivale a $1 \mathrm{kV} / \mathrm{mm}$.
} 


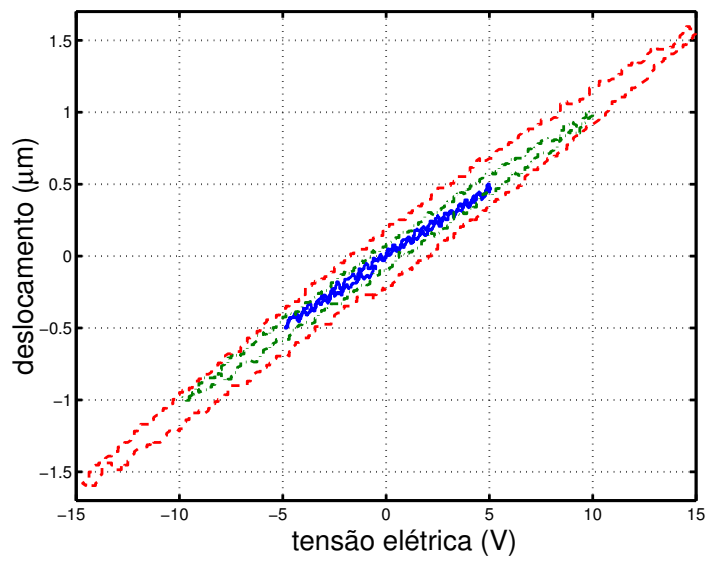

(a)

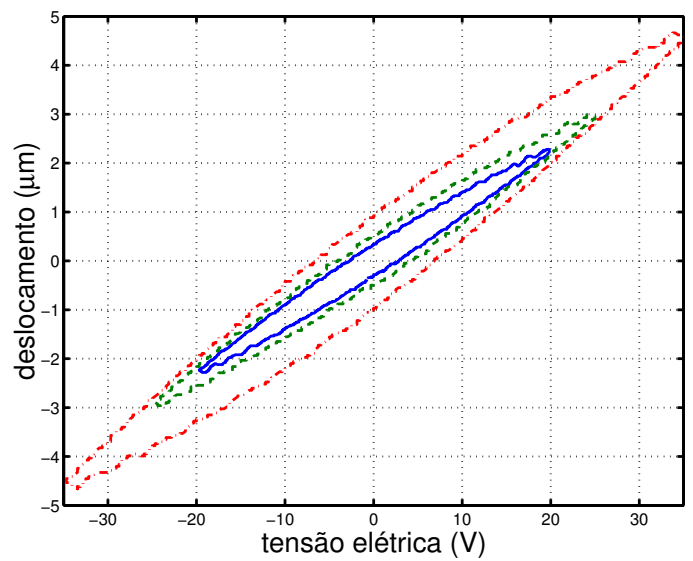

(b)

Figura 6.44. Resposta do deslocamento das pilhas piezoatuadores nuas: (a) Intervalo linear e (b) intervalo não linear.

100 V de amplitude. A Figura 6.45(a) ilustra a resposta do deslocamento em função do tempo e a Figura 6.45(b) ilustra a mesma resposta do deslocamento em função da tensão elétrica. A histerese da deformação, obtida para a tensão elétrica de $100 \mathrm{~V}$ é conhecida como loop borboleta, devido a sua forma [68], este comportamento surge em cerâmicas piezelétricas quando estão sobre um alto campo elétrico coercitivo.
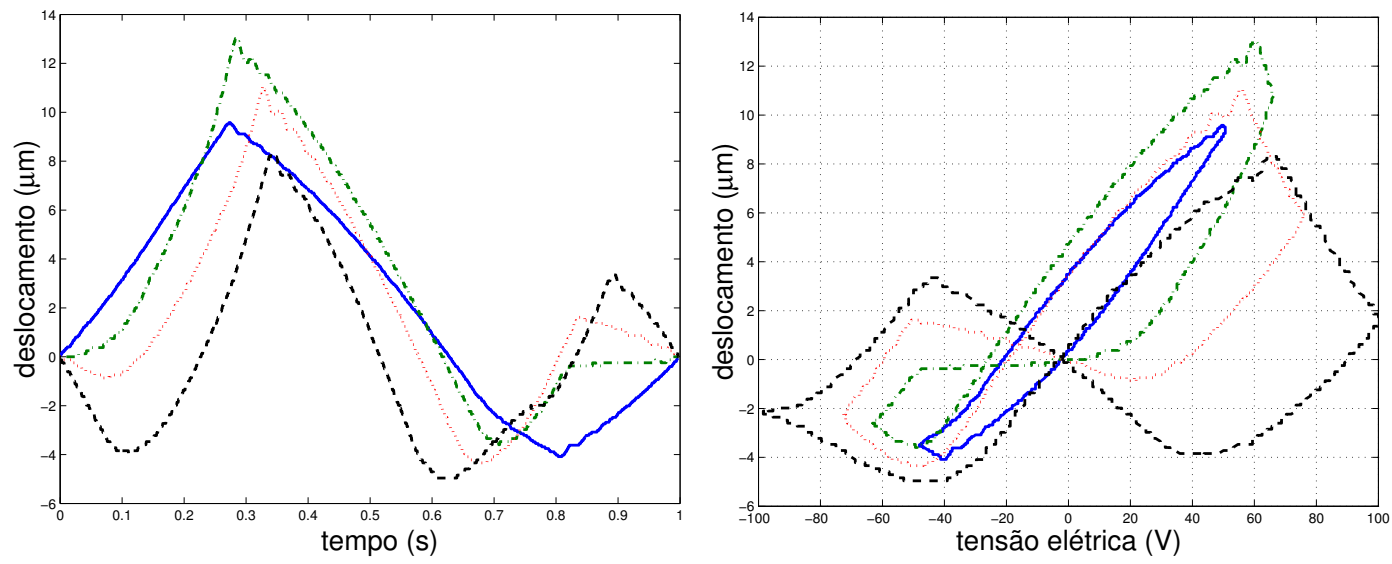

Figura 6.45. Comportamento não-linear das pilhas piezoatuadores para alto campo elétrico coercitivo: (a) resposta do deslocamento pelo tempo e (b) resposta do deslocamento por tensão elétrica.

Após a fixação da pilha piezoatuadora nas estruturas flexíveis observou-se que a tensão elétrica limite para que os atuadores flextensionais respondam linearmente é $5 \mathrm{~V}$ de amplitude, como mostrado na Figura 6.46. Até $10 \mathrm{~V}$ o comportamento é praticamente linear. No entanto, deve ser notado que o f3a0930 desloca-se aprox- 
imadamente $0,3 \mu \mathrm{m}$ para $5 \mathrm{~V}$, enquanto o f3a1030 desloca-se aproximadamente 0,7 $\mu \mathrm{m}$ para essa mesma tensão [Figura 6.46(a) e (b), respectivamente]. Na comparação com a pilha piezoatuadora, o deslocamento para a tensão elétrica de $10 \mathrm{~V}$ é $0,5 \mu \mathrm{m}$ para o f3a0930 e 1,3 $\mu \mathrm{m}$ para o f3a1030. O flextensional f3a0930 possui um deslocamento pequeno, em relação à pilha e ao f3a1030, porque acidentalmente nas primeiras análises este atuador esteve submetido a um sinal transiente que extrapolou o limite de tensão elétrica, danificando o atuador, como é mostrado mais a frente, através da comparação dos resultados obtidos para o deslocamento do flextensional sob tensão elétrica maior.

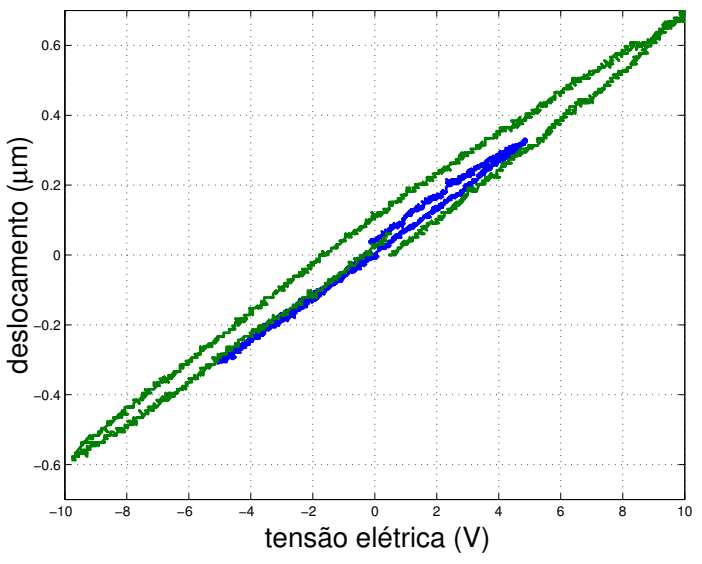

(a)

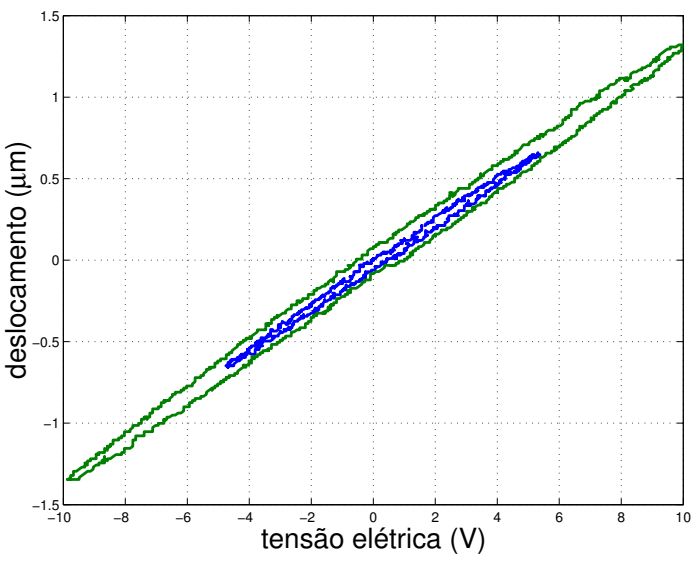

(b)

Figura 6.46. (a) Resposta do f3a0930 e (b) resposta do f3a1030.

A curva de histerese do deslocamento acentua-se ao atingir patamares mais altos de tensão elétrica, como mostra a Figura 6.47. O f3a1030 pode ser utilizado até um limite de $50 \mathrm{~V}$ de amplitude, com um deslocamento para essa tensão em torno de $10 \mu \mathrm{m}$. Porém não há controle sobre a relação tensão elétrica deslocamento, para tensões elétricas acima dos $10 \mathrm{~V}$.

O f3a0930, por ter sido danificado, apresenta um limite de operação a $30 \mathrm{~V}$, acima desse valor o atuador começa a apresentar histerese em loop borboleta. A Figura 6.48(a) mostra as curvas de resposta em função do tempo, e a Figura 6.48(b) mostra a resposta em função da tensão elétrica.

A comparação entre os deslocamentos da direção 3 da pilha piezoatuadora, com os da direção 1 do flextensional (ver Figura 6.43) mostra que o f3a1030 possui um deslocamento cerca de 30\% superior ao da pilha piezoatuadora, até 30 V. O f3a0930, 


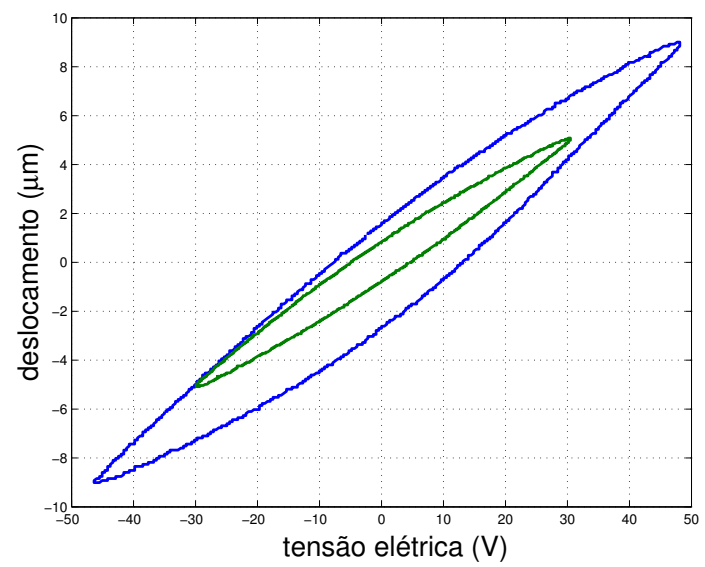

Figura 6.47. Resposta do f3a1030 até o limite de $50 \mathrm{~V}$ de amplitude.

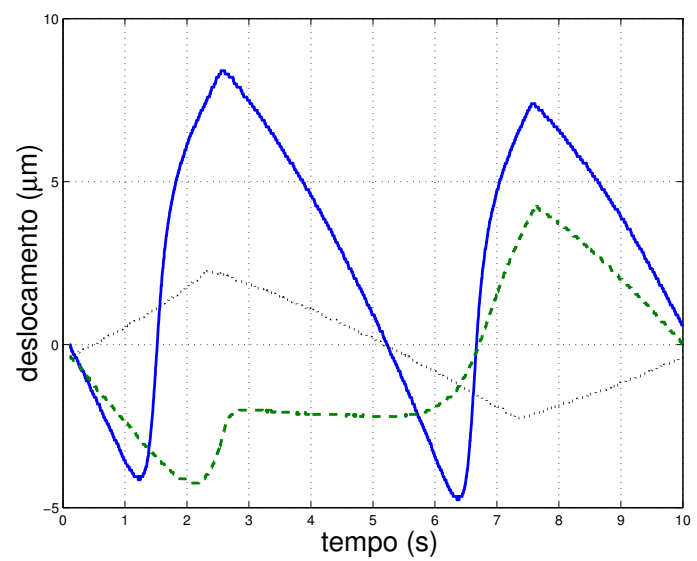

(a)

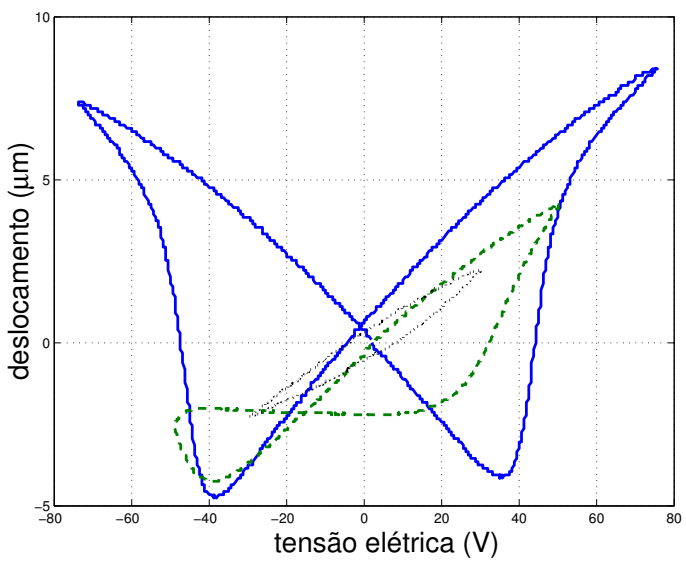

(b)

Figura 6.48. Atuador f1c0930 submetido a campo elétrico acima de $30 \mathrm{~V}$ de amplitude. (a) resposta pelo tempo e (b) resposta por tensão.

que foi danificado, apresenta um deslocamento inferior em cerca de 50\%. Contudo, esses atuadores podem ser utilizados como atuadores, operando no intervalo de segurança entre $-30 \mathrm{~V}$ e $+30 \mathrm{~V}$, produzindo um deslocamento entre $-4 \mu \mathrm{m} \mathrm{e}+4 \mu \mathrm{m}$.

\subsection{Medição das Propriedades Eletro-piezo-mecâ- nicas}

Algumas propriedades eletro-piezo-mecânicas das cerâmicas piezelétricas PZT-5A foram obtidas experimentalmente para verificar se os valores fornecidos em tabelas e usados nas simulações estavam próximos. A Tabela 6.5 mostra as dimensões 
$(d, t, l, w)$, freqüências $\left(f_{p}, f_{s}, f_{-1 / 2}, f_{+1 / 2}\right)$, densidade $(\rho)$, capacitância a $1 \mathrm{kHz}\left(C_{1 k H z}\right)$, fator de qualidade mecânico $\left(Q_{m}\right)$ e constante dielétrica relativa $\epsilon_{33}^{T} / \epsilon_{0}$ dos PZT-5A utilizados na caracterização elétrica. A Tabela 6.6 mostra a comparação entre os valores obtidos experimentalmente e os fornecidos pelos fabricantes.

Tabela 6.5. Discos e placas piezelétricas PZT-5A utilizados na caracterização.

\begin{tabular}{lllll}
\hline \hline & disco 1 & disco 2 & placa 1 & placa 2 \\
\hline$d$ & $25,31 \mathrm{~mm}$ & $12,76 \mathrm{~mm}$ & - & - \\
$t$ & $1,98 \mathrm{~mm}$ & $0,50 \mathrm{~mm}$ & $0,96 \mathrm{~mm}$ & $4,97 \mathrm{~mm}$ \\
$l$ & - & - & $29,87 \mathrm{~mm}$ & $29,90 \mathrm{~mm}$ \\
$w$ & - & - & $13,95 \mathrm{~mm}$ & $13,90 \mathrm{~mm}$ \\
$\rho$ & $7708 \mathrm{~kg} \cdot \mathrm{m}^{-3}$ & $7589,61 \mathrm{~kg} \cdot \mathrm{m}^{-3}$ & $7674,00 \mathrm{~kg} \cdot \mathrm{m}^{-3}$ & $7591,00 \mathrm{~kg} \cdot \mathrm{m}^{-3}$ \\
$C_{1 k H z}$ & $3,98 \mathrm{nF}$ & $3,63 \mathrm{nF}$ & $8,31 \mathrm{nF}$ & $1,57 \mathrm{nF}$ \\
$f_{s}$ & $943,71 \mathrm{kHz}$ & $3907,50 \mathrm{kHz}$ & $2087,00 \mathrm{kHz}$ & $426,15 \mathrm{kHz}$ \\
$f_{p}$ & $1066,35 \mathrm{kHz}$ & $4446,00 \mathrm{kHz}$ & $2331,00 \mathrm{kHz}$ & $443,40 \mathrm{kHz}$ \\
$f_{-1 / 2}$ & $1062,97 \mathrm{kHz}$ & $4426,00 \mathrm{kHz}$ & $2321,62 \mathrm{kHz}$ & $441,70 \mathrm{kHz}$ \\
$f_{+1 / 2}$ & $1069,80 \mathrm{kHz}$ & $4465,00 \mathrm{kHz}$ & $2338,50 \mathrm{kHz}$ & $445,20 \mathrm{kHz}$ \\
$Q_{m}$ & 78,12 & 57,00 & 69,07 & 63,34 \\
$\epsilon_{33}^{T} / \epsilon_{0}^{*}$ & 1764,20 & 1602,59 & 2162,11 & 2125,87 \\
\hline \hline & $*$
\end{tabular}

Os valores mostrados na Tabela 6.5 são os utilizados nos cálculos das constantes longitudinais (1 e 2) e transversais (3). Não foram obtidos os parâmetros pelos quais são calculadas as constantes de cisalhamento. A capacitância é inversamente proporcional à espessura e diretamente proporcional à área do eletrodo, na superfície da piezocerâmica, o que justifica os valores mostrados na Tabela 6.5.

A Tabela 6.6 mostra o valor das constantes obtidas diretamente pelos procedimentos experimentais. Os outros valores podem ser determinados através das relações fornecidas na seção 2.3 .

A determinação de muitas constantes depende dos valores de $s_{11}^{E}, s_{33}^{D}$ e $k_{33}$. No entanto, o valor determinado para essas constantes apresentou uma diferença em 
Tabela 6.6. Propriedades do PZT-5A.

\begin{tabular}{lllll}
\hline \hline & medido** $^{* *}$ & tabelado & erro & unidades \\
\hline$s_{11}^{E}$ & 8,11 & - & $22 \%$ & $\times 10^{-12} \mathrm{~m}^{2} \cdot \mathrm{N}^{-1}$ \\
$s_{33}^{D}$ & 7,28 & 9,46 & $23 \%$ & $\times 10^{-12} \mathrm{~m}^{2} \cdot \mathrm{N}^{-1}$ \\
$c_{33}^{D}$ & - & 15,0 & $0,3 \%$ & $\times 10^{10} \mathrm{~N} \cdot \mathrm{m}^{-2}$ \\
$k_{31}$ & 0,31 & 0,34 & $9 \%$ & \\
$k_{33}$ & 0,52 & 0,70 & $26 \%$ & \\
$k_{p}$ & 0,59 & 0,60 & $2 \%$ & \\
\hline \hline
\end{tabular}

** Medido de acordo com as normas do IEEE [29],IRE [30, 31, 32]

e HOLAND e EERNISSE [33].

relação aos valores tabelados, de até $45 \%$, dificultando a determinação do valor das outras constantes. 


\section{Capítulo 7}

\section{Conclusões e Perspectivas Futuras}

\subsection{Conclusões}

Foram avaliados métodos experimentais e numéricos de análise e caracterização de transdutores piezelétricos. Os métodos experimentais de análise foram técnicas ópticas e elétricas, e o numérico foi o método de elementos finitos. Estas técnicas permitiram um estudo sobre a influência das condições de contorno experimentais e como modelá-las nas simulações, verificar o valor das constantes eletro-piezomecânicas das cerâmicas piezelétrica e a determinação do coeficiente de amortecimento mecânico, tanto das piezocerâmicas, quanto do alumínio e do vidro.

Foi mostrado, através dos resultados obtidos, a importância de trabalhar em conjunto com técnicas experimentais e numéricas, pois a partir da convergência desses resultados pode-se obter confiabilidade tanto nos procedimentos experimentais como computacionais.

Os métodos experimental e empírico de determinação do amortecimento de cerâmicas piezelétricas mostrou-se válido, pois a comparação dos resultados experimentais e simulados das curvas de admitância elétrica das piezocerâmicas e da resposta transiente dos piezoatuadores flextensionais mostraram resultados com boa concordância. Não há como comparar os resultados obtidos para amortecimento com o de outros autores ou tabelas, pois não há relatos sobre o valor deste parâmetro.

$\mathrm{Na}$ análise dos piezoatuadores flextensionais verificou-se os resultados experimentais e simulados, do deslocamento, da amplificação e das freqüências de ressonância casam muito bem. Na comparação entre os resultados experimentais, obtidos por 
técnicas ópticas e elétricas, verificou-se que a resina epóxi tem pouca influência no comportamento dos flextensionais f1a1025, f2b0830 e f1c0815 que utilizam a deformação longitudinal da piezocerâmica, atuando por compressão nas paredes internas da estrutura flexível, para produzir a amplificação da estrutura em alumínio. No entanto, no caso dos flextensionais f1a0820 e f1b0820, que utilizam tanto a deformação da espessura quanto a deformação longitudinal da piezocerâmica para produzir a amplificação do deslocamento na estrutura em alumínio, verificou-se que há influência da resina epóxi. Esta influência ocorre principalmente devido à deformação longitudinal da piezocerâmica ser transferida à estrutura flexível através de cisalhamento na resina epóxi.

O sistema utilizado para engastar os flextensionais, nas análises experimentais, nos sistemas ópticos mostrou-se satisfatório. Quando os três parafusos, que seguram o piezoatuador pela cerâmica (dois na parte inferior e um na parte superior), são utilizados apertados de modo a minimizarem a deformação da cerâmica na direção da largura, as simulações bidimensionais no ANSYS podem ser realizadas assumindo que a piezocerâmica está no estado plano de deformações mecânicas, enquanto que a estrutura em alumínio está no estado plano de tensões mecânicas.

Nas análises das piezocerâmicas foi verificada a influência da fixação de espelhos rígidos na superfície destas, assim como da fixação para análise no sistema interferométrico. O espelho influência no comportamento das piezocerâmicas a freqüências na faixa de alguns $\mathrm{kHz}$, produzindo novas freqüências de ressonância, modos de vibração e produzindo curvaturas na piezocerâmica, onde o espelho é fixado. A melhor solução para análise do deslocamento de superfície de uma piezocerâmica é utilizar fitas de poliéster metalizado. Pois estes materiais têm baixa rigidez, pequena massa, assim possuem pouca influência na deformação da piezocerâmica, não produzindo alteração na freqüência natural de ressonância ou no amortecimento.

O engaste com três parafusos, utilizados sem problema na fixação dos piezoatuadores flextensionais, influenciaram o comportamento das piezocerâmicas, dificultando a modelagem do engaste no ANSYS, pois os parafusos apresentavam pouca rigidez. Dessa forma, foram utilizados elementos LINK1, simulando molas, para engastar a cerâmica piezelétrica e os resultados experimentais e simulados aproximaram- 
se. Porém, ao fixar ao fixar o conjunto piezocerâmica/espelho sobre uma estrutura em alumínio, os resultados experimentais e simulados apresentaram boa concordância.

Outro atuador piezelétrico analisado neste trabalho foi o bilaminar engastado como um cantiléver. Determinou-se o deslocamento máximo do bilaminar engastado com 40 mm livre e também como engastá-lo para que possa ser utilizado na estabilização de interferômetros a laser. Essa condição foi obtida ao utilizar dois paralelepípedos de alumínio, com grandes dimensões em relação ao bilaminar, fixando o bilaminar com $14 \mathrm{~mm}$ livres.

As análises experimentais do deslocamento da pilhas piezoatuadoras mostram que estas podem ser utilizadas como atuadores até o limite de tensão elétrica de $30 \mathrm{~V}$, e a faixa linear da relação deslocamento por campo elétrico possui limite em aproximadamente $10 \mathrm{~V}$.

Para as análises experimentais de deslocamento foram desenvolvidos interferômetros a laser. O interferômetro tipo-Michelson não utiliza qualquer sistema de controle de vibração ou de eliminação do ruído por qualquer técnica. As medições podem ser realizadas com uma boa precisão $(1 \mathrm{~nm})$, no entanto há necessidade de calibração constante do interferômetro. O outro interferômetro montado é um Mach-Zehnder modificado em regime de detecção de sinais em quadratura. Com este interferômetro é possível obter os sinais de resposta das amostras analisadas eliminando o ruído ambiente do sinal de resposta através da subtração dos sinais ópticos (defasados de $\pi / 2$ ) detectados por dois fotodetectores.

\subsection{Perspectivas Futuras}

No interferômetro tipo-Michelson será implementado um sistema de estabilização com um filtro amplificador passa-baixas $(1 \mathrm{kHz})$ conectado ao fotodetector, o qual controlará o atuador bilaminar ou o flextensional f1c0815 no espelho de referência do interferômetro. Após ser implementado o sistema de estabilização, esse interferômetro somente poderá ser utilizado para medições de amplitudes de vibração a freqüências acima de $1 \mathrm{kHz}$.

O interferômetro Mach-Zehnder modificado, em quadratura, será adaptado para 
um interferômetro heteródino, introduzindo um modulador acusto-óptico entre os divisores de feixe polarizadores. Com esse interferômetro, a resolução será subangströms e a faixa de medição de deslocamento desde variações estáticas até vibrações alguns $\mathrm{MHz}$.

Nos projetos de transdutores piezelétricos de ultra-som verificar a influência do amortecimento e determinar as constantes multiplicadoras da matriz de rigidez e de massa (se houver), para as freqüências de trabalho entre $1 \mathrm{MHz}$ e $5 \mathrm{MHz}$.

Determinação das forças de bloqueio dos atuadores piezelétricos flextensionais, e aplicar estes, assim como as pilhas piezoatuadoras, como posicionadores finos XYZ e no controle de inclinação dos espelhos nos interferômetros. 


\section{Referências Bibliográficas}

[1] SCRUBY, C. B.; DRAIN, L. E., Laser Ultrasonics, Techniques and Applications. EUA: Adam Hilger, 1990.

[2] MONCHALIN, J., Optical detection of ultrasound, IEEE Transactions on Ultrasonics, Ferroelectrics and Frequency Control, v. 33, n. 5, p. 485 - 499, 1986.

[3] ROYER, D., Génération et détection optiques d'ondes élastiques, Techniques de L'Ingènieur, v. E4415, p. 1-17, 1997.

[4] ROYER, D.; DIEULESAINT, E., Optical detection of sub-angstrom transient mechanical displacements, em IEEE Ultrasonic Symposium Proceeding, p. 527-530, 1986.

[5] ShiRAhige, A. B.; NADER, G.; ADAMOWSkI, J. C.; SILVA, E. C. N., Characterization of a bimorph piezoactuator to apply in laser interferometer control vibration, Annals of Optics - XXV Encontro Nacional de Física da Materia Condensada, v. 4, p. 145 - 148, 2002.

[6] ROYER, D.; CASULA, O., Quantitative imaging of transient acoustic fields by optical heterodyne interferometry, em IEEE Ultrasonic Symposium Proceeding, p. 1153 - 1162, 1994.

[7] LAWALL, J.; KESSLER, E., Michelson interferometer with 10 pm accuracy, Review of Scientific Instruments, v. 71, n. 7, p. 2669 - 2676, 2000.

[8] BLACKSHIRE, J. L.; SATHISH, S., Characterization of MEMS transducer performance using near-field sacanning interferometry, IEEE - Transac- 
tions on Ultrasonics, Ferroelectrics and Frequency Control, v. 49, n. 5, p. 669-674, 2002.

[9] VILKOMERSON, D., Measuring Pulsed Picometer-displacement Vibrations by Optical Interferometry, Applied Physics Letter, v. 29, p. 183-185, agosto 1976.

[10] ZHANG, Q. M.; PAN, W. Y.; CROSS, L. E., Laser Interferometry for the Study of Piezoelectric and Electrostrictive Strains, Journal of Applied Physics, v. 63, p. 2492-3496, abril 1988.

[11] POLYTEC, , OFV-3001 Modular Vibrometer Controller. Catálogo do fabricante.

[12] DJELOUAH, H.; BABOUX, J. C., Transient ultrasonic field radiated by a circular transducer in a solid medium, Journal of the Acoustical Society of America, v. 92, n. 5, p. 2932-2941, 1992.

[13] GUENTHER, R., Modern Optics. Nova Iorque - EUA: John Wiley \& Sons, 1990.

[14] ING, R. K.; MONCHALIN, J. P., Broadband optical detection of ultrasound by two-wave mixing in a photorefractiv cyrstal, Applied Physics Letter, v. 59, n. 25, p. 3233-3235, 1991.

[15] Delaye, P.; BLOUIN, A.; DROlet, D.; MONCHAlin, J. P., Heterodyne detection of ultrasound from rough surfaces using a double phase conjugate mirror, Applied Physics Letter, v. 67, n. 22, p. 3251-3253, 1995.

[16] Delaye, P.; Blouin, A.; DrOlet, D.; DE MONTMORILlON, L. A.; ROOSEN, G.; MONCHALIN, J. P., Detection of ultrasounic motion of a scatering surface by photorefractive InP:Fe under an applied dc field, Journal of the Optical Society America B, v. 14, n. 7, p. 1723-1734, 1997.

[17] POUET, B. F.; ING, R. K.; KRISHNASWAMY, S.; ROYER, D., Heterodyne interferometer with two-wave mixing in phtorefractive crystals for ultrasound detection on rough surfaces, Applied Physics Letter, v. 69, n. 25, p. 3782$3784,1996$. 
[18] YEH, P., Introduction to Photorefractive Nonlinear Optics. Nova Iorque - EUA: John Wiley \& Sons, INC, 1993.

[19] NASHIF, A. D.; JONES, D. I. G.; HENDERSON, J. P., Vibration Damping. New York - EUA: John Wiley \& Sons, 1985.

[20] MEIROVITCH, L., Elements fo Vibration Analisys. Tokio - Japão: McGraw-Hill Kogakusha, LTD., 1975.

[21] KOHNKE, P. C., ANSYS 5.7.1 Help. On line Manual, 2001.

[22] SLOCUM, A. H., Precision Machine Design. New Jersey - EUA: Pretence Hall.

[23] ALLIK, H.; HUGHES, T. J. R., Finite element method for piezoelectric vibration, International Journal for Numerical Methods in Engineering, v. 2 , p. $151-157,1970$.

[24] NAILlON, M.; COURSANT, R. H.; BESNIER, F., Analysis of Piezoelectric Structures by a Finite Element Method, Acta Electronica, v. 25, n. 4, p. 3341-362, 1983.

[25] OSTERGAARD, D. F.; PAWLAK, T. P., Three-dimensional Finite Element for Analyzing Piezoelectric Structures, Ultrasonic Symposium, p. 639-644, 1986.

[26] LERCH, R., Simulation of Piezoelectric Devices by Two- and ThreeDimensional Finite Element, IEEE - Transactions on Ultrasonics, Ferroelectrics and Frequency Control, v. 37, n. 2, p. 233-247, 1990.

[27] CAI, C.; ZHENG, H.; KHAN, M. S.; HUNG, K. C., Modeling of Material Damping Properties in ANSYS, ANSYS conference - Petersburg, abril 2002 .

[28] WANG, E.; NELSON, T., Structural Dynamic Capabilities of ANSYS, ANSYS conference - Petersburg, abril 2002. 
[29] IEEE - Standard on Piezoelectricity 176-1987, IEEE - Transactions on Ultrasonics, Ferroelectrics and Frequency Control, v. 43, n. 5, p. 5-54, 1996.

[30] IRE Standards on Piezoelectric Crystals, 1949, Proceedings of the IRE, v. 37, p. 1378-1395, 1949.

[31] IRE Standards on Piezoelectric Crystals: Determination of the Elastic, Piezoelectric, and Dielectric Constants - The Electromechanical Coupling Factor, 1958, Proceedings of the IRE, v. 46, p. 764-778, 1958.

[32] IRE Standards on Piezoelectric Crystals: Measurements of Piezoelectric Ceramics, 1961, Proceedings of the IRE, v. 49, p. 1161-1169, 1961.

[33] HOLLAND, R.; EERNISSE, E. P., Accurate Measurement of Coefficients in a Ferroelectric Ceramic, IEEE- Transactions on Sonics And Ultrasonics, v. SU-16, n. 4, 1969.

[34] SMITS, J. G., Iterative Method for Accurate Determination of The Real and Imaginary Parts of the Materials Coefficients of Piezoelectric Ceramics, IEEE- Transactions on Sonics And Ultrasonics, v. SU-23, n. 6, p. 393402, 1976.

[35] SILVA, E. C. N.; NISHIWAKI, S.; KICHUCHI, N., Topology optimization design of flextensional actuators, IEEE - Transactions on Ultrasonics, Ferroelectrics and Frequency Control, v. 47, n. 3, p. 657-671, 2000.

[36] XU, Q. C.; DOGAN, A.; TRESSLER, J., Ceramic-Metal Composite Actuator, Ultrasonic Symposium, p. 923-928, 1991.

[37] NEWNHAM, R. E.; DOGAN, A.; XU, Q. C.; ONITSUKA, K.; TRESSLER, J.; YOSHIKAWA, S., Flextensional "Moonie" Actuators, Ultrasonic Symposium, 1993.

[38] DOGAN, A.; UCHINO, K.; NEWNHAM, R. E., Composite piezoelectric transducer with truncated conical endcaps "Cymbal", IEEE - Transactions on Ultrasonics, Ferroelectrics and Frequency Control, v. 44, p. 597-605, 1997. 
[39] BARILlOT, F.; LETTY, R. L.; CLAEYSSEN, F.; LHERMET, N.; YORCK, M.; BOUCHILLOUX, P., Design and experimental evaluation of a piezoelectric XY stage, SPIE conference on Smart Structures and Integrated Systems, v. 3985, p. 217-227, março 2000.

[40] SILVA, E. C. N., Design of piezoelectric motors using topology optimization, Smart Structures and Materials: smart structures and integrated systems, v. 4326, p. 513-524, 2001.

[41] ROLT, K. D., History of the Flextensional Electroacoustic Transducer, Journal of the Acoustical Society of America, v. 87, n. 3, p. 1340-1349, 1990.

[42] ONITSUKA, K.; DOGAN, A.; TRESSLER, J. F.; XU, Q.; YOSHIKAWA, S.; NEWNHAM, R. E., Metal-ceramic composite transducer, "the Moonie", Journal of Intelligent Material Systems and Structures, v. 6, p. 447$455,1995$.

[43] LERCH, R., Finite Element Analysis of Piezoelectric Transducers, Ultrasonic Symposium, p. 643-654, 1988.

[44] KIM, J.; VARADAN, V. V.; VARADAN, V. K.; BAO, X.-Q., Finite-element modeling of a smart cantilever plate and comparison with experiments, Smart Material and Structures, v. 5, n. 2, p. 165-170, 1996.

[45] NADER, G.; SILVA, E. C. N.; ADAMOWSKI, J. C., Characterization of Novel Flextensional Transducers Designed by Using Topology Optimization Method, Anais do IEEE - Ultrasonics, 2001.

[46] WANG, J. S.; OSTERGAARD, D. F., A finite element-electric circuit coupled simulation method for piezoelectric transducer, IEEE Ultrasonic Symposium, p. 1105-1108, 1999.

[47] NADER, G.; SILVA, E. C. N.; ADAMOWSKI, J. C., Experimental verification of flextensional transducers designed by using topology optimization method, em Proceedings of Spie - Smart Structures and Materials, 2001. 
[48] NADER, G.; SHIRAHIGE, A. B.; SILVA, E. C. N.; ADAMOWSKI, J. C., Laser Interferometry Technique Applied to the Measurement of Flextensional Transducers Displacements, Anais do XVI Congresso Brasileiro de Engenharia Mecânica - Robotics and Control - CD-ROM, p. 360-368, 2001.

[49] NADER, G.; SHIRAHIGE, A. B.; SIlVA, E. C. N.; ADAMOWSKI, J. C., Simulação e Verificação Experimental de Atuadores Piezelétricos Flexitensionais Modelados por Otimização Topológica, II Jornadas IIberoamericanas de Ultrasonidos, La Rábida, agosto 2001.

[50] SILVA, E. C. N.; NADER, G.; SHIRAHIGE, A. B.; ADAMOWSKI, J. C., Characterization of Novel Flextensional Actuators Designed by Using Topology Optimization Method, Journal of Intelligent Material and Structures, v. submetido, 2002.

[51] BUIOCHI, F., Medição de Viscosidade de Líquidos por Ultra-Som. Tese de doutorado, São Paulo - Brasil, 2000, Escola Politécnica da Universidade de São Paulo.

[52] HIGUTI, R. T., Caracterização de Líquidos por Ultra-som. Tese de doutorado, São Paulo - Brasil, novembro 2001, Escola Politécnica da Universidade de São Paulo.

[53] ADAMOWSKI, J. C.; BUIOCHI, F.; KUCHPIL, C., Transmissão acústica de dados em colunas de produção de petróleo, Anais do III IEEE - INDUSCON - São Paulo, p. 62-65, 1998.

[54] FURUKAWA, C. M.; ADAMOWSKI, J. C.; CAMERINI, C. S., Desenvolvimento de um PIG instrumentado para inspeção de oleodutos por ultra-som, Anais do III IEEE - INDUSCON - São Paulo, p. 62-65, 1998.

[55] SILVA, E. C. N.; KIKUCHI, N., Design of piezoelectric transducers using topology optimization, Journal of Smart Materials and Structures, v. 8, p. 350-364, 1999. 
[56] RODRIGUES, H. L. P.; IBRAHIM, R. C., Determinação de características de funcionamento de um motor piezelétricos para deslocamentos lineares, Anais do XVI Congresso Brasileiro de Engenharia Mecânica - Robotics and Control - CD-ROM, p. 301-306, 2001.

[57] DE LIMA, C. R., Projeto de Mecanismos Flexíveis Usando Método de Otimização Topológica dissertação de mestrado, São Paulo - Brasil, 2002, Escola Politécnica da Universidade de São Paulo.

[58] AULD, B. A., Acoustic Fields and Waves in Solids, v. I. Florida - EUA: Robert E. Krieger Publishing Company, $2^{a} \underline{a}$ ed., 1990.

[59] KINO, G. S., Acoustic Waves: Devices, Imaging and Analog Signal Processing. Pretence-Hall - EUA, 1987.

[60] CLAEYSSEN, F.; LETTY, R. L.; BARILlOT, F.; LHERMET, N.; FABBRO, H.; GUAY, P.; YORCK, M.; BOUCHILLOUX, P., Mechanism based on piezo actuators, SPIE conference on Smart Materials, v. aceito, 2001.

[61] MASE, G., Continuum Mechanics - Schaum's Outlines. Nova Iorque EUA: McGraw-Hill, 1970.

[62] ROSEnBAUM, J. F., Bulk Acoustic Wave Theory and Devices. Londres - Inglaterra: Artech House, 1988.

[63] SILVA, E. C. N.; FONSECA, J. S. O.; DE ESPINOSA, F. M.; CRUMM, A. T.; BRADY, G. A.; HALLORAN, J. W.; KIKUCHI, N., Design of Piezocomposite Material and Piezoelectric Transducers Using Topology Optimization - Part I, Archives of Computacional Methods in Engineering, v. 6, n. 2, p. 117$182,1998$.

[64] SILVA, E. C. N.; NISHIWAKI, S.; KIKUCHI, N., Design of Piezocomposite Material and Piezoelectric Transducers Using Topology Optimization - Part II, Archives of Computacional Methods in Engineering, v. 6, n. 2, p. 191-222, 1998.

[65] BORISENDO, A.; TARAPOV, I., Vector and Tensor Analisys - With Applications. New York - EUA: Dover, 1968. 
[66] SELFRIDGE, A. R., Approximate Material Properties in Isotropic Materials, IEEE Transactions on Sonics and Ultrasonics, v. SU-32, n. 3, p. 381394, 1985.

[67] JONA, F.; SHIRANE, G., Ferroelectric Crystals. New York - EUA: Dover Publications, Inc., 1960.

[68] BUCHANAN, R. C., Ceramic Materials for Electronics, cap. 3, p. 129 205. Electrical Engineering and Electronics, New York - EUA: Marcel Dekker, Inc., second ed., 1991.

[69] ASHCROft, N. W.; MERMIN, N. D., Solid State Physics. New York EUA: Saunders College Publishing, international edition ed., 1976.

[70] IKEDA, T., Fundamentals of Piezoelectricity. Oxford - Inglaterra: Oxford University Press, 1996.

[71] KWOK, K. W.; CHAN, H. L. W.; CHOY, C. L., Evaluation of the Material Parameters of Piezoelectric Material by Various Methods, IEEE - Transactions on Ultrasonics, Ferroelectrics and Frequency Control, v. 44, n. 4, p. 733-742, 1997.

[72] Vernitron Limited - Measuring Properties of Piezoelectric Ceramics. Bulletin - 66017/B, Março 1976.

[73] LETHIECQ, M.; TRAN-HUU-HUE, L. P.; PATAT, F.; POURCCELOT, L., Measurement of Losses in Five Piezoelectric Ceramics Between 2 and $50 \mathrm{MHz}$, IEEE - Transactions on Ultrasonics, Ferroelectrics and Frequency Control, v. 40, n. 3, p. 232-236, 1993.

[74] COOK, R. D., Finite Element Modelling for Stress Analysis. Nova York - EUA: John Wiley \& Sons, 1995.

[75] SILVA, E. C. N., Modelagem Vibracional de Transdutores de Ultrasom Piezelétricos pelo Método de Elementos Finitos dissertação de mestrado, São Paulo - Brasil, 1993, Escola Politécnica da Universidade de São Paulo. 
[76] MOAVENI, S., Finite Element Analysis. New Jersey - EUA: Pretence Hall, 1999.

[77] Physik Instrumente - Theory and Applications of Piezo Actuators and PZT NanoPositioning Systems. http://www.physikinstrumente.com/tutorial.

[78] MOSKALIK, A. J.; BREI, D., Force-Deflection Characterization of Series Array of Piezoelectric C-Block Actuators, SPIE Conference of Smart Structures and Integrated System, v. 3329, p. 659-669, março 1998.

[79] PICKELMANN, L., Piezomechanical Stackactuators. http://www.piezomechanik.com.

[80] TRESSLER, J. F.; NEWNHAM, R. E., Doubly resonant cymbal-type transducer, IEEE Transactions on Ultrasonics, Ferroelectrics and Frequency Control, v. 44, p. 1175-1177, 1997.

[81] XU, Q. C.; YOSHIKAWA, S.; BELSICK, J. R.; NEWNHAM, R. E., Piezoelectric composites with high sensitivity and high capacitance for use at high pressures, IEEE Transactions on Ultrasonics, Ferroelectrics and Frequency Control, v. 38, p. 634-639, 1991.

[82] ELLIS, E. M., Low-cost Bimorph Mirrors in Adaptative Optics. tese de doutorado, 1999, Imperial College of Science, Technology and Medicine University of London - Londres - Inglaterra.

[83] SMITS, J. G.; CHOI, W.-S., The Constituent Equations of Piezoelectric Heterogeneous Bimorphs, IEEE - Transactions on Ultrasonics, Ferroelectrics and Frequency Control, v. 38, n. 3, p. 256-270, 1991.

[84] SMITS, J. G.; DALKE, S. I.; COONEY, T. K., The Constituent Equations of Piezoelectric Bimorphs, Sensors and Actuators, v. 28, p. 41-61, 1991.

[85] COUGHLIN, M. F.; STAMENOVIC, D.; SMITS, J. G., Determining Spring Stiffness by the Resonance Frequency of Cantilevered Piezoelectric Bimorphs, IEEE - Transactions on Ultrasonics, Ferroelectrics and Frequency Control, v. 44, n. 4, p. 730-732, 1997. 
[86] PAPOUlIS, A., System and Transforms With Applications in Optics. Nova Iorque - EUA: McGraw-Hill, 1968.

[87] COLlieR, R.; BURCKHARDT, C. B.; LIN, L. H., Optical Holography. Orlando - EUA: Academic Press, INC, 1971.

[88] WILLIANS, D. C., Optical Methods in Engineering Metrology. Londres - Inglaterra: Chapman \& Hall, 1993.

[89] WHITEHOUSE, D. J., Handbook of Surface Metrology. Philadelphia EUA: Institute of Physics Publishing Bristol and Philadelphia.

[90] YATAGAI, T., Introdução à Metrologia Óptica. Tradução: O. Horikawa - circulação interna da EPUSP.

[91] STEGEMAN, G. I., III. Optical Probing of Surface Waves and Surface Wave Devices, IEEE - Transactions on Sonics and Ultrasonics, v. SU-23, p. 33-63, janeiro 1976.

[92] BABOUX, J. C., Etude theorique et experimentale des champs ultrasonores impulsionnels dans les liquides et dans les solides. Tese de doutorado, Lion - França, 1987, Instituit National des sciences Appliquees de Lyon - Universite Claude Bernard Lyon I.

[93] NUÑEZ, I., Estudio de Campos Ultrasónicos por Métodos Ópticos de Alta Resolucíon dissertação de mestrado, 1996, Instituto de Física Facultad de Ciencias - Universidad de la República.

[94] MTI-2000, , Instruction Manual - MTI-2000 Fotonic Sensor. Manual do sistema.

[95] PAN, W. Y.; CROSS, L. E., A Sensitive Double Beam Laser Interferometer for Studying high-frequency Piezoelectric and Electrostrictive Strains, Review of Scientific Instruments, v. 60, n. 8, p. 2701-2705, 1989.

[96] HECHT, E., Optics. California - EUA: Addison-Wesley, 2a ed., 1987.

[97] BORN, M.; WOLF, E., Principles of Optics. Cambridge - Inglaterra: Cambridge University Press, 6ㅁ ed., 1997. 
[98] GINDRE, M.; URBACH, W.; COURSANT, R. H.; FINK, M., Mechanical displacement induced in a piezoelectric structure: Experimental measurement by laser interferometry and simulation by a finite element method, Journal of the Acoustical Society of America, v. 84, n. 1, p. 11-19, 1988.

[99] VANDERLUGT, A., Optical Signal Processing. Nova Iorque - EUA: John Wiley \& Sons, 1992.

[100] NUÑEZ, I., Generación de ondas de Lamb. Funciones de Green y su aplicación en los procesos de Inversión Temporal Acústica. Tese de doutorado, Montevidéu - Uruguai, 2000, Instituto de Fisica - Facultad de Ciencias - Universidad de la República.

[101] BARRIÈRE, C.; ROYER, D., Optical measurement of large transient mechanical displacements, Applied Physics Letter, v. 79, p. 878-880, agosto 2001.

[102] APC-Flexure Elements: Bimorph. http://www.thomasregister.com/olc/apc/notes3.htm.

[103] The Newport Resource. Catálogo da Newport, 2002. 


\section{APÊNDICES}




\section{Apêndice A}

\section{Tensores do Materiais}

\section{Piezelétricos - Conversão para o}

\section{ANSYS}

Em modelos bidimensionais, a direção padrão da polarização no ANSYS é a $y$. No entanto, em alguns modelos é necessário utilizar a polarização na direção $x$. Este apêndice traz as matrizes invertidas e o processo de inversão.

\section{A.1 Polarização na direção $z$}

Para uma cerâmica piezelétrica da classe de simetria $6 \mathrm{~mm}$, como as da família PZT, com a polarização na direção $z$, a contribuição de um campo elétrico aplicado na direção $z, x$ ou $y$ é ilustrada na Figura A.1. As equações constitutivas são escritas da forma seguinte:
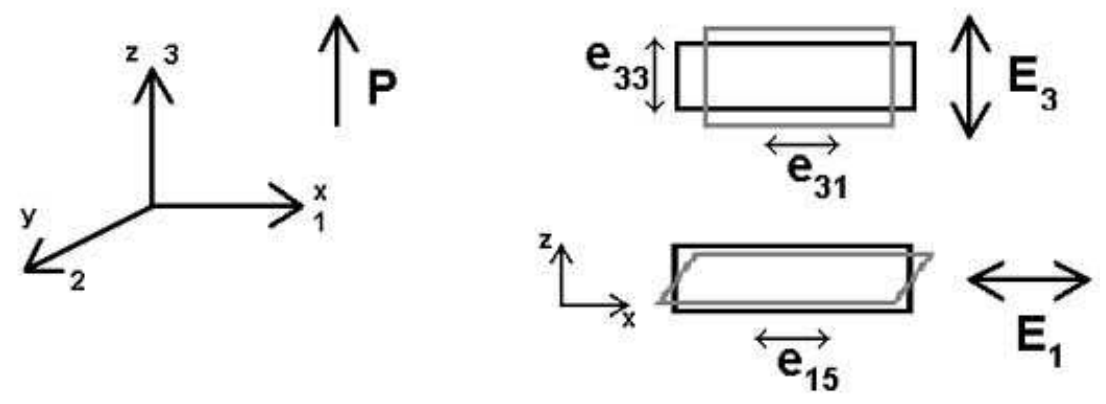

Figura A.1. Cerâmica piezelétrica com polarização na direção $z$. 


$\left[\begin{array}{c}T_{x x} \\ T_{y y} \\ T_{z z} \\ T_{y z} \\ T_{x z} \\ T_{x y} \\ D_{x} \\ D_{y} \\ D_{z}\end{array}\right]=\left[\begin{array}{cccccc|ccc}c_{11}^{E} & c_{12}^{E} & c_{13}^{E} & 0 & 0 & 0 & 0 & 0 & -e_{31} \\ c_{12}^{E} & c_{11}^{E} & c_{13}^{E} & 0 & 0 & 0 & 0 & 0 & -e_{31} \\ c_{13}^{E} & c_{13}^{E} & c_{33}^{E} & 0 & 0 & 0 & 0 & 0 & -e_{33} \\ 0 & 0 & 0 & c_{44}^{E} & 0 & 0 & 0 & -e_{15} & 0 \\ 0 & 0 & 0 & 0 & c_{44}^{E} & 0 & -e_{15} & 0 & 0 \\ 0 & 0 & 0 & 0 & 0 & c_{66}^{E} & 0 & 0 & 0 \\ \hline 0 & 0 & 0 & 0 & e_{15} & 0 & \epsilon_{11}^{S} & 0 & 0 \\ 0 & 0 & 0 & e_{15} & 0 & 0 & 0 & \epsilon_{11}^{S} & 0 \\ e_{31} & e_{31} & e_{33} & 0 & 0 & 0 & 0 & 0 & \epsilon_{33}^{S}\end{array}\right]\left[\begin{array}{c}S_{x x} \\ S_{y y} \\ S_{z z} \\ S_{y z} \\ S_{x z} \\ S_{x y} \\ E_{x} \\ E_{y} \\ E_{z}\end{array}\right]$.

Da qual obtém-se a contribuição de cada termo:

$$
\begin{aligned}
T_{x x} & =c_{11}^{E} S_{x x}+c_{12}^{E} S_{y y}+c_{13}^{E} S_{z z}-e_{31} E_{z} \\
T_{y y} & =c_{12}^{E} S_{x x}+c_{11}^{E} S_{y y}+c_{13}^{E} S_{z z}-e_{31} E_{z} \\
T_{z z} & =c_{13}^{E} S_{x x}+c_{13}^{E} S_{y y}+c_{33}^{E} S_{z z}-e_{33} E_{z} \\
T_{y z} & =c_{44}^{E} S_{y z}-e_{15} E_{y} \\
T_{x z} & =c_{44}^{E} S_{x z}-e_{15} E_{x} \\
T_{x y} & =c_{66}^{E} S_{x y} \\
D_{x} & =e_{15} S_{x z}+\epsilon_{11}^{S} E_{x} \\
D_{y} & =e_{15} S_{y z}+\epsilon_{11}^{S} E_{y} \\
D_{z} & =e_{31} S_{x x}+e_{31} S_{y y}+e_{33} S_{z z}+\epsilon_{33}^{S} E_{z}
\end{aligned}
$$

\section{A.2 Polarização na direção $y$}

Em modelagens bidimensionais no ANSYS, assume-se a direção y como a da polarização, nessa caso há necessidade de uma inversão de bases. As alterações dos eixos das coordenadas e os comportamentos da cerâmica sob campos elétricos nas direções $y, x$ e $z$ são mostrados na Figura A.2.

As equações para a polarização na direção $y$ escrevem-se.

$$
\begin{aligned}
& T_{x x}^{\prime}=c_{11}^{E} S_{x x}^{\prime}+c_{13}^{E} S_{y y}^{\prime}+c_{12}^{E} S_{z z}^{\prime}-e_{31} E_{y}^{\prime} \\
& T_{y y}^{\prime}=c_{13}^{E} S_{x x}^{\prime}+c_{33}^{E} S_{y y}^{\prime}+c_{13}^{E} S_{z z}^{\prime}-e_{33} E_{y}^{\prime} \\
& T_{z z}^{\prime}=c_{12}^{E} S_{x x}^{\prime}+c_{13}^{E} S_{y y}^{\prime}+c_{11}^{E} S_{z z}^{\prime}-e_{31} E_{y}^{\prime}
\end{aligned}
$$



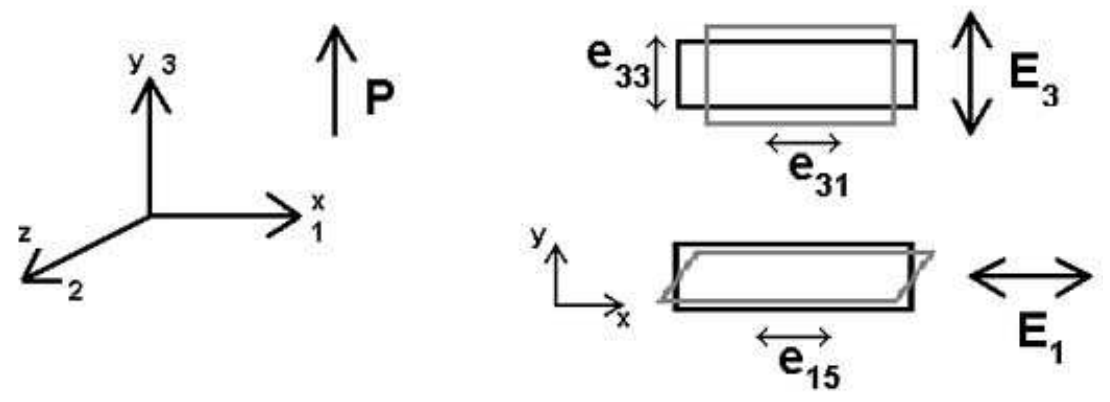

Figura A.2. Cerâmica piezelétrica com polarização na direção y.

$$
\begin{aligned}
T_{y z}^{\prime} & =c_{44}^{E} S_{y z}^{\prime}-e_{15} E_{z}^{\prime} \\
T_{x z}^{\prime} & =c_{66}^{E} S_{x z}^{\prime} \\
T_{x y}^{\prime} & =c_{44}^{E} S_{x y}^{\prime}-e_{15} E_{x}^{\prime} \\
D_{x}^{\prime} & =e_{15} S_{x y}^{\prime}+\epsilon_{11}^{S} E_{x}^{\prime} \\
D_{y}^{\prime} & =e_{31} S_{x x}^{\prime}+e_{33} S_{y y}^{\prime}+e_{31} S_{z z}^{\prime}+\epsilon_{33}^{S} E_{y}^{\prime} \\
D_{z}^{\prime} & =e_{15} S_{y z}^{\prime}+\epsilon_{11}^{S} E_{z}^{\prime}
\end{aligned}
$$

A ordem da notação reduzida no ANSYS é

$$
\left\{T_{x x} T_{y y} T_{z z} T_{x y} T_{y z} T_{x z} D_{x} D_{y} D_{z}\right\}^{t}
$$

dessa forma, a matriz a ser inserida no ANSYS é:

$$
\left[\begin{array}{c}
T_{x x}^{\prime} \\
T_{y y}^{\prime} \\
T_{z z}^{\prime} \\
T_{x y}^{\prime} \\
T_{y z}^{\prime} \\
T_{x z}^{\prime} \\
D_{x}^{\prime} \\
D_{y}^{\prime} \\
D_{z}^{\prime}
\end{array}\right]=\left[\begin{array}{cccccc|ccc}
c_{11}^{E} & c_{13}^{E} & c_{12}^{E} & 0 & 0 & 0 & 0 & -e_{31} & 0 \\
c_{13}^{E} & c_{33}^{E} & c_{13}^{E} & 0 & 0 & 0 & 0 & -e_{33} & 0 \\
c_{12}^{E} & c_{13}^{E} & c_{11}^{E} & 0 & 0 & 0 & 0 & -e_{31} & 0 \\
0 & 0 & 0 & c_{44}^{E} & 00 & 0 & -e_{15} & 0 & 0 \\
0 & 0 & 0 & 0 & c_{44}^{E} & 0 & 0 & 0 & -e_{15} \\
0 & 0 & 0 & 0 & 0 & c_{66}^{E} & 0 & 0 & 0 \\
\hline 0 & 0 & 0 & e_{15} & 0 & 0 & \epsilon_{11}^{S} & 0 & 0 \\
e_{31} & e_{33} & e_{31} & 0 & 0 & 0 & 0 & \epsilon_{33}^{S} & 0 \\
0 & 0 & 0 & 0 & e_{15} & 0 & 0 & 0 & \epsilon_{11}^{S}
\end{array}\right]\left[\begin{array}{c}
S_{x x}^{\prime} \\
S_{y y}^{\prime} \\
S_{z z}^{\prime} \\
S_{x y}^{\prime} \\
S_{y z}^{\prime} \\
S_{x z}^{\prime} \\
E_{x}^{\prime} \\
E_{y}^{\prime} \\
E_{z}^{\prime}
\end{array}\right]
$$

\section{A.3 Polarização na direção $x$}

Em alguns casos há necessidade de utilizar a cerâmica com polarização na direção do eixo $x$ nas simulações. Nesse caso não há inversão dos eixos das ordenadas, apenas da direção da polarização, como mostra a Figura A.3. A partir da eq. A.4 e com 
os mesmos procedimentos adotados na seção anterior, chega-se a seguinte forma tensorial das equações constitutivas
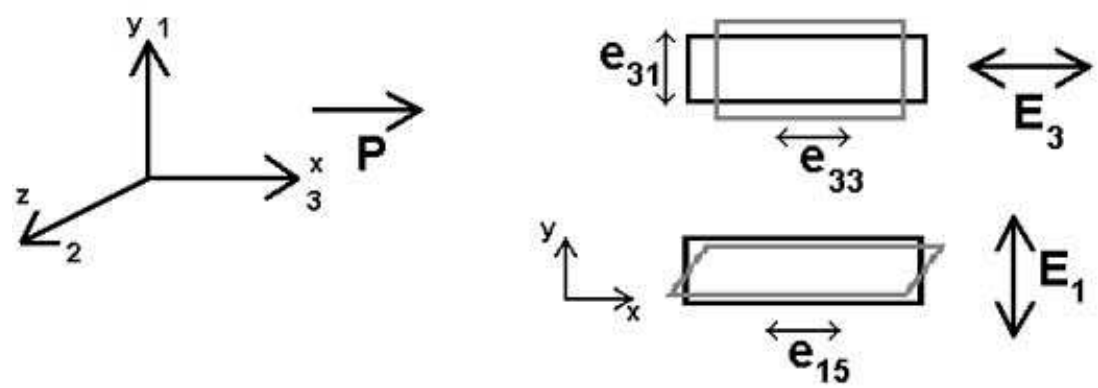

Figura A.3. Cerâmica piezelétrica com polarização na direção $x$.

$$
\begin{aligned}
T_{x x}^{\prime \prime} & =c_{33}^{E} S_{x x}^{\prime \prime}+c_{13}^{E} S_{y y}^{\prime \prime}+c_{13}^{E} S_{z z}^{\prime \prime}-e_{33} E_{x}^{\prime \prime} \\
T_{y y}^{\prime \prime} & =c_{13}^{E} S_{x x}^{\prime \prime}+c_{11}^{E} S_{y y}^{\prime \prime}+c_{12}^{E} S_{z z}^{\prime \prime}-e_{31} E_{x}^{\prime \prime} \\
T_{z z}^{\prime \prime} & =c_{13}^{E} S_{x x}^{\prime \prime}+c_{12}^{E} S_{y y}^{\prime \prime}+c_{11}^{E} S_{z z}^{\prime \prime}-e_{31} E_{x}^{\prime \prime} \\
T_{x y}^{\prime \prime} & =c_{44}^{E} S_{x y}^{\prime \prime}-e_{15} E_{y}^{\prime \prime} \\
T_{y z}^{\prime \prime} & =c_{66}^{E} S_{y z}^{\prime \prime} \\
T_{x z}^{\prime \prime} & =c_{44}^{E} S_{x z}^{\prime \prime}-e_{15} E_{z}^{\prime \prime} \\
D_{x}^{\prime \prime} & =e_{33} S_{x x}^{\prime \prime}+e_{31} S_{y y}^{\prime \prime}+e_{31} S_{z z}^{\prime \prime}+\epsilon_{33}^{S} E_{x}^{\prime \prime} \\
D_{y}^{\prime \prime} & =e_{15} S_{x y}^{\prime \prime}+\epsilon_{11}^{S} E_{y}^{\prime \prime} \\
D_{z}^{\prime \prime} & =e_{15} S_{x z}^{\prime \prime}+\epsilon_{11}^{S} E_{z}^{\prime \prime}
\end{aligned}
$$

$$
\left[\begin{array}{c}
T_{x x}^{\prime \prime} \\
T_{y y}^{\prime \prime} \\
T_{z z}^{\prime \prime} \\
T_{y z}^{\prime \prime} \\
T_{x z}^{\prime \prime} \\
T_{x y}^{\prime \prime} \\
D_{x}^{\prime \prime} \\
D_{y}^{\prime \prime} \\
D_{z}^{\prime \prime}
\end{array}\right]=\left[\begin{array}{cccccc|ccc}
c_{33}^{E} & c_{13}^{E} & c_{13}^{E} & 0 & 0 & 0 & -e_{33} & 0 & 0 \\
c_{13}^{E} & c_{11}^{E} & c_{12}^{E} & 0 & 0 & 0 & -e_{31} & 0 & 0 \\
c_{13}^{E} & c_{12}^{E} & c_{11}^{E} & 0 & 0 & 0 & -e_{31} & 0 & 0 \\
0 & 0 & 0 & c_{44}^{E} & 0 & 0 & 0 & -e_{15} & 0 \\
0 & 0 & 0 & 0 & c_{66}^{E} & 0 & 0 & 0 & 0 \\
0 & 0 & 0 & 0 & 0 & c_{44}^{E} & 0 & 0 & -e_{15} \\
\hline e_{33} & e_{31} & e_{31} & 0 & 0 & 0 & \epsilon_{33}^{S} & 0 & 0 \\
0 & 0 & 0 & e_{15} & 0 & 0 & 0 & \epsilon_{11}^{S} & 0 \\
0 & 0 & 0 & 0 & 0 & e_{15} & 0 & 0 & \epsilon_{11}^{S}
\end{array}\right]\left[\begin{array}{c}
S_{x x}^{\prime \prime} \\
S_{y y}^{\prime \prime} \\
S_{z z}^{\prime \prime} \\
S_{y z}^{\prime \prime} \\
S_{x z}^{\prime \prime} \\
S_{x y}^{\prime \prime} \\
E_{x}^{\prime \prime} \\
E_{y}^{\prime \prime} \\
E_{z}^{\prime \prime}
\end{array}\right]
$$




\section{Apêndice B}

\section{Coerência Temporal e Espacial}

Para haver interferência entre dois feixes de luz, é necessário que estes possuam coerência temporal e espacial. A primeira está relacionada com a fase das ondas eletromagnéticas que irão interferir. A segunda está relacionada com a forma da frente de onda. Uma breve definição de coerência temporal e espacial é dada a seguir. Para isso, utiliza-se um interferômetro de Michelson clássico.

\section{B.1 Coerência Temporal}

A coerência temporal, também conhecida como comprimento de coerência de uma fonte de luz, está relacionada com a duração do tempo para o qual a fonte de luz mantém a fase entre dois feixes luminosos. Esses dois feixes luminosos, para se interferirem, necessitam ter origem na mesma fonte de luz. Utilizando um interferômetro de Michelson como exemplo, para obter esses dois feixes luminosos, divide-se o feixe de luz em dois, através do (BS), como mostra a Figura B.1. Após divididos, um dos feixes passa a se chamar feixe de referência e incide no espelho de referência (R), o outro feixe, passa a se chamar feixe sinal e incide no espelho sinal (S). Os percursos de BS a S ou de BS a R são chamados braços do interferômetro.

O feixe de referência após percorrer duas vezes (ida e volta) o caminho óptico $L_{R}$ encontra-se com o feixe sinal que também percorreu duas vezes (ida e volta) o caminho óptico $L_{S}$. Ao se encontrarem, esses feixes se interferem, caso a diferença

de fase entre eles (ver Figura B.2) esteja dentro do limite de tempo. No entanto, se o espelho $\mathrm{S}$ é deslocado de um comprimento $\delta$ para o qual a fase entre os dois feixes 


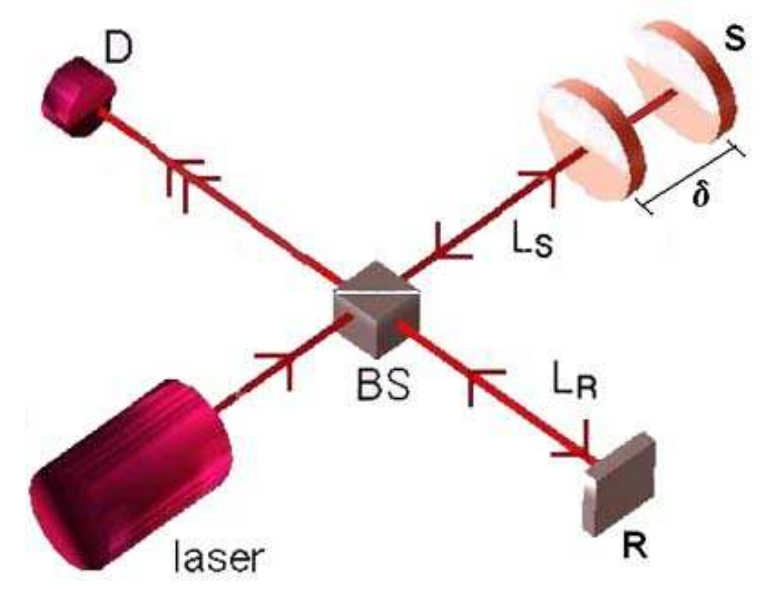

Figura B.1. Interferômetro de Michelson, ilustrando a diferença $\delta$ no caminho óptico entre os feixes referência e sinal.

esteja acima do limite de tempo da coerência temporal, eles não irão interferir.

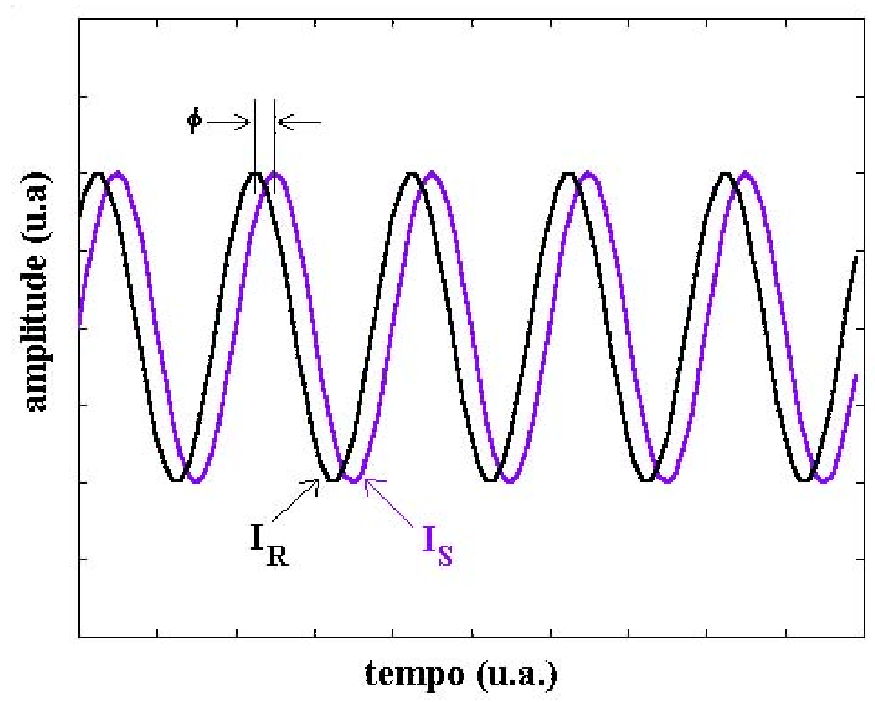

Figura B.2. Fase $\phi$ entre duas ondas eletromagnéticas.

A Figura B.2 mostra duas ondas eletromagnéticas defasadas de $\phi$. Nessa figura, $I_{R}$ representa a intensidade da onda eletromagnética de referência e $I_{S}$ a intensidade da onda eletromagnética sinal. Para que haja a interferência, a fonte luminosa deve ser perfeitamente coerente. O laser é uma fonte de luz que satisfaz esse requisito. Uma fonte de luz branca possui um comprimento de coerência muito pequeno, a diferença de caminho óptico máxima entre os feixes sinal e referência para que haja interferência de luz branca é de aproximadamente $1 \mu \mathrm{m}$. Uma fonte de sódio possui o comprimento de coerência da ordem de $1 \mathrm{~mm}$. O laser de argônio possuiu um 
comprimento de coerência de aproximadamente $0,20 \mathrm{~m}$. Enquanto que um laser totalmente monomodo e monocromático pode ter um comprimento de coerência de até $6 \mathrm{~km}$. A coerência temporal está relacionada, principalmente, com a monocromaticidade de uma fonte de luz. Por isso, algumas fontes laser He-Ne multimodo e que não são totalmente monocromáticas, possuem um comprimento de coerência de aproximadamente $0,20 \mathrm{~m}$, enquanto que fontes laser He-Ne monocromáticas podem chegar a um comprimento de coerência de 100 m. Por isso, para obter uma boa interferência, independente da fonte laser utilizada, deve-se sempre trabalhar com os caminhos ópticos dos feixes referência e sinal praticamente iguais.

\section{B.2 Coerência Espacial}

A coerência temporal é associada como uma propriedade da onda na direção da propagação. O outro tipo de coerência é a espacial, que está relacionada com a propriedade da onda na direção transversal à propagação. Se a onda é perfeitamente plana, então há uma fase uniforme no plano perpendicular à propagação da onda, como mostra a Figura B.3.

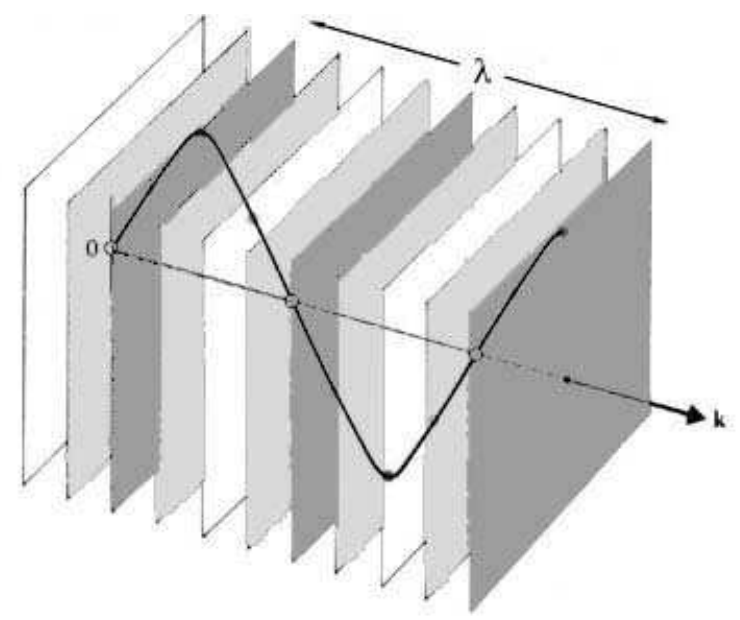

Figura B.3. Onda harmônica plana. A fase é constante ao longo da direção transversal da onda.

A fase de uma onda plana pode exibir flutuações, no entanto, todos os pontos da onda plana terão flutuações idênticas. A onda plana é dita coerente espacialmente. A coerência temporal é associada com a distribuição de freqüência da fonte de luz, 
enquanto que a coerência espacial é associada com a distribuição de propagação do vetor de onda (k), ou seja, com uma onda plana. As fontes laser possuem grande coerência espacial. Mesmo que a onda do feixe sinal não seja plana, ela irá interferir com onda do feixe de referência, caso essa seja plana ou esférica. 


\section{Apêndice $\mathrm{C}$}

\section{Sistema Óptico a Fibras Ópticas}

O texto e as figuras desse apêndice são baseados ou retirados do manual de utilização do MTI-2000 Fotonic Sensor ${ }^{T M}$ [94].

O sistema óptico MTI-2000 possui um módulo sensor de deslocamento utilizando fibras ópticas transmissoras e receptoras de luz alinhadas aleatoriamente (Figura C.1), para uma alta sensibilidade ao deslocamento em intervalos curtos. O princípio de funcionamento é baseado na interação entre os campos de iluminação/transmissão (fibras fonte) e os campos de visão do receptor (fibras detectoras). Um esquema simplificado é ilustrado na Figura C.2. A fonte de luz é um diodo laser operando no visível (vermelho).

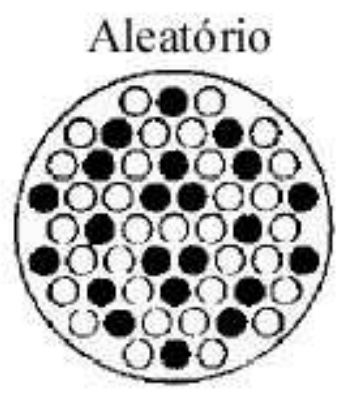

\section{O fibras transmissoras \\ - fibras receptoras}

Figura C.1. Distribuição aleatória das fibras emissoras e sensoras de luz do MTI-2000.

Princípio de operação: quando as fibras ópticas estão em contado com a superfície analisada (distância zero) as luzes emitidas pelas fibras emissoras, refletem, 


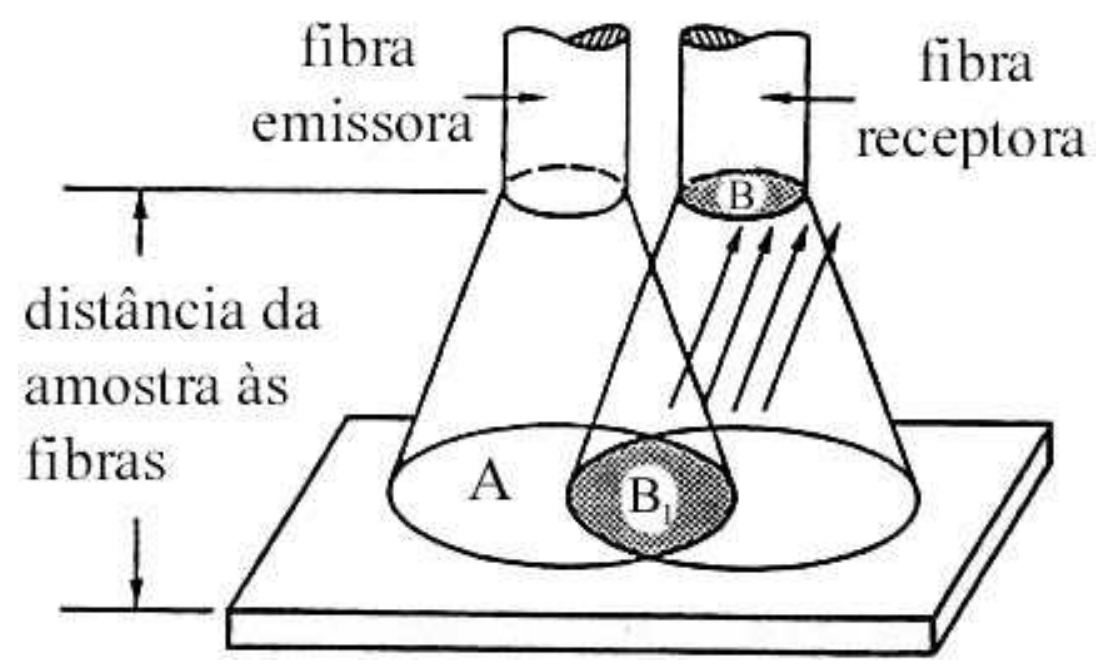

Figura C.2. Detecção das intensidades refletidas pela amostra, a medida que esta afasta-se das fibras.

em sua maior parte, sobre elas mesmas, tal que a quantidade de luz detectada pelas fibras receptoras é mínima, produzindo um sinal de saída praticamente nulo. A Figura C.3 mostra a curva de resposta do sensor com relação à distância. Essa curva é interpretada da seguinte forma: a partir da distância zero (fibra em contato com a amostra), afastam-se as fibras ópticas. Com o aumento da distância entre a superfície em analise e as fibras, aumenta a quantidade de luz incidente nas fibras receptoras. A relação aumento de distância, aumento de intensidade continua até que todas as fibras receptoras estejam capturando a toda a luz refletida da superfície analisada. Esse é o ponto de máxima intensidade adquirida. Se a distância continua a aumentar, as fibras receptoras passam a não receber toda a luz refletida pela superfície analisada, pois essa é espalhada pela superfície, e com o aumento da distância a intensidade incidente nas fibras passa a diminuir. A Figura C.2 mostra um esquema geométrico simplificado da relação intensidade de luz refletida adquirida, pela distância da fibra à amostra analisada.

Esta figura também ilustra que há dois intervalos de detecção de sinal, chamados na Figura C.3 de Intervalo 1 e Intervalo 2, assim como o pico de intensidade (Pico). O Intervalo 1 é o inicial que é muito mais sensível e possui resposta positiva, ou seja, se o deslocamento é na direção z positiva, a intensidade refletida aumenta. Esse intervalo vai da posição zero (contato) até o máximo de intensidade (Pico). O intervalo 2 é menos sensível e a resposta é negativa, ou seja, se a o deslocamento 


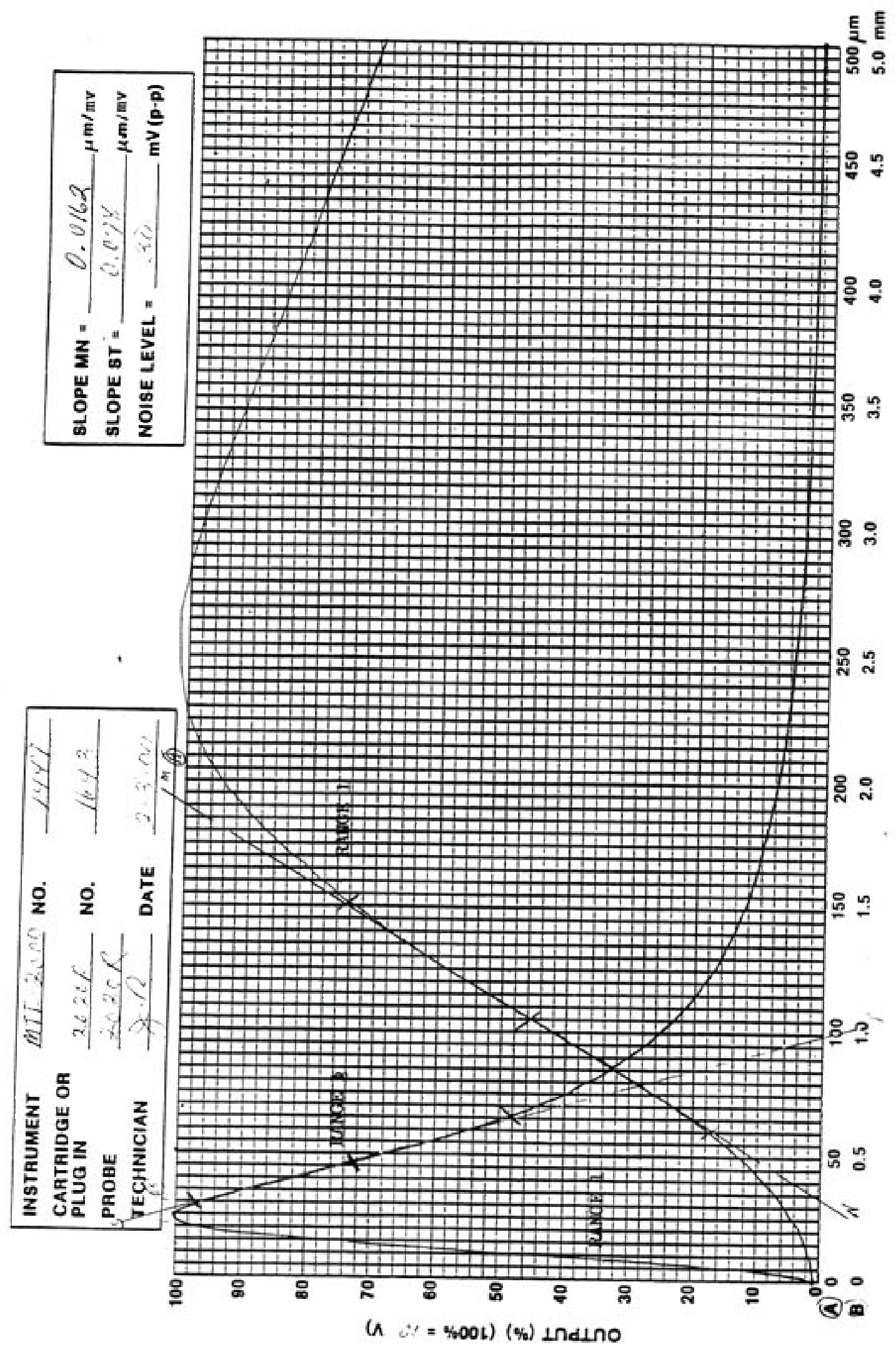

Figura C.3. Curva de calibração do sensor a fibra MTI-2000. 
Tabela C.1. Especificações da sonda à fibras ópticas.

\begin{tabular}{ccccc}
\hline \hline modelo & $\begin{array}{c}\text { resolução } \\
\text { intervalo } \mathbf{1}\end{array}$ & $\begin{array}{c}\text { resolução } \\
\text { intervalo } 2\end{array}$ & $\begin{array}{c}\text { sensibilidade } \\
\text { intervalo } \mathbf{1}\end{array}$ & $\begin{array}{c}\text { sensibilidade } \\
\text { intervalo 2 }\end{array}$ \\
\hline \hline $2020 \mathrm{R}$ & $30 \mathrm{~nm}$ & $250 \mathrm{~nm}$ & $16 \mathrm{~nm} / \mathrm{mV}$ & $90 \mathrm{~nm} / \mathrm{V}$ \\
\hline \hline
\end{tabular}

é na direção z positiva, a intensidade refletida diminui. Esse intervalo vai do pico de intensidade até uma distância de alguns milímetros. As especificações das fibras utilizadas são mostradas na Tabela C.1.

As características desses dois intervalos são:

- Intervalo 1 - A resposta é função do diâmetro da fibra; da posição das fibras transmissão e recepção; e da abertura numérica das fibras.

- Intervalo 2 - A resposta é primeiramente função da intensidade da luz refletida; inversamente proporcional ao quadrado da função.

Ao utilizar esse sistema óptico, deve-se sempre trabalhar na região linear da curva de calibração. A Figura C.3 mostra que a região linear do intervalo 1 é de 101 $\mu \mathrm{m}$ e do intervalo 2 de $1457 \mu \mathrm{m}$.

A amostra a ser analisada deve possuir uma superfície capas de refletir luz, mesmo que essa reflexão seja difusa. Pois, como o aumento da luz refletida, obtémse uma precisão melhor do sistema.

A calibração é realizada procurando deixar a superfície analisada perpendicular às fibras ópticas, e buscando a posição de máxima intensidade refletida, adquirida pelo sistema óptico. Esse é o ponto da intensidade máxima da curva da Figura C.3. O passo seguinte é escolher o intervalo para realizar as medições e faz-se a calibração automática do sistema, na qual o equipamento assume que a máxima intensidade equivale a $10 \mathrm{~V}$ e que a sonda à fibras ópticas está a $25 \mu \mathrm{m}$ da amostra analisada. Se a escolha for para trabalhar no intervalo 1, aproxima-se a amostra da fibra, até que o aparelho indique 4,5 V (centro da região linear desse intervalo). Os deslocamentos medido não podem ultrapassar os $101 \mu \mathrm{m}$ da região linear. Se a escolha for para utilizar o intervalo 2, afasta-se a amostra da sonda à fibras ópticas até a leitura indicar 7,25 V. Os deslocamentos medidos não podem ultrapassar os $1457 \mu \mathrm{m}$ da região linear. 